\title{
A STATISTICAL MODEL TO FORECAST SHORT-TERM ATLANTIC HURRICANE INTENSITY
}

\author{
DISSERTATION \\ Presented in Partial Fulfillment of the Requirements for \\ the Degree Doctor of Philosophy in the Graduate \\ School of The Ohio State University
}

By

Kevin T. Law, M.S.

$* * * * *$

The Ohio State University

2006

Dissertation Committee:

Professor Jay S. Hobgood, Adviser

Approved by

Professor Jeffrey C. Rogers

Professor Lawrence Krissek

Adviser

Graduate Program in Atmospheric Science 



\begin{abstract}
The accuracy of hurricane intensity forecasts has lagged the accuracy of hurricane track forecasts thereby creating a need for improvement. Many models struggle capturing the rapid intensification period and identifying when it will occur which causes a large amount of error in the intensity forecasts. The method described in this paper uses a discriminant function analysis (DFA) to help identify how intense the tropical cyclone will become and also how close it is to the rapid intensification period. Identifying the proximity to the rapid intensification period is a key factor in improving the intensity forecasts.
\end{abstract}

Based upon the intensity and its proximity to its rapid intensification period, as selected by the DFA, an appropriate regression model is applied to forecast the 24-hour and 6-hour pressure reduction and wind speed increase. Other statistical intensity models apply the same regression model throughout the entire lifecycle of the tropical cyclone. This model relies on the premise that factors which cause intensification affect the tropical cyclone differently throughout its life cycle. Therefore, by using the DFA, different stages in its life cycle are identified, which allows the regression model to use the most significant variables at the particular stage. They are shown to improve the intensity forecasts at the stages leading up to and during the rapid intensification, which 
happen to be the most difficult stages to predict. The forecasts were validated with 13 independent case studies and compared with the official National Hurricane Center (NHC) forecasts. 


\section{ACKNOWLEDGMENTS}

I wish to thank my adviser, Jay Hobgood, for always having the time to answer questions and correct errors. In addition, I would like to thank Gustavo Goni for personally making the AOML Hurricane Heat Potential data readily available. Both of whom without their support, this dissertation would not have been possible. 
VITA

July $9,1976 \ldots \ldots \ldots \ldots \ldots \ldots \ldots \ldots$ Born - Parkersburg, West Virginia

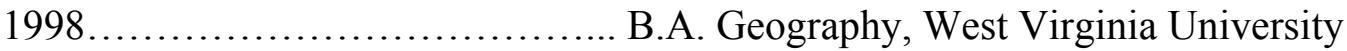

1999-present.................... Graduate Teaching Associate, The Ohio State University

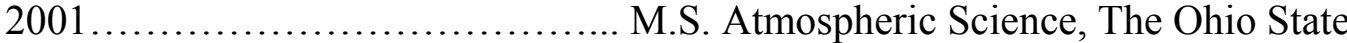
University

\section{FIELDS OF STUDY}

Major Field: Atmospheric Science 


\section{TABLE OF CONTENTS}

Abstract... Pcknowledgments

Chapters:

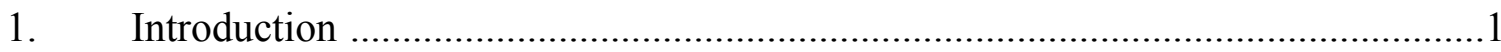

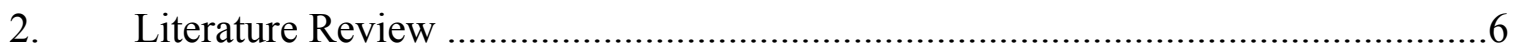

2.1 Environmental Influences on Tropical Cyclone Intensity Change ....................6

2.2 Potential Rapid Intensification Predictors ……….........................................

2.3 Other Factors Affecting Rapid Intensification ..............................................

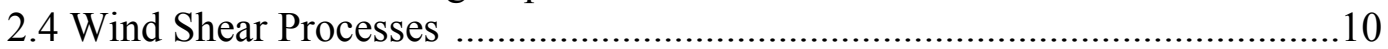

2.5 Vertical Wind Shear Numerical Simulation Studies ......................................13

2.6 Vertical Wind Shear Observational Studies ..............................................15

2.7 Vertical Wind Shear Individual Case Studies ..............................................16

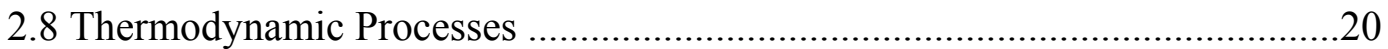

2.9 Statistical Modeling of Tropical Cyclone Intensification ...............................25

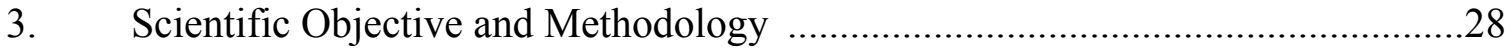

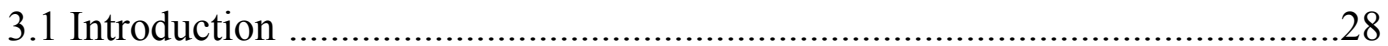

3.2 Tropical Cyclone Selection and (HURDAT) Data ......................................29

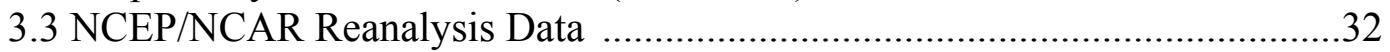

3.4 AOML Tropical Cyclone Heat Potential ………………................................34

3.5 Variables and Data Used in the Study .........................................................37

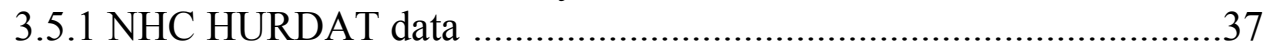

3.5.2 Vertical Wind Shear and Relative Humidity ....................................39

3.5.3 Holland MPI................................................................................4

3.5.4 Attained MPI.............................................................................. 43

3.5.5. Tropical Cyclone Heat Potential.......................................................44

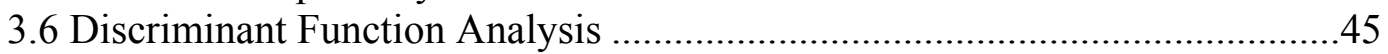

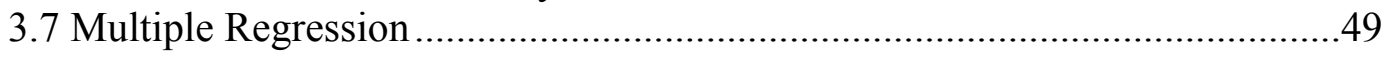


3.8 Testing the Models with an Independent Dataset ........................................51

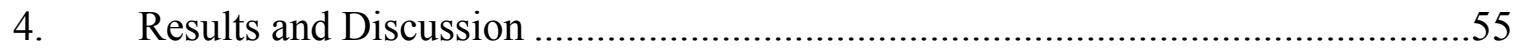

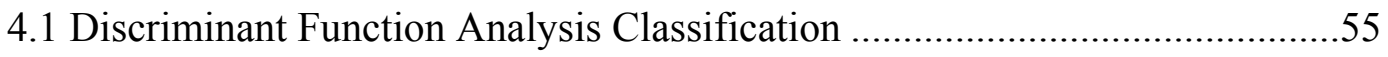

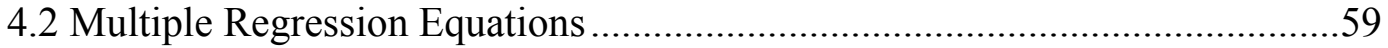

4.3 Evaluation of the Models with an Independent Dataset ..............................67

4.3.1 Hurricane Alex............................................................................68

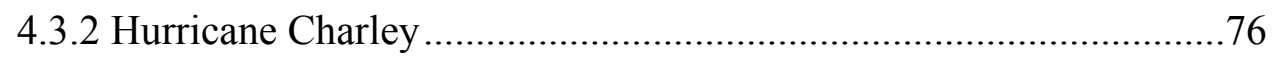

4.3.3 Hurricane Danielle .....................................................................84

4.3.4 Hurricane Frances .................................................................92

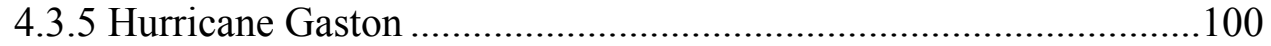

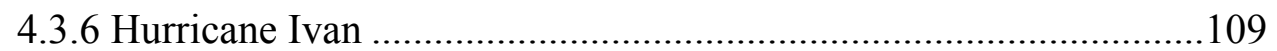

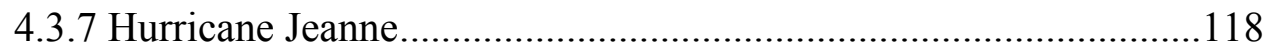

4.3.8 Hurricane Karl .........................................................................126

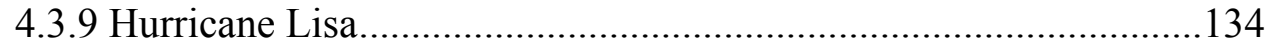

4.3.10 Hurricane Dennis ...................................................................142

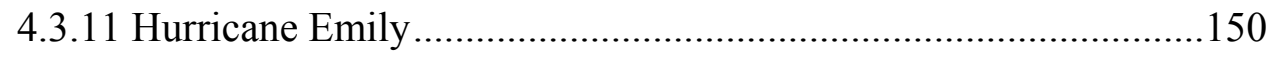

4.3.12 Hurricane Irene .................................................................... 158

4.3.13 Hurricane Katrina................................................................166

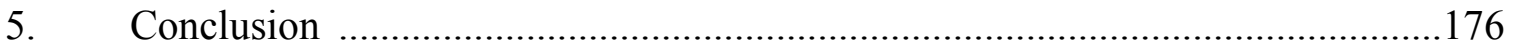

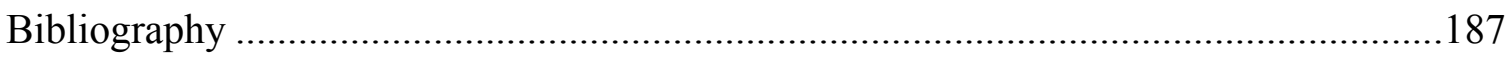

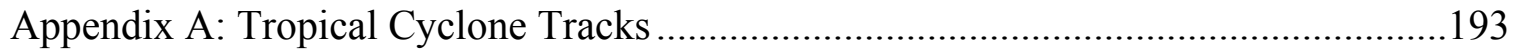




\section{LIST OF TABLES}

Table

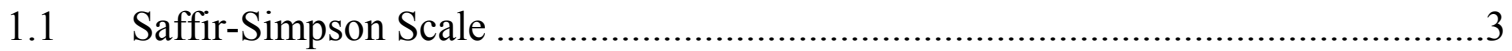

3.1 Tropical cyclone selection list from 1988-2003. Storms that are in boldface are considered "major" ................................................................ 31

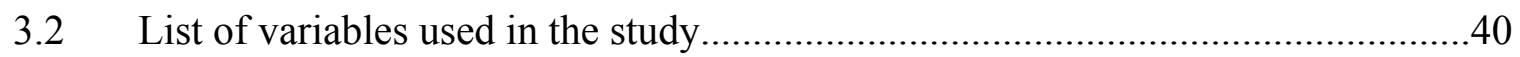

3.3 Number of cases in each category for the multiple regression analysis ...............52

3.4 List of Hurricanes in the Independent Dataset..............................................53

4.1 Classification results for step one of the discriminant analysis .........................56

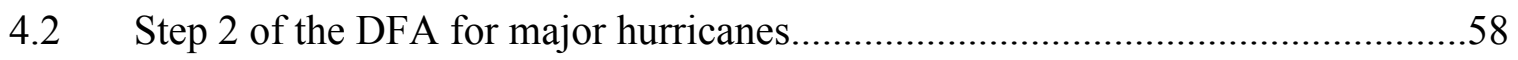

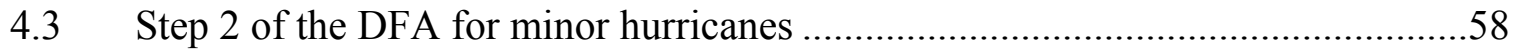

4.4 Future 24-hour pressure drop regression equations .....................................63

4.5 Future 24-hour wind speed increase regression equations ...............................64

4.6 Future 6-hour pressure drop regression equations ....................................65

4.7 Future 6-hour wind speed increase regression equations ...............................66

4.8 24-hour pressure drop model for Hurricane Alex.......................................... 70

4.9 24-hour wind speed increase model for Hurricane Alex ................................72

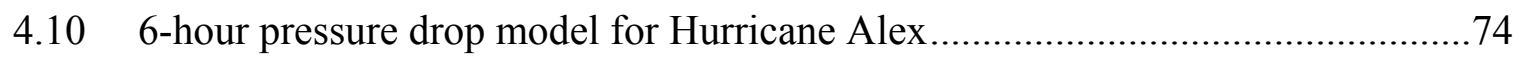

4.116 -hour wind speed increase model for Hurricane Alex ...................................75

4.12 24-hour pressure drop model for Hurricane Charley ......................................78 
4.13 24-hour wind speed increase model for Hurricane Charley ...............................80

4.14 6-hour pressure drop model for Hurricane Charley ........................................ 81

4.15 6-hour wind speed increase model for Hurricane Charley ................................83

4.16 24-hour pressure drop model for Hurricane Danielle .......................................86

4.17 24-hour wind speed increase model for Hurricane Danielle ..............................88

4.18 6-hour pressure drop model for Hurricane Danielle .......................................90

4.19 6-hour wind speed increase model for Hurricane Danielle ................................91

4.20 24-hour pressure drop model for Hurricane Frances .......................................94

4.21 24-hour wind speed increase model for Hurricane Frances...............................96

4.22 6-hour pressure drop model for Hurricane Frances ........................................98

4.23 6-hour wind speed increase model for Hurricane Frances..................................99

4.24 24-hour pressure drop model for Hurricane Gaston .......................................103

4.25 24-hour wind speed increase model for Hurricane Gaston................................105

4.26 6-hour pressure drop model for Hurricane Gaston ........................................107

4.27 6-hour wind speed increase model for Hurricane Gaston..................................108

4.28 24-hour pressure decrease model for Hurricane Ivan ....................................111

4.29 24-hour wind speed increase model for Hurricane Ivan ..................................113

4.30 6-hour pressure drop model for Hurricane Ivan ...........................................115

$4.31 \quad 6$-hour wind speed increase model for Hurricane Ivan ..................................117

4.32 24-hour pressure drop model for Hurricane Jeanne.......................................120

4.33 24-hour wind speed increase model for Hurricane Jeanne ..............................122

4.34 6-hour pressure drop model for Hurricane Jeanne.......................................124 
4.35 6-hour wind speed increase model for Hurricane Jeanne ................................125

4.36 24-hour pressure drop model for Hurricane Karl ..........................................128

4.37 24-hour wind speed increase model for Hurricane Karl ...................................130

4.38 6-hour pressure drop model for Hurricane Karl ..........................................131

4.39 6-hour wind speed increase model for Hurricane Karl .....................................133

4.40 24-hour pressure drop model for Hurricane Lisa..........................................136

4.41 24-hour wind speed increase model for Hurricane Lisa ...................................138

4.42 6-hour pressure drop model for Hurricane Lisa.............................................140

4.43 6-hour wind speed increase model for Hurricane Lisa ....................................141

4.44 24-hour pressure drop model for Hurricane Dennis ....................................... 144

4.45 24-hour wind speed increase model for Hurricane Dennis................................146

4.46 6-hour pressure drop model for Hurricane Dennis ..........................................148

4.47 6-hour wind speed increase model for Hurricane Dennis.................................149

4.48 24-hour pressure drop model for Hurricane Emily .......................................152

4.49 24-hour wind speed increase model for Hurricane Emily ................................154

$4.50 \quad 6$-hour pressure drop model for Hurricane Emily ........................................156

4.51 6-hour wind speed increase model for Hurricane Emily .................................157

4.52 24-hour pressure drop model for Hurricane Irene ........................................160

4.53 24-hour wind speed increase model for Hurricane Irene .................................162

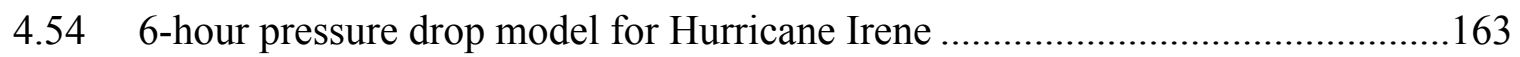

4.55 6-hour wind speed increase model for Hurricane Irene...................................165

4.56 24-hour pressure drop model for Hurricane Katrina......................................169 
4.57 24-hour wind speed increase model for Hurricane Katrina ..............................171

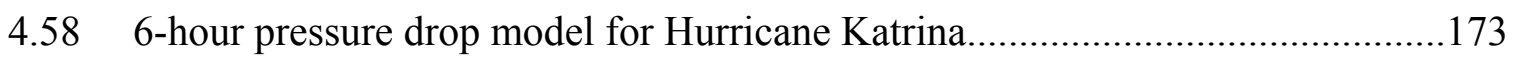

4.59 6-hour wind speed increase model for Hurricane Katrina .................................175

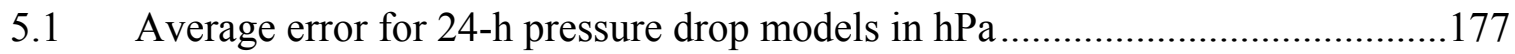

5.2 Average error for 24-h wind speed increase models in knots...........................179

5.3 T-test of the difference between the average errors of the DFA, CSM, and NHC.

5.4 Average error for 6-h pressure drop models in $\mathrm{hPa}$....................................... 183

5.5 Average error for 6-h wind speed increase models in knots.............................185 


\section{LIST OF FIGURES}

$\begin{array}{ll}\text { Figure } & \text { Page }\end{array}$

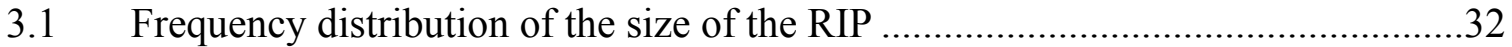

3.2 Schematic of two-layer ocean model approach to compute upper level thickness and eventually tropical cyclone heat potential (courtesy Goni et al. 1996)

3.3 Tracks of the 103 hurricanes are shown. The minor hurricanes are depicted in yellow and major hurricanes are depicted in red...............................38

3.4 The 5 by 5 grid "box" averaging technique ..................................................

3.5 Flowchart representation of the procedures used in the statistical analyses ..........48

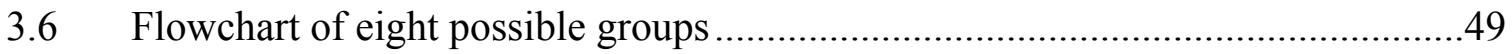

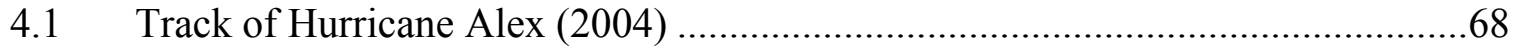

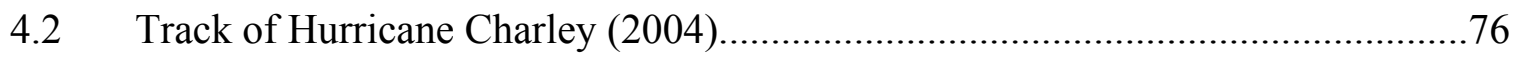

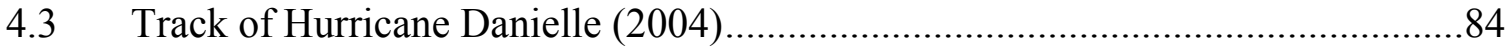

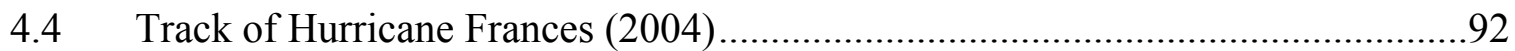

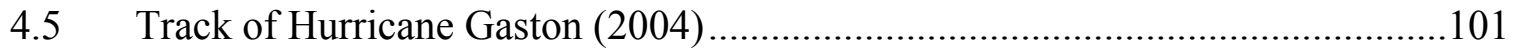

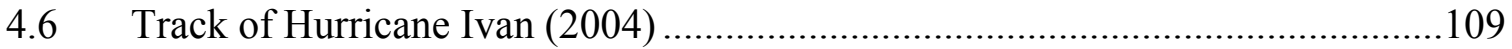

4.7 Track of Hurricane Jeanne (2004) ........................................................ 118

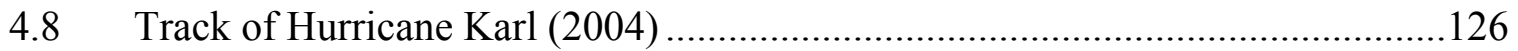

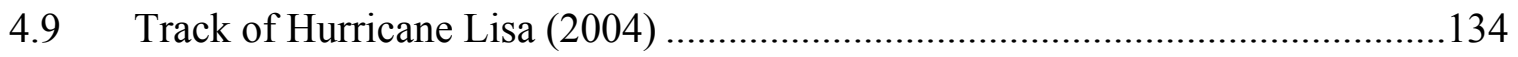

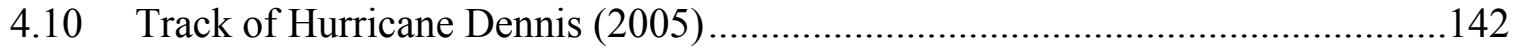


4.11 Track of Hurricane Emily (2005) ……………...........................................150

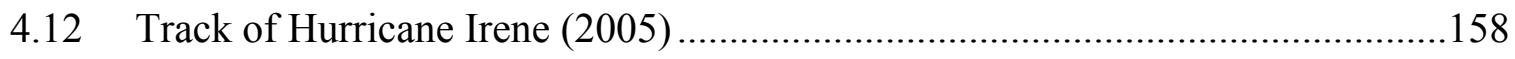

4.13 Track of Hurricane Katrina (2005) ...................................................................

A.1 The figure shows Hurricane Debby's (1988) track prior to

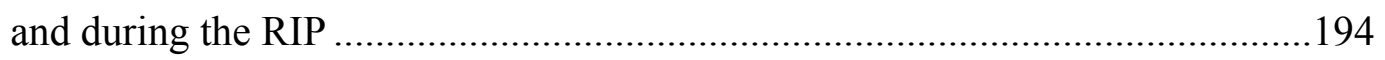

A.2 As in Figure A.1, except for Hurricane Florence (1988) .......................................194

A.3 As in Figure A.1, except for Hurricane Gilbert (1988).......................................195

A.4 As in Figure A.1, except for Hurricane Helene (1988).......................................195

A.5 As in Figure A.1, except for Hurricane Joan (1988)............................................196

A.6 As in Figure A.1, except for Hurricane Keith (1988) .........................................196

A.7 As in Figure A.1, except for Hurricane Chantal (1989) ………………….........197

A.8 As in Figure A.1, except for Hurricane Dean (1989) ……………………..........197

A.9 As in Figure A.1, except for Hurricane Erin (1989) ...........................................198

A.10 As in Figure A.1, except for Hurricane Felix (1989)............................................198

A.11 As in Figure A.1, except for Hurricane Gabrielle (1989) ......................................199

A.12 As in Figure A.1, except for Hurricane Hugo (1989) .........................................199

A.13 As in Figure A.1, except for Hurricane Jerry (1989) ..........................................200

A.14 As in Figure A.1, except for Hurricane Bertha (1990) …………........................200

A.15 As in Figure A.1, except for Hurricane Diana (1990) ........................................201

A.16 As in Figure A.1, except for Hurricane Gustav (1990).......................................201

A.17 As in Figure A.1, except for Hurricane Isidore (1990)......................................202

A.18 As in Figure A.1, except for Hurricane Josephine (1990) ..................................202 
A.19 As in Figure A.1, except for Hurricane Klaus (1990)....................................203

A.20 As in Figure A.1, except for Hurricane Lili (1990) .........................................203

A.21 As in Figure A.1, except for Hurricane Nana (1990) ......................................204

A.22 As in Figure A.1, except for Hurricane Bob (1991) .........................................204

A.23 As in Figure A.1, except for Hurricane Claudette (1991)................................205

A.24 As in Figure A.1, except for Hurricane Grace (1991) .....................................205

A.25 As in Figure A.1, except for Hurricane Andrew (1992) ...................................206

A.26 As in Figure A.1, except for Hurricane Bonnie (1992) ..................................206

A.27 As in Figure A.1, except for Hurricane Charley (1992) ...................................207

A.28 As in Figure A.1, except for Hurricane Frances (1992) .................................207

A.29 As in Figure A.1, except for Hurricane Emily (1993) .....................................208

A.30 As in Figure A.1, except for Hurricane Floyd (1993)....................................208

A.31 As in Figure A.1, except for Hurricane Gert (1993) .....................................209

A.32 As in Figure A.1, except for Hurricane Harvey (1993) ...................................209

A.33 As in Figure A.1, except for Hurricane Chris (1994) .....................................210

A.34 As in Figure A.1, except for Hurricane Florence (1994) ..................................210

A.35 As in Figure A.1, except for Hurricane Gordon (1994).................................211

A.36 As in Figure A.1, except for Hurricane Allison (1995) ..................................211

A.37 As in Figure A.1, except for Hurricane Erin (1995) ....................................212

A.38 As in Figure A.1, except for Hurricane Felix (1995) ....................................212

A.39 As in Figure A.1, except for Hurricane Humberto (1995)...............................213

A.40 As in Figure A.1, except for Hurricane Iris (1995)......................................213 
A.41 As in Figure A.1, except for Hurricane Luis (1995) .....................................214

A.42 As in Figure A.1, except for Hurricane Marilyn (1995) ..................................214

A.43 As in Figure A.1, except for Hurricane Noel (1995) .....................................215

A.44 As in Figure A.1, except for Hurricane Opal (1995) .....................................215

A.45 As in Figure A.1, except for Hurricane Roxanne (1995) ................................216

A.46 As in Figure A.1, except for Hurricane Tanya (1995) ...................................216

A.47 As in Figure A.1, except for Hurricane Bertha (1996) ...................................217

A.48 As in Figure A.1, except for Hurricane Cesar (1996) ....................................217

A.49 As in Figure A.1, except for Hurricane Dolly (1996)....................................218

A.50 As in Figure A.1, except for Hurricane Edouard (1996) .................................218

A.51 As in Figure A.1, except for Hurricane Fran (1996) ........................................219

A.52 As in Figure A.1, except for Hurricane Hortense (1996) ................................219

A.53 As in Figure A.1, except for Hurricane Isidore (1996) ...................................220

A.54 As in Figure A.1, except for Hurricane Lili (1996) ........................................220

A.55 As in Figure A.1, except for Hurricane Marco (1996) ....................................221

A.56 As in Figure A.1, except for Hurricane Bill (1997) ......................................221

A.57 As in Figure A.1, except for Hurricane Danny (1997) ..................................222

A.58 As in Figure A.1, except for Hurricane Erika (1997) .....................................222

A.59 As in Figure A.1, except for Hurricane Bonnie (1998) .................................223

A.60 As in Figure A.1, except for Hurricane Danielle (1998) .................................223

A.61 As in Figure A.1, except for Hurricane Earl (1998) .....................................224

A.62 As in Figure A.1, except for Hurricane Georges (1998).................................224 
A.63 As in Figure A.1, except for Hurricane Ivan (1998) .....................................225

A.64 As in Figure A.1, except for Hurricane Jeanne (1998) .....................................225

A.65 As in Figure A.1, except for Hurricane Karl (1998) .......................................226

A.66 As in Figure A.1, except for Hurricane Lisa (1998) .......................................226

A.67 As in Figure A.1, except for Hurricane Mitch (1998) .....................................227

A.68 As in Figure A.1, except for Hurricane Nicole (1998) .....................................227

A.69 As in Figure A.1, except for Hurricane Bret (1999) ........................................228

A.70 As in Figure A.1, except for Hurricane Cindy (1999) ....................................228

A.71 As in Figure A.1, except for Hurricane Dennis (1999)...................................229

A.72 As in Figure A.1, except for Hurricane Floyd (1999)....................................229

A.73 As in Figure A.1, except for Hurricane Gert (1999) ........................................230

A.74 As in Figure A.1, except for Hurricane Irene (1999) ......................................230

A.75 As in Figure A.1, except for Hurricane Jose (1999) .......................................231

A.76 As in Figure A.1, except for Hurricane Lenny (1999)....................................231

A.77 As in Figure A.1, except for Hurricane Alberto (2000)...................................232

A.78 As in Figure A.1, except for Hurricane Debby (2000) ..................................232

A.79 As in Figure A.1, except for Hurricane Florence (2000) ................................233

A.80 As in Figure A.1, except for Hurricane Isaac (2000) ....................................233

A.81 As in Figure A.1, except for Hurricane Joyce (2000) ....................................234

A.82 As in Figure A.1, except for Hurricane Keith (2000) ...................................234

A.83 As in Figure A.1, except for Hurricane Michael (2000) .................................235

A.84 As in Figure A.1, except for Hurricane Erin (2001) .....................................235 
A.85 As in Figure A.1, except for Hurricane Felix (2001)........................................236

A.86 As in Figure A.1, except for Hurricane Gabrielle (2001) ..................................236

A.87 As in Figure A.1, except for Hurricane Humberto (2001)..................................237

A.88 As in Figure A.1, except for Hurricane Iris (2001)...........................................237

A.89 As in Figure A.1, except for Hurricane Karen (2001) .......................................238

A.90 As in Figure A.1, except for Hurricane Michelle (2001)....................................238

A.91 As in Figure A.1, except for Hurricane Noel (2001) ..........................................239

A.92 As in Figure A.1, except for Hurricane Olga (2001) .........................................239

A.93 As in Figure A.1, except for Hurricane Gustav (2002)........................................240

A.94 As in Figure A.1, except for Hurricane Isidore (2002) ......................................240

A.95 As in Figure A.1, except for Hurricane Kyle (2002) ............................................241

A.96 As in Figure A.1, except for Hurricane Lili (2002) .............................................241

A.97 As in Figure A.1, except for Hurricane Claudette (2003)..................................242

A.98 As in Figure A.1, except for Hurricane Danny (2003) .....................................242

A.99 As in Figure A.1, except for Hurricane Erika (2003) ..........................................243

A.100 As in Figure A.1, except for Hurricane Fabian (2003) .......................................243

A.101 As in Figure A.1, except for Hurricane Isabel (2003) ........................................244

A.102 As in Figure A.1, except for Hurricane Juan (2003)........................................244

A.103 As in Figure A.1, except for Hurricane Kate (2003) ........................................245 


\section{CHAPTER 1}

\section{INTRODUCTION}

Tropical cyclones are the most destructive and costliest of atmospheric phenomena. In fact, 6 of the 10 most expensive weather disasters in United States history were by direct result from tropical cyclones (Elsner and Kara 1999). The coastal population has been increasing all over the United States, but especially along the U.S. Gulf and Atlantic coasts, which are the most susceptible to tropical cyclone damage. The rise in population primarily came during the 1970's and early 1980's, which was a time period of reduced frequency in the landfall of major hurricanes. With the increased populations along the coastline, today's society is more vulnerable to tropical cyclones than ever.

The average annual losses due to hurricanes in the early 1980's were approximately $\$ 1$ billion, which is about five times the average annual damage during the 1950’s (Chen 1995). More recently, Hurricane Andrew (1992) and Hurricane Hugo (1989) caused a combined $\$ 35$ billion (not adjusted for inflation) in insured property losses. As a result of this catastrophic impact on the property insurance industry, nine companies filed for bankruptcy (Changnon et al. 1997). This incident caused more awareness of the potential economic impacts of tropical cyclones. During the active 2004 
and 2005 hurricane seasons, five of the six costliest hurricanes in history struck the U.S. with a combined estimated value of over $\$ 100$ billion in damage

Tropical cyclones cause their damage through storm surge, wind, and flooding. Storm surge is responsible for the majority of the damage along the coastline as the wind and falling pressure cause the sea level to rise. As previously noted, the increased economic damage is due to the dramatic increase in coastal population and infrastructure over recent years. Wind stress also causes most of its damage near the coastline. Heavy rainfall that often accompanies tropical cyclones is also the most abundant near the coastline. Sometimes as the storm moves further inland, a secondary maximum in rainfall can be located near the Appalachian Mountains where the orographic lifting can cause the rainfall to intensify further.

The potential damage caused by tropical cyclones rises with increasing tropical cyclone intensity. To help compare storms and estimate the potential hazardous impacts of flooding and other property damage, the Saffir-Simpson scale is widely used (Table 1.1). The five category scale classifies hurricanes based on the maximum sustained winds of the tropical cyclone, and provides characteristics that are representative of each category of storm. Typically, a hurricane that is Category 1 or Category 2 is considered "minor" while hurricanes that are Category 3 or greater (winds greater than $111 \mathrm{mph}$ ) are generally regarded as "major". 


\begin{tabular}{|c|c|c|c|}
\hline Category & Winds (mph) & Winds (m s ${ }^{-1}$ ) & Minimum \\
\hline 1 & $74-95$ & $33.3-43.2$ & $\geq 980$ \\
\hline 2 & $96-110$ & $43.2-50$ & $965-979$ \\
\hline 3 & $111-130$ & $50-59$ & $945-964$ \\
\hline 4 & $131-155$ & $59-69.75$ & $920-944$ \\
\hline 5 & $>155$ & $>69.75$ & $<920$ \\
\hline
\end{tabular}

Table 1.1: Saffir-Simpson Scale

Since major hurricanes are more likely to cause damage due to their greater intensity, prediction of the development of major hurricanes would be an enormous benefit. The majority of major hurricanes undergo a very deep rapid intensification period or RIP. In other words, these major storms experience a very rapid drop in minimum surface pressure over a short time period which causes them to intensify quickly. Different factors contribute to the process of rapid intensification ultimately creating a major hurricane.

Currently, predicting which tropical cyclones will develop into major hurricanes is extremely difficult. Contemporary models are often inaccurate or slow to predict major hurricane development, which makes finding a better way to predict major hurricane development and an accurate intensity prediction scheme all the more essential to produce accurate warnings of land falling tropical cyclones. By and large, slow 
tropical cyclone intensification is predicted relatively well. Average 24-hour intensity forecasts produce errors on the order of $10 \mathrm{kt}$ or $5 \mathrm{~m} \mathrm{~s}^{-1}$ (Titley and Elsberry 1999). On the other hand, rapid intensification prediction needs improvement since $5 \%$ of the 24 hour intensity forecasts have errors greater than $40 \mathrm{kt}$ or $20 \mathrm{~m} \mathrm{~s}^{-1}$. Large forecasting errors of a rapidly intensifying tropical cyclone could be catastrophic given that the public would not have adequate time to respond. Since the majority of major hurricanes undergo a very deep RIP, it is important to understand the physical mechanisms that produce rapid intensification. Knowledge of the relative importance of the different variables that factor into rapid intensification will improve the ability to predict the short term central pressure drop and wind speed increase. Once the skill exists to predict the degree of intensification, via central pressure decrease or wind speed increase, it will greatly improve the accuracy of prediction of the formation of a major hurricane. The prediction of tropical cyclone rapid intensification is especially crucial because of the increasing coastal populations.

The purpose of the research described in this dissertation is to improve the intensity prediction of Atlantic hurricanes. Since the accuracy of intensity forecasts lag the accuracy of track forecasts, it extremely important to develop this aspect of hurricane forecasting. By identifying when a tropical cyclone is about to undergo rapid intensification, it will help to forecast the short-term pressure reduction and wind speed increase. This research implements a statistical method, discriminant function analysis, to help identify how intense the tropical cyclone will become and how close it is to rapidly intensifying. Based upon the intensity and its proximity to its rapid intensification period, an appropriate regression model is applied to forecast the 24-hour 
and 6-hour pressure reduction and wind speed increase. This method distinguishes itself by relying on the premise that factors which cause intensification affect the tropical cyclone differently throughout its life cycle. The discriminant function analysis helps identify those different stages and characteristics, which in turn allows the regression model to use the most significant variables at that particular stage. Therefore, this will help improve the intensity forecasts at the stages leading up to and during the rapid intensification, which happen to be the most difficult stages to predict.

The literature review of prior research on this topic is presented in Chapter 2 and the scientific objective and methodology of this research are presented in Chapter 3. The model results for the 13 independent case studies which are used to validate the accuracy of the forecasts are shown in Chapter 4, while Chapter 5 is a summary and conclusion of the study. 


\section{CHAPTER 2}

\section{LITERATURE REVIEW}

\subsection{Environmental Influences on Tropical Cyclone Intensity Change}

Rapid intensification of recent tropical cyclones has alerted forecasters to the need to improve its prediction. Among the improvements that need to be addressed include the timing, duration, and magnitude of the rapid intensification periods (RIPs) (Kaplan and DeMaria 2002). In order to attempt to improve the prediction of the magnitude of these RIPs, key predictors of rapid intensification must first be identified. From the values of these key predictors, it is hypothesized that the magnitude of rapid intensification can be predicted and therefore the prediction of major hurricanes will be improved. Such hypothesized predictors that have been investigated include vertical wind shear and maximum potential intensity. Few studies, until recently, have been performed in this area making it an essential priority. For example, the Kaplan and DeMaria study (2002) attempted to utilize the SHIPS (DeMaria and Kaplan 1999) model to estimate the probability of rapid intensification over a 24 -hour period. The purpose of that analysis was to discover potential predictors that could be used as a rapid intensification forecasting tool. 


\subsection{Potential Rapid Intensification Predictors}

In the Kaplan and DeMaria $(1999,2000)$ study, the dataset consisted of Atlantic basin tropical cyclones that were at least tropical depression strength during the years 1989-2000. A collection of climatological and persistence and synoptic variables were examined for the their potential links to rapid intensification. For the purpose of their study, a rapid intensification period was defined as having an increase in maximum sustained wind speed of $15.4 \mathrm{~m} \mathrm{~s}^{-1}$ over a 24-hour period. This corresponded with the $95^{\text {th }}$ percentile of all 24-hour tropical cyclone intensity changes in the Atlantic basin. Each of the variables was then assessed for each 24-hour period. Values were calculated for the rapid intensification cases as well as the non-rapid intensification cases. As a result, threshold values for rapid intensification were determined for each variable. By comparing the threshold value with the initial value of each case, the probability of occurrence was then calculated. Kaplan and DeMaria found five variables with the highest individual probability and their respective threshold values: 12 - hour intensity change ( $\left.\geq 4.6 \mathrm{~m} \mathrm{~s}^{-1}\right) ; 850-200 \mathrm{mb}$ vertical wind shear $\left(\leq 4.9 \mathrm{~m} \mathrm{~s}^{-1}\right)$; maximum potential intensity minus maximum sustained winds $\left(\geq 47.9 \mathrm{~m} \mathrm{~s}^{-1}\right)$; sea surface temperature ( $\geq 28.4$ $\left.{ }^{\circ} \mathrm{C}\right)$; and $850-700 \mathrm{mb}$ relative humidity $(\geq 70 \%)$.

Alone, these variables only produced probabilities of rapid intensification on the order of $6 \%$, with the highest individual variable producing a $15 \%$ probability of rapid intensification. However, when all five of these variables were satisfied, the probability of rapid intensification increased to $40 \%$. The results suggested that many different physical processes must be taken into account when examining rapid intensification. 
This was a promising study in showing potential for these variables being used as a forecasting tool. It is particularly important given the fact approximately $80 \%$ of all major hurricanes in the Atlantic basin that developed during 1989-2000 underwent a rapid intensification period (Pielke and Landsea 1998). The most intense tropical cyclones usually undergo a period of rapid intensification which validates the importance of understanding this problem.

\subsection{Other Factors Affecting Rapid Intensification}

Not only is it important to understand the factors that drive rapid intensification, but the reasons for rapid weakening are equally important. For example, the rapid deterioration of Hurricane Opal as it approached the Gulf Coast has garnered a great amount of interest regarding the physical processes involved. There are four factors generally regarded as having the most impact in the de-intensification process. First, large vertical wind shear is believed to be extremely adverse for intensification. DeMaria and Huber (1998) and Jones (1998) stated that vertical wind shear above a particular threshold level seemed to prohibit intensification especially when the storm was at least tropical storm status. On the other hand, Molinari (1998) cautioned that some storms have intensified in spite of high vertical wind shear because of the relationships with upper-level troughs. Some have even questioned the reliability of vertical wind shear estimates due to the sparse data in the Tropics (Elsberry and Jeffries 1996). This could be the essential reason why intensification predictions are poor. When the vertical wind shear is low, that is below some critical threshold, there is less agreement as to if and how a tropical cyclone will intensify. Zehr (1998) has suggested that vertical wind shear was 
the only atmospheric mechanism affecting tropical cyclone intensity, while others have advocated that the role of other atmospheric mechanisms have in intensity change depended on the amount of shear involved (DeMaria and Huber 1998).

The second process affecting tropical cyclone intensification is the interaction with upper-level troughs. However, this issue is also strongly debated. Pfeffer (1958) was the first to recognize that a nearby trough can cause an eddy angular momentum flux convergence in the upper-levels. Molinari (1998) called this a "good trough" that would enhance tropical cyclone intensification. This positioning of the trough was thought to feature positive potential vorticity which would boost the development of the storm. On the other hand, the positioning of the trough may increase the vertical wind shear and then would be considered a "bad trough" for intensification. DeMaria et al. (1993) have studied the effects of eddy angular momentum flux events on tropical cyclone intensity changes. However, they found the flux events were not always correlated with the intensity changes. This suggested the timing and where the flux occurred were just as important as the overall strength of the storm at the time of the forcing. Therefore, the role of trough interaction upon tropical cyclone intensification has still not been satisfactorily determined.

Sea surface temperatures are also regarded as a key factor impacting intensification. It has long been generally accepted that water temperatures of at least $26^{\circ} \mathrm{C}$ are needed for tropical cyclones to form (Palmen 1948). High sea surface temperatures create an energy source for the tropical cyclone. An enormous amount of water vapor is extracted from the ocean, which ultimately condenses releasing latent energy and further "fuels" the storm. 
The fourth issue is the internal dynamics of how energy is gained and released to the boundary layer. There are two predominant theories for explaining tropical cyclone intensification. The first theory, Conditional Instability of the Second Kind (CISK), hypothesized that the cumulus cell supplies the heat for driving the depression and the depression then produces the low-level convergence into the cumulus cell (Charney and Eliassen 1964). Therefore, the release of latent energy drives the circulation, which then provides moisture into the system. The second theory hypothesized that the surface fluxes are important in the development and intensification of tropical cyclones (Emanuel 1986). This theory, Wind Induced Surface Heat Exchange or WISHE, involves air-sea transfers of latent and internal energy.

\subsection{Wind Shear Processes}

Vertical wind shear has been the key predictor of rapid intensification that has been studied more than the other predictors. In fact, the effects of vertical wind shear on tropical cyclone intensity change have been discussed for many years. Weightman (1919) made some of the first primitive observations of irregular easterly winds that were influential in the creation of a hurricane that moved through the Florida Keys into the Gulf of Mexico. He noticed that when upper-level winds shifted from the west to the east, the storm intensified. When upper-level wind data became accessible in 1935, Riehl and Shafer (1944) showed that large wind shear between the upper-level westerlies and the lower-level easterlies often prohibited the development and strengthening of a hurricane in the Atlantic basin. Other investigations (Gray 1968; Merrill 1988; Zehr 
1992) have shown the negative impacts of vertical wind shear during the genesis and the intensification stages of tropical cyclone development.

Studies have consistently shown that vertical wind shear has a harmful effect on intensification and genesis, but different hypotheses have been proposed to explain the physical association. Riehl and Shafer (1944) suggested a dynamic effect by claiming "strong shear prevents the development of intense rotating vortices" (DeMaria and Huber 1998). Subsequently, Gray (1968) advanced one of the most common explanations for wind shear effects. In order for the surface pressure to decrease, there must be slightly more net tropospheric mass divergence than mass convergence. Gray noticed that large vertical wind shears tended to be major inhibitors to hurricane development. He hypothesized that large vertical wind shears "do not allow for area concentration of the tropospheric distributed cumulonimbus condensation.” In other words, the shear redirected the heat away from the disturbance. Gray stated that the latent heat of condensation "released by the cumulus to the upper troposphere is advected in a different direction relative to the released heat at lower levels. Concentration of heat through the entire troposphere becomes more difficult." This is known as the "ventilation" effect. It offered a good explanation of the physical mechanisms involved and clarified why vertical wind shear played a negative influence on hurricane development.

A second explanation for wind shear effects was generated when Tuleya and Kurihara (1981) and Bender (1997) used numerical simulations to analyze wind shear. They suggested a "secondary circulation effect" which assumed the cyclone will go through an area with strong shear, and an asymmetric inflow and outflow will result. The area of heating will not remain in phase with the warm core, thereby reducing the storm 
intensity. The secondary circulations could also reduce intensity by bringing cool, dry air near the eye wall.

Overwhelming evidence demonstrates that large-scale vertical wind shear has a negative impact on tropical cyclone formation (Gray 1968, 1979; Tuleya and Kurihara 1981). It is also generally recognized that mature tropical cyclones are more resilient to vertical wind shear than developing tropical cyclones. Merrill (1988) examined the upper-tropospheric environmental flows for intensifying and non-intensifying tropical cyclones. In his study, he noticed that vertical wind shear tended to be less for intensifying tropical cyclones. This was particularly valid at radii of at least $1000 \mathrm{~km}$. He justified his conclusion by asserting that no intensifying tropical cyclone had greater vertical wind shear than a non-intensifying tropical cyclone in his study. However, there were no significant differences in vertical wind shear between the two categories. These results were not unanticipated because they were consistent with previous studies (e.g. Erickson 1974; Simpson and Riehl 1958). Nevertheless, strong vertical wind shear is widely accepted as being detrimental to the intensification of tropical cyclones.

However, vertical wind shear does not entirely have a negative effect. Gray suggested (1968 and 1975) that vertical wind shear below some critical threshold value was favorable for tropical cyclone development. McBride and Zehr (1981) drew similar conclusions citing a certain threshold shear magnitude that was critical for development. The National Hurricane Center (NHC) of the National Oceanographic and Atmospheric Administration (NOAA) currently uses vertical wind shear as a predictor in its Statistical Hurricane Intensity Prediction Scheme (SHIPS) (DeMaria and Kaplan 1994, 1999). 
SHIPS was developed for use in the Atlantic basin and employs a variety of climatological, persistence, and synoptic predictors to forecast the intensity of tropical cyclones. The research used to develop SHIPS primarily examined the vertical wind shear on Atlantic tropical cyclones and demonstrated that as the vertical wind shear increased between $200 \mathrm{mb}$ and $850 \mathrm{mb}$, the tropical cyclone decreased in intensity. The results of this research showed that vertical wind shear of approximately $8 \mathrm{~m} \mathrm{~s}^{-1}$ over the core of the tropical cyclone typically caused the storm to weaken. These results are similar to the findings of Fitzpatrick (1996), which also showed that vertical wind shear values between the $200 \mathrm{mb}$ and $850 \mathrm{mb}$ levels of more than the threshold value of $8.5 \mathrm{~m}$ $\mathrm{s}^{-1}$, were unfavorable to tropical cyclone amplification. Zehr (1992) used the Australian Bureau of Meteorology real-time analyses on North Pacific Ocean tropical cyclones to demonstrate that tropical cyclones in the western North Pacific did not intensify when the vertical wind shear was more than the threshold value of $12 \mathrm{~m} \mathrm{~s}^{-1}$. Additional studies investigating vertical wind shear have suggested that a "pocket" of minimum vertical wind shear might be located between two areas of large vertical wind shear. Other observational analyses have investigated the relationships between vertical wind shear and the distribution of convection around the eyewall region. These examinations have shown the typical area for maximum rainfall usually occurs on the downshear, left side (Marks et al. 1992; Franklin et al. 1993).

\subsection{Vertical Wind Shear Numerical Simulation Studies}

The effects of vertical wind shear on tropical cyclone intensification have been tested in numerical simulations. Frank and Ritchie (2001) analyzed the simulations of 
vortices in a shear environment and compared those to vortices implanted in a uniform zonal flow environment. They noticed a series of characteristics as the storm weakened due to the shear. First, the structure of the storm core became asymmetric in terms of vertical motion, cloud water, and rain water almost directly after the shear was applied to the simulation. Consistent with previous studies (Marks et al. 1992; Franklin et al. 1993), the asymmetries were most prominent on the downshear, left side of the shear. Secondly, the warm core in the upper levels deteriorated which allowed the surface pressure to rise, thereby weakening the circulation. As this asymmetric configuration continued with time, the depth of the primary circulation became shallower which weakened the storm. However, since the primary circulation is usually stronger at the lower levels, the weakening may stop at some point leading to a stability of the storm well below its maximum potential intensity. Finally, their studies showed that vertical wind shear near $15 \mathrm{~m} \mathrm{~s}^{-1}$ severely weakened tropical systems, while $5 \mathrm{~m} \mathrm{~s}^{-1}$ shears still allowed the storm to remain a weak hurricane.

Montgomery and Kallenbach (1997) stated that asymmetries in idealized tropical cyclones tend to weaken over time because the energy is axisymmetrized and distributed into the mean flow. In the Frank and Ritchie simulation, the storms were able to also withstand the shear for a given duration of time. With shear of $5 \mathrm{~m} \mathrm{~s}^{-1}$, the storms maintained their structure for about a day and a half. The storms maintained their structure for about 24-30 hours in $10 \mathrm{~m} \mathrm{~s}^{-1}$ shear. Therefore, the simulated tropical cyclones were able to endure a certain level of vertical wind shear, which lent credibility to the critical threshold value argument. 


\subsection{Vertical Wind Shear Observational Studies}

Only a small number of observational studies have analyzed the role of vertical wind shear on tropical cyclone asymmetry. It has been recognized that updrafts rise in a helical pattern in the center of intense tropical cyclones (Franklin et al. 1993). This is due in part to the convective instability and slight vertical movement in the center of the tropical cyclone (Bogner et al. 2000; Black et al. 1996) and the significant tangential velocity near the center of the storm. The reason the vertical updraft is a helical pattern is because the time needed for the air to rise from the surface to the tropopause is of the same magnitude as the horizontal circulation. Therefore, there is a displacement between the beginning of the updraft, the maximum updraft velocity, and the maximum precipitation (Corbosiero and Molinari 2002). Strong vertical wind shear tends to accentuate this displacement, and maximum eyewall reflectivity has been known to occur $180^{\circ}$ from the shear vector. In other words, because of strong vertical wind shear, the maximum eyewall reflectivity can actually occur upshear (Franklin et al. 1993). More recently, Frank and Ritchie (2001) have shown that the area of maximum rainfall tended to range from $90^{\circ}$ left of the shear vector to upshear of the vector in the eyewall. All of this was transpiring while the maximum upward motion was $45^{\circ}$ left of the shear vector.

Altogether, several analyses have drawn similar conclusions with regard to the role of vertical wind shear in the storm's center (Franklin et al. 1993; Gamache et al. 1995; Reasor et al. 2000). When vertical wind shear was between 7 and $15 \mathrm{~m} \mathrm{~s}^{-1}$, updrafts generated downshear, the maximum vertical motion in the center of the storm was downshear left, and the area of maximum precipitation spread counterclockwise. However, when the vertical wind shear was near $3 \mathrm{~m} \mathrm{~s}^{-1}$, the storm exhibited a more 
axisymmetric configuration (Gamache et al. 1995; Reasor et al. 2000). It is important to note that these studies did not include the possibility of convective asymmetries outside the interior region.

\subsection{Vertical Wind Shear Individual Case Studies}

Zehr (1998) studied the effects of vertical wind shear on Hurricane Bertha. He noticed that the direction of the shear played a major role in the intensification process. In the case of Hurricane Bertha, the change of shear direction helped align the storm vertically. Hurricane Bertha was initially sheared from the west but changed to the southeast before it made landfall. This allowed the storm to align itself vertically and also coincided with its rapid intensification. Observations showed the minimum surface pressure in Hurricane Bertha dropped from $991 \mathrm{mb}$ to $974 \mathrm{mb}$ in under 9 hours. Zehr hypothesized that vertical wind shear is the most important atmospheric influence intensity change potential.

Elsberry and Jeffries (1996) intended to show that real-time wind analyses may not give reasonable vertical wind shear values in the areas of tropical cyclone genesis and intensification. They examined and calculated the vertical wind shear for analyzed winds between 200 and $850 \mathrm{mb}$ for Tropical Storm Steve and Tropical Cyclone Omar. The observations and the numerical models were taken from the Fleet Numerical Meteorology and Oceanography Center. The Center's analyses showed strong winds at the $200 \mathrm{mb}$ level, which led to large vertical wind shear. The vertical shear surpassed Zehr's (1992) threshold value of $12 \mathrm{~m} \mathrm{~s}^{-1}$, yet these storms intensified. The outflow from the developing storm offset the strong upper-level winds. Therefore, the tropical storm 
did not become "tilted" but remained stacked vertically, which is the most efficient orientation for heat transfer. In other words, the upper-level outflow did not become separated from the lower-level circulation. The $200 \mathrm{mb}$ winds were actually deflected around the convective outflow. When Elsberry and Jeffries took this into account and interpolated the vertical wind shear, their interactive analyses produced values less than Zehr's threshold value, which is in agreement with the observed intensification of Tropical Storm Steve and Tropical Cyclone Omar. They also hypothesized that the large vertical wind shear is actually located in a shallow layer concentrated around the $200 \mathrm{mb}$ layer in lower latitude storms. Conversely, the vertical wind shear was distributed more evenly in mid-latitude storms. Furthermore, they assumed that the outflow from a tropical cyclone would be more effectively offset from the shallow layer wind shear associated with lower-latitude circulations.

Weak vertical shear was one of the key factors in Typhoon Flo's intensification. Wu and Cheng (1999) suggested that although the vertical wind shear was weak, there was just enough wind shear to produce a favorable effect. A Tropical UpperTropospheric Trough (TUTT) enhanced the outflow from Typhoon Flo, which created mass divergence at the upper levels and allowed the storm to deepen. Wu and Cheng speculated that the determining intensification factor with vertical wind shear was the positioning of the upper-level trough relative to the storm. They hypothesized that if the upper-level trough was positioned directly over the center of the storm the strong vertical wind shear could "tear the storm apart". However, if the upper-level trough was positioned a certain distance to the north from the storm center, the outflow can 
counteract the negative vertical wind shear effects from the trough. These are known as "good trough" versus "bad trough" arguments.

Titley and Elsberry (2000) similarly analyzed the rapid intensification of Supertyphoon Flo but cautioned that a single case study cannot adequately explain all of the factors responsible for tropical cyclone intensification. However, they summarized some of the characteristics that may have been conducive for intensification. The sea surface temperatures were relatively high between $28^{\circ}$ and $28.5^{\circ} \mathrm{C}$. Therefore, they suggested that the commonly regarded $26^{\circ} \mathrm{C}$ threshold sea surface temperature was not a factor. Also, the maximum potential intensity (MPI), which is based primarily on sea surface temperatures, would imply that Flo could attain a maximum sustained wind speed of $70 \mathrm{~m} \mathrm{~s}^{-1}$. Flo probably surpassed its potential maximum sustained wind speed. High sea surface temperatures are necessary for an intense tropical cyclone however, they do not necessarily guarantee rapid intensification (Titley and Elsberry 2000). Flo exhibited a warmer upper troposphere which helped create a good environment for rapid intensification.

As with Wu and Cheng (1999), Titley and Elsberry found weak 850-200 mb vertical wind shear in Flo. The vertical wind shear was very low compared to Zehr's (1992) threshold. While Flo intensified, the vertical wind shear diminished. On the other hand, they pointed out that Typhoon Ed had lower vertical wind shear than Flo, but did not intensify. Therefore, low $850-200 \mathrm{mb}$ vertical wind shear seems to be essential for rapid intensification, but low shear is not sufficient for intensification since some nonintensifying storms exhibit low wind shear. In this study, some of the aircraft observations in the inner core were insufficient, so many rapid intensification 
characteristics could not be determined. For example, the $850-200 \mathrm{mb}$ vertical wind shear in Flo reached a minimum during its most intense period, but this was more than likely an indicator, rather than a condition of rapid intensification. Flo also exhibited a strong outflow, which has been used as a forecasting tool for rapid intensification. However, Flo's radially averaged wind lessened which contradicted this stipulation. Hurricane Opal encountered both positive and negative vertical wind shear effects. Opal reacted with an upper-level trough and more specifically to a trough tail/jet entrance region (Bosart et al. 2000). The 850-200 mb vertical wind shear within $500 \mathrm{~km}$ of the center was approximately $2-3 \mathrm{~m} \mathrm{~s}^{-1}$. This "good trough" had a favorable effect and helped trigger intensification. At Opal's initial point of rapid intensification, the 850-200 mb vertical wind shear was approximately $1 \mathrm{~m} \mathrm{~s}^{-1}$ (Bosart et al. 2000). As Opal moved closer to the trough, it was located in the jet entrance region of a large-scale trough and came across strong 850-200 mb vertical wind shear. Opal's unfavorable storm-trough interaction or "bad trough" interaction resulted in rapid weakening. In summary, the positioning of the tropical cyclone relative to the upper-level trough was shown to be critical in the role of tropical cyclone intensification.

Black et al. (2002) looked at the inhibiting role of vertical wind shear on two eastern Pacific hurricanes, Hurricane Jimena of 1991 and Hurricane Olivia of 1994. They used airborne radar and in situ observation in order to better understand the effect of vertical wind shear on the storm's structure and intensity. Both storms were observed on two consecutive days. At first, each had a small eye with a radius of approximately 16-18 $\mathrm{km}$. The maximum winds were about $57 \mathrm{~m} \mathrm{~s}^{-1}$ in an easterly shear environment and the storms were located in an area of $>28^{\circ} \mathrm{C}$ sea surface temperatures. Jimena 
weakened slightly over a 2 day period while in $13-20 \mathrm{~m} \mathrm{~s}^{-1}$ vertical wind shear. Olivia, on the other hand, intensified while in $8 \mathrm{~m} \mathrm{~s}^{-1}$ vertical wind shear. When the shear increased to more than $15 \mathrm{~m} \mathrm{~s}^{-1}$, Olivia started to weaken. However, it could also be attributed to the cooler sea surface temperatures and the drier air that infiltrated the storm.

Black et al. (2002) concluded that shear controlled the convective structure of both storms. While in weak shear, Olivia intensified because the convection was structured in an axisymmetric manner. In the strong shear, the highest reflectivity was found on the left side of the shear thereby exhibiting asymmetric properties. Further proof could be found by observing the characteristics of the radar echoes. In the weaker shear, the radar echoes were located around the eye. Conversely, in the stronger shear no radar echoes were located around the eye. Instead they developed downshear and were also short lived.

\subsection{Thermodynamic Processes}

The majority of studies to date have examined the extensive, dynamic role of vertical wind shear. However, there also have been studies that have investigated the thermodynamic processes involved with tropical cyclone intensification. A thermodynamic method to treat tropical cyclones as heat engines was developed by Emanuel (1986). Additional studies by Emanuel $(1988,1991)$ showed that the work done by surface friction balances the energy released into the troposphere as air rises moist adiabatically. Usually the heat engine is in equilibrium with the surface at temperatures near $300 \mathrm{~K}$ and near the tropopause at temperatures near $200 \mathrm{~K}$. This equilibrium central pressure is the maximum potential intensity or MPI. Therefore, it is 
primarily a function of the sea surface temperature and the outflow temperature near the tropopause. Axisymmetric influences have also been used to estimate the MPI of a tropical cyclone in a given environment and thermodynamic configuration. The thermodynamic configuration is associated with the sea surface temperature, the depth of the troposphere, and the vertical stability of the extensive environment (Emanuel 1988; Holland (1997). DeMaria and Kaplan (1994) found that the most powerful Atlantic hurricanes for a given sea surface temperature produce MPIs which agree closely with this thermodynamic formula.

The majority of tropical cyclones fail to reach their MPI. The reasons are predominantly because of the detrimental effects of vertical wind shear and cooler storminduced sea surface temperatures. Tropical cyclones usually reach their MPI only when the storm is in its later stages or when it is traveling over colder water as it weakens or begins the transition to an extratropical system. However, when a tropical cyclone comes close to reaching its MPI in the tropics, it typically displays extraordinary symmetric properties. There have been different rationalizations for the tendency of storms to remain below their estimated MPIs. One explanation concerns the reduction of ocean energy fluxes to the storm. This is due to contact with the ocean mixed layer which cools the surface water, and other processes such as sea spray that can affect the nature of the near-surface layer. Another explanation concerns the role of asymmetry in the storm's core. Nearly every tropical cyclone exhibits some kind of asymmetry in vertical velocity, rainwater, or wind patterns in the inner core or in the outflow. The key is to find the reasons why the asymmetries prevent a tropical cyclone from reaching its MPI. Vertical wind shear is the most widely accepted process that is detrimental to tropical cyclone 
intensity because shear increases asymmetrical configurations. Another hypothesis acknowledges the role of vertical wind shear in inhibiting tropical cyclone formation when the shear is joined with other thermodynamic factors (Holland 1997). Early researchers believed that vertical wind shear prevented intensification because differential advection separated the upper warm anomaly from the low-level circulation (Simpson and Riehl 1958). However, it is now suggested that the vortex tilts downshear when shear is initiated (Jones 1995). The upper circulation is projected downward and the lower circulation is projected upward. This in turn causes the centers to rotate cyclonically around the mid-levels. In due course, the rotation stops, but the tilting of the axis increases. Therefore the shear combines with these weak thermodynamic factors to destabilize a tropical cyclone and ultimately prevents the storm from reaching its estimated MPI.

Emanuel (1999) utilized a coupled air-ocean model that showed Atlantic hurricane intensities may continue near their MPI because of the mixed layer ocean cooling that takes place. The study demonstrated that a storm's MPI may be influenced by this interaction more than originally thought. The coupled atmosphere-ocean model developed by Schade and Emanuel (1999) investigated the impact of oceanic interaction upon intensification. This model utilized such parameters as boundary layer humidity, sea surface temperature, tropopause temperature, storm size, storm translational velocity, oceanic mixed layer stratification, and the Coriolis parameter. Their results showed a stronger negative feedback that inhibits intensification when the storm moved slower, the potential intensity (equivalent to MPI) was larger, the oceanic mixed layer was thinner, the storm size was larger, higher relative humidity was in the boundary layer, and the 
storm was at lower latitudes. In fact, the model showed that oceanic feedback could reduce the hurricane's intensity by more than $50 \%$, which further demonstrated the important role of ocean thermodynamics on hurricane intensification.

In a similar study, Chan, Duan, and Shay (2000) showed in their oceanatmosphere coupled model that tropical cyclone intensification occurred when there is a sharp SST gradient and a locally deep ocean mixed layer. Again, it explained the importance of oceanic interaction. Other studies have tried to quantify how much the ocean can help in the intensification process. Shay et al. (2000) calculated the upper ocean heat content, which was defined as the thickness between the sea surface and the $20^{\circ} \mathrm{C}$ isotherm. This isotherm was chosen because it is a good indicator of the upper layer flow created by salinity differences. They also calculated the tropical cyclone heat potential by integrating the vertical temperature between the surface and the $26^{\circ} \mathrm{C}$ isotherm. Tropical cyclone heat potential is a good indicator of how much heat can be extracted from the available warm water. The $26^{\circ} \mathrm{C}$ threshold was chosen since this is the ocean temperature that is often deemed necessary to form and sustain a tropical cyclone. If the depth of the $26^{\circ} \mathrm{C}$ isotherm becomes shallow, then the tropical cyclone heat potential decreases and the tropical cyclone has less available warm water to "fuel" the storm. Conversely, if the $26^{\circ} \mathrm{C}$ isotherm becomes deeper, the tropical cyclone heat potential increases giving it more available warm water. In the case of Hurricane Opal, which passed through a warm core ring, they (Shay et. al. 2000) particularly noted that the depth of the $26^{\circ} \mathrm{C}$ isotherm became much shallower. This was indicative of cold upwelling which eventually weakened the storm prior to landfall. 
Cione and Uhlhorn (2003) further examined the upper-ocean thermal structure and its impact on changes in storm intensity. The factors that drive storm intensity change are still not well understood mostly due to inadequate grid resolution, simplified parameterization schemes, and the lack of observations within the inner core. The introduction of GPS dropwindsondes and airborne expendable bathythermographs allowed observations of the tropical cyclone inner and outer core boundary layer. Cione and Uhlhorn used this data in conjunction with archived SST data to analyze the differences in SSTs within the inner core and the ocean environment ahead of the storm. Their results showed that the difference between the inner core and the environmental SSTs were significantly less than horizontal SST changes in the post storm, "cold wake" environment. Differences in the SSTs between the inner core and the ambient environment were on the order of $0^{\circ}-2^{\circ} \mathrm{C}$ while the post storm differences were between $4^{\circ}-5^{\circ} \mathrm{C}$. They also found that the upper ocean heat content was at least an order of magnitude greater than the energy extracted by the storm and that a small alteration in inner core SSTs could significantly change the air-sea fluxes. Furthermore, Cione and Uhlhorn showed that the difference between the inner core and ambient SST change was statistically linked to tropical cyclone intensity change. This implied that the less inner core SST cooling that took place, the more likely it was for a storm to intensify due to the increased surface fluxes.

Dunion and Velden (2004) looked for possible factors that might suppress the intensity of tropical cyclones in the Atlantic. The North Atlantic averages about 10 named tropical cyclones a year, which is about $40 \%-60 \%$ less than the eastern and western North Pacific. They investigated the role of the Saharan Air Layer (SAL), which 
they hypothesized suppressed tropical cyclone activity in the North Atlantic. The SAL is a dry, mixed layer that forms in the late spring and continues through the autumn. It extends to approximately $500 \mathrm{mb}$ over Africa during the summer and is then undercut by a cool, low-level jet, which actually creates the SAL. The SAL is a warm inversion layer created by enhanced radiation absorption. This layer stabilizes the environment which inhibits tropical cyclone formation. Furthermore, an easterly jet enhances the vertical wind shear which is also detrimental to tropical cyclone formation. This causes a stabilizing inversion.

The SAL appeared to inhibit tropical cyclone formation by three methods. First, it brought dry, stable air into the system. Secondly, it enhanced the midlevel easterly jet which increased the vertical wind shear. Lastly, it enhanced the trade wind inversion, which tended to stabilize the atmosphere. Dunion and Velden looked at individual Atlantic storms that could have been affected by the SAL. For example, Hurricane Joyce (2000) was forecasted to increase in intensity from the period of September 28 through September 30. However, Joyce actually decreased in intensity on September 28 and continued to weaken through October 1 . This weakening was found to likely result from the interaction with the SAL and the resulting increased vertical wind shear. The study showed the importance of the combined dynamic and thermodynamic effects of the SAL on tropical cyclone intensification.

\subsection{Statistical Modeling of Tropical Cyclone Intensification}

Statistical intensity models have been able to outperform dynamic intensity models, especially in the short term forecast. DeMaria and Kaplan (1999) showed that 
the SHIPS model and Statistical Hurricane Forecast (SHIFOR) had less error than the Geophysical Fluid Dynamics Laboratory Interpolated (GFDI) model at the 24-hour forecast period. The average statistical 24-hour forecast errors for Atlantic Tropical Cyclones during the 1996-1997 season was approximately 11 knots, while error for the dynamic GFDI model was slightly higher at 11.6 knots.

The performance of these statistical models has driven further development of longer term intensity models and rapid intensification models. DeMaria and Kaplan (2003) have investigated the large-scale characteristics that may be responsible for a tropical cyclone undergoing rapid intensification. They found that rapidly intensifying tropical cyclones tended to form farther south and west and had a more westward component of motion. In addition, they tended to form in areas of warmer SSTs, had higher lower-tropospheric relative humidity values, weaker vertical wind shear, and were farther from their maximum potential intensity. The accuracy of track forecasts out to 5 days has created a demand for the development of intensity models out to 5 days as well. Knaff et al. (2003) developed their statistical 5-day intensity model and derived it from climatology and persistence data. Their model possessed similar errors, approximately 20 knots, in the Atlantic basin as with previous models.

However, these errors can be much greater with intense hurricanes. Franklin (2005) compared the average error of the statistical intensity models with the errors of dynamic intensity models for the 2004 hurricane season. The average 24 -hour forecast error ranged from 10.9 knots, which was the official NHC forecast, to 15.8 knots predicted by the dynamic Adjusted Global Forecast System, formerly Aviation, (GFSI) model. Only two dynamic models, Geophysical Fluid Dynamics Laboratory (GFDL) 
variants, were consistently more accurate. The average error for the 5-day Statistical Hurricane Forecast (SHIFOR5) model was 14.5 knots, approximately 25\% higher than the official NHC forecast, but this statistical model still performed better than many of the dynamic intensity models. This shows that statistical models currently have more skill than dynamic models but improvements can be made considering that the official NHC forecasts still have average 24-hour forecast errors in excess of 10 knots. The large errors for intensity forecasts in cases of rapid intensification demonstrate the need for research of the type presented in this dissertation. 


\section{CHAPTER 3}

\section{SCIENTIFIC OBJECTIVE AND METHODOLOGY}

\subsection{Introduction}

The purpose of this study is to provide an alternative method to improve 24-hour and 6-hour Atlantic tropical cyclone intensity forecasts. Currently, the official NHC issues $12,24,36,48,72,96$, and 120 hour forecasts every 6 hours. The average official NHC intensity forecasts outperform all intensity models at the 24-hour forecast period and all models with the exception of the Florida State Super-ensemble (FSSE) at all other time periods (Franklin 2005). Even though the official NHC forecasts remain the best, however the average error remains approximately 11 knots at the 24 -hour forecast period. Therefore, intensity forecasts can still be greatly improved at the 24-hour forecast period; in addition, shorter term forecasts (e.g. 6-hour) need to be added to provide better intensity forecasts.

This study gathers data from 3 sources: the NHC's Hurricane "Best Track"

dataset or HURDAT, the National Centers for Environmental Prediction/National Center for Atmospheric Research (NCEP/NCAR) Reanalysis dataset, and the Atlantic Oceanographic and Meteorological Laboratory (AOML) Tropical Cyclone Heat Potential dataset to formulate discriminant functions and regression equations to forecast central 
pressure and wind speed. The models presented in this study uniquely utilize a discriminant function analysis (DFA) to select from a collection of models derived from a multiple regression analysis. The method differs from previous studies in that not only are there different predictors used in the regression model equations, but different regression models can be selected by the DFA for different phases of a hurricane, as opposed to a single regression equation applied to the hurricane over its entire life. The DFA can be used to select the appropriate regression model based upon the characteristics of the hurricane, which gives this method more flexibility than currently used models. Performance of the constructed and selected models will be tested and compared with the official NHC forecasts to show the accuracy.

\subsection{Tropical Cyclone Selection and (HURDAT) Data}

All Atlantic hurricanes from 1988-2003 were selected to be used in this study. This time period was chosen because it contained a variety of hurricanes, some of which were very powerful including Hurricane Gilbert (1988), Hurricane Hugo (1989), and Hurricane Andrew (1992). In total, 103 tropical cyclones during this period that attained hurricane status, 42 of which attained "major" hurricane status (i.e. Category 3 or greater on the Saffir-Simpson Scale), while the other 61 were "minor" hurricanes (i.e. Category 1 or 2). A list of all of the hurricanes can be found in Table 3.1. The track coordinates, wind speed, and central pressure of each hurricane were obtained from the NHC's Hurricane Best Track dataset or HURDAT (www.nhc.noaa.gov/pastall). This dataset contains 6-hourly storm center locations, which is given in tenths of degrees for both latitude and longitude. The one minute maximum sustained winds are given in knots, 
while the minimum central pressure is given in millibars. Storm archives are available in this dataset from 1851-present. More information can be found in the NOAA Technical Memorandum, NWS NHC 22 "A Tropical Cyclone Data Tape for the North Atlantic Basin, 1886-1983: Contents, Limitations, and Uses" (Jarvinen et. al., 1984).

The entire storm track of each hurricane was not analyzed. Only the 24-hour Rapid Intensification Period (RIP) and the 60-hour period prior to the RIP were examined for each hurricane. For the purpose of this study, the RIP is defined as the 24-hour period that experienced the greatest central pressure reduction. Currently, hurricane intensity models and forecasts have difficulty predicting a RIP. Often times, a hurricane is near its minimum central pressure, generally producing a strong hurricane at the end of the RIP. Since the RIP can produce an intense hurricane, it is critical to examine the conditions prior to the RIP, (i.e. what makes a hurricane enter a RIP) and furthermore improve the forecasting of the RIP.

Figure 3.1 shows a frequency diagram of the magnitude of the decline in minimum surface pressure during the RIP. The mode of the distribution is $15 \mathrm{mb}$ or 15 $\mathrm{hPa}$ and the distribution is skewed due to the outliers (e.g. Hurricane Gilbert (72 hPa), Hurricane Mitch (54 hPa), and Hurricane Hugo (52 hPa)) on the right of the diagram. All major hurricanes had a RIP of at least $15 \mathrm{hPa}$, while the minor hurricanes' RIP ranged from $4 \mathrm{hPa}$ to $29 \mathrm{hPa}$. 


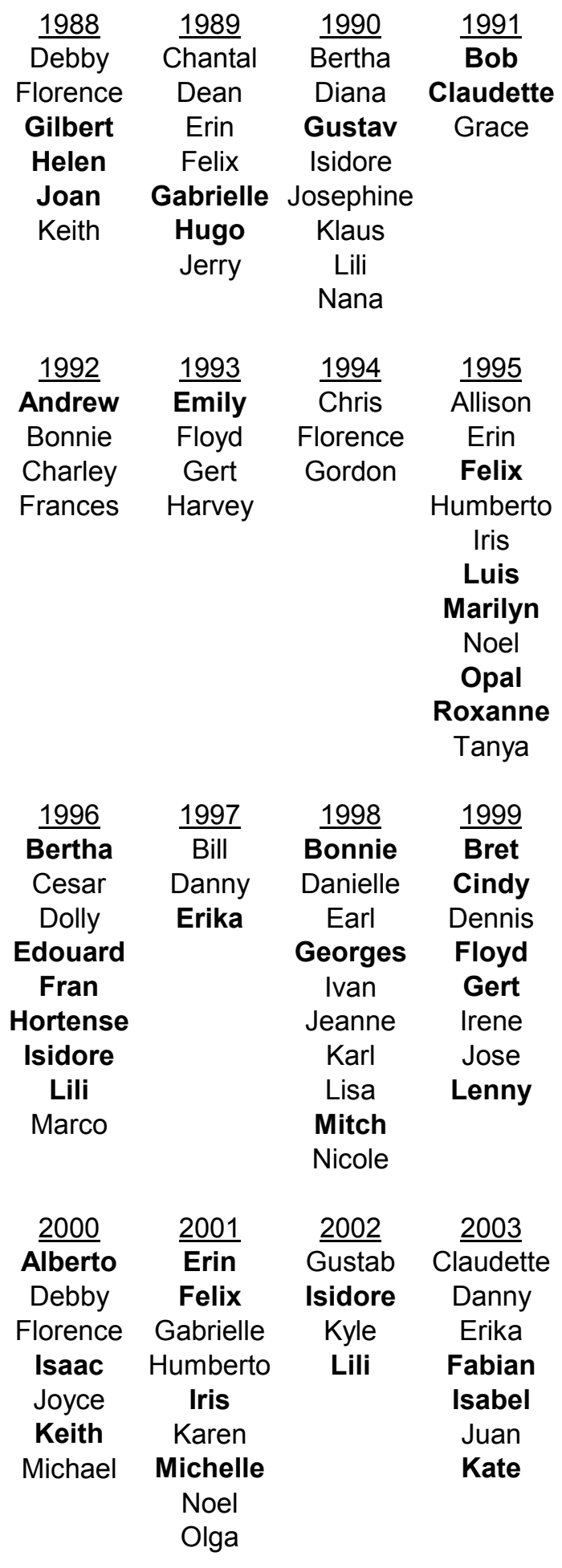

Table 3.1: Tropical cyclone selection list from 1988-2003. Storms that are in boldface are considered "major". 


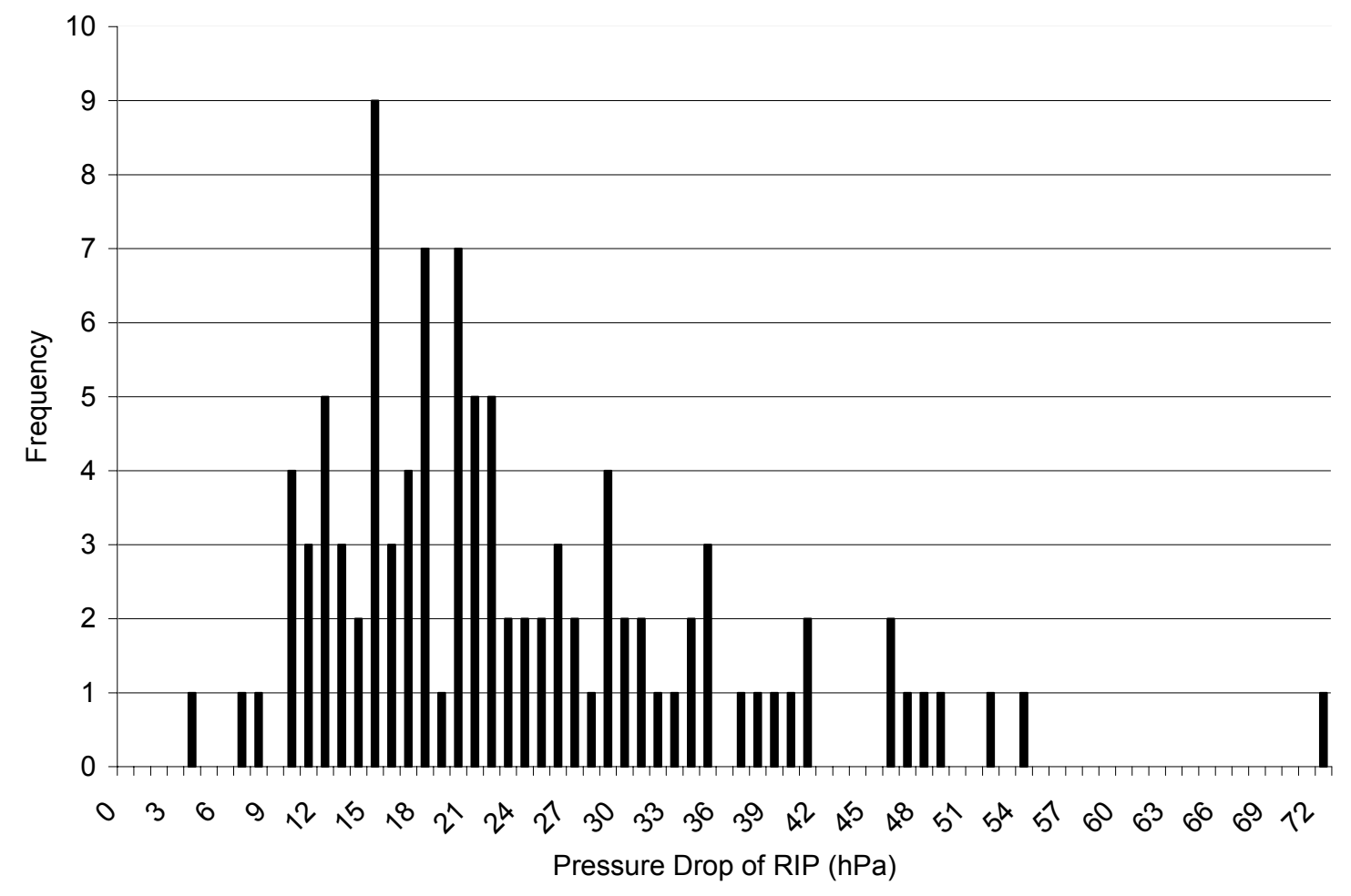

Figure 3.1: Frequency distribution of the size of the RIP.

\subsection{NCEP/NCAR Reanalysis Data}

The NCEP/NCAR reanalysis is a project that began in 1991 due to the development of the National Meteorological Center (NMC), the predecessor to NCEP, Climate Data Assimilation System (CDAS) project. The rationale for the development of the CDAS project was the perceived "climate changes" that occurred from the changes established in the NMC operational Global Data Assimilation System (GDAS) (Kalnay et al. 1996). By using a frozen state-of-the-art analysis forecast system, climate researchers can evaluate whether climate anomalies are significant when compared with long-term reanalysis without changing the data assimilation. The 40-year reanalysis 
period from 1957-1996 eliminates any perceived climate spikes with this frozen data assimilation system.

The reanalysis involves the "recovery of land surface, ship, rawinsonde, pibal, aircraft, satellite, and other data" (Kalnay et al. 1996). These data are assimilated and used in a model that has a T62 (about $210 \mathrm{~km}$ ) horizontal resolution which translates into a $2.5^{\circ}$ by $2.5^{\circ}$ latitude/longitude grid. Data for the reanalysis have been provided by different countries and organizations and have been enhanced with several observational sources, but it is not yet available for operation in real-time. Reanalysis variables are classified as Type A, which are variables that are strongly influenced by observational data, Type B, which are variables that have observational data affecting the value but strongly influenced by the model, and Type $\mathrm{C}$, which have no observational data directly affecting the value and are solely derived from the model. All reanalysis variables used in this study were Type A, which are the most reliable, except for relative humidity which was Type B.

Reanalysis data output are available in different formats, such as GRIB (Gridded binary) format and netCDF (network Common Data Form). NetCDF data output is available through the Climate Diagnostics Center (CDC) website at http://www.cdc.noaa.gov/cdc/reanalysis/. The CDC has recently merged into the new Earth System Research Laboratory (ESRL), which is a division of the National Oceanic and Atmospheric Administration (NOAA). All data at the CDC is stored in netCDF, which is a compressed format developed by the Unidata Program Center in Boulder, Colorado, and is an interface to store the array-oriented data. NetCDF files can be read and decoded using different programming languages such as Fortran, C, and IDL. In this 
study, IDL was used to decode the netCDF files into readable text format. For more information about netCDF and how to read these files see the following Unidata website at http://www.unidata.ucar.edu/software/netcdf/.

\subsection{AOML Tropical Cyclone Heat Potential}

The role of the upper ocean in tropical cyclone intensification had been thought to only be minor until a series of hurricanes underwent rapid intensification when they passed over warm oceanic features. In addition to the favorable atmospheric conditions, such as atmospheric trough interactions and low vertical wind shear which provide favorable outflow conditions aloft, the upper ocean provides the heat for the boundary layer allowing the central pressure to deepen. The investigation of warm core rings has shown them to be very important in the role of intensification, particularly in the case of Hurricane Opal (1995) (Shay et al. 2000). Hurricanes often rapidly intensify when they interact with the Loop Current, which happens to be much warmer than the surrounding water in the Gulf of Mexico. Therefore, when investigating the causes of rapid tropical cyclone intensification the thermal structure of the upper ocean must be considered.

The tropical cyclone heat potential (or sometimes referred to as hurricane heat potential) is defined as the integrated vertical temperature from the sea surface to the depth of the $26^{\circ} \mathrm{C}$ isotherm. This is calculated using four points from altimeter-derived vertical temperature profile estimates in the upper ocean. Those four points include the sea surface temperature obtained from the Tropical Rainfall Measuring Mission's (TRMM) Microwave Imager (TMI) fields, the altimeter estimates of the $20^{\circ} \mathrm{C}$ isotherm 
within a two layer reduced gravity scheme (Goni et al. 1997), and the depth of the $26^{\circ} \mathrm{C}$ isotherm from a climatological relationship between the depths of both the $20^{\circ} \mathrm{C}$ and the $26^{\circ} \mathrm{C}$.

A two-layer reduced gravity ocean model (Figure 3.2) is used to monitor the upper layer thickness (Goni et al. 1997), which is defined as the depth from the sea surface to the $20^{\circ} \mathrm{C}$ isotherm. The $20^{\circ} \mathrm{C}$ isotherm is selected because it lies in the middle of the main thermocline which is often seen as an indicator of the upper layer flow especially found in the Gulf of Mexico and the western tropical Atlantic. Therefore, the $20^{\circ} \mathrm{C}$ isotherm separates two layers of differing densities. The upper layer thickness $\left(\mathrm{h}_{1}\right)$ can be estimated from the altimeter-derived sea height anomaly $\left(\eta^{\prime}\right)$ if the mean upper level thickness $\left(\overline{h_{1}}\right)$ and reduced gravity $\left(\mathrm{g}^{\prime}\right)$ fields are known based upon the following equation:

$$
h_{1}(x, y, t)=\overline{h_{1}}(x, y)+\frac{g}{g^{\prime}(x, y)} \eta^{\prime}(x, y, t)
$$

where $\mathrm{g}^{\prime}=\varepsilon \mathrm{g}, \mathrm{g}$ is the acceleration of gravity and

$$
\varepsilon(x, y)=\frac{\rho_{2}(x, y)-\rho_{1}(x, y)}{\rho_{2}(x, y)}
$$

where $\rho_{1}(\mathrm{x}, \mathrm{y})$ and $\rho_{2}(\mathrm{x}, \mathrm{y})$ represent the upper and lower level densities respectively. Climatology based on Levitus (1984) is used to estimate the reduced gravity ( $\left.\mathrm{g}^{\prime}\right)$ and mean upper level thickness $\left(\overline{h_{1}}\right)$. 
The tropical cyclone heat potential is then computed using the method defined by Leipper and Volgenau (1972) as the heat content of the upper layer relative to the depth on the $26^{\circ} \mathrm{C}$ isotherm:

$$
Q(x, y, t)=\rho c_{p} \Delta T(x, y, t) \Delta z(x, y, t)
$$

where $\rho$ is the average oceanic density $\left(1.026 \mathrm{~g} \mathrm{~cm}^{-3}\right), \mathrm{c}_{\mathrm{p}}$ is the specific heat at constant pressure $\left(1 \mathrm{cal} \mathrm{gm}^{-1}{ }^{\circ} \mathrm{C}^{-1}\right), \Delta \mathrm{T}$ is the difference between the SST and $26^{\circ} \mathrm{C}$ established over a depth $\Delta \mathrm{Z}$. The depth of the $26^{\circ} \mathrm{C}$ isotherm was found using a climatological relationship between the depths of the $20^{\circ} \mathrm{C}$ isotherm and the $26^{\circ} \mathrm{C}$ isotherm.

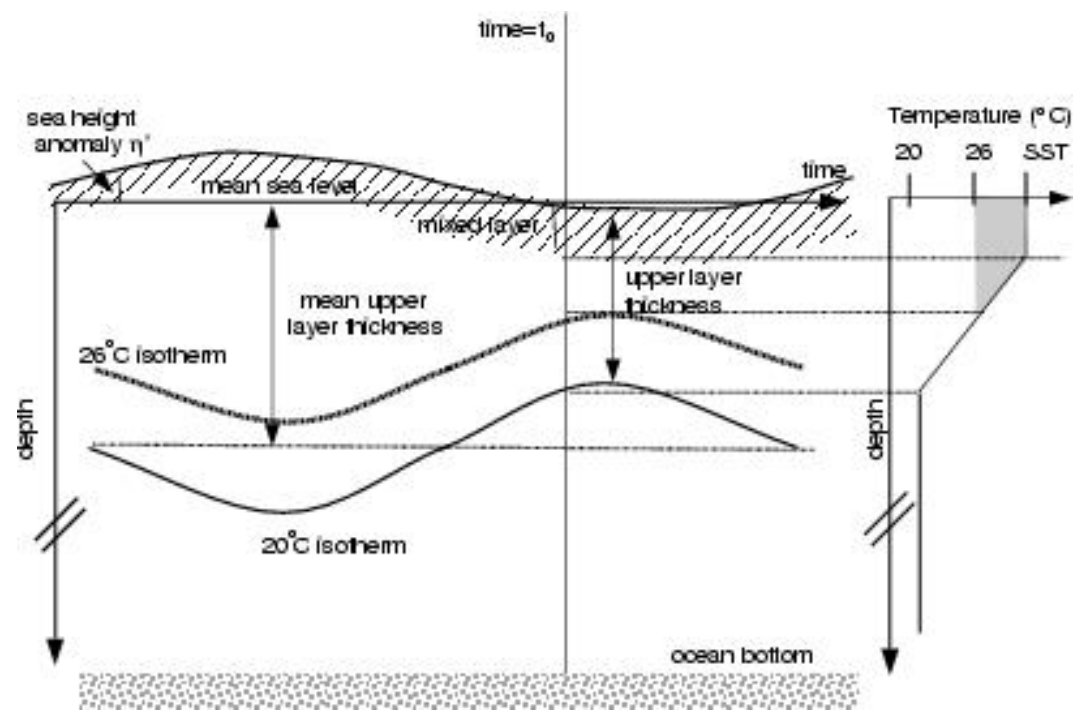

Figure 3.2: Schematic of two-layer ocean model approach to compute upper level thickness and eventually tropical cyclone heat potential (courtesy Goni et al. 1996). 


\subsection{Variables and Data Used in the Study \\ 3.5.1 NHC HURDAT data}

The entire storm track for each of the 103 hurricanes was not used in the study. This study was concerned with the RIP and the potential factors that may cause a hurricane to rapidly intensify. Therefore, the 24-hour period when the central pressure decreased the most was selected for each hurricane. In addition, the 60-hour period leading up to the RIP was also selected to examine the possible causes of rapid intensification. The study divided the track into 6-hour time intervals making 16 6-hour time intervals for each hurricane. Figure 3.3 shows the portions of the tracks that were studied for the 103 hurricane sample. The yellow lines show the tracks of the 61 minor hurricanes while the red lines show the tracks of the 42 major hurricanes. A cluster of major hurricanes is located between $10^{\circ} \mathrm{N}$ and $20^{\circ} \mathrm{N}$ latitude while a cluster of minor hurricanes is located around $25^{\circ} \mathrm{N}$ latitude. This is indicative of the high oceanic heat content that is found in the Tropical Atlantic between $10^{\circ} \mathrm{N}$ and $20^{\circ} \mathrm{N}$ latitude, which is necessary to form and sustain a major hurricane.

A list of the 25 variables that were calculated is given in Table 3.2. Each variable was calculated at each 6-hour interval for all 103 hurricanes. The variables were obtained from the NHC HURDAT dataset, the NCEP/NCAR reanalysis dataset, and the AOML tropical cyclone heat potential dataset. The NHC HURDAT archive contained exact hurricane coordinates of the latitude (Lat), longitude (Long), central pressure 


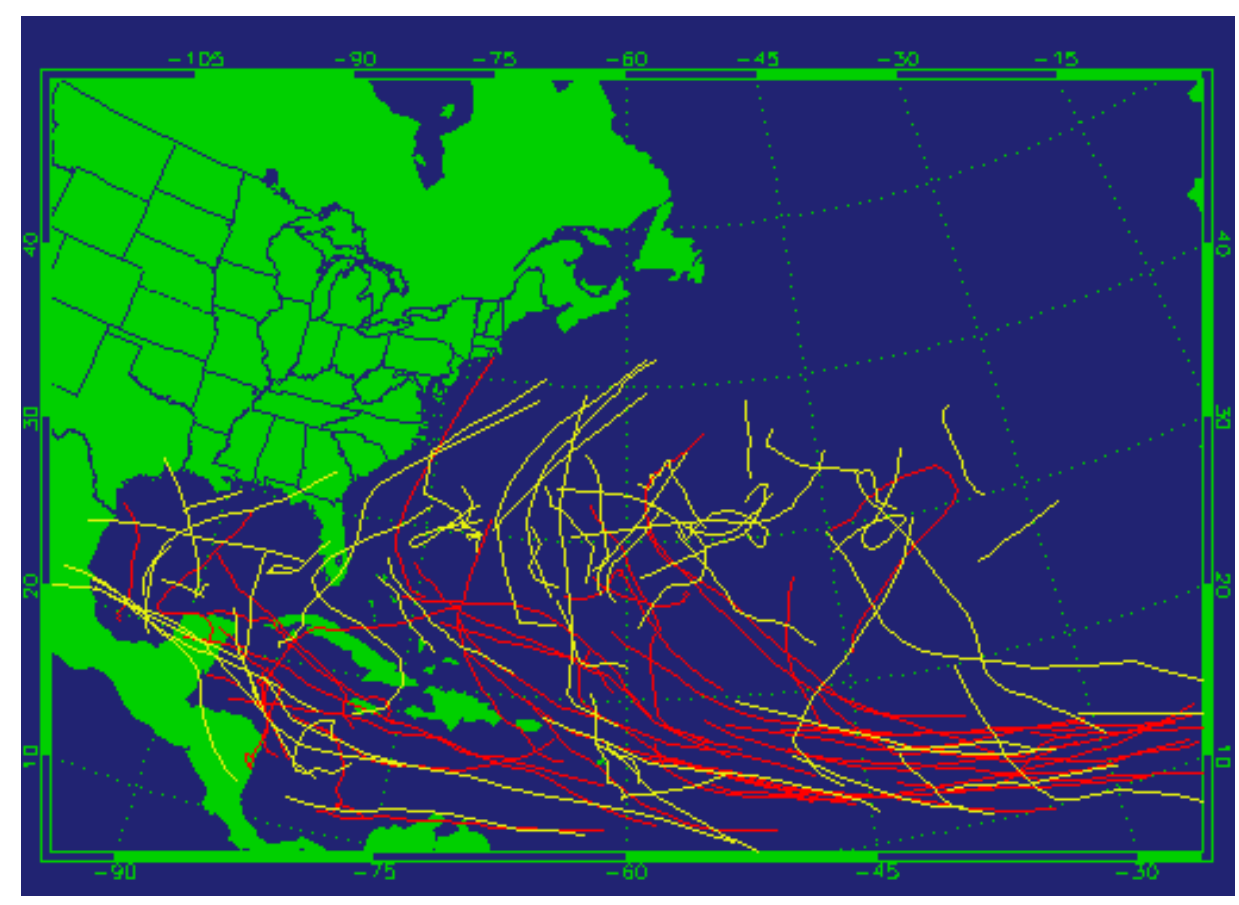

Figure 3.3: Tracks of the 103 hurricanes are shown. The minor hurricanes are depicted in yellow and major hurricanes are depicted in red.

(CentPres), and the maximum sustained winds (WindSp). From the maximum sustained wind data, the 6-hour wind speed change (Prev6) was calculated, and from the latitude and longitude coordinates, the translational speed (TransSp) was computed. The following formula was used to calculate the translational speed of the hurricane motion in meters per second.

$$
\frac{6371 \mathrm{~km} * 1000 m}{21600 \mathrm{sec}} * \arccos (\sin (\text { lat } 1) * \sin (\text { lat } 2)+\cos (\text { lon } 1-\text { lon } 2) * \cos (\text { lat } 1) * \cos (\text { lat } 2))
$$

where lat 1 is the latitude of the hurricane at $\mathrm{t}=0$,

lon 1 is the longitude of the hurricane at $\mathrm{t}=0$, 
lat 2 is the latitude of the hurricane at $\mathrm{t}+6$ hours, and

lon 2 is the longitude of the hurricane at $\mathrm{t}+6$ hours

\subsubsection{Vertical Wind Shear and Relative Humidity}

Since the NCEP/NCAR reanalysis data were available on a 6 -hourly, $2.5^{\circ}$ by $2.5^{\circ}$ latitude/longitude grid, the center of the hurricane often fell in between this grid scale. The value of these variables was not simply calculated under the center of the hurricane but rather averaged across a $5^{\circ}$ latitude/longitude radius from the center to capture the environmental effects. An IDL program was used first to decode the data from netCDF then a formula was applied to average the grid points. Figure 3.4 shows the 5 by 5 grid point "box" that was used to give an average for each reanalysis variable. Other size grid point "boxes" were tested such as the 3 by 3 and the 7 by 7 , but the 5 by 5 proved to be the most reliable since the 3 by 3 did not capture many of the factors near the periphery of the hurricane and the 7 by 7 was too large and captured many extraneous factors. 


\begin{tabular}{|l|l|l|}
\hline Variable & Units & Definition \\
\hline Lat & ${ }^{\circ} \mathrm{N}$ & Latitude \\
\hline Long & ${ }^{\circ} \mathrm{W}$ & Longitude \\
\hline $850-500 \mathrm{shr}$ & $\mathrm{m} \mathrm{s}^{-1}$ & $850-500 \mathrm{hPa}$ vertical shear \\
\hline 850-500 dir & ${ }^{\circ}$ & $850-500 \mathrm{hPa}$ vertical shear direction \\
\hline $850-200 \mathrm{shr}$ & $\mathrm{m} \mathrm{s}^{-1}$ & $850-200 \mathrm{hPa}$ vertical shear \\
\hline $850-200 \mathrm{dir}$ & ${ }^{\circ}$ & $850-200 \mathrm{hPa}$ vertical shear direction \\
\hline $850-100 \mathrm{shr}$ & $\mathrm{m} \mathrm{s}^{-1}$ & $850-100 \mathrm{hPa}$ vertical shear \\
\hline $850-100 \mathrm{dir}$ & $\mathrm{o}^{-1}$ & $850-100 \mathrm{hPa}$ vertical shear direction \\
\hline $500-200 \mathrm{shr}$ & $\mathrm{m} \mathrm{s}^{-1}$ & $500-200 \mathrm{hPa}$ vertical shear \\
\hline $500-200 \mathrm{dir}$ & ${ }^{\circ}$ & $500-200 \mathrm{hPa}$ vertical shear direction \\
\hline $925 \mathrm{RH}$ & $\%$ & $925 \mathrm{hPa}$ relative humidity \\
\hline $850 \mathrm{RH}$ & $\%$ & $850 \mathrm{hPa}$ relative humidity \\
\hline $700 \mathrm{RH}$ & $\%$ & $700 \mathrm{hPa}$ relative humidity \\
\hline $500 \mathrm{RH}$ & $\%$ & $500 \mathrm{hPa}$ relative humidity \\
\hline MSLP & $\mathrm{\% Pa}$ & Mean sea level pressure \\
\hline SST & $\mathrm{K}$ & Sea surface temperature \\
\hline MPI & $\mathrm{hPa}$ & Maximum potential intensity \\
\hline CentPres & $\mathrm{hPa}$ & Central pressure \\
\hline AttMPI & $\%$ & Attained MPI \\
\hline TransSp & $\mathrm{m} \mathrm{s}$ & Translational speed \\
\hline HeatPot & $\mathrm{kJ} \mathrm{cm}-2$ & Hurricane heat potential \\
\hline CoreHP & $\mathrm{kJ} \mathrm{cm}{ }^{-2}$ & Core hurricane heat potential \\
\hline Incep & $\mathrm{h}$ & Inception time \\
\hline Prev6 & $\mathrm{kts}$ & Previous 6 hour wind speed change \\
\hline WindSp & $\mathrm{kts}$ & Wind speed \\
\hline & &
\end{tabular}

Table 3.2: List of variables used in the study. 


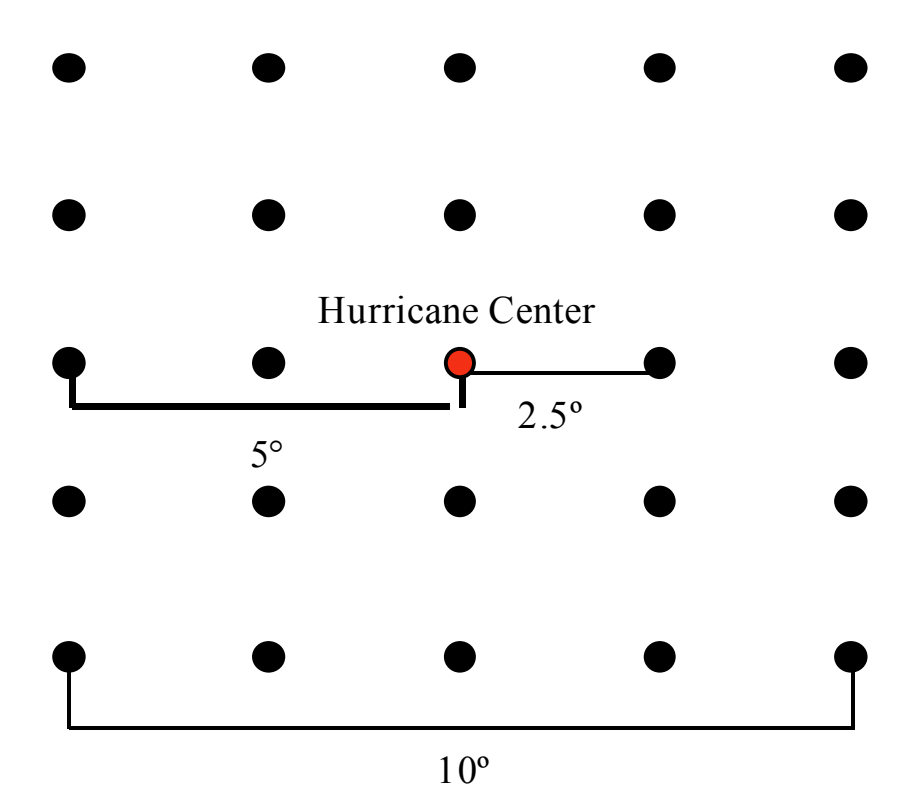

Figure 3.4: The 5 by 5 grid "box" averaging technique.

Available from the reanalysis were the $\mathrm{U}$ component winds at the 850, 500, 200 and $100 \mathrm{hPa}$ levels and the $\mathrm{V}$ component winds at the 850,500, 200, and $100 \mathrm{hPa}$ levels. These were used to compute both the magnitude and the direction of the vertical wind shear over 4 different levels: $850 \mathrm{hPa}-500 \mathrm{hPa} ; 850 \mathrm{hPa}-200 \mathrm{hPa} ; 850 \mathrm{hPa}-100 \mathrm{hPa}$; and $500 \mathrm{hPa}-200 \mathrm{hPa}$. Relative humidity values were available at the 925, 850, 700, and $500 \mathrm{hPa}$ levels (925RH; 850RH; 700RH; and 500RH). Five by 5 "box" averaging was used to compute the relative humidity at four levels.

\subsubsection{Holland MPI}

The mean sea level pressure (MSLP), sea surface temperature (SST) and the temperature profile at 12 significant levels $(925,850,700,600,500,400,300,250,200$, 150,100 , and $70 \mathrm{hPa}$ ) were used from the NCEP/NCAR reanalysis to calculate additional 
parameters, the maximum potential intensity (MPI) and the attained maximum potential intensity (AttMPI). The Holland method was used to compute MPI in this study. Since tropical cyclones derive their energy from latent heat release in the environment, the MPI is estimated as a function of the available thermodynamic energy in the environment and usually expressed in terms of pressure. Therefore, the MPI is simply the lowest theoretical pressure a tropical cyclone can achieve under ideal conditions. The Holland method (Holland 1997) is a purely thermodynamic approach of predicting the MPI of tropical cyclones.

The Holland method consists of three parts. First, the moist adiabatic lapse rate is calculated. Next, an iterative process is used to estimate the equivalent potential temperature. The surface equivalent potential temperature is calculated from the environmental temperature and pressure, in addition to the sea surface temperature and eye wall relative humidity. Once the equivalent potential temperature is calculated, the pressure of the column drops hydrostatically due to subsidence warming. A new surface pressure causes a new equivalent potential temperature to be recalculated. The process continues until the surface pressure changes less than $1 \mathrm{hPa}$. When the surface pressure calculations converge, the eye temperature profile and the hydrostatic decrease central pressure due to the formation of the eye are calculated if the eye wall deficit is more than $20 \mathrm{hPa}$ from the environment. From these calculations, the MPI is estimated:

$$
M P I=P_{\text {Senv }}-\Delta P_{S \max }
$$

where $\mathrm{P}_{\text {Senv }}$ is the surface pressure of the environment and $\Delta \mathrm{P}_{\text {Smax }}$ is the maximum achievable surface pressure fall. The hydrostatic change in surface pressure can be found by the following: 


$$
\Delta P_{S}=\frac{P_{S}}{T_{v}\left(P_{S}\right)} \int_{P_{S}}^{P_{T}} \Delta T_{v} d \ln p
$$

Usually lower central pressures indicate more intense tropical cyclones.

Therefore, if a hurricane has a low MPI, it has great potential to become a powerful hurricane assuming there are no detrimental factors affecting it. The MPI was calculated using a FORTRAN program (courtesy of Greg Holland) for all 103 hurricanes in the case study at each 6-hour time interval.

\subsubsection{Attained MPI}

The MPI by itself is not a good indicator of the intensity of a tropical cyclone since it is a measure of what the hurricane could potentially become. It does not show how close the central pressure is to its maximum potential. For instance, a hurricane could be in a favorable thermodynamic environment and have a MPI of $900 \mathrm{hPa}$ but have a minimum central surface pressure of $975 \mathrm{hPa}$. However, a hurricane that has a MPI of $930 \mathrm{hPa}$ may not initially seem as dangerous, but if the other environmental factors are favorable and a limited number of detrimental effects are occurring, the minimum central surface pressure could be $950 \mathrm{hPa}$, meaning this hurricane is much closer to its maximum potential. Therefore, the hurricane has a central pressure close to its MPI and is almost as intense as the environment will allow it to become. The following attained MPI (AttMPI) equation was developed to express as a percentage how close a hurricane is to its MPI as a function of the minimum central pressure and mean sea level pressure: 


$$
\left[\frac{[1-(\text { MPI }- \text { Central pressure })]}{(\text { MPI-Mean sea level pressure })}\right] * 100 \%
$$

Using this equation, a hurricane with a MPI of $900 \mathrm{hPa}$, mean seal level pressure of $1000 \mathrm{hPa}$, and a central pressure of $950 \mathrm{hPa}$, would have an attained MPI of $50 \%$. The attained MPI is a better indicator of how strong a hurricane is and how much the hurricane has intensified. Early in the stages of hurricane development, a hurricane often has a very low attained MPI, and has the potential to intensify rapidly. As the life cycle of the hurricane progresses and the hurricane starts to intensify, the attained MPI gradually increases. When a hurricane is near its MPI, it has a high attained MPI, which indicates that it has little chance of intensifying significantly. Thus, when hurricanes have high attained MPIs, they are unlikely to undergo a RIP. The average attained MPI for a major hurricane at the onset of the RIP has been shown to approximately be $33.5 \%$ (Law 2001). The attained MPI was calculated for all hurricanes in the case study at each 6-hour time interval in the track sample.

\subsubsection{Tropical Cyclone Heat Potential}

AOML Tropical Cyclone Heat Potential data are available from 1992 - present in all hurricane basins around the world. In the Atlantic basin from 1992-2003, the data are available on a $1^{\circ}$ latitude/longitude grid at a weekly timescale. These data to calculate the heat potential (HeatPot) were averaged in a manner similar to that applied to the other variables except that an 11 by 11 "box" technique was used instead of a 5 by 5 technique. This allowed for the heat potential to be averaged over the same geographical distance 
from the center of the hurricane as the other variables. The heat potential was calculated using an IDL program at each 6-hour interval for all 103 hurricanes in the study. In order to capture the heat potential values directly under the center of the storm, the core heat potential (CoreHP) was also calculated. A 3 by 3 "box" averaging technique was used for the core heat potential giving an approximate $1^{\circ}$ radius from the hurricane center. The core heat potential was calculated likewise at each 6-hour interval for all 103 hurricanes.

\subsection{Discriminant Function Analysis}

Discriminant Function Analysis (DFA) is a statistical technique where the differences between two or more groups with respect to several variables can be examined simultaneously (Klecka 1980). DFA determines which predictors or variables best discriminate, better than chance, between two or more groups. The weightings of the variables create a discriminant function, which is a linear combination of the variable weightings (Cramer 2003). In general, a discriminant function will consist of the following:

$$
\text { Group }=a+b_{1} * x_{1}+b_{2} * x_{2}+\ldots+b_{m} * x_{m}
$$

where Group is the discriminant score, $a$ is a constant and $b_{1}$ through $b_{m}$ are regression coefficients. The variables with the largest standardized coefficients are the variables that are the most significant. These contribute the most toward predicting the group association. Assuming the variables differ among the groups, the DFA will help classify each case into a particular group that is closely corresponds.

In order to apply DFA, basic assumptions need to be considered (Klecka 1980; Cramer 2003). First, there must be more than two groups and at least two cases per 
group. There can be any number of discriminating variables as long as it is two less than the total number of cases. Each discriminating variable also needs to be evaluated at the interval level. No discriminating variable can be a linear combination of any other discriminating variable, that is, it cannot be the sum of one or more other variables. Two variables that are perfectly correlated would not add any new information beyond what is already known in the original variable and are therefore redundant. Another assumption is the covariance matrices for each group must be approximately equal. However, minor deviations of the homogeneity of the variances across the groups are not critical. Lastly, the variables must represent a normal distribution, although violating this assumption has proven not to be fatal if the results are interpreted with caution (Lachenbrauch 1975).

The premise of this study is that different statistical models must be applied for different types of hurricanes and at different stages during the life cycle of the hurricane. The DFA is applied in order to correctly identify the type and stage of the hurricane. By examining the characteristics of the hurricanes in the sample, the variables will be combined into a mathematical equation to predict which group each case belongs. The basic role of the DFA in this study was to analyze the differences between the groups and to present a technique to classify cases into a group they most closely resemble. The methodology of this study was highlighted by a two-step DFA as can been seen in Fig. 3.5. The hurricane sample contained 103 hurricanes with 16 time intervals in each giving a total of 1648 cases. The standard or direct DFA method was applied, meaning that all 25 predictors were entered at the same time. In step one, the DFA examined each case and determined if it more closely resembled a major hurricane or a minor hurricane. After classifying each case in one of the two groups, the DFA then classified each valid 
case according to its proximity to the RIP. To do this, the "major hurricane" and "minor hurricane" cases from step one were separated and a second DFA was performed on each group. Step two of the DFA classified the cases into one of the four following categories:

- Time Segment 1: More than 48 hours before the RIP

- Time Segment 2: Between 24 and 48 hours before the RIP

- Time Segment 3: Less than 24 hours before the RIP

- Time Segment 4: The Rapid Intensification Period (RIP)

Therefore after both steps of the DFA, each case is classified into one of eight possible groups (see Fig. 3.6). Eight multiple regression models will then be created and applied to the appropriate cases. 


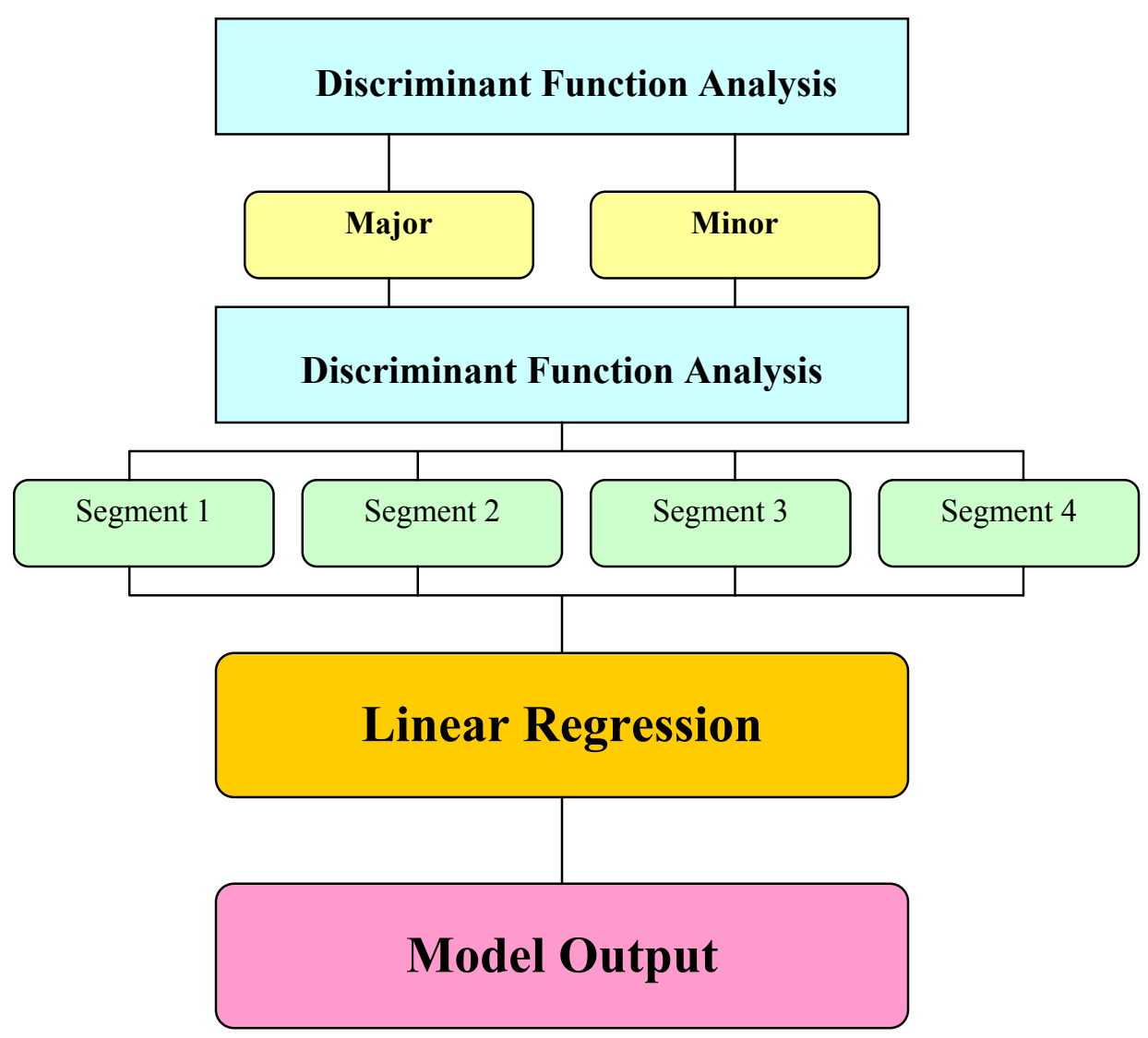

Figure 3.5: Flowchart representation of the procedures used in the statistical analyses. 

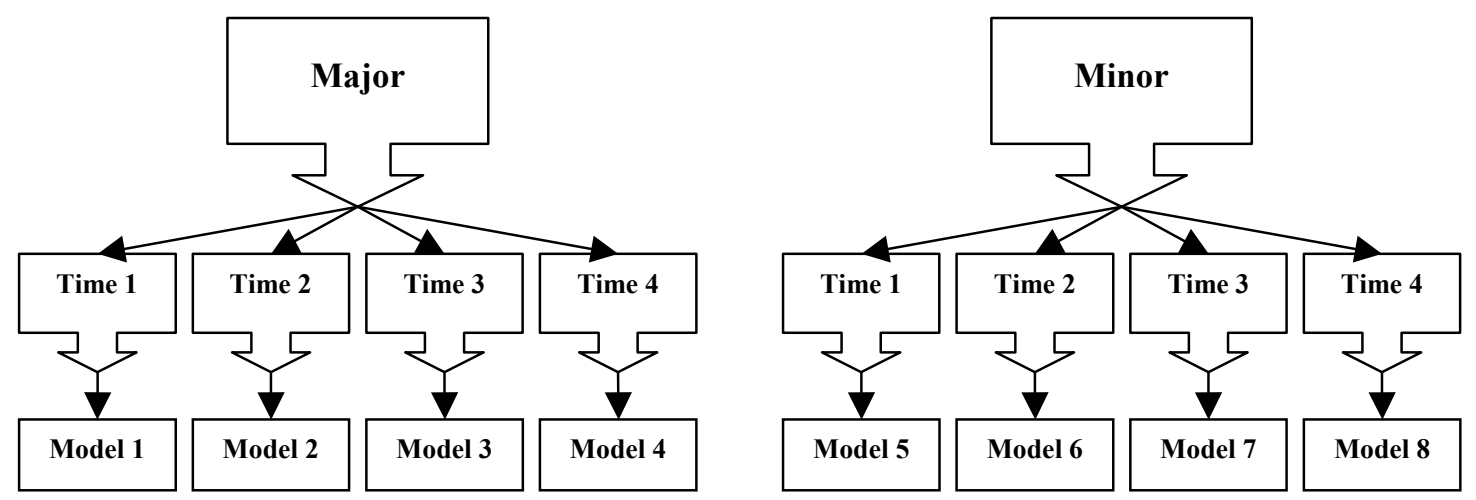

Figure 3.6: Flowchart of eight possible groups.

\subsection{Multiple Regression}

The purpose of multiple regression is to examine the relationship between several independent or predictor variables and the dependent variable. Multiple regression helps to determine which variables explain the greatest and most significant proportion of the variance in the dependent variable (Cramer 2003). This is usually done by a technique called stepwise multiple regression. In stepwise multiple regression, the predictor variable that has the highest correlation and is statistically significant at a particular threshold is entered into the regression. The next variable to be entered into the regression, assuming it is statistically significant, is the one that has the next highest correlation with the dependent variable while controlling for the variable that has already been entered. If the first variable still explains a significant amount of the variance while the second variable is controlled then it is kept in the regression analysis. If not, the first variable is omitted from the analysis. This stepwise procedure is continued until there is no further significant increase in the explained variance by the independent variables (Cramer 2003). 
A multiple regression equation estimates a linear equation of the following form:

$$
y=a+b_{1} * x_{1}+b_{2} * x_{2}+\ldots+b_{p} * x_{p}
$$

where $y$ is the dependent variable, $a$ is the constant, $b$ is the slope of the line, and $x$ is the predictor variable. In multiple regression, it is assumed that the relationship between the variables is linear, however the procedure is not greatly affected by minor deviations from this assumption (Hill 2006). It is also assumed that the residuals are normally distributed although the results have been shown to be robust when this assumption is violated.

Models for four different dependent variables were constructed using multiple regression analysis. The dependent variables were the following:

- Future 24-hour pressure drop

- Future 6-hour pressure drop

- Future 24-hour wind speed increase

- Future 6-hour wind speed increase

Eight different models were constructed for each of the dependent variables giving a total of 32 multiple regression equations. In this model, a stepwise multiple regression was 
applied after the DFA selected the appropriate category for the case (see Fig. 3.5). The stepwise multiple regression was applied to all 1648 cases in the study. The cases were grouped into the eight possible combinations (see Fig. 3.5), not by which the DFA selected, but by what actually occurred. Table 3.3 shows the number of cases in each of the eight categories. Each variable had to be significant at the $95 \%$ confidence interval to be used in the model.

\subsection{Testing the Models with an Independent Dataset}

In order to test the accuracy of the hurricane intensity models, an independent dataset was used. The independent dataset consisted of 13 hurricanes from the 2004-05 hurricane seasons (see Table 3.4). As with the 1988-2003 sample only the RIP and the 60-hour time period prior to the RIP were examined giving 16 time intervals for each hurricane. 


\begin{tabular}{|c|c|}
\hline Category & Number of Cases \\
\hline Major / Time Segment 1 & 168 \\
\hline Major / Time Segment 2 & 168 \\
\hline Major / Time Segment 3 & 168 \\
\hline Major / Time Segment 4 & 168 \\
\hline Minor / Time Segment 1 & 244 \\
\hline Minor / Time Segment 2 & 244 \\
\hline Minor / Time Segment 3 & 244 \\
\hline Minor / Time Segment 4 & 244 \\
\hline Total & $\mathbf{1 6 4 8}$ \\
\hline
\end{tabular}

Table 3.3: Number of cases in each category for the multiple regression analysis 


\begin{tabular}{|c|c|}
\hline Hurricane & Major/Minor \\
\hline Hurricane Alex (2004) & Major \\
\hline Hurricane Charley (2004) & Major \\
\hline Hurricane Danielle (2004) & Minor \\
\hline Hurricane Frances (2004) & Major \\
\hline Hurricane Gaston (2004) & Minor \\
\hline Hurricane Ivan (2004) & Major \\
\hline Hurricane Jeanne (2004) & Major \\
\hline Hurricane Karl (2004) & Major \\
\hline Hurricane Lisa (2004) & Minor \\
\hline Hurricane Dennis (2005) & Major \\
\hline Hurricane Emily (2005) & Major \\
\hline Hurricane Irene (2005) & Minor \\
\hline Hurricane Katrina (2005) & Major \\
\hline
\end{tabular}

Table 3.4: List of Hurricanes in the Independent Dataset. 
A similar procedure was followed, as shown in Figure 3.5, where the two-step DFA was applied to all 13 independent hurricanes. The DFA then selected the appropriate category (i.e. minor vs. major and the time segment) for the 16 time intervals for each hurricane. All four multiple regression models (i.e. future 24-hour and 6-hour pressure drop and future 24-hour and 6-hour wind speed increase) were then run for each case. The model results were then compared to the actual observations and the percent error was calculated. In the case of the future 24-hour wind speed increase, the model results were also compared with the NHC intensity forecasts. The NHC only issues intensity forecasts in terms of wind speed so the pressure reduction models could not be compared. Also, the NHC's shortest intensity forecasts are for the 12-hour forecast period so the 6-hour model results could not be compared with the NHC. 


\section{CHAPTER 4}

\section{RESULTS AND DISCUSSION}

\subsection{Discriminant Function Analysis Classification}

The first step of the discriminant function analysis classified the cases into the most suitable category, which in this case was either a major or a minor hurricane. In the sample dataset which consisted of 103 hurricanes, there were a total of 1648 possible cases (103 hurricanes x 16 time intervals each). Of the 1648 total cases, there were 432 cases that had at least one missing discriminant variable and were invalid. These cases were from the hurricanes in the sample from 1988 - early 1992 because the heat potential data were not yet available. Even though these were invalid cases for the discriminant analysis, they were still important and were used in the multiple regression analysis discussed in Section 4.2. Therefore a total of 1216 valid cases were analyzed in the first step of the discriminant analysis.

Of the 1216 total cases, there were 528 cases which described major hurricanes and 688 cases which described minor hurricanes (Table 4.1). The discriminant analysis was able to correctly classify 450 of the 528 major hurricane cases for an accuracy rate of $85.2 \%$. For the minor hurricanes, it was able to correctly classify 568 of the 688 minor 
hurricane cases for an accuracy rate of $82.6 \%$. Overall, the discriminant analysis was able to correctly classify 1018 of the 1216 total valid cases or $83.7 \%$ which is more accurate than would be achieved through random selection (50\%). The key predictors that discriminated the most between major and minor hurricanes were Inception time, Central Pressure, Wind Speed, 850-200 hPa wind shear, and Heat Potential. These variables intuitively made sense since major hurricane typically have longer inception times, lower central pressure, higher wind speeds, lower 850-200 hPa wind shear, and higher heat potential than minor hurricanes.

\begin{tabular}{|l|c|c|l|}
\hline \multirow{2}{*}{} & \multicolumn{2}{|c|}{ Predicted Group Membership } & Total Cases \\
\cline { 2 - 3 } & Major & Minor & \\
\hline Major & 450 & 78 & 528 \\
\hline Minor & 120 & 568 & 688 \\
\hline \% Major & 85.2 & 14.8 & 100.0 \\
\hline \% Minor & 17.4 & 82.6 & 100.0 \\
\hline
\end{tabular}

Table 4.1: Classification results for step one of the discriminant analysis.

The first step of the discriminant analysis predicted a total of 570 major and 646 minor hurricanes from the 1216 valid cases (Table 4.1). This represents a slight tendency to overestimate the intensity of the hurricanes. In the second step of the discriminant analysis, the time segment in relationship to the RIP was classified, as defined in Section 3.6, from both the predicted major and minor hurricanes. The second step of the 
discriminant analysis was able to correctly classify $65.1 \%, 43.8 \%, 50.6 \%$, and $69.8 \%$ of the major hurricane cases for Time segments 1, 2, 3, and 4, respectively (Table 4.2). Overall, out of the 570 total major hurricane cases 330 cases were classified correctly for a $57.9 \%$ accuracy rate. The second step was also able to correctly classify $66.7 \%$, $37.5 \%, 50.7 \%$, and $77.9 \%$ of the minor hurricane cases for Time segments $1,2,3$, and 4 , respectively, (Table 4.3) while correctly classifying 369 of the 646 total cases for a $57.1 \%$ accuracy. The time selection accuracy rates for both types of hurricanes $(57.9 \%$ for major and $57.1 \%$ for minor), were more accurate than would have predicted by random selection, which would have been $25 \%$ in this case.

The key predictors that were able to discriminate the time segment among major hurricanes were Wind Speed, Central Pressure, and Attained MPI. The wind speed gradually increases as the hurricane approaches its RIP, while the central pressure gradually decreases. Attained MPI values have been show to approximately reach $28 \%$ at the onset of the RIP for major hurricanes (Law 2001). As for minor hurricanes, the key time segment discriminating predictors were Wind Speed, Central Pressure, and Translational Speed. The wind speed and central pressure vary similarly to major hurricanes except that the wind speeds are lower and the central pressures are higher. Most minor hurricanes have low translational speeds at early stages of their development, while some minor hurricanes can have high translational speeds at late stages in their development due to the storm being "captured" by the midlatitude westerlies and undergoing extratropical transition. 


\begin{tabular}{|l|c|c|c|c|c|}
\hline & \multicolumn{5}{|c|}{ Predicted Group Membership } \\
\hline & Time Seg. 1 & Time Seg. 2 & Time Seg. 3 & Time Seg. 4 & Total Cases \\
\hline Time Seg. 1 & 69 & 26 & 11 & 0 & 106 \\
\hline Time Seg. 2 & 38 & 56 & 28 & 6 & 128 \\
\hline Time Seg. 3 & 18 & 31 & 78 & 27 & 154 \\
\hline Time Seg. 4 & 7 & 8 & 40 & 127 & 182 \\
\hline \% Time Seg. 1 & 65.1 & 24.5 & 10.4 & 0.0 & 100.0 \\
\hline \% Time Seg. 2 & 29.7 & 43.8 & 21.9 & 4.7 & 100.0 \\
\hline \% Time Seg. 3 & 11.7 & 20.1 & 50.6 & 17.5 & 100.0 \\
\hline \% Time Seg. 4 & 3.8 & 4.4 & 22.0 & 69.8 & 100.0 \\
\hline
\end{tabular}

Table 4.2: Step 2 of the DFA for major hurricanes.

\begin{tabular}{|l|c|c|c|c|c|}
\hline & \multicolumn{5}{|c|}{ Predicted Group Membership } \\
\hline & Time Seg. 1 & Time Seg. 2 & Time Seg. 3 & Time Seg. 4 & Total Cases \\
\hline Time Seg. 1 & 132 & 34 & 23 & 9 & 198 \\
\hline Time Seg. 2 & 57 & 66 & 34 & 19 & 176 \\
\hline Time Seg. 3 & 23 & 21 & 76 & 30 & 150 \\
\hline Time Seg. 4 & 0 & 3 & 24 & 95 & 122 \\
\hline \% Time Seg. 1 & 66.7 & 17.2 & 11.6 & 4.5 & 100.0 \\
\hline \% Time Seg. 2 & 32.4 & 37.5 & 19.3 & 10.8 & 100.0 \\
\hline \% Time Seg. 3 & 15.3 & 14.0 & 50.7 & 20.0 & 100.0 \\
\hline \% Time Seg. 4 & 0.0 & 2.5 & 19.7 & 77.9 & 100.0 \\
\hline
\end{tabular}

Table 4.3: Step 2 of the DFA for minor hurricanes. 


\subsection{Multiple Regression Equations}

Two types of multiple regression equations were developed in the study. The first type predicted the future central pressure reduction while the second type predicted the increase in the maximum sustained winds. Equations were developed for two forecast time periods, a 24-hour forecast period and a 6-hour forecast period for each type. This procedure resulted in four categories of models as discussed in Section 3.7.

The multiple regression equations were derived from data associated with the appropriate major and minor hurricanes and the time intervals prior to the RIP (Table 3.3). Each type of model (e.g. Future 24-hour pressure drop) had 8 different models for four time intervals each for major and minor hurricanes for the different classifications. All of the significant variables are shown in bold in the following regression equations (Tables $4.4-4.7$ ) and are significant at the 95\% confidence level. The most significant variables are the last variables in the equation (next to the constant) and the least significant variable is the first variable in each equation. Table 4.4 shows the regression equations that were used to predict the 24-hour pressure drop and Table 4.5 shows the regression equations used to forecast the 24-hour increase in the maximum sustained winds. The 6-hour regression equations that were used to predict the central pressure reduction and the increase in the maximum sustained winds are shown in Tables 4.6 and 4.7, respectively. In each of the tables the first four models (Models 1-4) were used when the discriminant analysis selected a major hurricane and Models 5-8 were used when a minor hurricane was selected. Models 1 and 5 were used during Time Interval 1, Models 2 and 6 were used for Time Interval 2, Models 3 and 7 were used for Time Interval 3, and Models 4 and 8 were used for Time Interval 4. 
In the 24-hour pressure drop equations (Table 4.4) there was little repetition in the variables used in the 8 models which seem to suggest that different factors are responsible for intensification at different stages for both major and minor hurricanes. Variable repetition also was limited in the 24-hour wind speed increase equations (Table 4.5). However, there was variable repetition between similar models for the 24-hour pressure drop and wind speed increase. This seems to make sense since both the pressure fall and the wind speed increase are measures of how much the hurricane intensifies. For example, major hurricanes at Time Interval 1 (Model 1) included mean sea level pressure (MSLP), translational speed (TransSp), and core heat potential (CoreHP) as predictors for both 24-hour pressure drop and wind speed increase. The core heat potential and the translational speed was the most significant for Model 1 as major hurricanes typically have high heat potential at early stages. As the major hurricane progresses, SST and MPI are the most significant as these hurricanes have low MPIs and are over areas of high SSTs. Near the onset of the RIP, the wind speed and the core heat potential are usually high when Model 3 is applied. During the RIP (Model 4), mean sea level pressure (MSLP), longitude (Long), translational speed (TransSp), and central pressure (CentPres) were used both as predictors for 24-hour pressure drop and wind speed increase. Typically the mean sea level pressures are low, the heat potential is high, and the translational speed is low enough for the hurricane to take advantage of the ocean energy.

As for the minor hurricane models, Model 5 primarily uses the most significant variable, inception time, which often is very short due to the fact that these storms have not developed very long. Model 6 uses wind speed, MSLP, and SST, but these variables have negative coefficient which explains why this minor hurricane model predicts less 
pressure drop than the major hurricane models. Model 7 specifically looks at the previous 6-hour change in wind speed and the $850 \mathrm{hPa}$ relative humidity. The more humid the $850 \mathrm{hPa}$ layer is and the more the wind speed increases, the more pressure reduction is predicted. Finally, Model 8 uses wind speed, longitude, and $850-100 \mathrm{hPa}$ shear. The wind speed has a negative coefficient meaning that strong minor hurricanes will usually not intensify much preventing them from becoming major hurricanes.

The major 24-hour wind speed models (Table 4.5), primarily look at the previous 6-hour wind speed, core heat potential, and translational speed during early stages (Model 1). This is consistent with the pressure models as high heat potential and higher translational speed predict stronger intensification. Model 2 uses attained MPI, 850-200 shear, and translational speed. Major hurricanes typically have lower attained MPIs leading up to the RIP as this is a sign it has more potential to intensify. The negative coefficient for the $850-200$ shear indicates that shear needs to be low for the hurricane to intensify, while the translational speed needs to continue to be higher. Near the onset of the RIP, Model 3 uses MPI (negative coefficient) as lower MPIs forecast a higher increase in wind speeds. During the RIP (Model 4), the wind speed increase will start to taper as indicated by the strong negative wind speed coefficient. Higher translational speeds also tend to be more detrimental during the RIP, as this can be a sign that the storm as been "captured" by the midlatitude westerlies and an extratropical transition has begun. During the early stages for minor hurricanes, Model 5 uses previous 6-hour wind speed and inception time. Model 6 primarily uses wind speed, central pressure, MSLP, and translational speed as seen with the pressure models and Model 7 also uses wind speed and central pressure. Often the wind speeds are lower and central pressures are 
lower for minor hurricanes leading up to the RIP, explaining why their coefficients are negative. Finally, Model 8 included the $850-100 \mathrm{hPa}$ shear (850-100shr), the $850-500$ $\mathrm{hPa}$ shear direction (850-500dir), longitude (Long), and the central pressure (CentPres) for both types of models. This further suggests that the intensification of hurricanes at similar stages in their life cycle tend to be affected by similar factors.

The 6-hour pressure drop and 6-hour wind speed models (Tables 4.6 and 4.7) had slightly more repetition among the variables and also had fewer significant variables than the 24-hour intensification models. Specifically the previous 6-hour wind speed change (Prev6) was used in 7 of the 8 6-hour wind speed increase models and 6 out of the 8 6hour pressure drop models. This was indicative of the models strongly relying on the short-term trend of the maximum sustained winds. Only Models 4 and 8 did not use the previous wind speed change for the pressure models. Coincidently Models 4 and 8 had more significant variables than the others and did not have to rely on persistence as much. Only Model 4 did not use the previous 6-hour wind speed change in the 6-hour wind speed increase models. The common variables for Model 8 were the attained MPI (AttMPI) and the central pressure (CentPres) for both pressure and wind speed models as the minor hurricanes have very low attained MPIs and high central pressures. 


\begin{tabular}{|c|c|}
\hline Model & Regression Equation \\
\hline $\begin{array}{l}\text { Major - Time Interval } 1 \\
\text { (Model 1) }\end{array}$ & -.692 MSLP + .648 Trans Sp. + .096 CoreHP + 702.316 \\
\hline $\begin{array}{c}\text { Major - Time Interval } 2 \\
\text { (Model 2) }\end{array}$ & -.783 (850-500shr) + .08 MPI + 4.785 SST -1502.349 \\
\hline $\begin{array}{c}\text { Major - Time Interval } 3 \\
\text { (Model 3) }\end{array}$ & .092 CoreHP -.046 Incep +.216 WindSp +.245 (500RH) -.591 \\
\hline $\begin{array}{l}\text { Major - Time Interval } 4 \\
\text { (Model 4) }\end{array}$ & $\begin{array}{l}-1.012 \text { MSLP }+.314 \text { HeatPot }-.427 \text { Long }-3.148 \text { TransSp }+.631 \\
\text { CentPress }+460.375\end{array}$ \\
\hline $\begin{array}{l}\text { Minor - Time Interval } 1 \\
\text { (Model 5) }\end{array}$ & $-.051(700 R H)-13.567$ AttMPI +.347 Prev6 +.112 Lat +.024 Incep +2.698 \\
\hline $\begin{array}{l}\text { Minor - Time Interval } 2 \\
\text { (Model 6) }\end{array}$ & $\begin{array}{l}-.08 \text { (850RH) }-.722 \text { SST }+.291 \text { TransSp }-.117 \text { WindSp }-.355 \text { MSLP }+.017 \\
(\mathbf{8 5 0 - 1 0 0 d i r ) ~}+587.07\end{array}$ \\
\hline $\begin{array}{l}\text { Minor - Time Interval } 3 \\
\text { (Model 7) }\end{array}$ & $-.194(\mathbf{9 2 5 R H})+.203(\mathbf{8 5 0 R H})+.468$ Prev6 +11.394 \\
\hline $\begin{array}{l}\text { Minor - Time Interval } 4 \\
\text { (Model 8) }\end{array}$ & $\begin{array}{l}-.390 \text { (850-100shr) - .024 (850-500dir) - . } 182 \text { Long - .357 WindSp + } \\
44.081\end{array}$ \\
\hline
\end{tabular}

Table 4.4: Future 24-hour pressure drop regression equations. 


\begin{tabular}{|c|c|}
\hline Model & Regression Equation \\
\hline $\begin{array}{l}\text { Major - Time Interval } 1 \\
\text { (Model 1) }\end{array}$ & .517 TransSp $+.260(\mathbf{9 2 5 R H})+.138$ CoreHP +.575 Prev6 -14.351 \\
\hline $\begin{array}{c}\text { Major - Time Interval } 2 \\
\text { (Model 2) }\end{array}$ & $\begin{array}{l}.016 \text { (850-500dir) }-.018 \text { (850-200dir) }+.157 \text { (700RH) }+.958 \text { TransSp }-.642 \\
(\mathbf{8 5 0 - 2 0 0 s h r )}-40.290 \text { AttMPI }+13.012\end{array}$ \\
\hline $\begin{array}{c}\text { Major - Time Interval } 3 \\
\text { (Model 3) }\end{array}$ & -.199 Long +.325 (500RH) -.248 MPI +248.834 \\
\hline $\begin{array}{l}\text { Major - Time Interval } 4 \\
\text { (Model 4) }\end{array}$ & .394 HeatPot -4.067 TransSp - .593 Long -.700 WindSp + 122.571 \\
\hline $\begin{array}{c}\text { Minor - Time Interval } 1 \\
\text { (Model 5) }\end{array}$ & .025 Incep +.827 Prev6 +3.08 \\
\hline $\begin{array}{c}\text { Minor }- \text { Time Interval } 2 \\
\text { (Model 6) }\end{array}$ & $\begin{array}{l}.780 \text { (850-500shr) }+.019 \text { (500-200dir) }-.159 \text { (500RH) }-.700 \text { MSLP }-.395 \\
(\mathbf{8 5 0 - 2 0 0 s h r )}-.390 \text { (850RH) }-.794 \text { CentPres }+.923 \text { TransSp }-.796 \text { WindSp } \\
+1570.089\end{array}$ \\
\hline $\begin{array}{c}\text { Minor - Time Interval } 3 \\
\text { (Model 7) }\end{array}$ & .02 (850-500dir) + .665 Prev6 - .524 CentPres -.528 WindSp +560.58 \\
\hline $\begin{array}{c}\text { Minor - Time Interval } 4 \\
\text { (Model 8) }\end{array}$ & $\begin{array}{l}.098 \text { MPI }+.323 \text { HeatPot }-.467 \text { CentPres }-.770 \text { (850-100shr) }-.343 \text { Long }- \\
1.095 \text { WindSp }+465.604\end{array}$ \\
\hline
\end{tabular}

Table 4.5: Future 24-hour wind speed increase regression equations 


\begin{tabular}{|c|c|}
\hline Model & \multicolumn{1}{|c|}{ Regression Equation } \\
(Model 1) & \\
\hline $\begin{array}{c}\text { Major - Time Interval 1 } \\
\text { (Model 2) }\end{array}$ & -.143 MSLP +.629 SST +.216 TransSp +.138 Prev6 -44.147 \\
\hline $\begin{array}{c}\text { Major - Time Interval 3 } \\
\text { (Model 3) }\end{array}$ & .03 CoreHP +.181 Prev6 +1.640 \\
\hline $\begin{array}{c}\text { Major - Time Interval 4 } \\
\text { (Model 4) }\end{array}$ & -.197 Lat +.486 (850-100shr) +.018 (850-100dir) -12.506 AttMPI +11.584 \\
\hline $\begin{array}{c}\text { Minor - Time Interval 1 } \\
\text { (Model 5) }\end{array}$ & .106 Prev6 +.128 TransSp +.086 \\
\hline $\begin{array}{c}\text { Minor - Time Interval 2 } \\
\text { (Model 6) }\end{array}$ & .094 Prev6 +.464 \\
\hline $\begin{array}{c}\text { Minor - Time Interval 4 } \\
\text { (Model 8) }\end{array}$ & .02 MPI - .174 AttMPI - .007 (850-500dir) +.094 CentPres -106.992 \\
(Model 7) & \\
\hline
\end{tabular}

Table 4.6: Future 6-hour pressure drop regression equations. 


\begin{tabular}{|c|l|}
\hline Model & \multicolumn{1}{|c|}{ Regression Equation } \\
(Model 1) & \\
\hline $\begin{array}{c}\text { Major - Time Interval 1 } \\
\text { (Model 2) }\end{array}$ & .031 CoreHP +.451 Prev6 +.788 \\
\hline $\begin{array}{c}\text { Major - Time Interval 3 } \\
\text { (Model 3) }\end{array}$ & .075 (500RH) +.241 Prev6 +1.063 \\
\hline $\begin{array}{c}\text { Major - Time Interval 4 } \\
\text { (Model 4) }\end{array}$ & -.141 (925RH) -.291 Lat -.123 WindSp +35.398 \\
\hline $\begin{array}{c}\text { Minor - Time Interval 1 } \\
\text { (Model 5) }\end{array}$ & .265 Prev6 +.305 TransSp +.273 \\
\hline $\begin{array}{c}\text { Minor - Time Interval 2 } \\
\text { (Model 6) }\end{array}$ & -.084 (850RH) +.268 TransSp - .244 CentPres +.218 Prev6 -.216 WindSp + \\
(Model 8) & 258.328 \\
\hline Minor - Time Interval 3 & -.095 Lat +.368 Prev6 + 4.288 \\
(Model 7) & \\
\hline Minor - Time Interval 4 & .207 Prev6 - .204 AttMPI - .239 CentPres -.356 WindSp +262.034 \\
\hline
\end{tabular}

Table 4.7: Future 6-hour wind speed increase regression equations. 


\subsection{Evaluation of the Models with an Independent Dataset}

The independent dataset used to evaluate the regression models discussed in the previous sections consisted of 13 hurricanes from the 2004 and 2005 seasons. A brief synoptic history is provided for each hurricane and the performance of the 4 types of models (24-hour pressure drop, 24-hour wind speed increase, 6-hour pressure drop, and 6-hour wind speed increase) is described. The percentage error for each model is given where applicable. In cases where the DFA selected the wrong model, the correctly selected model (CSM) prediction, which would have been the forecast had the discriminant function analysis (DFA) selected the correct model, is given. The amount of improvement of the CSM is also given for these cases. The results from the 24-hour wind speed model are compared to the official NHC forecasts and their percentage errors are shown. 


\subsubsection{Hurricane Alex (2004)}

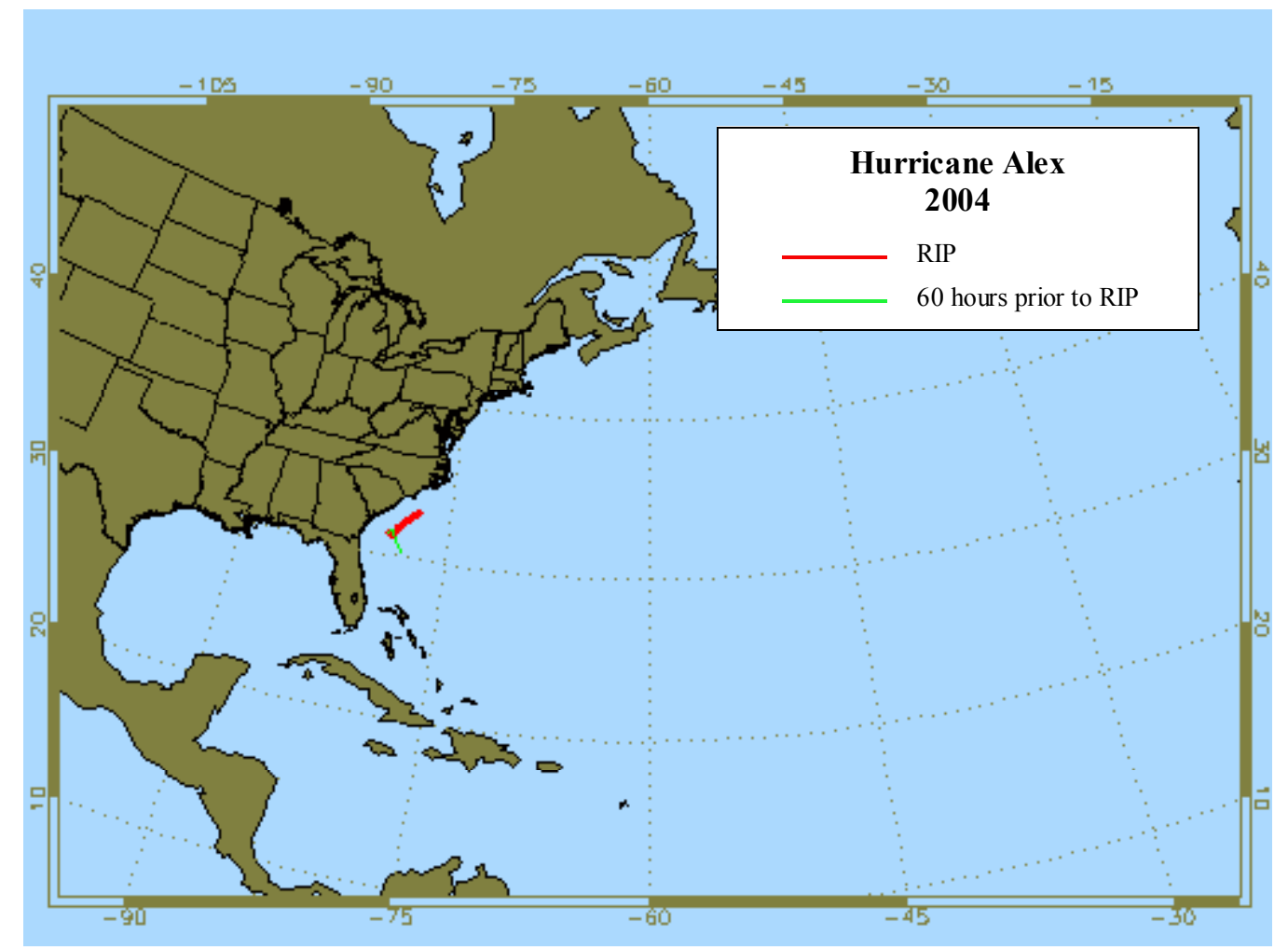

Figure 4.1: Track of Hurricane Alex (2004).

Figure 4.1 shows the track of Alex over the period of the study. Alex was a broad area of low pressure on July 30 north of the central Bahamas during Time Interval 1. Over the next 36 hours, Alex moved toward the northwest and became better defined. On August 1, the translational speed slowed and Alex was nearly stationary for over a day. During this time, Alex remained poorly organized due to strong northeasterly shear. Not until an upper level trough approached from the west did the shear weaken causing Alex to intensify and enter its RIP. Alex became a tropical storm at 18Z August 1 and 
started to move toward the northeast. With the combination of the low wind shear and the warm Gulf Stream waters, Alex was able to attain Category 2 strength by the end of the RIP but it would eventually become a major Category 3.

The DFA misclassified all of the time intervals, because it mistakenly predicted that Alex would maintain minor hurricane status. This was primarily because of the high wind shear observations $\left(850 \mathrm{hPa}-200 \mathrm{hPa}\right.$ values were above $\left.10 \mathrm{~m} \mathrm{~s}^{-1}\right)$ and low hurricane heat potential that usually accompany minor hurricanes. It did not rapidly intensify until an upper level trough approached, which caused the shear to relax, and it eventually formed a major hurricane. The relatively high northerly latitude of Alex was also unusual for a storm that intensified into a major hurricane. In fact, only one hurricane formed into major hurricane status farther north than Alex (Hurricane Ellen of 1973). All of these factors contributed to the DFA misclassifications. Therefore when predicting the 24-hour pressure drop (Table 4.8), the model predictions were higher than observations until Time Interval 8, and lower than observations the remainder of the period. The misclassified time intervals resulted in high percentage errors for the entire period. However, had the DFA used the correctly selected model (CSM), it would have offered dramatic improvement beginning at Time Interval 9 or 18 hours before the RIP. Use of the major hurricane models captured the RIP and would have resulted in approximately a $20 \mathrm{hPa} 24$-hour decrease at Time Interval 12 or the onset of the RIP. Alex actually dropped $22 \mathrm{hPa}$ over the next 24 hours to become a hurricane with a pressure of $983 \mathrm{hPa}$. 


\begin{tabular}{|c|c|c|c|c|c|c|c|c|}
\hline $\begin{array}{l}\text { Date } \\
\text { (2004) }\end{array}$ & $\begin{array}{c}\text { Time } \\
\text { Interval }\end{array}$ & Model & $\begin{array}{c}\text { Central } \\
\text { Pressure } \\
(\mathrm{hPa})\end{array}$ & $\begin{array}{c}\text { 24-hour } \\
\text { Obs. }\end{array}$ & $\begin{array}{c}\text { 24-hour } \\
\text { Press } \\
\text { Model } \\
\text { (hPa) }\end{array}$ & $\%$ error & $\begin{array}{c}\text { Correct } \\
\text { Selected } \\
\text { Model } \\
(\mathrm{hPa})\end{array}$ & $\begin{array}{c}\text { Improve } \\
(\mathrm{hPa})\end{array}$ \\
\hline $7 / 3012 Z$ & 1 & 5 & 1010 & 0 & 2.72 & $\mathrm{~N} / \mathrm{a}$ & 1.46 & 1.25 \\
\hline $7 / 3018 \mathrm{Z}$ & 2 & 5 & 1010 & 0 & 2.90 & $\mathrm{~N} / \mathrm{a}$ & 1.84 & 1.06 \\
\hline $7 / 310 Z$ & 3 & 5 & 1010 & 1 & 3.10 & 210.8 & 2.47 & 0.63 \\
\hline $7 / 316 Z$ & 4 & 5 & 1010 & 1 & 3.35 & 235.6 & 2.12 & 1.23 \\
\hline $7 / 3112 Z$ & 5 & 5 & 1010 & 1 & 3.35 & 235.4 & 9.63 & -6.27 \\
\hline $7 / 3118 Z$ & 6 & 6 & 1010 & 1 & 5.27 & 427.9 & 10.64 & -5.36 \\
\hline $8 / 10 Z$ & 7 & 6 & 1009 & 2 & 6.03 & 201.9 & 11.17 & -5.13 \\
\hline $8 / 16 Z$ & 8 & 6 & 1009 & 4 & 4.87 & 22.0 & 9.69 & -4.81 \\
\hline $8 / 112 Z$ & 9 & 6 & 1009 & 17 & 3.21 & 81.1 & 17.90 & 12.88 \\
\hline $8 / 118 Z$ & 10 & 6 & 1009 & 16 & 4.03 & 74.8 & 18.44 & 9.51 \\
\hline $8 / 20 Z$ & 11 & 6 & 1007 & 20 & 3.55 & 82.2 & 19.80 & 16.24 \\
\hline $8 / 26 Z$ & 12 & 6 & 1005 & 22 & 3.18 & 85.5 & 19.55 & 16.36 \\
\hline $8 / 212 Z$ & 13 & 8 & 992 & 18 & 6.67 & 62.9 & 24.43 & 4.89 \\
\hline $8 / 218 Z$ & 14 & 7 & 993 & 21 & 11.75 & 44.0 & 22.83 & 7.40 \\
\hline $8 / 30 Z$ & 15 & 8 & 987 & 13 & 5.36 & 58.7 & 17.74 & 2.89 \\
\hline $8 / 36 Z$ & 16 & 8 & 983 & 10 & 1.42 & 85.7 & 12.63 & 5.94 \\
\hline
\end{tabular}

Table 4.8: 24-hour pressure drop model for Hurricane Alex. 
Similarly, the 24-hour wind speed model (Table 4.9) struggled to predict the correct wind speed due to the misclassification. The model percentage errors were above $50 \%$ with the exception of Time Intervals 5 and 6. The NHC forecasts struggled as well with percentage errors of at least 50\% with the exception of Time Intervals 6 and 10 . Both models were poor during this period because this was point when the trough interacted thereby reducing the shear. Alex began to undergo the transformation into a major hurricane. As Alex entered its RIP, the NHC forecasts still did not capture the rapid intensification well. They only forecasted an increase of 15, 10 and 15 knots during Time Intervals 12-14 respectively, thus underestimating the winds by 15,25 , and 20 knots. The CSM would have dramatically improved the accuracy of the model beginning at Time Interval 8 ( 24 hours before the RIP), and would have outperformed the official NHC forecasts at all intervals after Time Interval 8. In particular, the CSM predicted a 24-hour increase of approximately 24, 37, and 33 knots during Time Intervals 12-14. These produced errors of only 6, 2, and 2 knots suggesting that the CSM was able to capture the RIP much better than the official NHC forecasts. This was partly due to the fact that Model 4 incorporates Heat Potential while Models 6 and 7 (which were selected to be used) do not. The Gulf Stream was able to provide enough energy for Alex to intensify into a major hurricane.

The central pressure of Alex did not deepen rapidly due to its nearly stationary movement and large vertical wind shear between the 6-hour time intervals with the exception of Time Interval 12 (Table 4.10), when the pressure dropped $13 \mathrm{hPa}$ over the next 6 hours. Even with the misclassified models, the forecasts predicted minimal decreases in the central pressure as shown by the observed values. 


\begin{tabular}{|c|c|c|c|c|c|c|c|c|c|}
\hline $\begin{array}{c}\text { Time } \\
\text { Int. }\end{array}$ & Model & $\begin{array}{l}\text { Max. } \\
\text { Sus. } \\
\text { Wind } \\
\text { (kts) }\end{array}$ & $\begin{array}{c}\text { 24-hour } \\
\text { Obs. }\end{array}$ & $\begin{array}{c}\text { 24-hour } \\
\text { Model } \\
\text { (kts) }\end{array}$ & $\%$ error & $\begin{array}{c}\text { NHC } \\
24 \text { hour } \\
\text { For. }\end{array}$ & $\begin{array}{c}\text { NHC } \\
\% \\
\text { error }\end{array}$ & $\begin{array}{l}\text { CSM } \\
(\mathrm{kts})\end{array}$ & $\begin{array}{c}\text { Improv. } \\
(\mathrm{kts})\end{array}$ \\
\hline 1 & 5 & 25 & 0 & 2.48 & $\mathrm{~N} / \mathrm{a}$ & $\mathrm{N} / \mathrm{a}$ & $\mathrm{N} / \mathrm{a}$ & 7.81 & -5.33 \\
\hline 2 & 5 & 25 & 0 & 2.63 & $\mathrm{~N} / \mathrm{a}$ & $\mathrm{N} / \mathrm{a}$ & $\mathrm{N} / \mathrm{a}$ & 6.17 & -3.54 \\
\hline 3 & 5 & 25 & 0 & 2.78 & $\mathrm{~N} / \mathrm{a}$ & $\mathrm{N} / \mathrm{a}$ & $\mathrm{N} / \mathrm{a}$ & 6.54 & -3.76 \\
\hline 4 & 5 & 25 & 0 & 2.93 & $\mathrm{~N} / \mathrm{a}$ & $\mathrm{N} / \mathrm{a}$ & $\mathrm{N} / \mathrm{a}$ & 7.08 & -4.15 \\
\hline 5 & 5 & 25 & 5 & 3.08 & 38.4 & $\mathrm{~N} / \mathrm{a}$ & $\mathrm{N} / \mathrm{a}$ & 13.66 & -6.74 \\
\hline 6 & 6 & 25 & 10 & 9.51 & 4.9 & 10 & 0.0 & 17.99 & -7.50 \\
\hline 7 & 6 & 25 & 0 & 11.5 & N/a & 5 & $\mathrm{~N} / \mathrm{a}$ & 21.77 & -10.23 \\
\hline 8 & 6 & 25 & 15 & 7.37 & 50.8 & 5 & 66.7 & 18.76 & 3.86 \\
\hline 9 & 6 & 30 & 20 & -2.08 & 110.4 & 5 & 75.0 & 22.02 & 20.06 \\
\hline 10 & 6 & 35 & 15 & -3.27 & 121.8 & 10 & 33.3 & 20.08 & 13.18 \\
\hline 11 & 6 & 35 & 25 & -3.45 & 113.8 & 10 & 60.0 & 24.71 & 28.17 \\
\hline 12 & 6 & 40 & 30 & -6.41 & 121.4 & 15 & 50.0 & 23.81 & 30.22 \\
\hline 13 & 8 & 50 & 35 & 9.09 & 74.0 & 10 & 71.4 & 37.57 & 23.32 \\
\hline 14 & 7 & 50 & 35 & 14.96 & 57.3 & 15 & 57.1 & 33.46 & 18.49 \\
\hline 15 & 8 & 60 & 20 & 2.86 & 85.7 & 5 & 75.0 & 22.55 & 14.58 \\
\hline 16 & 8 & 70 & 10 & -5.46 & 154.7 & 5 & 50.0 & 11.86 & 13.60 \\
\hline
\end{tabular}

Table 4.9: 24-hour wind speed increase model for Hurricane Alex. 
The CSM did not offer much improvement over the original model during the period. Both models failed to capture the short-term intensification seen during Time Interval 12 but Alex was an unusual hurricane in that it eventually achieved major hurricane status that far north. As for the 6-hour wind speed increase (Table 4.11), the model was able to capture the minimal wind speed increase through Time Interval 10 (12 hours before the RIP), while the conditions were relatively persistent. However, the CSM provided improvement to the original model beginning with Time Interval 11 near the onset of the RIP. The CSM predicted wind speed increases near 7-10 knots from Time Interval 13-16 when the observations ranged from 0-15 knots. 


\begin{tabular}{|c|c|c|c|c|c|c|c|c|}
\hline Date & $\begin{array}{l}\text { Time } \\
\text { Int. }\end{array}$ & Model & $\begin{array}{c}\text { Cent. } \\
\text { Pressure } \\
(\mathrm{hPa})\end{array}$ & $\begin{array}{l}\text { 6-hour Pres. } \\
\text { Drop Obs. }\end{array}$ & $\begin{array}{c}\text { 6-hour } \\
\text { Model } \\
\text { (hPa) }\end{array}$ & $\begin{array}{l}\% \\
\text { error }\end{array}$ & $\begin{array}{l}\text { CSM } \\
(\mathrm{hPa})\end{array}$ & $\begin{array}{c}\text { Improv. } \\
(\mathrm{hPa})\end{array}$ \\
\hline $7 / 3012 Z$ & 1 & 5 & 1010 & 0 & 0.08 & $\mathrm{~N} / \mathrm{a}$ & 0.22 & -0.13 \\
\hline $7 / 3018 \mathrm{Z}$ & 2 & 5 & 1010 & 0 & 0.08 & $\mathrm{~N} / \mathrm{a}$ & 0.29 & -0.21 \\
\hline $7 / 310 Z$ & 3 & 5 & 1010 & 0 & 0.08 & $\mathrm{~N} / \mathrm{a}$ & 0.31 & -0.22 \\
\hline $7 / 316 Z$ & 4 & 5 & 1010 & 0 & 0.08 & $\mathrm{~N} / \mathrm{a}$ & 0.23 & -0.15 \\
\hline $7 / 3112 Z$ & 5 & 5 & 1010 & 0 & 0.08 & $\mathrm{~N} / \mathrm{a}$ & 1.53 & -1.44 \\
\hline $7 / 3118 Z$ & 6 & 6 & 1010 & 1 & 0.46 & 53.6 & 1.53 & 0.01 \\
\hline $8 / 10 Z$ & 7 & 6 & 1009 & 0 & 0.46 & $\mathrm{~N} / \mathrm{a}$ & 1.53 & -1.06 \\
\hline $8 / 16 Z$ & 8 & 6 & 1009 & 0 & 0.46 & $\mathrm{~N} / \mathrm{a}$ & 1.53 & -1.06 \\
\hline $8 / 112 Z$ & 9 & 6 & 1009 & 0 & 0.93 & $\mathrm{~N} / \mathrm{a}$ & 2.91 & -1.97 \\
\hline $8 / 118 Z$ & 10 & 6 & 1009 & 2 & 0.93 & 53.3 & 2.91 & 0.15 \\
\hline $8 / 20 Z$ & 11 & 6 & 1007 & 2 & 0.46 & 76.8 & 2.00 & 1.53 \\
\hline $8 / 26 Z$ & 12 & 6 & 1005 & 13 & 0.93 & 92.8 & 2.91 & 1.97 \\
\hline $8 / 212 Z$ & 13 & 8 & 992 & -1 & 3.39 & 439.9 & 10.16 & -6.76 \\
\hline $8 / 218 Z$ & 14 & 7 & 993 & 6 & 1.60 & 73.2 & 8.76 & 1.62 \\
\hline $8 / 30 Z$ & 15 & 8 & 987 & 4 & 3.54 & 11.3 & 8.46 & -4.00 \\
\hline $8 / 36 Z$ & 16 & 8 & 983 & 9 & 3.12 & 65.3 & 6.69 & 3.56 \\
\hline
\end{tabular}

Table 4:10: 6-hour pressure drop model for Hurricane Alex. 


\begin{tabular}{|c|c|c|c|c|c|c|c|c|}
\hline Date & $\begin{array}{l}\text { Time } \\
\text { Int. }\end{array}$ & Model & $\begin{array}{l}\text { Max. Sus. } \\
\text { Winds (kts) }\end{array}$ & $\begin{array}{c}\text { 6-hour } \\
\text { Wind } \\
\text { Speed Obs. }\end{array}$ & $\begin{array}{c}\text { 6-hour } \\
\text { Model } \\
\text { (kts) }\end{array}$ & $\%$ error & $\begin{array}{l}\text { CSM } \\
\text { (kts) }\end{array}$ & $\begin{array}{c}\text { Improv. } \\
\text { (kts) }\end{array}$ \\
\hline $7 / 3012 Z$ & 1 & 5 & 25 & 0 & 0.27 & $\mathrm{~N} / \mathrm{a}$ & 1.54 & -1.26 \\
\hline $7 / 3018 Z$ & 2 & 5 & 25 & 0 & 0.27 & $\mathrm{~N} / \mathrm{a}$ & 1.54 & -1.26 \\
\hline $7 / 310 \mathrm{Z}$ & 3 & 5 & 25 & 0 & 0.27 & $\mathrm{~N} / \mathrm{a}$ & 1.54 & -1.26 \\
\hline $7 / 316 Z$ & 4 & 5 & 25 & 0 & 0.27 & $\mathrm{~N} / \mathrm{a}$ & 1.54 & -1.26 \\
\hline $7 / 3112 Z$ & 5 & 5 & 25 & 0 & 0.27 & $\mathrm{~N} / \mathrm{a}$ & 3.36 & -3.08 \\
\hline $7 / 3118 Z$ & 6 & 6 & 25 & 0 & 0.91 & $\mathrm{~N} / \mathrm{a}$ & 3.73 & -2.81 \\
\hline $8 / 10 Z$ & 7 & 6 & 25 & 0 & 2.11 & $\mathrm{~N} / \mathrm{a}$ & 3.48 & -1.37 \\
\hline $8 / 16 Z$ & 8 & 6 & 25 & 5 & 1.14 & 77.2 & 3.52 & 2.38 \\
\hline $8 / 112 Z$ & 9 & 6 & 30 & 5 & 0.23 & 95.3 & 5.94 & 3.82 \\
\hline $8 / 118 Z$ & 10 & 6 & 35 & 0 & -0.09 & $\mathrm{~N} / \mathrm{a}$ & 5.86 & -5.76 \\
\hline $8 / 20 Z$ & 11 & 6 & 35 & 5 & -0.71 & 114.3 & 5.15 & 5.56 \\
\hline $8 / 26 Z$ & 12 & 6 & 40 & 10 & -0.61 & 106.2 & 6.03 & 6.65 \\
\hline $8 / 212 \mathrm{Z}$ & 13 & 8 & 50 & 0 & 9.17 & $\mathrm{~N} / \mathrm{a}$ & 9.35 & -0.17 \\
\hline $8 / 218 Z$ & 14 & 7 & 50 & 10 & 1.26 & 87.3 & 9.39 & 8.12 \\
\hline $8 / 30 Z$ & 15 & 8 & 60 & 10 & 6.79 & 32.0 & 8.19 & 1.39 \\
\hline $8 / 36 Z$ & 16 & 8 & 70 & 15 & 4.18 & 72.1 & 7.08 & 2.90 \\
\hline
\end{tabular}

Table 4.11: 6-hour wind speed increase model for Hurricane Alex. 


\subsubsection{Hurricane Charley (2004)}

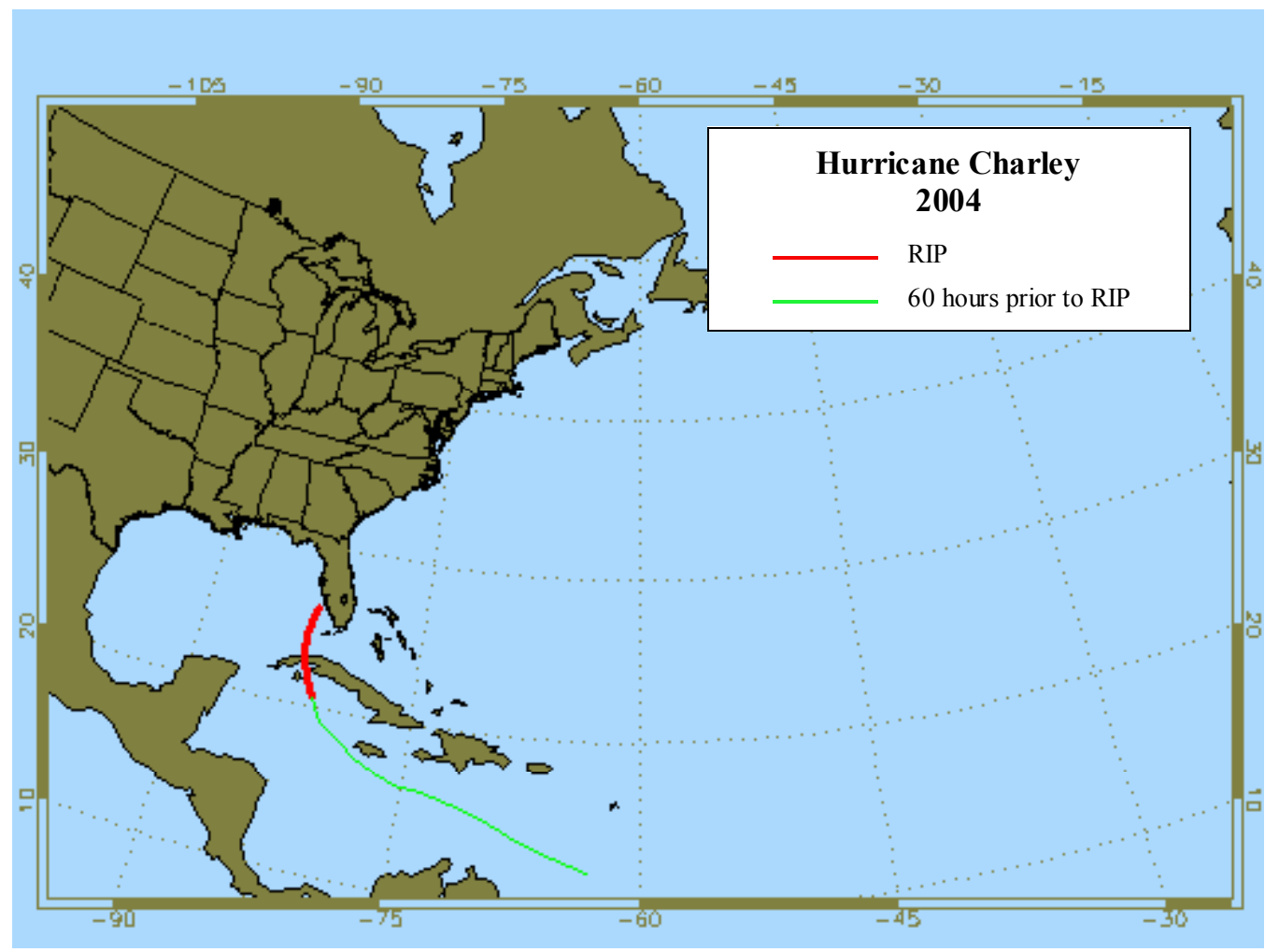

Figure 4.2: Track of Hurricane Charley (2004).

The track of Hurricane Charley began on August 10 in the southeastern Caribbean Sea when it developed into tropical storm status. Low wind shear and well-defined outflow enabled it to strengthen steadily as it moved toward the northwest into the central Caribbean. Charley officially became a hurricane around $18 \mathrm{Z}$ on August 11 when it was near the island of Jamaica. As it continued to progress toward western Cuba, it was upgraded to a Category 2. It then encountered a mid-tropospheric ridge, which made it 
turn to the north and pass just to the west of Havana, Cuba. Due to the short period of time it was over land, it weakened only slightly as it passed over Cuba and move toward the Dry Tortugas on August 13. Warm waters created high heat potential that contributed to the rapid intensification of Charley to Category 4 strength by the end of the RIP. A sharp trough that affected Charley in the eastern Gulf of Mexico also caused it to unexpectedly turn toward the east where Charley made landfall near Cayo Costa, FL around $20 \mathrm{Z}$ on August 13 as a Category 4 hurricane.

The DFA was able to correctly classify all 16 time intervals by forecasting Charley to become a major hurricane up to 4 days before it actually attained major hurricane status. Charley exhibited some of the features, such as low wind shear while located over areas with high heat potential, which many other major hurricanes have. As for the time classification, the DFA was able to correctly classify 14 out of the 16 intervals correctly. The two misclassifications occurred during Time Intervals 13 and 15 when it said to use Model 3 instead of Model 4. These intervals had lower shear and relatively higher central pressures, which were more characteristic of the time periods just prior to the RIP.

Table 4.12 shows the 24-hour pressure drop forecasts for Hurricane Charley. During the first 12 intervals, the percentage errors of the model results were below 35\% with the exception of 3 intervals (Time Intervals 4, 9, and 11). The models predicted the pressure drop very close to the observations, most notably at Time Interval 12 (the onset of the RIP), where it predicted a future 24-hour pressure drop of $32.19 \mathrm{hPa}$. At this point, the central pressure was $980 \mathrm{hPa}$ and the observed 24-hour drop was $43 \mathrm{hPa}$ giving 


\begin{tabular}{|c|c|c|c|c|c|c|c|c|}
\hline $\begin{array}{l}\text { Date } \\
\text { (2004) }\end{array}$ & $\begin{array}{c}\text { Time } \\
\text { Interval }\end{array}$ & Model & $\begin{array}{c}\text { Central } \\
\text { Pressure } \\
(\mathrm{hPa})\end{array}$ & $\begin{array}{c}\text { 24-hour } \\
\text { Obs. }\end{array}$ & $\begin{array}{l}\text { 24-hour } \\
\text { Press } \\
\text { Model } \\
\text { (hPa) }\end{array}$ & $\%$ error & $\begin{array}{c}\text { Correct } \\
\text { Selected } \\
\text { Model } \\
(\mathrm{hPa})\end{array}$ & $\begin{array}{r}\text { Improv. } \\
(\mathrm{hPa})\end{array}$ \\
\hline $8 / 100 Z$ & 1 & 1 & 1009 & 10 & 10.44 & 4.5 & $\mathrm{~N} / \mathrm{a}$ & $\mathrm{N} / \mathrm{a}$ \\
\hline $8 / 106 Z$ & 2 & 1 & 1007 & 8 & 9.65 & 20.7 & $\mathrm{~N} / \mathrm{a}$ & $\mathrm{N} / \mathrm{a}$ \\
\hline $8 / 1012 Z$ & 3 & 1 & 1004 & 9 & 11.98 & 33.1 & $\mathrm{~N} / \mathrm{a}$ & $\mathrm{N} / \mathrm{a}$ \\
\hline $8 / 1018 \mathrm{Z}$ & 4 & 1 & 1000 & 7 & 13.96 & 99.5 & $\mathrm{~N} / \mathrm{a}$ & $\mathrm{N} / \mathrm{a}$ \\
\hline $8 / 110 Z$ & 5 & 2 & 999 & 7 & 9.02 & 28.9 & $\mathrm{~N} / \mathrm{a}$ & $\mathrm{N} / \mathrm{a}$ \\
\hline $8 / 116 Z$ & 6 & 2 & 999 & 11 & 11.37 & 3.5 & $\mathrm{~N} / \mathrm{a}$ & $\mathrm{N} / \mathrm{a}$ \\
\hline $8 / 1112 Z$ & 7 & 2 & 995 & 11 & 9.53 & 13.3 & $\mathrm{~N} / \mathrm{a}$ & $\mathrm{N} / \mathrm{a}$ \\
\hline $8 / 1118 \mathrm{Z}$ & 8 & 2 & 993 & 13 & 9.90 & 23.8 & $\mathrm{~N} / \mathrm{a}$ & $\mathrm{N} / \mathrm{a}$ \\
\hline $8 / 120 Z$ & 9 & 3 & 992 & 16 & 26.52 & 65.8 & $\mathrm{~N} / \mathrm{a}$ & $\mathrm{N} / \mathrm{a}$ \\
\hline $8 / 126 Z$ & 10 & 3 & 988 & 22 & 23.48 & 6.8 & $\mathrm{~N} / \mathrm{a}$ & $\mathrm{N} / \mathrm{a}$ \\
\hline $8 / 1212 Z$ & 11 & 3 & 984 & 15 & 27.25 & 81.7 & $\mathrm{~N} / \mathrm{a}$ & $\mathrm{N} / \mathrm{a}$ \\
\hline $8 / 1218 Z$ & 12 & 3 & 980 & 43 & 32.19 & 25.2 & $\mathrm{~N} / \mathrm{a}$ & $\mathrm{N} / \mathrm{a}$ \\
\hline $8 / 130 Z$ & 13 & 3 & 976 & 6 & 30.34 & 405.7 & 10.28 & 20.06 \\
\hline $8 / 136 Z$ & 14 & 4 & 966 & -27 & -0.21 & 99.2 & $\mathrm{~N} / \mathrm{a}$ & $\mathrm{N} / \mathrm{a}$ \\
\hline $8 / 1312 Z$ & 15 & 3 & 969 & -19 & 30.50 & 260.5 & -1.47 & 31.97 \\
\hline $8 / 1318 Z$ & 16 & 4 & 947 & -53 & -26.74 & 49.5 & $\mathrm{~N} / \mathrm{a}$ & $\mathrm{N} / \mathrm{a}$ \\
\hline
\end{tabular}

Table 4.12: 24-hour pressure drop model for Hurricane Charley. 
Charley a central pressure of $947 \mathrm{hPa}$. Therefore, the model predicted that Charley would attain a pressure just under $958 \mathrm{hPa}$ at Time Interval 12 when it was on the south side of Cuba and approximately a day from U.S. landfall. The CSM did offer improvement during Time Intervals 13 and 15 but the main reason the model struggled from Time Intervals 13-16 was because Charley would be making landfall within 24 hours and the regression models do not take into account weakening due to movement over land.

The 24-hour wind speed increase model is shown in Table 4.13. The model forecasts were able to outperform the NHC forecasts on 9 of the first 12 intervals. During Time Interval 12 (the onset of the RIP), the model predicted the wind speed would increase 34.62 knots to approximately 125 knots or Category 4 strength over the next 24 hours. The actual observed increase was 35 knots making it a Category 4 at 125 knots, whereas the NHC said they would only increase 15 knots to 105 knots. It was likely due to the fact that the NHC underestimated the magnitude of heat potential, which really added strength to Charley. Since landfall occurred within 24 hours during Time Intervals 13-16, the model did overestimate the intensity. However, the CSM did improve both misclassified intervals (Time Intervals 13 and 15). The CSM did more accurately predict the intensity of Time Interval 13 than the NHC.

The 6-hour pressure drop model (Table 4.14) also performed well with percentage errors all below $50 \%$ for the first 12 intervals with the exceptions of Time Intervals 4,6 , and 8. Charley had modest 6-hour pressure reductions until the RIP. At Time Interval 13, the observed 6-hour drop was $10 \mathrm{hPa}$ but the model predicted a drop of approximately $3 \mathrm{hPa}$. However, the CSM was able to improve on the prediction by forecasting a drop of 


\begin{tabular}{|c|c|c|c|c|c|c|c|c|c|}
\hline $\begin{array}{c}\text { Time } \\
\text { Int. }\end{array}$ & Model & $\begin{array}{l}\text { Max. } \\
\text { Sus. } \\
\text { Wind } \\
\text { (kts) }\end{array}$ & $\begin{array}{c}\text { 24-hour } \\
\text { Obs. }\end{array}$ & $\begin{array}{c}\text { 24-hour } \\
\text { Model } \\
\text { (kts) }\end{array}$ & $\%$ error & $\begin{array}{c}\text { NHC } \\
24 \text { hour } \\
\text { For. }\end{array}$ & $\begin{array}{c}\text { NHC } \\
\% \\
\text { error }\end{array}$ & $\begin{array}{l}\text { CSM } \\
(\mathrm{kts})\end{array}$ & $\begin{array}{c}\text { Improv. } \\
(\mathrm{kts})\end{array}$ \\
\hline 1 & 1 & 30 & 25 & 15.82 & 36.7 & 5 & 80.0 & $\mathrm{~N} / \mathrm{a}$ & $\mathrm{N} / \mathrm{a}$ \\
\hline 2 & 1 & 35 & 20 & 16.95 & 15.2 & 10 & 50.0 & $\mathrm{~N} / \mathrm{a}$ & $\mathrm{N} / \mathrm{a}$ \\
\hline 3 & 1 & 40 & 20 & 18.73 & 6.3 & 10 & 50.0 & $\mathrm{~N} / \mathrm{a}$ & $\mathrm{N} / \mathrm{a}$ \\
\hline 4 & 1 & 45 & 20 & 19.19 & 4.0 & 10 & 50.0 & $\mathrm{~N} / \mathrm{a}$ & $\mathrm{N} / \mathrm{a}$ \\
\hline 5 & 2 & 55 & 10 & 18.92 & 89.2 & 10 & 0.0 & $\mathrm{~N} / \mathrm{a}$ & N/a \\
\hline 6 & 2 & 55 & 20 & 18.39 & 8.0 & 10 & 50.0 & $\mathrm{~N} / \mathrm{a}$ & $\mathrm{N} / \mathrm{a}$ \\
\hline 7 & 2 & 60 & 20 & 15.99 & 20.0 & 15 & 25.0 & $\mathrm{~N} / \mathrm{a}$ & N/a \\
\hline 8 & 2 & 65 & 25 & 13.38 & 46.5 & 15 & 40.0 & $\mathrm{~N} / \mathrm{a}$ & $\mathrm{N} / \mathrm{a}$ \\
\hline 9 & 3 & 65 & 25 & 28.17 & 12.7 & 15 & 40.0 & $\mathrm{~N} / \mathrm{a}$ & $\mathrm{N} / \mathrm{a}$ \\
\hline 10 & 3 & 75 & 30 & 27.65 & 7.8 & 10 & 66.7 & $\mathrm{~N} / \mathrm{a}$ & $\mathrm{N} / \mathrm{a}$ \\
\hline 11 & 3 & 90 & 15 & 32.78 & 118.6 & 20 & 33.3 & $\mathrm{~N} / \mathrm{a}$ & $\mathrm{N} / \mathrm{a}$ \\
\hline 12 & 3 & 90 & 35 & 34.62 & 1.1 & 15 & 57.1 & $\mathrm{~N} / \mathrm{a}$ & N/a \\
\hline 13 & 3 & 90 & -15 & 35.35 & 335.6 & 15 & 200 & 3.35 & 32.0 \\
\hline 14 & 4 & 105 & -30 & -12.40 & 58.7 & -15 & 50.0 & $\mathrm{~N} / \mathrm{a}$ & $\mathrm{N} / \mathrm{a}$ \\
\hline 15 & 3 & 95 & -30 & 36.30 & 221.0 & -35 & 16.7 & -9.68 & 45.98 \\
\hline 16 & 4 & 125 & -65 & -42.45 & 34.7 & -60 & 7.7 & $\mathrm{~N} / \mathrm{a}$ & $\mathrm{N} / \mathrm{a}$ \\
\hline
\end{tabular}

Table 4.13: 24-hour wind speed increase model for Hurricane Charley. 


\begin{tabular}{|c|c|c|c|c|c|c|c|c|}
\hline Date & $\begin{array}{l}\text { Time } \\
\text { Int. }\end{array}$ & Model & $\begin{array}{c}\text { Cent. } \\
\text { Pressure } \\
(\mathrm{hPa})\end{array}$ & $\begin{array}{l}\text { 6-hour Pres. } \\
\text { Drop Obs. }\end{array}$ & $\begin{array}{c}\text { 6-hour } \\
\text { Model } \\
\text { (hPa) }\end{array}$ & $\begin{array}{l}\% \\
\text { error }\end{array}$ & $\begin{array}{l}\text { CSM } \\
(\mathrm{hPa})\end{array}$ & $\begin{array}{r}\text { Improv. } \\
(\mathrm{hPa})\end{array}$ \\
\hline $8 / 100 Z$ & 1 & 1 & 1009 & 2 & 2.84 & 42.3 & $\mathrm{~N} / \mathrm{a}$ & $\mathrm{N} / \mathrm{a}$ \\
\hline $8 / 106 \mathrm{Z}$ & 2 & 1 & 1007 & 3 & 3.51 & 17.0 & $\mathrm{~N} / \mathrm{a}$ & $\mathrm{N} / \mathrm{a}$ \\
\hline $8 / 1012 Z$ & 3 & 1 & 1004 & 4 & 3.69 & 7.6 & $\mathrm{~N} / \mathrm{a}$ & $\mathrm{N} / \mathrm{a}$ \\
\hline $8 / 1018 Z$ & 4 & 1 & 1000 & 1 & 3.97 & 297.6 & $\mathrm{~N} / \mathrm{a}$ & $\mathrm{N} / \mathrm{a}$ \\
\hline $8 / 110 Z$ & 5 & 2 & 999 & 0 & 3.74 & $\mathrm{~N} / \mathrm{a}$ & $\mathrm{N} / \mathrm{a}$ & $\mathrm{N} / \mathrm{a}$ \\
\hline $8 / 116 Z$ & 6 & 2 & 999 & 4 & 1.53 & 61.7 & $\mathrm{~N} / \mathrm{a}$ & $\mathrm{N} / \mathrm{a}$ \\
\hline $8 / 1112 Z$ & 7 & 2 & 995 & 2 & 2.63 & 31.8 & $\mathrm{~N} / \mathrm{a}$ & $\mathrm{N} / \mathrm{a}$ \\
\hline $8 / 1118 Z$ & 8 & 2 & 993 & 1 & 2.63 & 163.6 & $\mathrm{~N} / \mathrm{a}$ & $\mathrm{N} / \mathrm{a}$ \\
\hline $8 / 120 \mathrm{Z}$ & 9 & 3 & 992 & 4 & 3.75 & 6.1 & $\mathrm{~N} / \mathrm{a}$ & $\mathrm{N} / \mathrm{a}$ \\
\hline $8 / 126 \mathrm{Z}$ & 10 & 3 & 988 & 4 & 4.10 & 2.25 & $\mathrm{~N} / \mathrm{a}$ & $\mathrm{N} / \mathrm{a}$ \\
\hline $8 / 1212 Z$ & 11 & 3 & 984 & 4 & 3.91 & 2.2 & $\mathrm{~N} / \mathrm{a}$ & $\mathrm{N} / \mathrm{a}$ \\
\hline $8 / 1218 Z$ & 12 & 3 & 980 & 4 & 5.19 & 29.8 & $\mathrm{~N} / \mathrm{a}$ & N/a \\
\hline $8 / 130 Z$ & 13 & 3 & 976 & 10 & 2.95 & 70.5 & 10.64 & 6.41 \\
\hline $8 / 136 \mathrm{Z}$ & 14 & 4 & 966 & -3 & 5.87 & 295.8 & $\mathrm{~N} / \mathrm{a}$ & $\mathrm{N} / \mathrm{a}$ \\
\hline $8 / 1312 Z$ & 15 & 3 & 969 & 22 & 0.93 & 95.8 & 8.26 & 7.33 \\
\hline $8 / 1318 Z$ & 16 & 4 & 947 & -23 & 7.04 & 130.6 & $\mathrm{~N} / \mathrm{a}$ & $\mathrm{N} / \mathrm{a}$ \\
\hline
\end{tabular}

Table 4.14: 6-hour pressure drop model for Hurricane Charley. 
just over $10 \mathrm{hPa}$. This was because Model 3 is dependent on the previous 6-hour wind speed change and the wind speed did not change during the previous 6 hours, whereas Model 4 does not consider this. The CSM was also able to provide improvement during Time Interval 15 for similar reasons.

The 6-hourly wind speed increase shown in Table 4.15 had success similar to that of the pressure reduction model since only 3 time intervals (Time Intervals 1, 4, and 9) had percentage errors of more than $50 \%$ during the first 12 time intervals. The model was able to do well when the wind speed increases were modest. However, when Charley started the RIP the model results were poorer. For example, during Time Interval 13 the observed 6-hour wind speed increase was 15 knots but the model only forecasted an increase of 4.61 knots. The CSM during this interval did improve the forecast by over 4 knots but it was still less than observed. The other misclassified interval, Time Interval 15, only predicted an increase of 2.29 knots when the observed increase was 30 knots. The CSM improved the forecast by over 5 knots but it still greatly underestimated the short-term intensity increase. This shows that the resolution for many of the variables is not fine enough to predict the shorter-term intensities. In this case, one of the key predictors that intensified Charley, heat potential, was not significant enough to be used in the 6-hourly intensity models. In fact, heat potential is not used in Model 3 or 4 to predict 6-hour wind speed increase. This absence is likely one of the reasons those models failed to predict the short-term intensity changes. 


\begin{tabular}{|c|c|c|c|c|c|c|c|c|}
\hline Date & $\begin{array}{l}\text { Time } \\
\text { Int. }\end{array}$ & Model & $\begin{array}{l}\text { Max. Sus. } \\
\text { Winds (kts) }\end{array}$ & $\begin{array}{c}\text { 6-hour } \\
\text { Wind } \\
\text { Speed Obs. }\end{array}$ & $\begin{array}{c}\text { 6-hour } \\
\text { Model } \\
\text { (kts) }\end{array}$ & $\%$ error & $\begin{array}{l}\text { CSM } \\
(\mathrm{kts})\end{array}$ & $\begin{array}{c}\text { Improv. } \\
\text { (kts) }\end{array}$ \\
\hline $8 / 100 \mathrm{Z}$ & 1 & 1 & 30 & 5 & 1.76 & 64.8 & $\mathrm{~N} / \mathrm{a}$ & $\mathrm{N} / \mathrm{a}$ \\
\hline $8 / 106 \mathrm{Z}$ & 2 & 1 & 35 & 5 & 3.76 & 24.7 & $\mathrm{~N} / \mathrm{a}$ & $\mathrm{N} / \mathrm{a}$ \\
\hline $8 / 1012 Z$ & 3 & 1 & 40 & 5 & 4.25 & 14.8 & $\mathrm{~N} / \mathrm{a}$ & $\mathrm{N} / \mathrm{a}$ \\
\hline $8 / 1018 Z$ & 4 & 1 & 45 & 10 & 4.49 & 55.1 & $\mathrm{~N} / \mathrm{a}$ & $\mathrm{N} / \mathrm{a}$ \\
\hline $8 / 110 \mathrm{Z}$ & 5 & 2 & 55 & 0 & 4.51 & $\mathrm{~N} / \mathrm{a}$ & $\mathrm{N} / \mathrm{a}$ & $\mathrm{N} / \mathrm{a}$ \\
\hline $8 / 116 Z$ & 6 & 2 & 55 & 5 & 2.67 & 46.6 & $\mathrm{~N} / \mathrm{a}$ & $\mathrm{N} / \mathrm{a}$ \\
\hline $8 / 1112 Z$ & 7 & 2 & 60 & 5 & 3.70 & 25.9 & $\mathrm{~N} / \mathrm{a}$ & $\mathrm{N} / \mathrm{a}$ \\
\hline $8 / 1118 Z$ & 8 & 2 & 65 & 0 & 3.75 & $\mathrm{~N} / \mathrm{a}$ & $\mathrm{N} / \mathrm{a}$ & $\mathrm{N} / \mathrm{a}$ \\
\hline $8 / 120 Z$ & 9 & 3 & 65 & 10 & 4.00 & 59.9 & $\mathrm{~N} / \mathrm{a}$ & $\mathrm{N} / \mathrm{a}$ \\
\hline $8 / 126 Z$ & 10 & 3 & 75 & 5 & 6.28 & 25.7 & $\mathrm{~N} / \mathrm{a}$ & $\mathrm{N} / \mathrm{a}$ \\
\hline $8 / 1212 Z$ & 11 & 3 & 90 & 10 & 5.31 & 46.8 & $\mathrm{~N} / \mathrm{a}$ & $\mathrm{N} / \mathrm{a}$ \\
\hline $8 / 1218 Z$ & 12 & 3 & 90 & 0 & 7.10 & $\mathrm{~N} / \mathrm{a}$ & $\mathrm{N} / \mathrm{a}$ & $\mathrm{N} / \mathrm{a}$ \\
\hline $8 / 130 Z$ & 13 & 3 & 90 & 15 & 4.61 & 69.2 & 9.01 & 4.4 \\
\hline $8 / 136 Z$ & 14 & 4 & 105 & -10 & 6.43 & 164.3 & $\mathrm{~N} / \mathrm{a}$ & $\mathrm{N} / \mathrm{a}$ \\
\hline $8 / 1312 Z$ & 15 & 3 & 95 & 30 & 2.29 & 92.4 & 7.76 & 5.47 \\
\hline $8 / 1318 Z$ & 16 & 4 & 125 & -50 & 3.56 & 107.1 & $\mathrm{~N} / \mathrm{a}$ & $\mathrm{N} / \mathrm{a}$ \\
\hline
\end{tabular}

Table 4.15: 6-hour wind speed increase model for Hurricane Charley. 


\subsubsection{Hurricane Danielle (2004)}

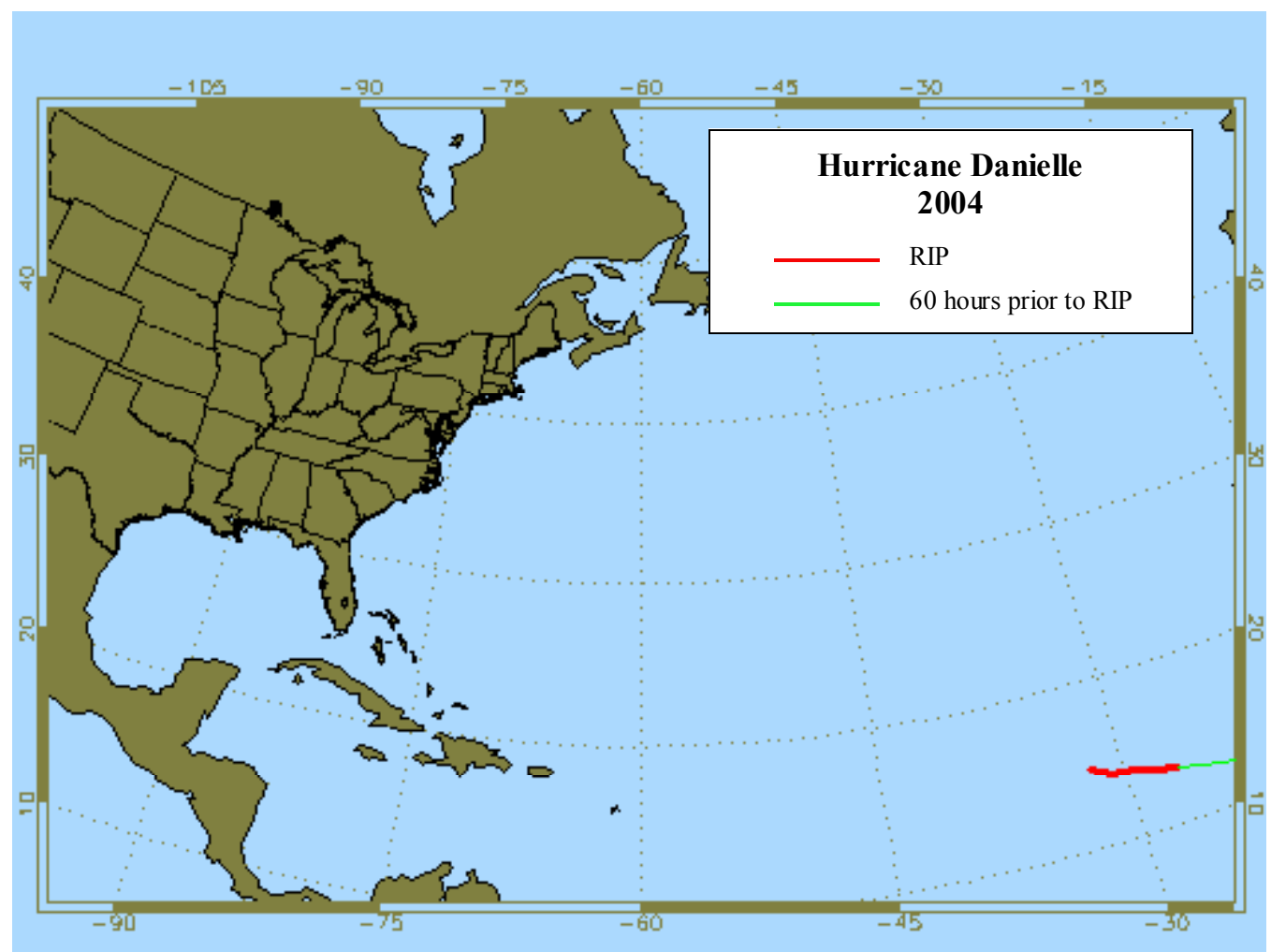

Figure 4.3: Track of Hurricane Danielle (2004).

Danielle moved off the west coast of Africa late August 11 into early August 12.

It was a very well defined tropical wave with deep convection and distinct outflow.

Danielle moved very slowly over the Atlantic near the Cape Verde Islands and intensified slightly until it started to turn toward the northwest with increased speed. As Danielle moved toward the northwest on August 13, it became better organized due to the low wind shear and warm sea surface temperatures. By 0Z August 14 Danielle had become a 
tropical storm and was about to undergo the RIP just 12 hours later. Danielle's central pressure would drop $26 \mathrm{hPa}$ and winds would increase 35 knots over the next 24 hours officially classifying it as a hurricane at $0 \mathrm{Z}$ August 15 . The warm sea surface temperatures and the favorable wind shear allowed Danielle to steadily strengthen until the end of the RIP. However, an upper level trough produced an area of southwesterly shear that quickly destroyed the deep convection and prevented Danielle from becoming a major hurricane.

The DFA only classified 7 of the 16 time intervals as a minor hurricane. This was largely due to fluctuations in the $850-200 \mathrm{hPa}$ wind shear. When the vertical wind shear was more than $7 \mathrm{~m} \mathrm{~s}^{-1}$, (not shown) then the DFA tended to select a minor model to be used. A major model was chosen when the shear was less than $7 \mathrm{~m} \mathrm{~s}^{-1}$. The wind shear initially started above this threshold (Time Intervals 1 and 2) but quickly reverted below it making the DFA select major models during Time Intervals 3 and 4. From Time Intervals 6-9, the wind shear once again increased above the threshold, forcing the DFA to select minor hurricane models, before the wind shear finally weakened again (Time Intervals 10-16) making the DFA select major hurricane models. The DFA selected Danielle to become a major hurricane primarily because of the low wind shear exhibited during the RIP but soon after Danielle encountered high wind shear inhibiting any chance of becoming a major hurricane. The DFA often classified the time segment correctly, but when combined with the hurricane type, it was able to correctly classify only 5 of the 16 cases.

Table 4.16 shows the 24-hour pressure model forecasts for Hurricane Danielle and only Time Intervals 1, 2, 6, 7, and 8 were classified correctly. These cases had low 


\begin{tabular}{|c|c|c|c|c|c|c|c|c|}
\hline $\begin{array}{l}\text { Date } \\
\text { (2004) }\end{array}$ & $\begin{array}{c}\text { Time } \\
\text { Interval }\end{array}$ & Model & $\begin{array}{c}\text { Central } \\
\text { Pressure } \\
(\mathrm{hPa})\end{array}$ & $\begin{array}{c}\text { 24-hour } \\
\text { Obs. }\end{array}$ & $\begin{array}{c}\text { 24-hour } \\
\text { Press } \\
\text { Model } \\
\text { (hPa) }\end{array}$ & $\%$ error & $\begin{array}{c}\text { Correct } \\
\text { Selected } \\
\text { Model } \\
(\mathrm{hPa})\end{array}$ & $\begin{array}{c}\text { Change } \\
\text { (hPa) }\end{array}$ \\
\hline $8 / 1118 \mathrm{Z}$ & 1 & 5 & 1009 & 0 & 1.06 & $\mathrm{~N} / \mathrm{a}$ & $\mathrm{N} / \mathrm{a}$ & $\mathrm{N} / \mathrm{a}$ \\
\hline $8 / 120 Z$ & 2 & 5 & 1009 & 0 & 0.85 & $\mathrm{~N} / \mathrm{a}$ & $\mathrm{N} / \mathrm{a}$ & $\mathrm{N} / \mathrm{a}$ \\
\hline $8 / 126 Z$ & 3 & 1 & 1009 & 0 & 2.53 & $\mathrm{~N} / \mathrm{a}$ & 1.14 & 1.39 \\
\hline $8 / 1212 Z$ & 4 & 1 & 1009 & 0 & 1.17 & $\mathrm{~N} / \mathrm{a}$ & 1.15 & 0.02 \\
\hline $8 / 1218 Z$ & 5 & 5 & 1009 & 0 & 1.64 & $\mathrm{~N} / \mathrm{a}$ & 6.56 & -4.92 \\
\hline $8 / 130 Z$ & 6 & 6 & 1009 & 0 & 5.77 & $\mathrm{~N} / \mathrm{a}$ & $\mathrm{N} / \mathrm{a}$ & $\mathrm{N} / \mathrm{a}$ \\
\hline $8 / 136 Z$ & 7 & 6 & 1009 & 5 & 6.09 & 21.9 & $\mathrm{~N} / \mathrm{a}$ & $\mathrm{N} / \mathrm{a}$ \\
\hline $8 / 1312 Z$ & 8 & 6 & 1009 & 5 & 5.47 & 9.5 & $\mathrm{~N} / \mathrm{a}$ & $\mathrm{N} / \mathrm{a}$ \\
\hline $8 / 1318 Z$ & 9 & 6 & 1009 & 15 & 7.91 & 47.2 & 12.45 & 4.54 \\
\hline $8 / 140 Z$ & 10 & 2 & 1009 & 22 & 7.48 & 66.0 & 12.63 & 5.15 \\
\hline $8 / 146 Z$ & 11 & 2 & 1004 & 23 & 7.60 & 66.9 & 12.42 & 4.82 \\
\hline $8 / 1412 Z$ & 12 & 2 & 1004 & 26 & 7.56 & 70.9 & 12.53 & 4.97 \\
\hline $8 / 1418 Z$ & 13 & 4 & 994 & 19 & 30.49 & 60.5 & 9.21 & 1.7 \\
\hline $8 / 150 Z$ & 14 & 4 & 987 & 17 & 25.95 & 52.7 & 5.11 & -2.94 \\
\hline $8 / 156 Z$ & 15 & 4 & 981 & 11 & 19.06 & 73.3 & 0.59 & -2.35 \\
\hline $8 / 1512 Z$ & 16 & 4 & 978 & 8 & 16.58 & 107.3 & -0.24 & 0.34 \\
\hline
\end{tabular}

Table 4.16: 24-hour pressure drop model for Hurricane Danielle. 
percentage errors however beginning at Time Interval 9, the percentage errors increased due to the model misclassification. Had the CSM been used (i.e. Model 7) during Time Intervals 9-12, the pressure forecast would have improved by approximately $5 \mathrm{hPa}$ for each interval. From Time Intervals 13-16, had the CSM (i.e. Model 8) been used, the pressure drop forecasts would have been much less than observed because this model is dependent on shear, and it was picking up higher values that Danielle would soon encounter.

The 24-hour wind speed model (Table 4.17) did struggle with the prediction largely due to the misclassification having percentage errors above $40 \%$ for all but two time intervals (Time Intervals 7 and 8). The NHC did not start issuing forecasts until Time Interval 8 but their forecasts were more accurate than the DFA selected model forecasts on 6 of the 9 time intervals (Time Intervals 8, 11, 12, and 14-16). However, the CSM was able to improve on all DFA selected models with the exception of two (Time Intervals 5 and 15) and was able to predict the wind speed more accurately than the NHC on all but the last three time intervals (Time Intervals 14-16). Again this was due to the models sensitivity to wind shear, which was gradually increasing. Even so, the NHC forecasts were not much more accurate than the CSM during these intervals. More importantly, the CSM was able to dramatically improve the prediction leading up to and just after the onset of the RIP (Time Intervals 9-13). The CSM (i.e. Model 7) was predicting increases on the order of 20 knots while the NHC was only predicting 10 knots due to the model misclassification. Had the CSM been used (i.e. Model 7) during Time Intervals 9-12, the pressure forecast would have improved by approximately $5 \mathrm{hPa}$ for each interval. From Time Intervals 13-16, had the CSM (i.e. Model 8) been used, the 


\begin{tabular}{|c|c|c|c|c|c|c|c|c|c|}
\hline $\begin{array}{c}\text { Time } \\
\text { Int. }\end{array}$ & Model & $\begin{array}{l}\text { Max. } \\
\text { Sus. } \\
\text { Wind } \\
\text { (kts) }\end{array}$ & $\begin{array}{c}\text { 24-hour } \\
\text { Obs. }\end{array}$ & $\begin{array}{c}\text { 24-hour } \\
\text { Model } \\
\text { (kts) }\end{array}$ & $\%$ error & $\begin{array}{c}\text { NHC } \\
24 \text { hour } \\
\text { For. }\end{array}$ & $\begin{array}{c}\text { NHC } \\
\% \\
\text { error }\end{array}$ & $\begin{array}{l}\text { CSM } \\
\text { (kts) }\end{array}$ & $\begin{array}{c}\text { Improv. } \\
\text { (kts) }\end{array}$ \\
\hline 1 & 5 & 30 & 0 & 2.18 & $\mathrm{~N} / \mathrm{a}$ & $\mathrm{N} / \mathrm{a}$ & $\mathrm{N} / \mathrm{a}$ & $\mathrm{N} / \mathrm{a}$ & $\mathrm{N} / \mathrm{a}$ \\
\hline 2 & 5 & 30 & 0 & 2.33 & $\mathrm{~N} / \mathrm{a}$ & N/a & $\mathrm{N} / \mathrm{a}$ & N/a & N/a \\
\hline 3 & 1 & 30 & 0 & 3.61 & $\mathrm{~N} / \mathrm{a}$ & $\mathrm{N} / \mathrm{a}$ & $\mathrm{N} / \mathrm{a}$ & 2.48 & 1.13 \\
\hline 4 & 1 & 30 & 0 & 3.08 & N/a & $\mathrm{N} / \mathrm{a}$ & $\mathrm{N} / \mathrm{a}$ & 2.63 & 0.45 \\
\hline 5 & 5 & 30 & 0 & 2.78 & N/a & $\mathrm{N} / \mathrm{a}$ & $\mathrm{N} / \mathrm{a}$ & 15.42 & -12.64 \\
\hline 6 & 6 & 30 & 5 & 12.59 & 151.8 & $\mathrm{~N} / \mathrm{a}$ & $\mathrm{N} / \mathrm{a}$ & $\mathrm{N} / \mathrm{a}$ & $\mathrm{N} / \mathrm{a}$ \\
\hline 7 & 6 & 30 & 10 & 11.81 & 18.1 & $\mathrm{~N} / \mathrm{a}$ & $\mathrm{N} / \mathrm{a}$ & $\mathrm{N} / \mathrm{a}$ & $\mathrm{N} / \mathrm{a}$ \\
\hline 8 & 6 & 30 & 15 & 9.21 & 38.6 & 10 & 33.3 & $\mathrm{~N} / \mathrm{a}$ & $\mathrm{N} / \mathrm{a}$ \\
\hline 9 & 6 & 30 & 25 & 14.91 & 40.3 & 10 & 60.0 & 21.74 & 6.83 \\
\hline 10 & 2 & 35 & 30 & 10.47 & 65.1 & 10 & 66.7 & 22.73 & 12.26 \\
\hline 11 & 2 & 40 & 35 & 9.63 & 72.4 & 10 & 71.4 & 22.85 & 13.22 \\
\hline 12 & 2 & 45 & 35 & 8.44 & 75.8 & 10 & 71.4 & 19.86 & 11.42 \\
\hline 13 & 4 & 55 & 30 & 44.54 & 48.4 & 15 & 50.0 & 21.27 & 5.81 \\
\hline 14 & 4 & 65 & 25 & 39.20 & 56.8 & 15 & 40.0 & 13.62 & 2.82 \\
\hline 15 & 4 & 75 & 15 & 25.21 & 68.0 & 10 & 33.3 & 4.35 & -0.44 \\
\hline 16 & 4 & 80 & 10 & 23.68 & 136.8 & 5 & 50.0 & 3.83 & 7.51 \\
\hline
\end{tabular}

Table 4.17: 24-hour wind speed increase model for Hurricane Danielle. 
pressure drop forecasts would have been much less than observed because this model is dependent on shear, and it was picking up higher values that Danielle would soon encounter. Therefore, the CSM was able to better capture the rapid intensification than the NHC.

The 6-hour pressure drop (Table 4.18) exhibited very little change through Time Interval 11 and the model therefore was able to predict pressure very well even with the misclassifications. But the percentage errors were relatively high beginning at the onset of the RIP (Time Interval 12). The DFA selected major models, which tended to overestimate the amount of deepening (Time Intervals 13-16), whereas the CSM more accurately predicted the amount of deepening by improving the 6-hourly prediction by approximately 3, 3, 8 and $4 \mathrm{hPa}$ respectively. This prediction further shows that Danielle had more characteristics of a minor hurricane even though it encountered low wind shear during some time intervals. The 6-hourly wind speed increases (Table 4.19) also did not exhibit any increase until Time Interval 9 and therefore the DFA selected model had little problem with the forecasts even though it was misclassified. For Time Intervals 9-16, the percentage errors were lower than the 6-hour pressure drop models. But like the pressure drop models, the wind speed models also tended to overestimate the amount of strengthening for Time Intervals 13-16. However, the amount of improvement the CSM provided was less for the 6-hour wind speed models than for the 6-hour pressure drop models during those same intervals. In fact, the CSM was slightly worse at Time Interval 14 than the DFA selected model suggesting that Danielle still maintained some potential to become a major hurricane. 


\begin{tabular}{|c|c|c|c|c|c|c|c|c|}
\hline Date & $\begin{array}{l}\text { Time } \\
\text { Int. }\end{array}$ & Model & $\begin{array}{c}\text { Cent. } \\
\text { Pressure } \\
(\mathrm{hPa})\end{array}$ & $\begin{array}{l}\text { 6-hour Pres. } \\
\text { Drop Obs. }\end{array}$ & $\begin{array}{c}\text { 6-hour } \\
\text { Model } \\
\text { (hPa) }\end{array}$ & $\begin{array}{l}\% \\
\text { error }\end{array}$ & $\begin{array}{l}\text { CSM } \\
\text { (hPa) }\end{array}$ & $\begin{array}{c}\text { Improv. } \\
(\mathrm{hPa})\end{array}$ \\
\hline $8 / 1118 \mathrm{Z}$ & 1 & 5 & 1009 & 0 & 0.08 & $\mathrm{~N} / \mathrm{a}$ & $\mathrm{N} / \mathrm{a}$ & $\mathrm{N} / \mathrm{a}$ \\
\hline $8 / 120 Z$ & 2 & 5 & 1009 & 0 & 0.08 & $\mathrm{~N} / \mathrm{a}$ & $\mathrm{N} / \mathrm{a}$ & $\mathrm{N} / \mathrm{a}$ \\
\hline $8 / 126 Z$ & 3 & 1 & 1009 & 0 & 0.30 & $\mathrm{~N} / \mathrm{a}$ & 0.8 & -0.5 \\
\hline $8 / 1212 Z$ & 4 & 1 & 1009 & 0 & 0.02 & $\mathrm{~N} / \mathrm{a}$ & 0.8 & -0.5 \\
\hline $8 / 1218 Z$ & 5 & 5 & 1009 & 0 & 0.08 & N/a & 0.46 & -0.38 \\
\hline $8 / 130 Z$ & 6 & 6 & 1009 & 0 & 0.46 & $\mathrm{~N} / \mathrm{a}$ & $\mathrm{N} / \mathrm{a}$ & $\mathrm{N} / \mathrm{a}$ \\
\hline $8 / 136 Z$ & 7 & 6 & 1009 & 0 & 0.46 & $\mathrm{~N} / \mathrm{a}$ & $\mathrm{N} / \mathrm{a}$ & N/a \\
\hline $8 / 1312 Z$ & 8 & 6 & 1009 & 0 & 0.46 & $\mathrm{~N} / \mathrm{a}$ & $\mathrm{N} / \mathrm{a}$ & $\mathrm{N} / \mathrm{a}$ \\
\hline $8 / 1318 Z$ & 9 & 6 & 1009 & 0 & 0.46 & N/a & 1.76 & -1.3 \\
\hline $8 / 140 Z$ & 10 & 2 & 1009 & 5 & 2.63 & 47.3 & 2.73 & 0.1 \\
\hline $8 / 146 Z$ & 11 & 2 & 1004 & 0 & 2.63 & $\mathrm{~N} / \mathrm{a}$ & 2.72 & -0.09 \\
\hline $8 / 1412 Z$ & 12 & 2 & 1004 & 10 & 2.63 & 73.6 & 2.67 & 0.04 \\
\hline $8 / 1418 Z$ & 13 & 4 & 994 & 7 & 13.90 & 98.6 & 2.77 & 2.67 \\
\hline $8 / 150 Z$ & 14 & 4 & 987 & 6 & 12.82 & 113.8 & 2.27 & 3.09 \\
\hline $8 / 156 Z$ & 15 & 4 & 981 & 3 & 12.90 & 330.3 & 1.23 & 8.13 \\
\hline $8 / 1512 Z$ & 16 & 4 & 978 & 3 & 8.65 & 188.6 & 1.09 & 3.74 \\
\hline
\end{tabular}

Table 4.18: 6-hour pressure drop model for Hurricane Danielle. 


\begin{tabular}{|c|c|c|c|c|c|c|c|c|}
\hline Date & $\begin{array}{l}\text { Time } \\
\text { Int. }\end{array}$ & Model & $\begin{array}{l}\text { Max. Sus. } \\
\text { Winds (kts) }\end{array}$ & $\begin{array}{c}\text { 6-hour } \\
\text { Wind } \\
\text { Speed Obs. }\end{array}$ & $\begin{array}{c}\text { 6-hour } \\
\text { Model } \\
\text { (kts) }\end{array}$ & $\%$ error & $\begin{array}{l}\text { CSM } \\
\text { (kts) }\end{array}$ & $\begin{array}{c}\text { Improv. } \\
\text { (kts) }\end{array}$ \\
\hline $8 / 1118 \mathrm{Z}$ & 1 & 5 & 30 & 0 & 0.27 & $\mathrm{~N} / \mathrm{a}$ & $\mathrm{N} / \mathrm{a}$ & $\mathrm{N} / \mathrm{a}$ \\
\hline $8 / 120 \mathrm{Z}$ & 2 & 5 & 30 & 0 & 0.27 & $\mathrm{~N} / \mathrm{a}$ & $\mathrm{N} / \mathrm{a}$ & $\mathrm{N} / \mathrm{a}$ \\
\hline $8 / 126 Z$ & 3 & 1 & 30 & 0 & 1.09 & $\mathrm{~N} / \mathrm{a}$ & 0.27 & 0.82 \\
\hline $8 / 1212 Z$ & 4 & 1 & 30 & 0 & 1.09 & $\mathrm{~N} / \mathrm{a}$ & 0.27 & 0.82 \\
\hline $8 / 1218 \mathrm{Z}$ & 5 & 5 & 30 & 0 & 0.27 & $\mathrm{~N} / \mathrm{a}$ & 0.59 & -0.32 \\
\hline $8 / 130 Z$ & 6 & 6 & 30 & 0 & 0.67 & $\mathrm{~N} / \mathrm{a}$ & $\mathrm{N} / \mathrm{a}$ & $\mathrm{N} / \mathrm{a}$ \\
\hline $8 / 136 Z$ & 7 & 6 & 30 & 0 & 0.39 & $\mathrm{~N} / \mathrm{a}$ & $\mathrm{N} / \mathrm{a}$ & N/a \\
\hline $8 / 1312 Z$ & 8 & 6 & 30 & 0 & 0.55 & $\mathrm{~N} / \mathrm{a}$ & $\mathrm{N} / \mathrm{a}$ & $\mathrm{N} / \mathrm{a}$ \\
\hline $8 / 1318 Z$ & 9 & 6 & 30 & 5 & 1.84 & 63.1 & 3.11 & 1.27 \\
\hline $8 / 140 Z$ & 10 & 2 & 35 & 5 & 4.89 & 2.1 & 4.93 & 0.04 \\
\hline $8 / 146 Z$ & 11 & 2 & 40 & 5 & 4.88 & 2.4 & 4.90 & 0.02 \\
\hline $8 / 1412 Z$ & 12 & 2 & 45 & 10 & 4.79 & 52.1 & 4.87 & 0.08 \\
\hline $8 / 1418 Z$ & 13 & 4 & 55 & 10 & 14.16 & 41.7 & 6.90 & 1.06 \\
\hline $8 / 150 Z$ & 14 & 4 & 65 & 10 & 12.99 & 29.9 & 4.99 & -2.02 \\
\hline $8 / 156 Z$ & 15 & 4 & 75 & 5 & 10.99 & 119.2 & 2.86 & 3.85 \\
\hline $8 / 1512 Z$ & 16 & 4 & 80 & 5 & 10.54 & 110.9 & 0.74 & 1.28 \\
\hline
\end{tabular}

Table 4.19: 6-hour wind speed increase model for Hurricane Danielle. 


\subsubsection{Hurricane Frances (2004)}

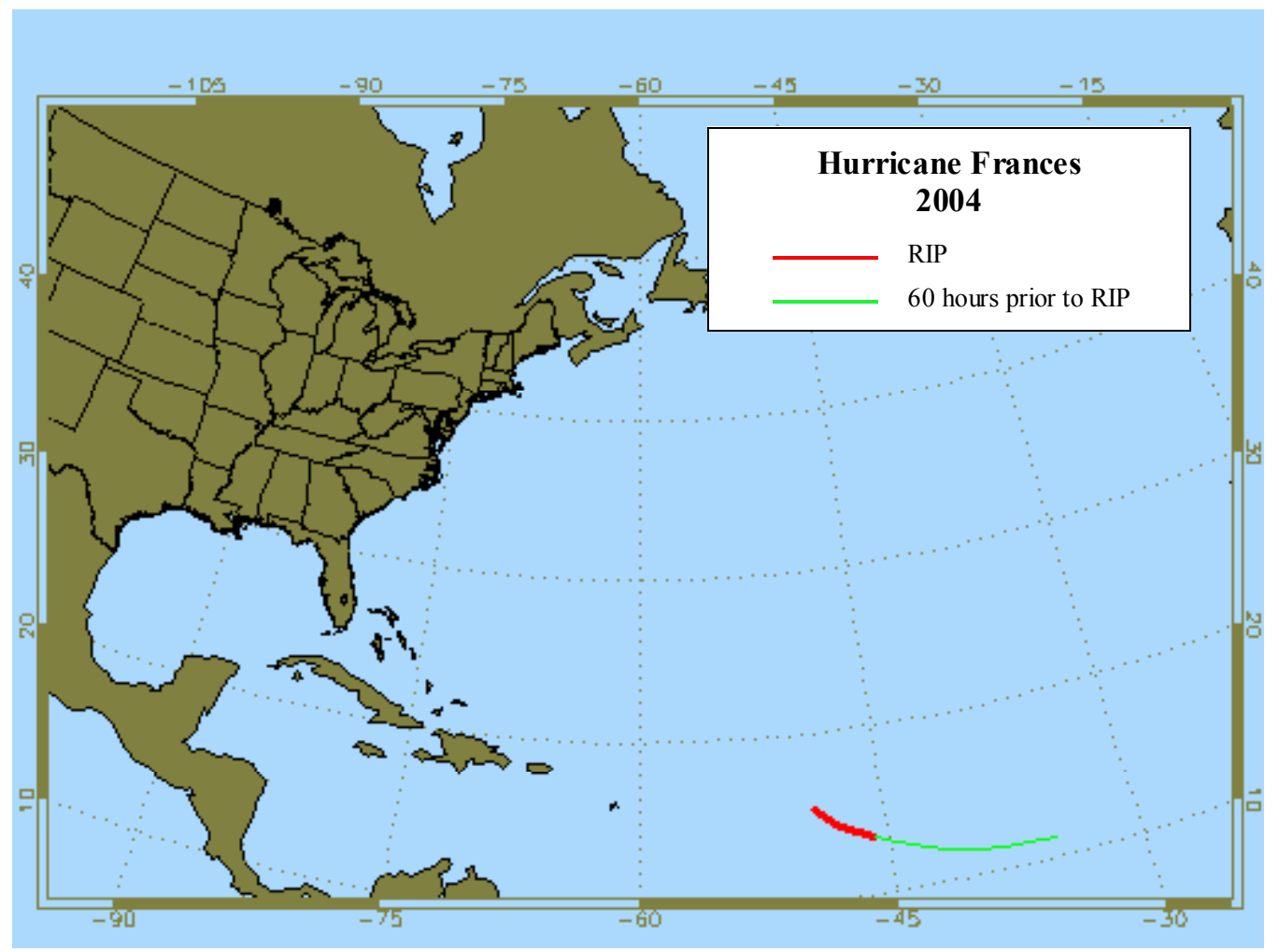

Figure 4.4: Track of Hurricane Frances (2004).

The analysis of Frances began with August 24 when it was approximately 500 miles west of the Cape Verde Islands. Frances quickly became a tropical storm late in the day on August 24 due to moderate $\left(850-200 \mathrm{hPa}\right.$ ) wind shear (approximately $7 \mathrm{~m} \mathrm{~s}^{-}$ $\left.{ }^{1}\right)$ and relatively high heat potential values $\left(21 \mathrm{~kJ} \mathrm{~cm}^{-2}\right)$. It then started to turn to the northwest on August 26 and officially became a hurricane at 18Z August 26. Over the next 24 hours, Frances underwent the RIP and became a Category 3 hurricane by the end of the period. Frances would eventually become a Category 4 mostly in part to very low 
$850-200 \mathrm{hPa}$ wind shear (approximately $5 \mathrm{~m} \mathrm{~s}^{-1}$ ) and higher heat potential values (approaching $40 \mathrm{~kJ} \mathrm{~cm}^{-2}$ ).

The DFA was able to correctly classify all 16 time intervals as eventually becoming a major hurricane since Frances had the classic characteristics of low wind shear and high heat potential, which allowed it to quickly become a Category 3 hurricane by the end of the RIP. The time interval classification was able to correctly classify 10 out of the 16 time intervals with the exceptions of Time Intervals 5, 7, 9, 11, 13, and 14 as the misclassified intervals. For Time Intervals 5 and 7, the DFA likely selected Model 1 instead of Model 2 since the $850-100 \mathrm{hPa}$ shear values were slightly higher and representative of the shear found in the earliest stages of development. At Time Intervals 9 and 11, the central pressure was at $1003 \mathrm{hPa}$ and $994 \mathrm{hPa}$ respectively and it is unusual for a RIP to occur when the central pressures are that high. That is why the DFA selected Model 2 instead of Model 3 because a RIP does not normally occur within 24 hours with relatively high central pressures. For similar reasons, the DFA selected Model 3 to be used for Time Intervals 13 and 14 instead of Model 4 because the central pressures were $984 \mathrm{hPa}$ and $980 \mathrm{hPa}$, respectively.

Table 4.20 shows the 24 -hour pressure drop model and it performed very well since only 3 intervals had percentage errors more than 56\% (Time Intervals 2, 5, and 15). Time Interval 2 had a high percentage error not because the prediction was erroneous but because the 24-hour observation was only $1 \mathrm{hPa}$. Time Interval 5 was misclassified but had Model 2 been used instead of Model 1, it would have slightly improved the prediction of the pressure. Time Interval 15 had the highest percentage error and the 


\begin{tabular}{|c|c|c|c|c|c|c|c|c|}
\hline $\begin{array}{l}\text { Date } \\
\text { (2004) }\end{array}$ & $\begin{array}{c}\text { Time } \\
\text { Interval }\end{array}$ & Model & $\begin{array}{c}\text { Central } \\
\text { Pressure } \\
(\mathrm{hPa})\end{array}$ & $\begin{array}{c}\text { 24-hour } \\
\text { Obs. }\end{array}$ & $\begin{array}{c}\text { 24-hour } \\
\text { Press } \\
\text { Model } \\
\text { (hPa) }\end{array}$ & $\%$ error & $\begin{array}{c}\text { Correct } \\
\text { Selected } \\
\text { Model } \\
(\mathrm{hPa})\end{array}$ & $\begin{array}{c}\text { Improv. } \\
(\mathrm{hPa})\end{array}$ \\
\hline $8 / 240 Z$ & 1 & 1 & 1009 & 0 & 0.52 & $\mathrm{~N} / \mathrm{a}$ & $\mathrm{N} / \mathrm{a}$ & $\mathrm{N} / \mathrm{a}$ \\
\hline $8 / 246 Z$ & 2 & 1 & 1009 & 1 & 1.85 & 85.7 & $\mathrm{~N} / \mathrm{a}$ & $\mathrm{N} / \mathrm{a}$ \\
\hline $8 / 2412 Z$ & 3 & 1 & 1009 & 2 & 0.94 & 52.8 & $\mathrm{~N} / \mathrm{a}$ & $\mathrm{N} / \mathrm{a}$ \\
\hline $8 / 2418 Z$ & 4 & 1 & 1009 & 4 & 3.17 & 20.7 & $\mathrm{~N} / \mathrm{a}$ & $\mathrm{N} / \mathrm{a}$ \\
\hline $8 / 250 Z$ & 5 & 1 & 1009 & 6 & 1.27 & 78.7 & 9.23 & 1.5 \\
\hline $8 / 256 Z$ & 6 & 2 & 1008 & 8 & 8.81 & 10.2 & $\mathrm{~N} / \mathrm{a}$ & $\mathrm{N} / \mathrm{a}$ \\
\hline $8 / 2512 Z$ & 7 & 1 & 1007 & 13 & 7.67 & 41.0 & 10.55 & 2.88 \\
\hline $8 / 2518 \mathrm{Z}$ & 8 & 2 & 1005 & 18 & 11.40 & 36.6 & $\mathrm{~N} / \mathrm{a}$ & $\mathrm{N} / \mathrm{a}$ \\
\hline $8 / 260 Z$ & 9 & 2 & 1003 & 19 & 10.85 & 42.9 & 16.48 & 5.63 \\
\hline $8 / 266 Z$ & 10 & 3 & 1000 & 20 & 17.21 & 13.9 & $\mathrm{~N} / \mathrm{a}$ & $\mathrm{N} / \mathrm{a}$ \\
\hline $8 / 2612 Z$ & 11 & 2 & 994 & 24 & 10.71 & 55.4 & 17.23 & 6.52 \\
\hline $8 / 2618 \mathrm{Z}$ & 12 & 3 & 987 & 25 & 20.54 & 17.8 & $\mathrm{~N} / \mathrm{a}$ & $\mathrm{N} / \mathrm{a}$ \\
\hline $8 / 270 Z$ & 13 & 3 & 984 & 22 & 22.50 & 2.3 & 29.18 & $\begin{array}{l}-6.68 \\
\end{array}$ \\
\hline $8 / 276 Z$ & 14 & 3 & 980 & 18 & 22.39 & 24.4 & 28.03 & -5.64 \\
\hline $8 / 2712 Z$ & 15 & 4 & 970 & 12 & 24.94 & 107.9 & $\mathrm{~N} / \mathrm{a}$ & $\mathrm{N} / \mathrm{a}$ \\
\hline $8 / 2718 Z$ & 16 & 4 & 962 & 14 & 17.61 & 25.9 & $\mathrm{~N} / \mathrm{a}$ & $\mathrm{N} / \mathrm{a}$ \\
\hline
\end{tabular}

Table 4.20: 24-hour pressure drop model for Hurricane Frances. 
regression calculation overestimated the amount of deepening. However, it was not misclassified. During this time interval, Model 4 was used and the heat potential, which is a key component of this particular model, was relatively high at this stage (approximately $40 \mathrm{~kJ} \mathrm{~cm}^{-2}$ ). At the same time, the $850-200 \mathrm{hPa}$ wind shear was starting to increase, which slowed the intensification, but this is not factored into Model 4 . Therefore, the model overestimated the amount of pressure reduction at this particular stage. The CSM did improve all of the misclassified intervals except Time Intervals 13 and 14. Model 4 would have overestimated the amount of deepening, but the selected model (Model 3) primarily looked at core heat potential, which is not weighted as heavily as the heat potential in Model 4. Therefore Model 3 did not predict as much of a pressure decrease but nevertheless it was more accurate.

The NHC did not start issuing forecasts (Table 4.21) until Time Interval 5. The selected 24-hour wind speed increase model was able to better predict the wind speed than the NHC on 8 out of the 12 time intervals, the exceptions being Time Intervals 5, 11, 12, and 15. During Time Interval 5, the NHC happened to predict the wind speed increase exactly and the CSM was not able to improve the prediction for the misclassified interval. For Time Interval 11, the NHC also had a better accuracy. However, this time the CSM would have better predicted the wind speed. As for Time Interval 12 the selected model prediction and the NHC prediction were virtually the same (24.91 knots and 25 knots respectively). Time Interval 15 had the poorest prediction overestimating the actual increase by over 13 knots. The reasons for the overestimation of the wind speed are similar to the reasons why the model overestimated the pressure reduction. 


\begin{tabular}{|c|c|c|c|c|c|c|c|c|c|}
\hline $\begin{array}{c}\text { Time } \\
\text { Int. }\end{array}$ & Model & $\begin{array}{l}\text { Max. } \\
\text { Sus. } \\
\text { Wind } \\
\text { (kts) }\end{array}$ & $\begin{array}{c}\text { 24-hour } \\
\text { Obs. }\end{array}$ & $\begin{array}{c}\text { 24-hour } \\
\text { Model } \\
\text { (kts) }\end{array}$ & $\%$ error & $\begin{array}{c}\text { NHC } \\
24 \text { hour } \\
\text { For. }\end{array}$ & $\begin{array}{c}\text { NHC } \\
\% \\
\text { error }\end{array}$ & $\begin{array}{l}\text { CSM } \\
\text { (kts) }\end{array}$ & $\begin{array}{c}\text { Improv. } \\
\text { (kts) }\end{array}$ \\
\hline 1 & 1 & 25 & 0 & 3.52 & $\mathrm{~N} / \mathrm{a}$ & $\mathrm{N} / \mathrm{a}$ & $\mathrm{N} / \mathrm{a}$ & $\mathrm{N} / \mathrm{a}$ & $\mathrm{N} / \mathrm{a}$ \\
\hline 2 & 1 & 25 & 5 & 4.91 & 1.7 & $\mathrm{~N} / \mathrm{a}$ & $\mathrm{N} / \mathrm{a}$ & N/a & N/a \\
\hline 3 & 1 & 25 & 5 & 5.32 & 6.4 & $\mathrm{~N} / \mathrm{a}$ & $\mathrm{N} / \mathrm{a}$ & N/a & $\mathrm{N} / \mathrm{a}$ \\
\hline 4 & 1 & 25 & 10 & 4.60 & 23.9 & $\mathrm{~N} / \mathrm{a}$ & $\mathrm{N} / \mathrm{a}$ & N/a & N/a \\
\hline 5 & 1 & 25 & 15 & 8.20 & 45.3 & 15 & 0.0 & 3.93 & -4.27 \\
\hline 6 & 2 & 30 & 15 & 11.69 & 22.0 & 10 & 33.3 & $\mathrm{~N} / \mathrm{a}$ & $\mathrm{N} / \mathrm{a}$ \\
\hline 7 & 1 & 30 & 25 & 14.05 & 43.8 & 10 & 60.0 & 15.68 & 1.63 \\
\hline 8 & 2 & 35 & 30 & 16.45 & 45.1 & 10 & 66.7 & $\mathrm{~N} / \mathrm{a}$ & $\mathrm{N} / \mathrm{a}$ \\
\hline 9 & 2 & 40 & 30 & 20.39 & 32.0 & 15 & 50.0 & 25.85 & 5.46 \\
\hline 10 & 3 & 45 & 30 & 27.17 & 9.4 & 20 & 33.3 & $\mathrm{~N} / \mathrm{a}$ & $\mathrm{N} / \mathrm{a}$ \\
\hline 11 & 2 & 55 & 35 & 10.47 & 70.1 & 20 & 42.9 & 22.74 & 12.27 \\
\hline 12 & 3 & 65 & 35 & 24.91 & 28.8 & 25 & 28.6 & $\mathrm{~N} / \mathrm{a}$ & $\mathrm{N} / \mathrm{a}$ \\
\hline 13 & 3 & 70 & 30 & 25.03 & 16.5 & 20 & 33.3 & 37.56 & -2.59 \\
\hline 14 & 3 & 75 & 25 & 24.47 & 2.1 & 15 & 40.0 & 33.50 & -7.97 \\
\hline 15 & 4 & 90 & 15 & 28.74 & 91.6 & 10 & 33.3 & N/a & N/a \\
\hline 16 & 4 & 100 & 15 & 18.46 & 23.1 & 10 & 33.3 & N/a & $\mathrm{N} / \mathrm{a}$ \\
\hline
\end{tabular}

Table 4.21: 24-hour wind speed increase model for Hurricane Frances. 
Model 4 includes the relatively high heat potential (approximately $40 \mathrm{~kJ} \mathrm{~cm}^{-2}$ ) but it does not include the wind shear which was starting to increase $(850-200 \mathrm{hPa}$ wind shear approximately $7 \mathrm{~m} \mathrm{~s}^{-1}$ ) at this particular point. Therefore, the wind speed did not increase as much as expected. In summary, the DFA selected model was able to capture much of the intensification, particularly Time Intervals 6-10, better than the NHC since Model 1 was able to factor the high values of heat potential, Model 2 was able to capture the low wind shear, and Model 3 was able to factor the MPI which was indicating a fairly low pressure. At Time Interval 14, the model was suggesting Frances would become a hurricane with winds of about 100 knots (Category 3) when the winds at the time were only 75 knots (Category 1). The NHC only predicted Frances would have winds of 90 knots (Category 2) at this same interval, but Frances actually became a Category 3 within 24 hours.

Table 4.22 shows the 6-hour pressure drop model and only 3 time intervals had percentage errors exceeding 50\% (Time Intervals 5, 6, and 14). Time Intervals 5 and 14 were misclassified and the CSM did improve these predictions slightly, especially the CSM during Time Interval 14. Model 4 would have come closer to predicting the $10 \mathrm{hPa}$ 6-hour pressure drop since this model relies on the attained MPI and $850-100 \mathrm{hPa}$ wind shear. The attained MPI at this interval was approximately $28 \%$ which is generally when major hurricanes start to undergo rapid intensification (Law 2001), and the $850-100 \mathrm{hPa}$ wind shear was very low at approximately $3 \mathrm{~m} \mathrm{~s}^{-1}$. Therefore, the combination of these factors helps explain why this particular model was able to better predict the short-term rapid intensification at that time. The 6-hour wind speed increase model (Table 4.23) had similar success with only 3 time intervals exhibiting percentage errors more than 54\% 


\begin{tabular}{|c|c|c|c|c|c|c|c|c|}
\hline Date & $\begin{array}{l}\text { Time } \\
\text { Int. }\end{array}$ & Model & $\begin{array}{c}\text { Cent. } \\
\text { Pressure } \\
(\mathrm{hPa})\end{array}$ & $\begin{array}{l}\text { 6-hour Pres. } \\
\text { Drop Obs. }\end{array}$ & $\begin{array}{l}\text { 6-hour } \\
\text { Model } \\
\text { (hPa) }\end{array}$ & $\begin{array}{l}\% \\
\text { error }\end{array}$ & $\begin{array}{l}\text { CSM } \\
\text { (hPa) }\end{array}$ & $\begin{array}{l}\text { Improv. } \\
(\mathrm{hPa})\end{array}$ \\
\hline $8 / 240 Z$ & 1 & 1 & 1009 & 0 & 0.02 & $\mathrm{~N} / \mathrm{a}$ & $\mathrm{N} / \mathrm{a}$ & $\mathrm{N} / \mathrm{a}$ \\
\hline $8 / 246 Z$ & 2 & 1 & 1009 & 0 & 0.30 & $\mathrm{~N} / \mathrm{a}$ & $\mathrm{N} / \mathrm{a}$ & $\mathrm{N} / \mathrm{a}$ \\
\hline $8 / 2412 Z$ & 3 & 1 & 1009 & 0 & 0.11 & $\mathrm{~N} / \mathrm{a}$ & $\mathrm{N} / \mathrm{a}$ & $\mathrm{N} / \mathrm{a}$ \\
\hline $8 / 2418 Z$ & 4 & 1 & 1009 & 0 & 0.57 & $\mathrm{~N} / \mathrm{a}$ & $\mathrm{N} / \mathrm{a}$ & $\mathrm{N} / \mathrm{a}$ \\
\hline $8 / 250 Z$ & 5 & 1 & 1009 & 1 & 0.18 & 82.0 & 1.53 & 0.29 \\
\hline $8 / 256 Z$ & 6 & 2 & 1008 & 1 & 2.63 & 163.6 & $\mathrm{~N} / \mathrm{a}$ & $\mathrm{N} / \mathrm{a}$ \\
\hline $8 / 2512 Z$ & 7 & 1 & 1007 & 2 & 2.11 & 5.7 & 1.53 & -0.36 \\
\hline $8 / 2518 Z$ & 8 & 2 & 1005 & 2 & 2.63 & 31.8 & $\mathrm{~N} / \mathrm{a}$ & $\mathrm{N} / \mathrm{a}$ \\
\hline $8 / 260 \mathrm{Z}$ & 9 & 2 & 1003 & 3 & 2.63 & 12.1 & 3.19 & 0.18 \\
\hline $8 / 266 Z$ & 10 & 3 & 1000 & 6 & 3.17 & 47.0 & $\mathrm{~N} / \mathrm{a}$ & $\mathrm{N} / \mathrm{a}$ \\
\hline $8 / 2612 Z$ & 11 & 2 & 994 & 7 & 3.74 & 46.6 & 3.19 & -0.55 \\
\hline $8 / 2618 Z$ & 12 & 3 & 987 & 3 & 4.40 & 47.0 & $\mathrm{~N} / \mathrm{a}$ & N/a \\
\hline $8 / 270 Z$ & 13 & 3 & 984 & 4 & 3.68 & 7.8 & 13.31 & -8.99 \\
\hline $8 / 276 Z$ & 14 & 3 & 980 & 10 & 3.73 & 62.6 & 12.48 & 3.79 \\
\hline $8 / 2712 Z$ & 15 & 4 & 970 & 8 & 11.36 & 42.1 & $\mathrm{~N} / \mathrm{a}$ & $\mathrm{N} / \mathrm{a}$ \\
\hline $8 / 2718 Z$ & 16 & 4 & 962 & 0 & 11.32 & $\mathrm{~N} / \mathrm{a}$ & $\mathrm{N} / \mathrm{a}$ & $\mathrm{N} / \mathrm{a}$ \\
\hline
\end{tabular}

Table 4.22: 6-hour pressure drop model for Hurricane Frances. 


\begin{tabular}{|c|c|c|c|c|c|c|c|c|}
\hline Date & Time & Model & Max. Sus. & 6-hour & $\mathbf{6 - h o u r}$ & $\%$ error & CSM & Improv. \\
& Int. & & Winds (kts) & Wind & Model & & (kts) & (kts) \\
& & & & Speed Obs. & $\mathbf{( k t s )}$ & & & \\
\hline $8 / 240 Z$ & 1 & 1 & 25 & 0 & $\mathbf{1 . 3 5}$ & N/a & N/a & N/a \\
\hline $8 / 246 Z$ & 2 & 1 & 25 & 0 & $\mathbf{1 . 3 5}$ & N/a & N/a & N/a \\
\hline $8 / 2412 Z$ & 3 & 1 & 25 & 0 & $\mathbf{1 . 3 5}$ & N/a & N/a & N/a \\
\hline $8 / 2418 Z$ & 4 & 1 & 25 & 0 & $\mathbf{1 . 3 5}$ & N/a & N/a & N/a \\
\hline $8 / 250 Z$ & 5 & 1 & 25 & 5 & $\mathbf{1 . 3 5}$ & 72.9 & 4.17 & 2.82 \\
\hline $8 / 256 Z$ & 6 & 2 & 30 & 0 & $\mathbf{5 . 2 1}$ & N/a & N/a & N/a \\
\hline $8 / 2512 Z$ & 7 & 1 & 30 & 5 & $\mathbf{1 . 4 5}$ & 70.9 & 4.40 & 2.95 \\
\hline $8 / 2518 Z$ & 8 & 2 & 35 & 5 & $\mathbf{4 . 3 1}$ & 13.7 & N/a & N/a \\
\hline $8 / 260 Z$ & 9 & 2 & 40 & 5 & $\mathbf{4 . 6 8}$ & 6.3 & 4.65 & -0.03 \\
\hline $8 / 266 Z$ & 10 & 3 & 45 & 10 & $\mathbf{4 . 6 5}$ & 53.4 & N/a & N/a \\
\hline $8 / 2612 Z$ & 11 & 2 & 55 & 10 & $\mathbf{5 . 1 5}$ & 48.4 & 5.18 & 0.03 \\
\hline $8 / 2618 Z$ & 12 & 3 & 65 & 5 & $\mathbf{5 . 4 2}$ & 8.4 & N/a & N/a \\
\hline $8 / 270 Z$ & 13 & 3 & 70 & 5 & $\mathbf{4 . 3 9}$ & 12.0 & 12.52 & -6.91 \\
\hline $8 / 276 Z$ & 14 & 3 & 75 & 15 & $\mathbf{4 . 0 6}$ & 72.9 & 11.53 & 6.47 \\
\hline $8 / 2712 Z$ & 15 & 4 & 90 & 10 & $\mathbf{9 . 7 5}$ & 2.5 & N/a & N/a \\
\hline $8 / 2718 Z$ & 16 & 4 & 100 & 0 & $\mathbf{8 . 5 4}$ & N/a & N/a & N/a \\
\hline
\end{tabular}

Table 4.23: 6-hour wind speed increase model for Hurricane Frances. 
(Time Intervals 5, 7, and 14). As with the 6-hour pressure models, the CSM was able to provide improvement to Time Intervals 5 and 14 . This is because at Time Interval 5 , the characteristics were of a more mature system (e.g. lower 850-200 hPa wind shear, wind speed started to increase) so Model 2 needed to be used. Time Interval 14 also exhibited characteristics of a more advanced system as the attained MPI was at the considered threshold for rapid intensification, and again helps explain why Model 4 was able to predict better than Model 3. Time Interval 7 which also had a relatively high percentage error, would have also been improved had the CSM been used. The only time interval where the CSM would not have provided substantial improvement was at Time Interval 13 where it evidently did not have the characteristics of being at the onset of rapid intensification. For all 4 types of models, at Time Interval 13, the CSM did not offer any improvement. Part of the explanation may be because it had a relatively high pressure (984 $\mathrm{hPa})$ and the average hurricane does not undergo rapid intensification until the pressure is around $980 \mathrm{hPa}$, which may clarify why Model 3 performed better than Model 4 at this point.

\subsubsection{Hurricane Gaston (2004)}

Figure 4.5 shows the track of the study for Hurricane Gaston, which began on August 25 as the formation of a low pressure from a weakening cold front. The remnants of the cold front remained as a disorganized low pressure until late August 26 and brought weak thunderstorm activity to the area off the east coast of the Carolinas. Gaston 
developed into a tropical depression by early August 27 as the convective activity began to increase. The system was nearly stationary throughout the early stages of the study as the steering currents were very weak. As the convection strengthened further, Gaston started to drift slowly to the west and was officially classified as a tropical storm on August 28. The RIP, albeit very modest, occurred on August 28 and ended at $0 \mathrm{Z}$ August 29. Gaston would eventually start to move toward the northwest and become a minor hurricane (Category 1) and make landfall north of Charleston, SC.

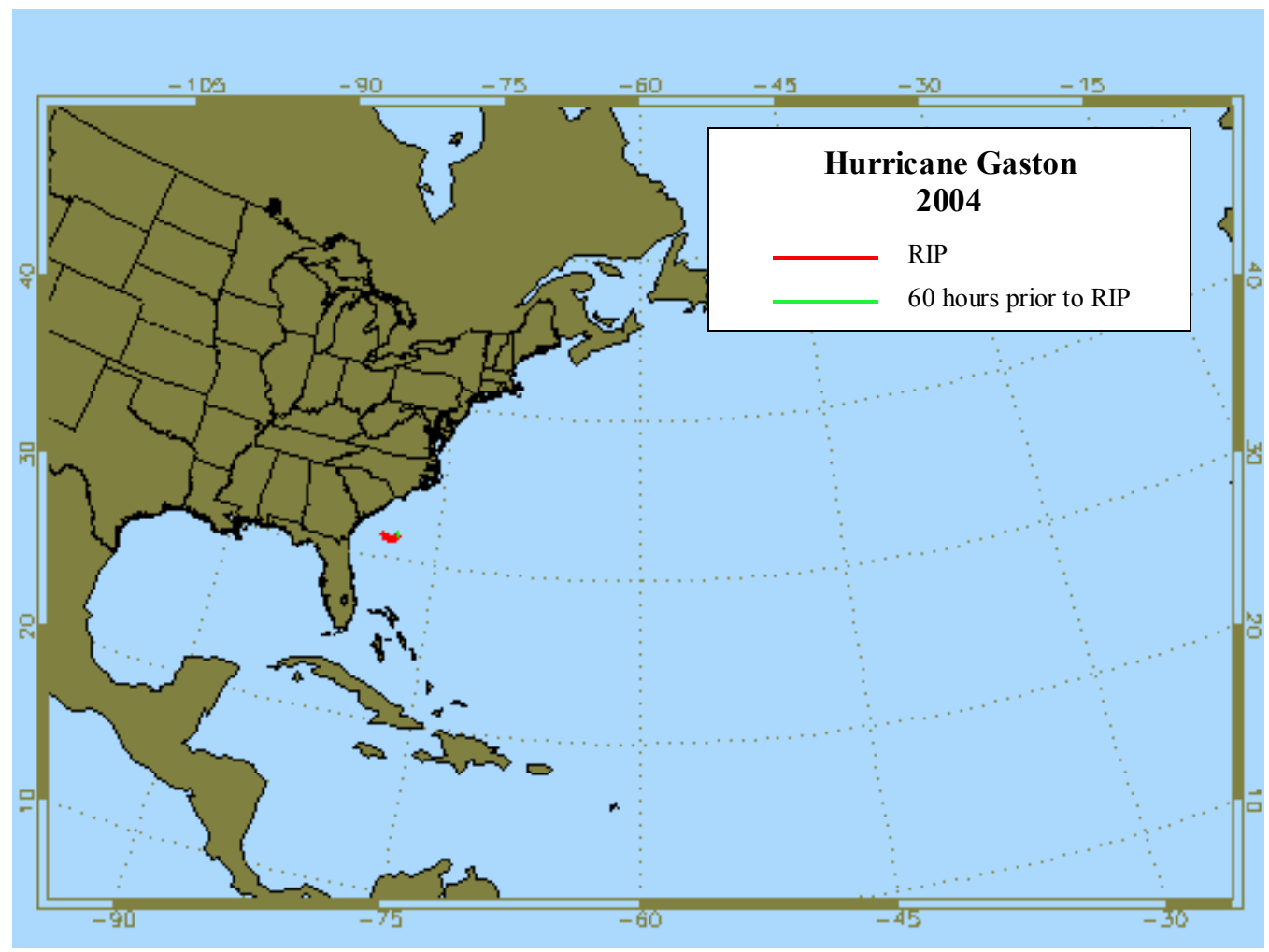

Figure 4.5: Track of Hurricane Gaston (2004). 
The DFA was able to classify all 16 time intervals correctly as a minor hurricane as Gaston showed many of the characteristics of minor hurricanes. Many hurricanes that develop from old cold fronts off of the U.S. east coast do not often develop into very strong hurricanes since they are too far north and lack the deep warm water needed to produce high heat potentials. Gaston may have had low wind shear but the heat potential was also low which inhibited strong intensification. To compound the problem, Gaston was nearly stationary causing upwelling in the same area, which cooled the water. This prevented Gaston from becoming a major hurricane and allowed it to barely achieve minor status. The time classification of the DFA was only able to correctly classify 8 of the 16 time intervals. The DFA wanted to use Model 6 for Time Intervals 6-12, which accounted for many of the misclassifications. Central pressures for Gaston remained very high throughout Time Interval 12 causing the DFA to predict it was still several hours away from the RIP, justifying the use of Model 6. However, Gaston's RIP occurred at an unusually high central pressure and was the reason for the majority of the misclassifications.

The 24-hour pressure model (Table 4.24) had relatively high percentage errors as only two time intervals had a error of less than $50 \%$ (Time Intervals 8 and 13). The early time intervals (Time Intervals 1-5) did not have a percentage error since the observations had predicted a $0 \mathrm{hPa}$ pressure decrease over the next 24 hours. Even so the selected models predicted pressure reductions ranging approximately from $2-3 \mathrm{hPa}$. The selected model did not begin making large errors until Time Interval 9, which was the start of 5 straight misclassified time intervals. From Time Interval 9-12, the DFA selected Model 6 to be used and each had large errors since they underestimated the amount of deepening. 


\begin{tabular}{|c|c|c|c|c|c|c|c|c|}
\hline $\begin{array}{l}\text { Date } \\
(2004)\end{array}$ & $\begin{array}{c}\text { Time } \\
\text { Interval }\end{array}$ & Model & $\begin{array}{c}\text { Central } \\
\text { Pressure } \\
(\mathrm{hPa})\end{array}$ & $\begin{array}{c}\text { 24-hour } \\
\text { Obs. }\end{array}$ & $\begin{array}{c}\text { 24-hour } \\
\text { Press } \\
\text { Model } \\
\text { (hPa) }\end{array}$ & $\%$ error & $\begin{array}{c}\text { Correct } \\
\text { Selected } \\
\text { Model } \\
(\mathrm{hPa})\end{array}$ & $\begin{array}{c}\text { Improv. } \\
(\mathrm{hPa})\end{array}$ \\
\hline $8 / 256 Z$ & 1 & 5 & 1015 & 0 & 2.54 & $\mathrm{~N} / \mathrm{a}$ & $\mathrm{N} / \mathrm{a}$ & $\mathrm{N} / \mathrm{a}$ \\
\hline $8 / 2512 Z$ & 2 & 6 & 1015 & 0 & 2.31 & $\mathrm{~N} / \mathrm{a}$ & 2.57 & -0.16 \\
\hline $8 / 2518 Z$ & 3 & 6 & 1015 & 0 & 2.38 & $\mathrm{~N} / \mathrm{a}$ & 2.65 & -0.27 \\
\hline $8 / 260 Z$ & 4 & 5 & 1015 & 0 & 3.20 & $\mathrm{~N} / \mathrm{a}$ & $\mathrm{N} / \mathrm{a}$ & $\mathrm{N} / \mathrm{a}$ \\
\hline $8 / 266 Z$ & 5 & 5 & 1015 & 0 & 3.45 & $\mathrm{~N} / \mathrm{a}$ & 2.72 & 0.73 \\
\hline $8 / 2612 Z$ & 6 & 6 & 1015 & 0 & 2.35 & $\mathrm{~N} / \mathrm{a}$ & $\mathrm{N} / \mathrm{a}$ & $\mathrm{N} / \mathrm{a}$ \\
\hline $8 / 2618 Z$ & 7 & 6 & 1015 & 1 & 3.12 & 212.0 & $\mathrm{~N} / \mathrm{a}$ & $\mathrm{N} / \mathrm{a}$ \\
\hline $8 / 270 Z$ & 8 & 6 & 1015 & 4 & 2.94 & 26.5 & $\mathrm{~N} / \mathrm{a}$ & $\mathrm{N} / \mathrm{a}$ \\
\hline $8 / 276 Z$ & 9 & 6 & 1015 & 10 & 3.16 & 68.4 & 10.72 & 6.12 \\
\hline $8 / 2712 Z$ & 10 & 6 & 1015 & 15 & 3.08 & 79.4 & 11.55 & 8.47 \\
\hline $8 / 2718 \mathrm{Z}$ & 11 & 6 & 1014 & 17 & 4.55 & 73.2 & 11.84 & 10.29 \\
\hline $8 / 280 Z$ & 12 & 6 & 1011 & 17 & 3.77 & 77.8 & 14.46 & 10.69 \\
\hline $8 / 286 Z$ & 13 & 7 & 1005 & 14 & 14.49 & 3.5 & 9.34 & -5.17 \\
\hline $8 / 2812 Z$ & 14 & 8 & 1000 & 14 & 3.08 & 78.0 & $\mathrm{~N} / \mathrm{a}$ & $\mathrm{N} / \mathrm{a}$ \\
\hline $8 / 2818 Z$ & 15 & 8 & 997 & 5 & 1.78 & 64.4 & $\mathrm{~N} / \mathrm{a}$ & $\mathrm{N} / \mathrm{a}$ \\
\hline $8 / 290 Z$ & 16 & 8 & 994 & -1 & 7.64 & 864.0 & $\mathrm{~N} / \mathrm{a}$ & $\mathrm{N} / \mathrm{a}$ \\
\hline
\end{tabular}

Table 4.24: 24-hour pressure drop model for Hurricane Gaston. 
Had the CSM (Model 7) been used, it would have improved each of these intervals dramatically. As stated earlier, the DFA selected Model 6 instead of 7 because of the relatively high central pressure Gaston possessed, and that would typically mean a tropical cyclone was still several hours from the onset of the RIP. However, Gaston did possess some typical characteristics of intensification leading up to the RIP, as the wind shear was very low and the system started to move slowly allowing it to churn toward warmer water. Specifically, Model 7 factored the previous 6-hour wind speed change, while Model 6 did not, which allowed the CSM to better predict the outcome since the wind speed was increasing during this time frame. The CSM did not improve on the selected model output during Time Interval 13 as the selected model missed the observed value by only $0.49 \mathrm{hPa}$. Model 8 , like Model 6, also did not factor the previous 6-hour wind speed change, which is likely why the CSM underestimated the amount of deepening.

Overall, the selected DFA had high percentage errors as only two intervals had errors less than $50 \%$ (Time Interval 13 and 14) primarily because of the misclassifications leading up to the RIP. The NHC did not issue an official 24-hour forecast until Time Interval 11 (Table 4.25) since the system was poorly organized and did not show any 24-hour wind speed increase through Time Interval 7. However, the NHC had high percentage errors too, as all 6 of their time intervals had errors of at least $50 \%$. The selected DFA model was able to outperform the NHC predictions on 3 of the 6 available time intervals (Time Intervals 13, 14, and 15). The CSM would have been able to improve on Time Intervals 11 and 12 also, which would have allowed it to be more accurate than the NHC on 5 of the 6 available intervals. Model 7 did an excellent job of 


\begin{tabular}{|c|c|c|c|c|c|c|c|c|c|}
\hline $\begin{array}{c}\text { Time } \\
\text { Int. }\end{array}$ & Model & $\begin{array}{l}\text { Max. } \\
\text { Sus. } \\
\text { Wind } \\
\text { (kts) }\end{array}$ & $\begin{array}{c}\text { 24-hour } \\
\text { Obs. }\end{array}$ & $\begin{array}{c}\text { 24-hour } \\
\text { Model } \\
\text { (kts) }\end{array}$ & $\%$ error & $\begin{array}{c}\text { NHC } \\
\text { 24hour } \\
\text { For. }\end{array}$ & $\begin{array}{c}\text { NHC } \\
\% \\
\text { error }\end{array}$ & $\begin{array}{l}\text { CSM } \\
(\mathrm{kts})\end{array}$ & $\begin{array}{c}\text { Improv. } \\
\text { (kts) }\end{array}$ \\
\hline 1 & 5 & 25 & 0 & 2.03 & $\mathrm{~N} / \mathrm{a}$ & $\mathrm{N} / \mathrm{a}$ & $\mathrm{N} / \mathrm{a}$ & $\mathrm{N} / \mathrm{a}$ & $\mathrm{N} / \mathrm{a}$ \\
\hline 2 & 6 & 25 & 0 & 3.47 & $\mathrm{~N} / \mathrm{a}$ & $\mathrm{N} / \mathrm{a}$ & $\mathrm{N} / \mathrm{a}$ & 2.18 & 1.29 \\
\hline 3 & 6 & 25 & 0 & -0.26 & $\mathrm{~N} / \mathrm{a}$ & $\mathrm{N} / \mathrm{a}$ & $\mathrm{N} / \mathrm{a}$ & 2.33 & -2.07 \\
\hline 4 & 5 & 25 & 0 & 2.48 & $\mathrm{~N} / \mathrm{a}$ & $\mathrm{N} / \mathrm{a}$ & $\mathrm{N} / \mathrm{a}$ & $\mathrm{N} / \mathrm{a}$ & $\mathrm{N} / \mathrm{a}$ \\
\hline 5 & 5 & 25 & 0 & 2.63 & $\mathrm{~N} / \mathrm{a}$ & $\mathrm{N} / \mathrm{a}$ & $\mathrm{N} / \mathrm{a}$ & -0.07 & 2.56 \\
\hline 6 & 6 & 25 & 0 & $\mathbf{0 . 3 3}$ & $\mathrm{N} / \mathrm{a}$ & $\mathrm{N} / \mathrm{a}$ & N/a & $\mathrm{N} / \mathrm{a}$ & $\mathrm{N} / \mathrm{a}$ \\
\hline 7 & 6 & 25 & 0 & 1.34 & $\mathrm{~N} / \mathrm{a}$ & $\mathrm{N} / \mathrm{a}$ & $\mathrm{N} / \mathrm{a}$ & $\mathrm{N} / \mathrm{a}$ & $\mathrm{N} / \mathrm{a}$ \\
\hline 8 & 6 & 25 & 5 & -0.43 & 108.7 & $\mathrm{~N} / \mathrm{a}$ & $\mathrm{N} / \mathrm{a}$ & $\mathrm{N} / \mathrm{a}$ & $\mathrm{N} / \mathrm{a}$ \\
\hline 9 & 6 & 25 & 10 & 1.74 & 82.6 & $\mathrm{~N} / \mathrm{a}$ & $\mathrm{N} / \mathrm{a}$ & 18.62 & -0.36 \\
\hline 10 & 6 & 25 & 20 & 1.45 & 92.7 & $\mathrm{~N} / \mathrm{a}$ & $\mathrm{N} / \mathrm{a}$ & 20.43 & 18.12 \\
\hline 11 & 6 & 25 & 25 & 7.23 & 71.1 & 10 & 60.0 & 18.27 & 11.04 \\
\hline 12 & 6 & 30 & 25 & 8.27 & 66.9 & 10 & 60.0 & 24.36 & 16.09 \\
\hline 13 & 7 & 35 & 25 & 26.32 & 5.3 & 10 & 60.0 & 21.58 & -2.1 \\
\hline 14 & 8 & 45 & 20 & 10.64 & 46.8 & 10 & 50.0 & $\mathrm{~N} / \mathrm{a}$ & $\mathrm{N} / \mathrm{a}$ \\
\hline 15 & 8 & 50 & -5 & 7.75 & 255.1 & 15 & 400 & $\mathrm{~N} / \mathrm{a}$ & $\mathrm{N} / \mathrm{a}$ \\
\hline 16 & 8 & 55 & -25 & 4.30 & 117.2 & 0 & 100 & $\mathrm{~N} / \mathrm{a}$ & $\mathrm{N} / \mathrm{a}$ \\
\hline
\end{tabular}

Table 4.25: 24-hour wind speed increase model for Hurricane Gaston. 
forecasting the wind speed increase from Time Intervals 10-13. As shown by the CSM in Time Intervals $10-12$, the model missed the observed values by $0.43,6.73$, and 0.64 knots respectively as it considered the previous 6-hour wind speed change, in which Model 6 did not. This was an important period of the storm as the observed 24-hour wind speed increase was 25 knots at the onset of the RIP. The NHC did not predict such a rapid intensification with a forecast of only 10 knots.

The 6-hour pressure decrease was very modest (Table 4.26) throughout the study as the maximum was a $6 \mathrm{hPa}$ drop at the onset of the RIP (Time Interval 12). Since the pressure decrease was so minimal through the majority of the study, the selected DFA model was able to predict the outcome reasonably well even with the misclassifications. The largest errors occurred at Time Intervals $11-12(84.6 \%$ and $84.5 \%$ error respectively), but the CSM (Model 7) would have been able to improve on these errors for similar reasons stated with the other types of models. The 6-hour wind speed increase (Table 4.27) did not change until Time Interval 11 and for that reason the selected DFA model output was able to predict the wind speed since it primarily factored the previous 6-hour wind speed change. The selected DFA model did not predict as well from Time Intervals 11-13 since they were misclassified but the CSM would have been able to improve the forecast. Model 8 (CSM Time Interval 13), made the most significant improvement to Model 7 since it factored more significant variables in the model. Model 7 only considers latitude and the previous 6-hour wind speed change, while Model 8 factors attained MPI, central pressure, and wind speed, in addition to the previous 6-hour wind speed change. 


\begin{tabular}{|c|c|c|c|c|c|c|c|c|}
\hline Date & $\begin{array}{l}\text { Time } \\
\text { Int. }\end{array}$ & Model & $\begin{array}{c}\text { Cent. } \\
\text { Pressure } \\
(\mathrm{hPa})\end{array}$ & $\begin{array}{l}\text { 6-hour Pres. } \\
\text { Drop Obs. }\end{array}$ & $\begin{array}{l}\text { 6-hour } \\
\text { Model } \\
\text { (hPa) }\end{array}$ & $\begin{array}{l}\% \% \\
\text { error }\end{array}$ & $\begin{array}{l}\text { CSM } \\
\text { (hPa) }\end{array}$ & $\begin{array}{c}\text { Improv. } \\
\text { (hPa) }\end{array}$ \\
\hline $8 / 256 Z$ & 1 & 5 & 1015 & 0 & 0.08 & $\mathrm{~N} / \mathrm{a}$ & $\mathrm{N} / \mathrm{a}$ & $\mathrm{N} / \mathrm{a}$ \\
\hline $8 / 2512 Z$ & 2 & 6 & 1015 & 0 & 0.46 & $\mathrm{~N} / \mathrm{a}$ & 0.08 & 0.38 \\
\hline $8 / 2518 Z$ & 3 & 6 & 1015 & 0 & 0.46 & $\mathrm{~N} / \mathrm{a}$ & 0.08 & 0.38 \\
\hline $8 / 260 \mathrm{Z}$ & 4 & 5 & 1015 & 0 & 0.08 & $\mathrm{~N} / \mathrm{a}$ & $\mathrm{N} / \mathrm{a}$ & $\mathrm{N} / \mathrm{a}$ \\
\hline $8 / 266 Z$ & 5 & 5 & 1015 & 0 & 0.08 & $\mathrm{~N} / \mathrm{a}$ & 0.46 & -0.38 \\
\hline $8 / 2612 Z$ & 6 & 6 & 1015 & 0 & 0.46 & $\mathrm{~N} / \mathrm{a}$ & $\mathrm{N} / \mathrm{a}$ & $\mathrm{N} / \mathrm{a}$ \\
\hline $8 / 2618 Z$ & 7 & 6 & 1015 & 0 & 0.46 & $\mathrm{~N} / \mathrm{a}$ & $\mathrm{N} / \mathrm{a}$ & $\mathrm{N} / \mathrm{a}$ \\
\hline $8 / 270 Z$ & 8 & 6 & 1015 & 0 & 0.46 & $\mathrm{~N} / \mathrm{a}$ & $\mathrm{N} / \mathrm{a}$ & N/a \\
\hline $8 / 276 Z$ & 9 & 6 & 1015 & 0 & 0.46 & $\mathrm{~N} / \mathrm{a}$ & 1.51 & -1.05 \\
\hline $8 / 2712 Z$ & 10 & 6 & 1015 & 1 & 0.46 & 54.0 & 1.59 & -0.05 \\
\hline $8 / 2718 \mathrm{Z}$ & 11 & 6 & 1014 & 3 & 0.46 & 84.6 & 1.76 & 1.3 \\
\hline $8 / 280 Z$ & 12 & 6 & 1011 & 6 & 0.93 & 84.5 & 2.55 & 1.62 \\
\hline $8 / 286 Z$ & 13 & 7 & 1005 & 5 & 2.67 & 46.6 & 3.06 & 0.39 \\
\hline $8 / 2812 Z$ & 14 & 8 & 1000 & 3 & 2.09 & 30.3 & $\mathrm{~N} / \mathrm{a}$ & $\mathrm{N} / \mathrm{a}$ \\
\hline $8 / 2818 Z$ & 15 & 8 & 997 & 3 & 1.76 & 41.3 & $\mathrm{~N} / \mathrm{a}$ & N/a \\
\hline $8 / 290 Z$ & 16 & 8 & 994 & 3 & 3.48 & 16.0 & $\mathrm{~N} / \mathrm{a}$ & $\mathrm{N} / \mathrm{a}$ \\
\hline
\end{tabular}

Table 4.26: 6-hour pressure drop model for Hurricane Gaston. 


\begin{tabular}{|c|c|c|c|c|c|c|c|c|}
\hline Date & $\begin{array}{l}\text { Time } \\
\text { Int. }\end{array}$ & Model & $\begin{array}{l}\text { Max. Sus. } \\
\text { Winds (kts) }\end{array}$ & $\begin{array}{c}\text { 6-hour } \\
\text { Wind } \\
\text { Speed Obs. }\end{array}$ & $\begin{array}{c}\text { 6-hour } \\
\text { Model } \\
\text { (kts) }\end{array}$ & $\%$ error & $\begin{array}{l}\text { CSM } \\
\text { (kts) }\end{array}$ & $\begin{array}{c}\text { Improv. } \\
\text { (kts) }\end{array}$ \\
\hline $8 / 256 Z$ & 1 & 5 & 25 & 0 & 0.27 & $\mathrm{~N} / \mathrm{a}$ & $\mathrm{N} / \mathrm{a}$ & $\mathrm{N} / \mathrm{a}$ \\
\hline $8 / 2512 Z$ & 2 & 6 & 25 & 0 & -0.57 & $\mathrm{~N} / \mathrm{a}$ & 0.27 & 0.30 \\
\hline $8 / 2518 Z$ & 3 & 6 & 25 & 0 & -0.71 & $\mathrm{~N} / \mathrm{a}$ & 0.27 & 0.50 \\
\hline $8 / 260 \mathrm{Z}$ & 4 & 5 & 25 & 0 & 0.27 & $\mathrm{~N} / \mathrm{a}$ & $\mathrm{N} / \mathrm{a}$ & $\mathrm{N} / \mathrm{a}$ \\
\hline $8 / 266 Z$ & 5 & 5 & 25 & 0 & 0.27 & N/a & -0.43 & -0.16 \\
\hline $8 / 2612 Z$ & 6 & 6 & 25 & 0 & -0.45 & $\mathrm{~N} / \mathrm{a}$ & $\mathrm{N} / \mathrm{a}$ & $\mathrm{N} / \mathrm{a}$ \\
\hline $8 / 2618 Z$ & 7 & 6 & 25 & 0 & -0.44 & $\mathrm{~N} / \mathrm{a}$ & $\mathrm{N} / \mathrm{a}$ & $\mathrm{N} / \mathrm{a}$ \\
\hline $8 / 270 Z$ & 8 & 6 & 25 & 0 & -0.61 & $\mathrm{~N} / \mathrm{a}$ & $\mathrm{N} / \mathrm{a}$ & $\mathrm{N} / \mathrm{a}$ \\
\hline $8 / 276 Z$ & 9 & 6 & 25 & 0 & -0.46 & $\mathrm{~N} / \mathrm{a}$ & 1.26 & -0.80 \\
\hline $8 / 2712 Z$ & 10 & 6 & 25 & 0 & -0.45 & N/a & 1.26 & -0.81 \\
\hline $8 / 2718 Z$ & 11 & 6 & 25 & 5 & 0.87 & 82.5 & 1.28 & 0.41 \\
\hline $8 / 280 Z$ & 12 & 6 & 30 & 5 & 2.14 & 57.1 & 3.14 & 1.00 \\
\hline $8 / 286 Z$ & 13 & 7 & 35 & 10 & 3.15 & 68.5 & 11.58 & 5.27 \\
\hline $8 / 2812 Z$ & 14 & 8 & 45 & 5 & 9.77 & 95.4 & N/a & $\mathrm{N} / \mathrm{a}$ \\
\hline $8 / 2818 Z$ & 15 & 8 & 50 & 5 & 7.66 & 53.4 & N/a & N/a \\
\hline $8 / 290 Z$ & 16 & 8 & 55 & 5 & 6.60 & 32.1 & $\mathrm{~N} / \mathrm{a}$ & $\mathrm{N} / \mathrm{a}$ \\
\hline
\end{tabular}

Table 4.27: 6-hour wind speed increase model for Hurricane Gaston. 


\subsubsection{Hurricane Ivan (2004)}

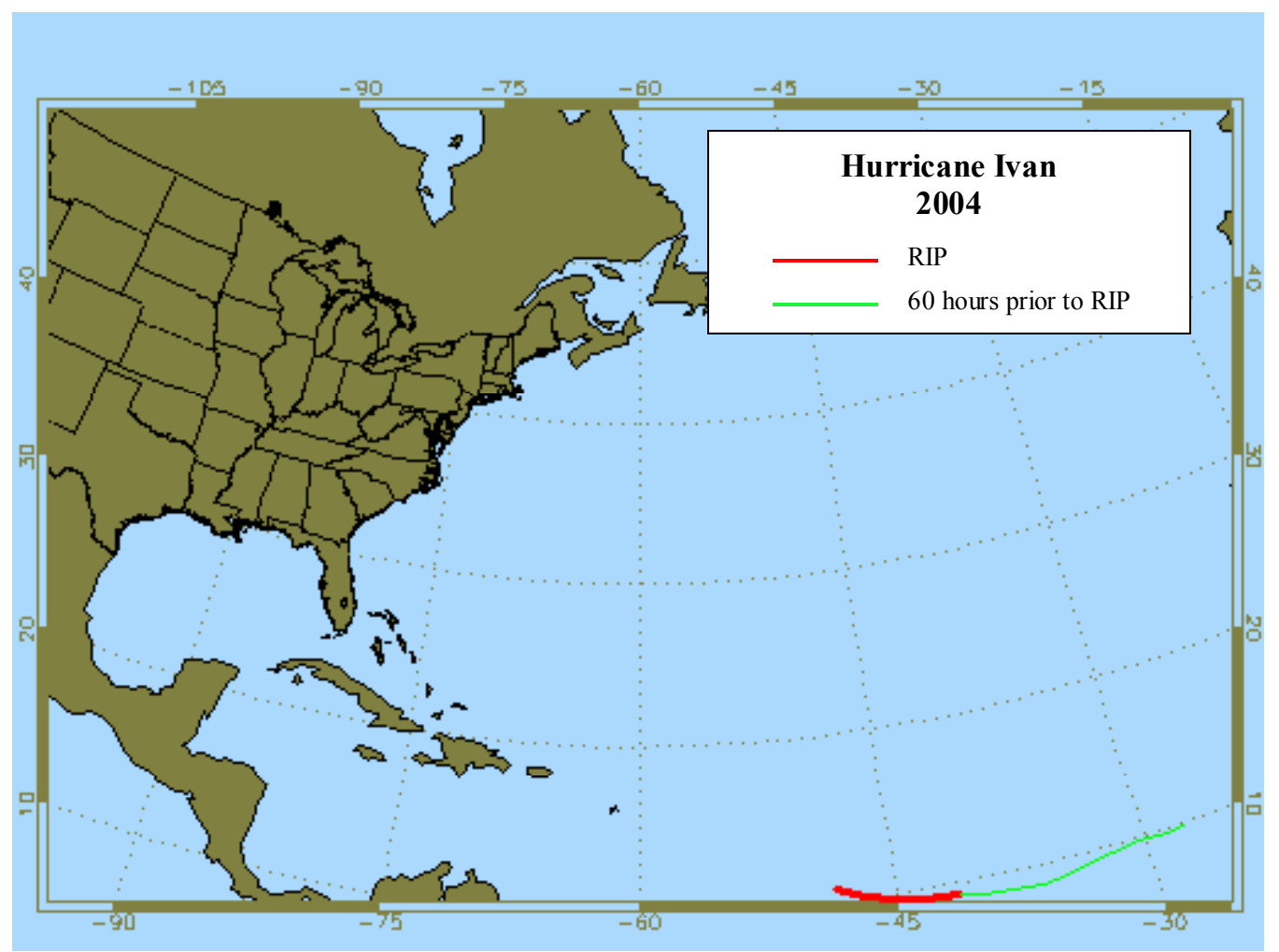

Figure 4.6: Track of Hurricane Ivan (2004).

The track for Hurricane Ivan began at $6 Z$ September 2, just 12 hours prior to Ivan being classified as a tropical depression. Due to favorable low wind shear and defined outflow, Ivan was able to develop into a tropical depression by $18 \mathrm{Z}$ September 2 . The deep convection continued and allowed it to quickly become a tropical storm 12 hours later even though it was at a low latitude $\left(9.7^{\circ} \mathrm{N}\right)$. Ivan would continue on a generally westward track and officially became a hurricane at $6 Z$ September 5 when it was about 1000 miles east of Tobago. At this point, Ivan was in the earliest stages of its RIP and a 
Category 1 hurricane, but at the end of the RIP Ivan was at Category 4 strength. Ivan intensified 55 knots and $43 \mathrm{hPa}$ over this 24 hour period, making it the southernmost major hurricane on record. The low shear environment and the high heat potential during this time period allowed Ivan to rapidly intensify. Beyond the period of this study, Ivan weakened to Category 3 strength due to dry air that prevented eyewall convection. But Ivan would intensify again, and eventually fluctuate between Category 4 and 5 the greater part of its lifespan, before making U.S. landfall near Gulf Shores, AL.

The DFA was able to correctly classify all of Ivan's 16 time intervals as ultimately becoming a major hurricane. Ivan exhibited the classic characteristics that favor development of a major hurricane such as low wind shear and particularly high heat potential since it developed very far south in the tropical Atlantic. Therefore, the DFA predicted Ivan would become a major hurricane even 60 hours before the RIP. For the time classifications, the DFA was able to correctly classify 10 out of the 16 time intervals. It had the most difficulty classifying Time Intervals 8-11, which were all misclassified. The DFA determined Ivan was at an earlier stage in relation to its RIP due to the high central pressure it showed. Therefore, it selected Model 1 to be used for Time Interval 8, and Model 2 to be used for Time Intervals 9-11 when it should have selected Model 2 for Time Interval 8 and Model 3 for Time Intervals 9-11.

Table 4.28 shows the 24-hour pressure decrease model for Hurricane Ivan and only 5 of the 16 time intervals had percentage errors greater than $50 \%$ (Time Intervals 2 , 3, 11, 15, and 16). During Time Intervals 2 and 3, the system was nearly stationary and since Model 1 is reliant on translational speed, it did not predict much deepening because the upwelling would be detrimental to the development. Time Interval 11 was 


\begin{tabular}{|c|c|c|c|c|c|c|c|c|}
\hline $\begin{array}{l}\text { Date } \\
\text { (2004) }\end{array}$ & $\begin{array}{c}\text { Time } \\
\text { Interval }\end{array}$ & Model & $\begin{array}{c}\text { Central } \\
\text { Pressure } \\
(\mathrm{hPa})\end{array}$ & $\begin{array}{c}\text { 24-hour } \\
\text { Obs. }\end{array}$ & $\begin{array}{l}\text { 24-hour } \\
\text { Press } \\
\text { Model } \\
\text { (hPa) }\end{array}$ & $\%$ error & $\begin{array}{c}\text { Correct } \\
\text { Selected } \\
\text { Model } \\
(\mathrm{hPa})\end{array}$ & $\begin{array}{c}\text { Improv. } \\
(\mathrm{hPa})\end{array}$ \\
\hline $9 / 26 Z$ & 1 & 1 & 1009 & 4 & 2.35 & 41.2 & $\mathrm{~N} / \mathrm{a}$ & $\mathrm{N} / \mathrm{a}$ \\
\hline $9 / 212 Z$ & 2 & 1 & 1009 & 6 & 1.23 & 79.4 & $\mathrm{~N} / \mathrm{a}$ & $\mathrm{N} / \mathrm{a}$ \\
\hline $9 / 218 Z$ & 3 & 1 & 1009 & 9 & 2.73 & 69.7 & $\mathrm{~N} / \mathrm{a}$ & $\mathrm{N} / \mathrm{a}$ \\
\hline $9 / 30 Z$ & 4 & 1 & 1007 & 8 & 4.91 & 38.5 & $\mathrm{~N} / \mathrm{a}$ & $\mathrm{N} / \mathrm{a}$ \\
\hline $9 / 36 Z$ & 5 & 1 & 1005 & 8 & 8.41 & 5.2 & 8.38 & 0.03 \\
\hline $9 / 312 Z$ & 6 & 2 & 1003 & 6 & 8.87 & 48.0 & $\mathrm{~N} / \mathrm{a}$ & $\mathrm{N} / \mathrm{a}$ \\
\hline $9 / 318 Z$ & 7 & 2 & 1000 & 6 & 6.90 & 15.1 & $\mathrm{~N} / \mathrm{a}$ & $\mathrm{N} / \mathrm{a}$ \\
\hline $9 / 40 Z$ & 8 & 1 & 999 & 8 & 7.14 & 10.6 & 6.50 & -0.64 \\
\hline $9 / 46 Z$ & 9 & 2 & 997 & 10 & 8.66 & 13.3 & 20.98 & -9.64 \\
\hline $9 / 412 Z$ & 10 & 2 & 997 & 20 & 11.24 & 43.8 & 19.60 & 8.36 \\
\hline $9 / 418 Z$ & 11 & 2 & 994 & 39 & 10.42 & 73.3 & 20.54 & 10.12 \\
\hline $9 / 50 Z$ & 12 & 3 & 991 & 43 & 22.27 & 48.2 & $\mathrm{~N} / \mathrm{a}$ & $\mathrm{N} / \mathrm{a}$ \\
\hline $9 / 56 Z$ & 13 & 3 & 987 & 37 & 22.95 & 38.0 & 23.24 & 0.29 \\
\hline $9 / 512 Z$ & 14 & 4 & 977 & 22 & 20.48 & 6.9 & $\mathrm{~N} / \mathrm{a}$ & $\mathrm{N} / \mathrm{a}$ \\
\hline $9 / 518 Z$ & 15 & 4 & 955 & -14 & 6.12 & 143.8 & $\mathrm{~N} / \mathrm{a}$ & $\mathrm{N} / \mathrm{a}$ \\
\hline $9 / 60 Z$ & 16 & 4 & 948 & -16 & 1.11 & 107.0 & $\mathrm{~N} / \mathrm{a}$ & $\mathrm{N} / \mathrm{a}$ \\
\hline
\end{tabular}

Table 4.28: 24-hour pressure decrease model for Hurricane Ivan. 
misclassified and the CSM (Model 3) would have provided much improvement over the selected model (Model 2). Model 3 included the core heat potential $\left(25 \mathrm{~kJ} \mathrm{~cm}^{-2}\right)$ and the current wind speed (55 knots), which were beginning to increase, while Model 2 did not. As for Time Intervals 15 and 16, Model 4 was not able to predict the amount of weakening that was taking place because of some mid level dry air that was destroying the convection. The CSM would have provided improvement for the misclassified intervals with the exceptions of Time Intervals 8 and 9. For Time Interval 8, the CSM (Model 2) would have been slightly less accurate but in Time Interval 9, the CSM (Model 3) overestimated the amount of deepening. Again Model 3 factored the high core heat potential available that did not affect the hurricane until a few time intervals later. All in all, the DFA selected models did forecast a rapid intensification and a reduction in that intensification at the end of the RIP.

Table 4.29 shows the 24-hour wind speed increase model for Hurricane Ivan and the NHC forecasts. The NHC did not issue forecasts for the first two time intervals, since Ivan had not become a tropical depression yet, therefore making only 14 intervals with official forecasts. The DFA selected model was able to improve on the NHC forecasts on 8 out of the 14 intervals. For many of the time intervals in the early stages of Ivan (Time Intervals 3-8), the NHC was able to predict the wind speed more accurately (5 out of 6 intervals). However, beginning at Time Interval 9, the model selected by the DFA was more accurate than the $\mathrm{NHC}$ on 7 out of the 8 remaining time intervals with the exception of Time Interval 11. During Time Interval 11, the CSM (Model 3) would have been more accurate making it outperform the NHC on all of the 8 last time intervals. Model 3 


\begin{tabular}{|c|c|c|c|c|c|c|c|c|c|}
\hline $\begin{array}{c}\text { Time } \\
\text { Int. }\end{array}$ & Model & $\begin{array}{l}\text { Max. } \\
\text { Sus. } \\
\text { Wind } \\
\text { (kts) }\end{array}$ & $\begin{array}{c}\text { 24-hour } \\
\text { Obs. }\end{array}$ & $\begin{array}{c}\text { 24-hour } \\
\text { Model } \\
\text { (kts) }\end{array}$ & $\%$ error & $\begin{array}{c}\text { NHC } \\
24 \text { hour } \\
\text { For. }\end{array}$ & $\begin{array}{c}\text { NHC } \\
\% \\
\text { error }\end{array}$ & $\begin{array}{l}\text { CSM } \\
(\mathrm{kts})\end{array}$ & $\begin{array}{c}\text { Improv. } \\
\text { (kts) }\end{array}$ \\
\hline 1 & 1 & 25 & 10 & 2.93 & 70.7 & $\mathrm{~N} / \mathrm{a}$ & $\mathrm{N} / \mathrm{a}$ & $\mathrm{N} / \mathrm{a}$ & $\mathrm{N} / \mathrm{a}$ \\
\hline 2 & 1 & 25 & 15 & 2.64 & 82.4 & $\mathrm{~N} / \mathrm{a}$ & $\mathrm{N} / \mathrm{a}$ & $\mathrm{N} / \mathrm{a}$ & $\mathrm{N} / \mathrm{a}$ \\
\hline 3 & 1 & 25 & 20 & 3.06 & 84.7 & 15 & 25.0 & $\mathrm{~N} / \mathrm{a}$ & $\mathrm{N} / \mathrm{a}$ \\
\hline 4 & 1 & 30 & 15 & 8.89 & 40.7 & 20 & 33.3 & $\mathrm{~N} / \mathrm{a}$ & $\mathrm{N} / \mathrm{a}$ \\
\hline 5 & 1 & 35 & 15 & 10.44 & 30.4 & 15 & 0.0 & 16.77 & 2.79 \\
\hline 6 & 2 & 40 & 10 & 16.90 & 69.0 & 15 & 50.0 & $\mathrm{~N} / \mathrm{a}$ & $\mathrm{N} / \mathrm{a}$ \\
\hline 7 & 2 & 45 & 10 & 14.50 & 45.1 & 15 & 50.0 & $\mathrm{~N} / \mathrm{a}$ & $\mathrm{N} / \mathrm{a}$ \\
\hline 8 & 1 & 45 & 15 & 10.15 & 32.3 & 15 & 0.0 & 10.79 & 0.64 \\
\hline 9 & 2 & 50 & 15 & 12.84 & 14.4 & 10 & 33.3 & 36.25 & -23.41 \\
\hline 10 & 2 & 50 & 35 & 13.33 & 61.9 & 10 & 71.4 & 34.30 & 20.97 \\
\hline 11 & 2 & 55 & 55 & 11.67 & 78.8 & 15 & 72.7 & 35.17 & 23.5 \\
\hline 12 & 3 & 60 & 55 & 35.18 & 36.0 & 10 & 81.8 & $\mathrm{~N} / \mathrm{a}$ & $\mathrm{N} / \mathrm{a}$ \\
\hline 13 & 3 & 65 & 45 & 37.61 & 16.4 & 10 & 77.8 & 27.34 & -10.27 \\
\hline 14 & 4 & 85 & 25 & 20.45 & 18.2 & 10 & 60.0 & $\mathrm{~N} / \mathrm{a}$ & $\mathrm{N} / \mathrm{a}$ \\
\hline 15 & 4 & 110 & -20 & 1.10 & 105.5 & 10 & 150 & $\mathrm{~N} / \mathrm{a}$ & $\mathrm{N} / \mathrm{a}$ \\
\hline 16 & 4 & 115 & -25 & -2.93 & 88.3 & 15 & 160 & $\mathrm{~N} / \mathrm{a}$ & $\mathrm{N} / \mathrm{a}$ \\
\hline
\end{tabular}

Table 4.29: 24-hour wind speed increase model for Hurricane Ivan. 
was able to capture the rapid intensification by factoring in the MPI, while Model 2 did not. This allowed for 24-hour wind speed predictions during Time Intervals 10 and 11 of 34.3 knots and 35.17 knots respectively. The observed increases were 35 and 55 knots, which meant that the model missed the observations by 0.7 and 24.83 knots respectively. Considering the NHC missed by 25 and 40 knots respectively during these same time intervals, the CSM provided substantial improvement. In addition to the period just prior to, and at the onset of the RIP, the DFA was able to detect some weakening at the end of the RIP whereas the NHC did not. During Time Intervals 15 and 16, the wind speed decreased 20 knots and 25 knots respectively and the selected model (Model 4) predicted a slight increase of 1.1 knot and a slight decrease of 2.93 knots respectively. However, the NHC still predicted steady strengthening, as it did through all of the time intervals, 10 knots and 15 knots. Therefore, the NHC did not detect any sign of weakening at the end of the RIP, whereas the model did predict signs that the winds were starting to decrease. More importantly, the NHC failed to detect any rapid intensification with Ivan when the winds rapidly increased 55 knots over the 24 hours during Time Intervals 11 and 12 . The model, especially Model 3, was able to detect the RIP, improving on the NHC forecasts by 20-30 knots.

The 6-hour pressure drop observations (Table 4.30) were very modest until the RIP. For that reason, the DFA was able to predict the observed value well even if the interval was misclassified. The CSM did not provide much improvement with small observed pressure reductions. At the onset of the RIP (Time Interval 12), the 6-hour pressure started to drop more rapidly. Model 4 was able to predict the rapid 


\begin{tabular}{|c|c|c|c|c|c|c|c|c|}
\hline Date & $\begin{array}{l}\text { Time } \\
\text { Int. }\end{array}$ & Model & $\begin{array}{c}\text { Cent. } \\
\text { Pressure } \\
(\mathrm{hPa})\end{array}$ & $\begin{array}{l}\text { 6-hour Pres. } \\
\text { Drop Obs. }\end{array}$ & $\begin{array}{c}\text { 6-hour } \\
\text { Model } \\
(\mathrm{hPa})\end{array}$ & $\begin{array}{l}\% \\
\text { error }\end{array}$ & $\begin{array}{l}\text { CSM } \\
(\mathrm{hPa})\end{array}$ & $\begin{array}{l}\text { Improve } \\
(\mathrm{hPa})\end{array}$ \\
\hline $9 / 26 Z$ & 1 & 1 & 1009 & 0 & 0.40 & $\mathrm{~N} / \mathrm{a}$ & $\mathrm{N} / \mathrm{a}$ & $\mathrm{N} / \mathrm{a}$ \\
\hline $9 / 212 Z$ & 2 & 1 & 1009 & 0 & 0.17 & $\mathrm{~N} / \mathrm{a}$ & $\mathrm{N} / \mathrm{a}$ & $\mathrm{N} / \mathrm{a}$ \\
\hline $9 / 218 Z$ & 3 & 1 & 1009 & 2 & 0.48 & 76.0 & $\mathrm{~N} / \mathrm{a}$ & $\mathrm{N} / \mathrm{a}$ \\
\hline $9 / 30 \mathrm{Z}$ & 4 & 1 & 1007 & 2 & 2.14 & 7.2 & $\mathrm{~N} / \mathrm{a}$ & $\mathrm{N} / \mathrm{a}$ \\
\hline $9 / 36 Z$ & 5 & 1 & 1005 & 2 & 3.10 & 55.4 & 2.63 & 0.67 \\
\hline $9 / 312 Z$ & 6 & 2 & 1003 & 3 & 2.63 & 12.1 & $\mathrm{~N} / \mathrm{a}$ & $\mathrm{N} / \mathrm{a}$ \\
\hline 9/3 18Z & 7 & 2 & 1000 & 1 & 2.63 & 163.6 & $\mathrm{~N} / \mathrm{a}$ & $\mathrm{N} / \mathrm{a}$ \\
\hline $9 / 40 Z$ & 8 & 1 & 999 & 2 & 2.09 & 4.7 & 2.63 & -0.54 \\
\hline $9 / 46 Z$ & 9 & 2 & 997 & 0 & 2.63 & $\mathrm{~N} / \mathrm{a}$ & 3.29 & -0.66 \\
\hline $9 / 412 Z$ & 10 & 2 & 997 & 3 & 1.53 & 49.0 & 2.44 & 0.90 \\
\hline $9 / 418 Z$ & 11 & 2 & 994 & 3 & 2.63 & 12.1 & 3.30 & 0.07 \\
\hline $9 / 50 Z$ & 12 & 3 & 991 & 4 & 3.64 & 8.8 & N/a & $\mathrm{N} / \mathrm{a}$ \\
\hline $9 / 56 Z$ & 13 & 3 & 987 & 10 & 3.67 & 63.2 & 13.45 & 2.88 \\
\hline $9 / 512 Z$ & 14 & 4 & 977 & 22 & 12.78 & 41.9 & $\mathrm{~N} / \mathrm{a}$ & $\mathrm{N} / \mathrm{a}$ \\
\hline $9 / 518 Z$ & 15 & 4 & 955 & 7 & 11.29 & 61.3 & $\mathrm{~N} / \mathrm{a}$ & $\mathrm{N} / \mathrm{a}$ \\
\hline $9 / 60 Z$ & 16 & 4 & 948 & -2 & 6.16 & 408.0 & $\mathrm{~N} / \mathrm{a}$ & $\mathrm{N} / \mathrm{a}$ \\
\hline
\end{tabular}

Table 4.30: 6-hour pressure drop model for Hurricane Ivan. 
intensification much better than Model 3 since there are more significant variables. The CSM (Model 4) during Time Interval 13 predicted a drop of about $13 \mathrm{hPa}$ when the observed drop was $10 \mathrm{hPa}$ and during Time Interval 14 it predicted a drop of $13 \mathrm{hPa}$ when the observation was $22 \mathrm{hPa}$. Therefore, the 6-hour pressure model suggested a shorter-term rapid intensification even though it underestimated the amount of deepening at Time Interval 14.

The 6-hour wind speed model (Table 4.31) exhibited a similar pattern to the pressure model with very modest increases in the wind speed until the onset of the RIP. The DFA selected models were able to predict these small increases well despite some misclassified intervals. Not until Time Interval 13 was there a dramatic increase in the wind speed, but had the CSM (Model 4) been used instead of Model 3, it would have better predicted that rapid increase. That is because Model 4 factors more significant variables than Model 3 such as $850-100 \mathrm{hPa}$ wind shear and the attained MPI. The shear was relatively low during Time Intervals $13-16$, and the attained MPI was gradually increasing. As the attained MPI increased to around 38\% (Time Intervals 15 and 16), the amount of predicted strengthening decreased, since this is above the considered rapid intensification threshold of 28\% (Law 2001). 


\begin{tabular}{|c|c|c|c|c|c|c|c|c|}
\hline Date & $\begin{array}{l}\text { Time } \\
\text { Int. }\end{array}$ & Model & $\begin{array}{l}\text { Max. Sus. } \\
\text { Winds (kts) }\end{array}$ & $\begin{array}{c}\text { 6-hour } \\
\text { Wind } \\
\text { Speed Obs. }\end{array}$ & $\begin{array}{c}\text { 6-hour } \\
\text { Model } \\
\text { (kts) }\end{array}$ & $\%$ error & $\begin{array}{l}\text { CSM } \\
\text { (kts) }\end{array}$ & $\begin{array}{c}\text { Improv. } \\
\text { (kts) }\end{array}$ \\
\hline $9 / 26 Z$ & 1 & 1 & 25 & 0 & 1.19 & $\mathrm{~N} / \mathrm{a}$ & $\mathrm{N} / \mathrm{a}$ & $\mathrm{N} / \mathrm{a}$ \\
\hline $9 / 212 Z$ & 2 & 1 & 25 & 0 & 1.19 & $\mathrm{~N} / \mathrm{a}$ & $\mathrm{N} / \mathrm{a}$ & $\mathrm{N} / \mathrm{a}$ \\
\hline $9 / 218 \mathrm{Z}$ & 3 & 1 & 25 & 5 & 1.19 & 76.1 & $\mathrm{~N} / \mathrm{a}$ & $\mathrm{N} / \mathrm{a}$ \\
\hline $9 / 30 Z$ & 4 & 1 & 30 & 5 & 3.42 & 31.4 & $\mathrm{~N} / \mathrm{a}$ & $\mathrm{N} / \mathrm{a}$ \\
\hline $9 / 36 Z$ & 5 & 1 & 35 & 5 & 3.44 & 31.1 & 3.40 & -0.04 \\
\hline $9 / 312 Z$ & 6 & 2 & 40 & 5 & 3.02 & 39.5 & $\mathrm{~N} / \mathrm{a}$ & $\mathrm{N} / \mathrm{a}$ \\
\hline 9/3 18Z & 7 & 2 & 45 & 0 & 4.31 & $\mathrm{~N} / \mathrm{a}$ & N/a & $\mathrm{N} / \mathrm{a}$ \\
\hline $9 / 40 Z$ & 8 & 1 & 45 & 5 & 1.53 & 69.4 & 3.70 & 2.17 \\
\hline $9 / 46 Z$ & 9 & 2 & 50 & 0 & 3.81 & $\mathrm{~N} / \mathrm{a}$ & 5.45 & -1.64 \\
\hline $9 / 412 Z$ & 10 & 2 & 50 & 5 & 2.83 & 43.4 & 3.86 & 1.03 \\
\hline $9 / 418 Z$ & 11 & 2 & 55 & 5 & 3.89 & 22.0 & 5.15 & 0.96 \\
\hline $9 / 50 Z$ & 12 & 3 & 60 & 5 & 5.10 & 2.2 & $\mathrm{~N} / \mathrm{a}$ & $\mathrm{N} / \mathrm{a}$ \\
\hline $9 / 56 Z$ & 13 & 3 & 65 & 20 & 5.04 & 74.8 & 14.15 & 9.11 \\
\hline $9 / 512 Z$ & 14 & 4 & 85 & 25 & 11.93 & 52.2 & $\mathrm{~N} / \mathrm{a}$ & $\mathrm{N} / \mathrm{a}$ \\
\hline $9 / 518 \mathrm{Z}$ & 15 & 4 & 110 & 5 & 8.43 & 68.8 & $\mathrm{~N} / \mathrm{a}$ & $\mathrm{N} / \mathrm{a}$ \\
\hline $9 / 60 Z$ & 16 & 4 & 115 & -5 & 8.54 & 270.9 & $\mathrm{~N} / \mathrm{a}$ & $\mathrm{N} / \mathrm{a}$ \\
\hline
\end{tabular}

Table 4.31: 6-hour wind speed increase model for Hurricane Ivan. 


\subsubsection{Hurricane Jeanne (2004)}

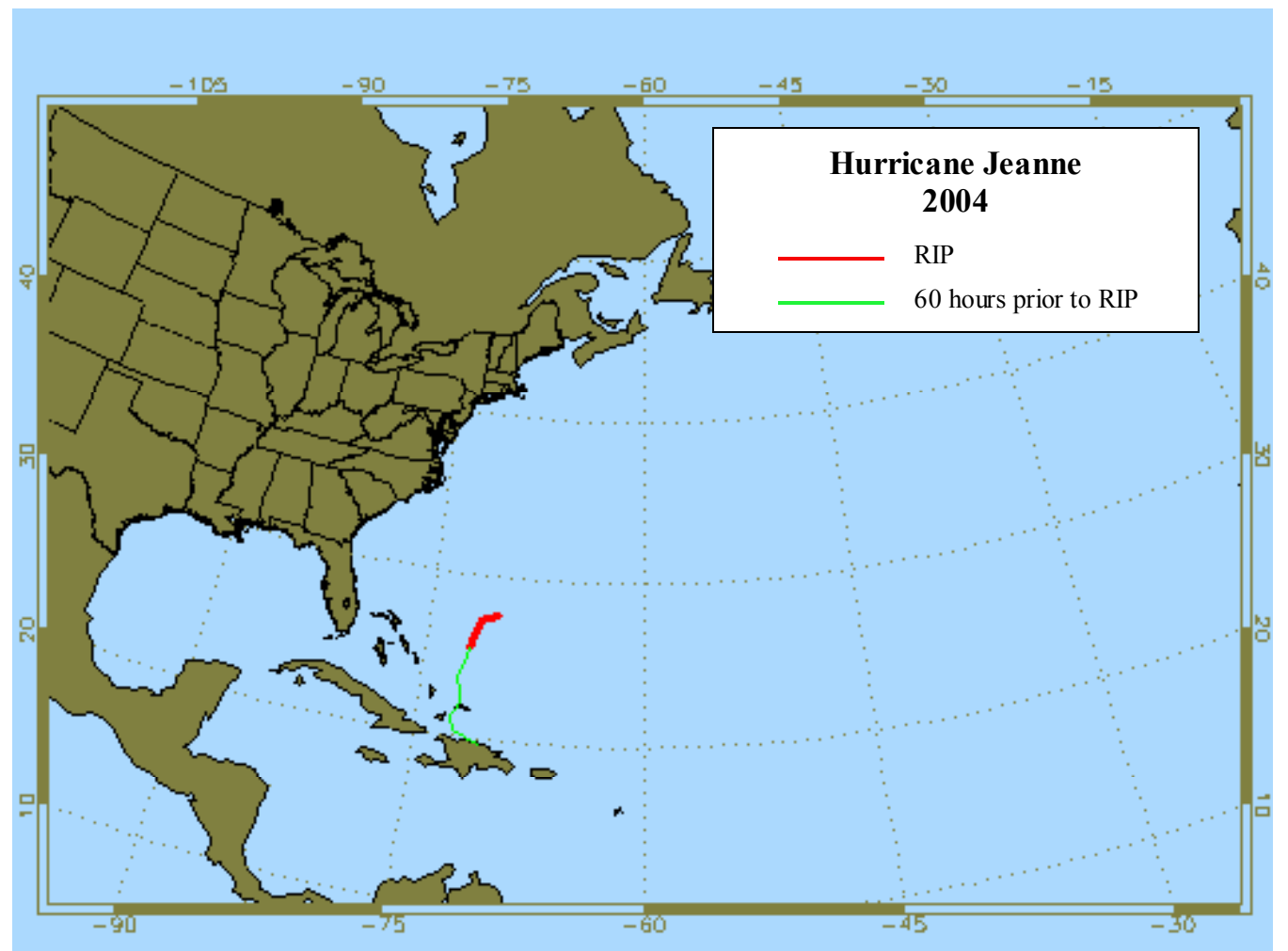

Figure 4.7: Track of Hurricane Jeanne (2004).

The study for Hurricane Jeanne began at $12 \mathrm{Z}$ on September 17 when it was passing over the rugged terrain of Hispaniola. The pressure was rising and the winds weakened to the point that Jeanne was reclassified as a tropical depression when it reentered the Atlantic at $0 \mathrm{Z}$ September 18. Jeanne continued in this weakened state as the center moved slowly westward until the original center of circulation dissipated and a new center developed to the northeast. This allowed for Jeanne to slowly move toward the northeast over the next four days and intensify into a hurricane by the end of the RIP. 
Jeanne would eventually form into a major hurricane as a strong ridge developed on the eastern U.S. coast causing Jeanne to circle in an anticyclonic loop toward Florida.

The DFA correctly classified 15 out of 16 time intervals as becoming a major hurricane. The lone exception was Time Interval 4, which mistakenly classified Jeanne as remaining as a minor hurricane. At the end of Time Interval 4, Jeanne had just undergone an overall rise in the central pressure of $10 \mathrm{hPa}$ over an 18 hour period. The maximum sustained winds had also weakened by 15 knots in 12 hours leading up to Time Interval 4. Therefore, the weakening that took place after Jeanne passed over Hispaniola caused the DFA to predict it would remain as a minor hurricane. However, the DFA quickly recognized the strong thermodynamic features in the Atlantic that would cause Jeanne to attain major status, and predicted it to become a major hurricane for the remainder of the time intervals. The DFA time interval classification was able to correctly classify 6 out of the 16 time intervals. Most of the misclassifications occurred from Time Interval 8-16 because the central pressure still remained relatively high and the DFA did not predict Jeanne was very close to the RIP. In fact, the DFA did not select Model 4 to be used at all meaning it did not recognize that the RIP had occurred yet. Compared to other major hurricanes, Jeanne had a modest RIP of only $20 \mathrm{hPa}$ over a 24 hour period, which is likely why the DFA did not select Model 4.

The 24-hour pressure model (Table 4.32) struggled with the prediction of the early time intervals (Time Intervals 1-4) because Jeanne had passed over Hispaniola and the models do not factor interaction with land. Even though Time Intervals 1-3 were not misclassified they predicted a slight deepening in the pressure when the 24-hour observed 


\begin{tabular}{|c|c|c|c|c|c|c|c|c|}
\hline $\begin{array}{l}\text { Date } \\
(2004)\end{array}$ & $\begin{array}{c}\text { Time } \\
\text { Interval }\end{array}$ & Model & $\begin{array}{c}\text { Central } \\
\text { Pressure } \\
(\mathrm{hPa})\end{array}$ & $\begin{array}{c}\text { 24-hour } \\
\text { Obs. }\end{array}$ & $\begin{array}{c}\text { 24-hour } \\
\text { Press } \\
\text { Model } \\
\text { (hPa) }\end{array}$ & $\%$ error & $\begin{array}{c}\text { Correct } \\
\text { Selected } \\
\text { Model } \\
(\mathrm{hPa})\end{array}$ & $\begin{array}{c}\text { Improv. } \\
\text { (hPa) }\end{array}$ \\
\hline $9 / 1712 Z$ & 1 & 1 & 990 & -10 & $\overline{5.45}$ & 154.5 & $\mathrm{~N} / \mathrm{a}$ & $\mathrm{N} / \mathrm{a}$ \\
\hline $9 / 1718 \mathrm{Z}$ & 2 & 1 & 1002 & -3 & 6.39 & 313.1 & $\mathrm{~N} / \mathrm{a}$ & $\mathrm{N} / \mathrm{a}$ \\
\hline $9 / 180 Z$ & 3 & 1 & 1000 & -2 & 4.69 & 334.7 & $\mathrm{~N} / \mathrm{a}$ & $\mathrm{N} / \mathrm{a}$ \\
\hline $9 / 186 Z$ & 4 & 7 & 1000 & -2 & 13.73 & 786.9 & 4.24 & 9.49 \\
\hline $9 / 1812 Z$ & 5 & 2 & 1000 & 0 & 11.42 & $\mathrm{~N} / \mathrm{a}$ & $\mathrm{N} / \mathrm{a}$ & $\mathrm{N} / \mathrm{a}$ \\
\hline $9 / 1818 Z$ & 6 & 1 & 1005 & 9 & 5.00 & 44.4 & 8.11 & 3.01 \\
\hline $9 / 190 Z$ & 7 & 2 & 1002 & 8 & 9.12 & 14.1 & $\mathrm{~N} / \mathrm{a}$ & $\mathrm{N} / \mathrm{a}$ \\
\hline $9 / 196 Z$ & 8 & 1 & 1002 & 10 & 5.27 & 47.2 & 9.87 & 4.60 \\
\hline $9 / 1912 Z$ & 9 & 2 & 1000 & 11 & 8.97 & 18.4 & 13.83 & -0.80 \\
\hline $9 / 1918 \mathrm{Z}$ & 10 & 2 & 996 & 12 & 8.99 & 25.1 & 15.01 & 0.00 \\
\hline $9 / 200 \mathrm{Z}$ & 11 & 3 & 994 & 12 & 16.79 & 40.0 & $\mathrm{~N} / \mathrm{a}$ & $\mathrm{N} / \mathrm{a}$ \\
\hline $9 / 206 \mathrm{Z}$ & 12 & 2 & 992 & 20 & 8.80 & 56.0 & 16.09 & 7.29 \\
\hline $9 / 2012 Z$ & 13 & 3 & 989 & 17 & 16.70 & 1.8 & 19.25 & -1.95 \\
\hline $9 / 2018 Z$ & 14 & 3 & 984 & 12 & 19.62 & 63.5 & 22.77 & -3.15 \\
\hline $9 / 210 Z$ & 15 & 3 & 982 & 10 & 17.72 & 77.3 & 23.41 & -5.69 \\
\hline $9 / 216 Z$ & 16 & 2 & 972 & 4 & 5.12 & 28.2 & 15.06 & -9.94 \\
\hline
\end{tabular}

Table 4.32: 24-hour pressure drop model for Hurricane Jeanne. 
pressure increased. Time Interval 4 had a large error because of the severe misclassification using a minor hurricane model (Model 7) but had the CSM been used (Model 1) it would have been closer to the observations. From Time Interval 6-16, all were misclassified with the exceptions of Time Intervals 7 and 11. Even with the misclassifications, all of these intervals had relatively low percentage errors, but the CSM was able to provide some improvement. For example, during Time Intervals 6 and 8 the CSM (Model 2) was able to improve upon the selected model (Model 1) because it factored the high SSTs and the low MPI which Model 1 does not. This allowed the CSM to predict more intensification. During Time Intervals 9 and 10, the CSM (Model 3) provided little improvement over the selected model (Model 2) but during Time Interval 12, the CSM was able to provide substantial improvement. At this interval the wind speed, which was factored by Model 3, was higher allowing it to predict more deepening. From Time Interval 13-16, the CSM (Model 4) did not improve on the selected model because Model 4 considered the Heat Potential much more than Model 3 and it therefore had a tendency to overestimate the amount of deepening.

The 24-hour wind speed increase model (Table 4.33) exhibited higher percentage errors than usual and produced poorer results for Jeanne. The DFA selected model was only able to predict 5 of the 16 time intervals better than the official NHC forecasts. Time Intervals 1-4 were all predicted better by the NHC because the models did not factor the recent land interaction. However, from Time Interval 5-11, the DFA selected model better predicted the wind speed on 5 of the 7 intervals. Had the CSM (Model 2) been used during Time Interval 8 , it would have improved on an additional time interval. 


\begin{tabular}{|c|c|c|c|c|c|c|c|c|c|}
\hline $\begin{array}{c}\text { Time } \\
\text { Int. }\end{array}$ & Model & $\begin{array}{l}\text { Max. } \\
\text { Sus. } \\
\text { Wind } \\
\text { (kts) }\end{array}$ & $\begin{array}{c}\text { 24-hour } \\
\text { Obs. }\end{array}$ & $\begin{array}{c}\text { 24-hour } \\
\text { Model } \\
\text { (kts) }\end{array}$ & $\%$ error & $\begin{array}{c}\text { NHC } \\
24 \text { hour } \\
\text { For. }\end{array}$ & $\begin{array}{c}\text { NHC } \\
\% \\
\text { error }\end{array}$ & $\begin{array}{l}\text { CSM } \\
\text { (kts) }\end{array}$ & $\begin{array}{c}\text { Improv. } \\
\text { (kts) }\end{array}$ \\
\hline 1 & 1 & 50 & -5 & 8.76 & 275.2 & 5 & 200 & $\mathrm{~N} / \mathrm{a}$ & $\mathrm{N} / \mathrm{a}$ \\
\hline 2 & 1 & 60 & 10 & -2.98 & 129.9 & 15 & 50.0 & N/a & N/a \\
\hline 3 & 1 & 40 & 0 & 12.42 & $\mathrm{~N} / \mathrm{a}$ & 0 & $\mathrm{~N} / \mathrm{a}$ & $\mathrm{N} / \mathrm{a}$ & $\mathrm{N} / \mathrm{a}$ \\
\hline 4 & 7 & 45 & -5 & 19.31 & 486.3 & 5 & 200 & 9.76 & 9.55 \\
\hline 5 & 2 & 45 & -5 & 13.65 & 373.1 & 15 & 400 & $\mathrm{~N} / \mathrm{a}$ & N/a \\
\hline 6 & 1 & 40 & 5 & 5.88 & 17.8 & 0 & 100 & 14.45 & -8.57 \\
\hline 7 & 2 & 40 & 10 & 16.38 & 63.8 & 5 & 50.0 & N/a & $\mathrm{N} / \mathrm{a}$ \\
\hline 8 & 1 & 40 & 15 & 8.98 & 40.1 & 10 & 33.3 & 14.60 & 5.62 \\
\hline 9 & 2 & 40 & 20 & 16.85 & 15.7 & 10 & 50.0 & 28.05 & -4.90 \\
\hline 10 & 2 & 45 & 30 & 14.62 & 51.2 & 10 & 66.7 & 26.96 & 12.34 \\
\hline 11 & 3 & 50 & 25 & 27.79 & 11.2 & 10 & 60.0 & N/a & $\mathrm{N} / \mathrm{a}$ \\
\hline 12 & 2 & 55 & 20 & 6.11 & 69.4 & 10 & 50.0 & 25.69 & 8.20 \\
\hline 13 & 3 & 60 & 15 & 24.24 & 61.6 & 10 & 33.3 & 22.91 & 0.33 \\
\hline 14 & 3 & 75 & 0 & 23.72 & N/a & 10 & $\mathrm{~N} / \mathrm{a}$ & 21.98 & 1.74 \\
\hline 15 & 3 & 75 & 5 & 21.31 & 323.3 & 5 & 0.0 & 24.36 & -3.05 \\
\hline 16 & 2 & 75 & 10 & -12.68 & 226.8 & 0 & 100 & 24.73 & 7.95 \\
\hline
\end{tabular}

Table 4.33: 24-hour wind speed increase model for Hurricane Jeanne. 
Model 2, since it considered the very low wind shear (less than $4 \mathrm{~m} \mathrm{~s}^{-1}$ ), was able to forecast moderate intensification. Model 3 was able to forecast the intensification even better, as seen in Time Interval 11 and the CSM in Time Interval 10 and 12, because Jeanne exhibited a low MPI (below $900 \mathrm{hPa}$ ). The final four time intervals (13-16) were forecasted better by the NHC, primarily because neither the DFA selected model nor the CSM in these cases factored the high $850-200 \mathrm{hPa}$ wind shear (more than $13 \mathrm{~m} \mathrm{~s}^{-1}$ ). Therefore the models (Models 3 and 4) overestimated the wind speed increase during Time Intervals 13-15 and Model 2 underestimated the increase during Time Interval 16.

The 6-hour pressure model (Table 4.34) struggled during similar time periods as seen in Time Intervals 1-5. However, from Time Interval 6-16, the selected DFA model was able to predict the pressure reduction respectably with the exception of Time Interval 15. The CSM during the majority of these intervals provided little or no improvement due to the minimal 6-hour pressure reduction. The CSM (Model 4) did provide improvement to the poorly predicted Time Interval 15 but did not in Time Interval 16 since it considered more significant variables such as the $850-100 \mathrm{hPa}$ wind shear. The 850-100 shear was low during Time Interval 15 which caused a short-term pressure drop but during Time Interval 16 the shear increased sharply causing the pressure to stabilize.

With the 6-hour wind speed model (Table 4.35), again Time Intervals 1-5 were poor due to landfall interaction. But the rest of the study did exhibit low percentage errors primarily because of the modest increase in short term wind speeds. The CSM (Model 4) was able to provide improvement to the time interval that did show rapid intensification (Time Interval 13) since Model 4 factored in the wind speed of the system (60 knots) whereas Model 3 does not. The DFA selected model (Model 3) also predicted 


\begin{tabular}{|c|c|c|c|c|c|c|c|c|}
\hline Date & $\begin{array}{l}\text { Time } \\
\text { Int. }\end{array}$ & Model & $\begin{array}{c}\text { Cent. } \\
\text { Pressure } \\
(\mathrm{hPa})\end{array}$ & $\begin{array}{l}\text { 6-hour Pres. } \\
\text { Drop Obs. }\end{array}$ & $\begin{array}{c}\text { 6-hour } \\
\text { Model } \\
\text { (hPa) }\end{array}$ & $\begin{array}{l}\% \\
\text { error }\end{array}$ & $\begin{array}{l}\text { CSM } \\
\text { (hPa) }\end{array}$ & $\begin{array}{c}\text { Improv. } \\
(\mathrm{hPa})\end{array}$ \\
\hline $9 / 1712 \mathrm{Z}$ & 1 & 1 & 990 & -12 & 1.83 & 115.3 & $\mathrm{~N} / \mathrm{a}$ & $\mathrm{N} / \mathrm{a}$ \\
\hline 9/17 18Z & 2 & 1 & 1002 & 2 & -0.80 & 140.0 & $\mathrm{~N} / \mathrm{a}$ & $\mathrm{N} / \mathrm{a}$ \\
\hline $9 / 180 Z$ & 3 & 1 & 1000 & 0 & 2.80 & $\mathrm{~N} / \mathrm{a}$ & $\mathrm{N} / \mathrm{a}$ & $\mathrm{N} / \mathrm{a}$ \\
\hline $9 / 186 \mathrm{Z}$ & 4 & 7 & 1000 & 0 & 2.24 & $\mathrm{~N} / \mathrm{a}$ & 2.20 & 0.04 \\
\hline $9 / 1812 Z$ & 5 & 2 & 1000 & -5 & 1.53 & 130.6 & $\mathrm{~N} / \mathrm{a}$ & N/a \\
\hline $9 / 1818 Z$ & 6 & 1 & 1005 & 3 & 0.86 & 71.1 & 0.42 & -0.44 \\
\hline $9 / 190 Z$ & 7 & 2 & 1002 & 0 & 1.53 & $\mathrm{~N} / \mathrm{a}$ & $\mathrm{N} / \mathrm{a}$ & N/a \\
\hline $9 / 196 Z$ & 8 & 1 & 1002 & 2 & 1.56 & 21.9 & 1.53 & -0.03 \\
\hline $9 / 1912 Z$ & 9 & 2 & 1000 & 4 & 1.53 & 61.7 & 2.10 & 0.57 \\
\hline 9/19 18Z & 10 & 2 & 996 & 2 & 2.63 & 31.8 & 3.10 & -0.47 \\
\hline $9 / 200 \mathrm{Z}$ & 11 & 3 & 994 & 2 & 3.10 & 55.0 & $\mathrm{~N} / \mathrm{a}$ & $\mathrm{N} / \mathrm{a}$ \\
\hline $9 / 206 Z$ & 12 & 2 & 992 & 3 & 2.63 & 12.1 & 3.04 & 0.33 \\
\hline $9 / 2012 Z$ & 13 & 3 & 989 & 5 & 3.04 & 39.1 & 6.58 & 0.38 \\
\hline $9 / 2018 Z$ & 14 & 3 & 984 & 2 & 4.93 & 146.8 & 6.74 & -1.81 \\
\hline $9 / 210 Z$ & 15 & 3 & 982 & 10 & 2.13 & 78.6 & 6.06 & 3.93 \\
\hline $9 / 216 Z$ & 16 & 2 & 972 & 0 & 1.53 & $\mathrm{~N} / \mathrm{a}$ & 8.55 & -7.02 \\
\hline
\end{tabular}

Table 4.34: 6-hour pressure drop model for Hurricane Jeanne. 


\begin{tabular}{|c|c|c|c|c|c|c|c|c|}
\hline Date & $\begin{array}{l}\text { Time } \\
\text { Int. }\end{array}$ & Model & $\begin{array}{l}\text { Max. Sus. } \\
\text { Winds (kts) }\end{array}$ & $\begin{array}{c}\text { 6-hour } \\
\text { Wind } \\
\text { Speed Obs. }\end{array}$ & $\begin{array}{c}\text { 6-hour } \\
\text { Model } \\
\text { (kts) }\end{array}$ & $\%$ error & $\begin{array}{l}\text { CSM } \\
\text { (kts) }\end{array}$ & $\begin{array}{c}\text { Improv. } \\
\text { (kts) }\end{array}$ \\
\hline $9 / 1712 Z$ & 1 & 1 & 50 & -20 & 1.12 & 105.6 & $\mathrm{~N} / \mathrm{a}$ & $\mathrm{N} / \mathrm{a}$ \\
\hline $9 / 1718 \mathrm{Z}$ & 2 & 1 & 30 & 10 & -7.72 & 177.3 & $\mathrm{~N} / \mathrm{a}$ & $\mathrm{N} / \mathrm{a}$ \\
\hline $9 / 180 Z$ & 3 & 1 & 40 & 5 & 5.80 & 16.1 & $\mathrm{~N} / \mathrm{a}$ & $\mathrm{N} / \mathrm{a}$ \\
\hline $9 / 186 Z$ & 4 & 7 & 45 & 0 & 4.19 & $\mathrm{~N} / \mathrm{a}$ & 3.32 & 0.87 \\
\hline $9 / 1812 Z$ & 5 & 2 & 45 & -5 & 3.38 & 167.7 & $\mathrm{~N} / \mathrm{a}$ & N/a \\
\hline $9 / 1818 \mathrm{Z}$ & 6 & 1 & 40 & 0 & -1.10 & $\mathrm{~N} / \mathrm{a}$ & 2.33 & -1.23 \\
\hline $9 / 190 Z$ & 7 & 2 & 40 & 0 & 3.43 & $\mathrm{~N} / \mathrm{a}$ & $\mathrm{N} / \mathrm{a}$ & N/a \\
\hline $9 / 196 Z$ & 8 & 1 & 40 & 0 & 1.08 & $\mathrm{~N} / \mathrm{a}$ & 3.39 & -2.31 \\
\hline $9 / 1912 Z$ & 9 & 2 & 40 & 5 & 3.44 & 31.1 & 4.42 & 0.98 \\
\hline $9 / 1918 \mathrm{Z}$ & 10 & 2 & 45 & 5 & 4.41 & 11.7 & 5.66 & -0.07 \\
\hline $9 / 200 \mathrm{Z}$ & 11 & 3 & 50 & 5 & 5.96 & 19.2 & $\mathrm{~N} / \mathrm{a}$ & N/a \\
\hline $9 / 206 \mathrm{Z}$ & 12 & 2 & 55 & 5 & 3.80 & 23.9 & 5.55 & 0.65 \\
\hline $9 / 2012 Z$ & 13 & 3 & 60 & 15 & 5.49 & 63.4 & 9.25 & 3.76 \\
\hline $9 / 2018 \mathrm{Z}$ & 14 & 3 & 75 & 0 & 7.81 & N/a & 7.87 & -0.06 \\
\hline $9 / 210 Z$ & 15 & 3 & 75 & 0 & 3.77 & $\mathrm{~N} / \mathrm{a}$ & 6.92 & -3.15 \\
\hline $9 / 216 Z$ & 16 & 2 & 75 & 0 & 2.46 & $\mathrm{~N} / \mathrm{a}$ & 6.61 & -4.15 \\
\hline
\end{tabular}

Table 4.35: 6-hour wind speed increase model for Hurricane Jeanne. 
less intensification during Time Intervals 15 and 16 since it factored the previous 6-hour wind speed change whereas Model 4 does not. Therefore, the selected model predicted less intensification than the CSM because there was no previous 6-hour wind speed change.

\subsubsection{Hurricane Karl (2004)}

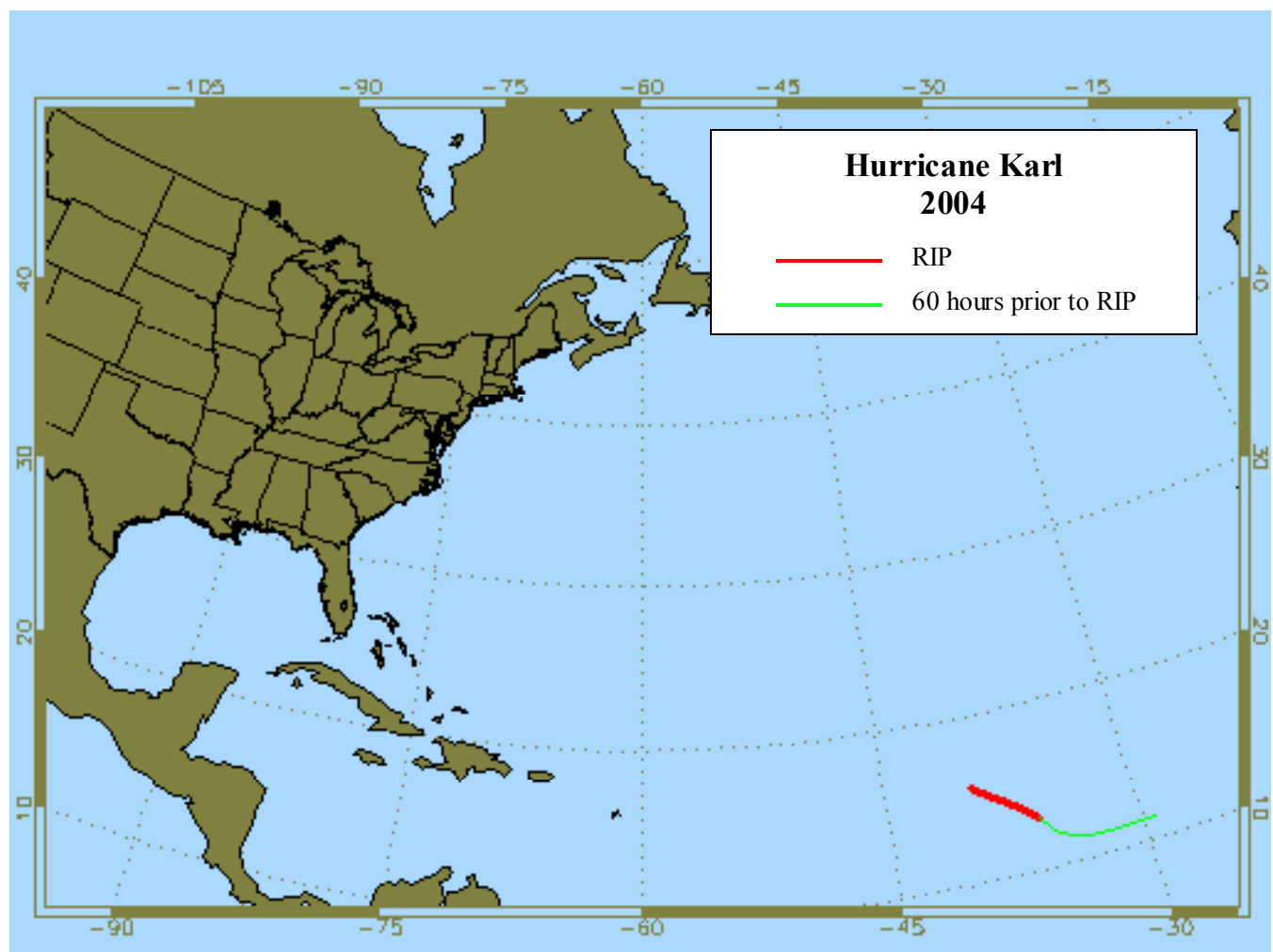

Figure 4.8: Track of Hurricane Karl (2004).

The period of study for Karl began very early in its life cycle on September 14 when it was a weak tropical depression 300 miles southwest of the Cape Verde Islands. 
Karl moved westward to the south of a subtropical ridge and became a tropical storm by $18 \mathrm{Z}$ on September 16. When it became a tropical storm, Karl started to turn toward the northwest and began the RIP at $18 \mathrm{Z}$ September 17. Rapidly, it became a hurricane and was almost Category 3 strength at the end of the RIP at $18 \mathrm{Z}$ September 18. Karl would continue to intensify and quickly attain Category 4 strength after the RIP before eventually traveling into the North Atlantic Ocean.

All 16 time intervals were correctly classified by the DFA as ultimately becoming a major hurricane. Karl exhibited low $850-200 \mathrm{hPa}$ wind shear below $6 \mathrm{~m} \mathrm{~s}^{-1}$ and increasing heat potential through the duration of the track study thereby demonstrating some of the key characteristics of major hurricanes. The DFA was able to classify 11 out of the 16 time intervals correctly only misclassifying Time Intervals 5-9. It retained using Model 1 through Time Interval 8 because the central pressure remained stationary through Time Interval 6 and the pressure was also relatively high at $1005 \mathrm{hPa}$ for Time Interval 8. The DFA did misclassify Time Interval 9 as well because of the tendency to predict gradual transitions into subsequent models.

Table 4.36 shows the 24-hour pressure drop model results which overall had low percentage errors. All time intervals with the exception of Time Interval 3 had a percentage error lower than $68.1 \%$. Time Interval 3 had a relatively high error because the observed value was only $1 \mathrm{hPa}$. Even the misclassified time intervals (Time Intervals 5-9) exhibited fairly low errors but all of these intervals could have been improved by using the CSM. In the cases of Time Intervals 5-8, using the CSM (Model 2) would have predicted larger 24-hour pressure drop values which were closer to the observed 


\begin{tabular}{|c|c|c|c|c|c|c|c|c|}
\hline $\begin{array}{l}\text { Date } \\
\text { (2004) }\end{array}$ & $\begin{array}{c}\text { Time } \\
\text { Interval }\end{array}$ & Model & $\begin{array}{c}\text { Central } \\
\text { Pressure } \\
(\mathrm{hPa})\end{array}$ & $\begin{array}{c}\text { 24-hour } \\
\text { Obs. }\end{array}$ & $\begin{array}{c}\text { 24-hour } \\
\text { Press } \\
\text { Model } \\
\text { (hPa) }\end{array}$ & $\%$ error & $\begin{array}{c}\text { Correct } \\
\text { Selected } \\
\text { Model } \\
(\mathrm{hPa})\end{array}$ & $\begin{array}{c}\text { Change } \\
\text { (hPa) }\end{array}$ \\
\hline $9 / 150 Z$ & 1 & 1 & 1008 & 0 & 1.42 & $\mathrm{~N} / \mathrm{a}$ & $\mathrm{N} / \mathrm{a}$ & $\mathrm{N} / \mathrm{a}$ \\
\hline $9 / 156 Z$ & 2 & 1 & 1008 & 0 & 2.93 & $\mathrm{~N} / \mathrm{a}$ & $\mathrm{N} / \mathrm{a}$ & $\mathrm{N} / \mathrm{a}$ \\
\hline $9 / 1512 Z$ & 3 & 1 & 1008 & 1 & 1.99 & 99.7 & $\mathrm{~N} / \mathrm{a}$ & $\mathrm{N} / \mathrm{a}$ \\
\hline $9 / 1518 \mathrm{Z}$ & 4 & 1 & 1008 & 3 & 3.01 & 0.5 & $\mathrm{~N} / \mathrm{a}$ & $\mathrm{N} / \mathrm{a}$ \\
\hline $9 / 160 Z$ & 5 & 1 & 1008 & 6 & 2.32 & 61.2 & 8.73 & 0.95 \\
\hline $9 / 166 Z$ & 6 & 1 & 1008 & 11 & 3.50 & 68.1 & 8.93 & 5.43 \\
\hline $9 / 1612 Z$ & 7 & 1 & 1007 & 13 & 6.69 & 48.5 & 9.26 & 2.57 \\
\hline $9 / 1618 Z$ & 8 & 1 & 1005 & 13 & 8.23 & 36.6 & 9.62 & 1.39 \\
\hline $9 / 170 Z$ & 9 & 2 & 1002 & 18 & 9.28 & 48.4 & 17.5 & 8.22 \\
\hline $9 / 176 Z$ & 10 & 3 & 997 & 22 & 20.07 & 8.7 & $\mathrm{~N} / \mathrm{a}$ & $\mathrm{N} / \mathrm{a}$ \\
\hline $9 / 1712 Z$ & 11 & 3 & 994 & 24 & 19.96 & 16.8 & $\mathrm{~N} / \mathrm{a}$ & $\mathrm{N} / \mathrm{a}$ \\
\hline $9 / 1718 \mathrm{Z}$ & 12 & 3 & 992 & 27 & 19.83 & 26.5 & $\mathrm{~N} / \mathrm{a}$ & $\mathrm{N} / \mathrm{a}$ \\
\hline $9 / 180 Z$ & 13 & 4 & 984 & 19 & 22.90 & 20.5 & $\mathrm{~N} / \mathrm{a}$ & $\mathrm{N} / \mathrm{a}$ \\
\hline $9 / 186 Z$ & 14 & 4 & 975 & 15 & 22.88 & 52.5 & $\mathrm{~N} / \mathrm{a}$ & $\mathrm{N} / \mathrm{a}$ \\
\hline $9 / 1812 Z$ & 15 & 4 & 970 & 15 & 22.34 & 49.0 & $\mathrm{~N} / \mathrm{a}$ & $\mathrm{N} / \mathrm{a}$ \\
\hline $9 / 1818 Z$ & 16 & 4 & 965 & 14 & 19.01 & 35.8 & $\mathrm{~N} / \mathrm{a}$ & $\mathrm{N} / \mathrm{a}$ \\
\hline
\end{tabular}

Table 4.36: 24-hour pressure drop model for Hurricane Karl. 
measurements. Again, the central pressure for Karl was relatively high at this point, which was primarily the reason why the DFA selected Model 1. From Time Intervals 1016 , the DFA selected the correct models to be used and the relatively low errors show that they were able to capture the rapid intensification particularly at the onset of the RIP.

The 24-hour wind speed model (Table 4.37) also produced low percentage errors throughout the duration of the study, however, the NHC did not start issuing forecasts until Time Interval 8. Of the 9 available time intervals, the model was able to outperform the NHC forecasts on only 4 time intervals (Time Intervals 10-13). The CSM would have provided improvement during Time Interval 9 thereby improving an additional interval ( 5 out of the 9 possible time intervals). It is important to note the model performed the best when Karl was starting to rapidly intensify. Model 3 was able to capture the low MPI (below $900 \mathrm{hPa}$ ) and forecast 24-hour wind speed increases in excess of 30 knots. During this same time, the NHC underestimated the intensification by 15-20 knots. Toward the end of the RIP (Time Intervals 14-16), Model 4 tended to overestimate the amount of intensification. It considered the heat potential but it failed to consider the 850-200 $\mathrm{hPa}$ wind shear that was starting to increase, causing the amount of intensification to lessen.

The 6-hour pressure drop model (Table 4.38) also had low percentage errors for all intervals (below 50\%) with the exception of Time Interval 12. The short-term pressure reductions were modest leading up to the RIP making it easier for the model to forecast even with the misclassifications during Time Intervals 5-9. The CSM did not provide any significant improvement during these intervals. The highest error occurred during Time Interval 12 because there was no previous 6-hour wind speed change. Since 


\begin{tabular}{|c|c|c|c|c|c|c|c|c|c|}
\hline $\begin{array}{c}\text { Time } \\
\text { Int. }\end{array}$ & Model & $\begin{array}{l}\text { Max. } \\
\text { Sus. } \\
\text { Wind } \\
\text { (kts) }\end{array}$ & $\begin{array}{c}\text { 24-hour } \\
\text { Obs. }\end{array}$ & $\begin{array}{c}\text { 24-hour } \\
\text { Model } \\
\text { (kts) }\end{array}$ & $\%$ error & $\begin{array}{c}\text { NHC } \\
24 \text { hour } \\
\text { For. }\end{array}$ & $\begin{array}{c}\text { NHC } \\
\% \\
\text { error }\end{array}$ & $\begin{array}{l}\text { CSM } \\
\text { (kts) }\end{array}$ & $\begin{array}{c}\text { Improv. } \\
\text { (kts) }\end{array}$ \\
\hline 1 & 1 & 30 & 0 & 5.43 & $\mathrm{~N} / \mathrm{a}$ & $\mathrm{N} / \mathrm{a}$ & $\mathrm{N} / \mathrm{a}$ & $\mathrm{N} / \mathrm{a}$ & $\mathrm{N} / \mathrm{a}$ \\
\hline 2 & 1 & 30 & 0 & 6.46 & $\mathrm{~N} / \mathrm{a}$ & N/a & $\mathrm{N} / \mathrm{a}$ & N/a & N/a \\
\hline 3 & 1 & 30 & 0 & 5.77 & N/a & N/a & $\mathrm{N} / \mathrm{a}$ & N/a & $\mathrm{N} / \mathrm{a}$ \\
\hline 4 & 1 & 30 & 5 & 5.96 & 19.3 & $\mathrm{~N} / \mathrm{a}$ & $\mathrm{N} / \mathrm{a}$ & N/a & N/a \\
\hline 5 & 1 & 30 & 10 & 5.98 & 40.1 & $\mathrm{~N} / \mathrm{a}$ & $\mathrm{N} / \mathrm{a}$ & 15.35 & $\begin{array}{l}-1.33 \\
\end{array}$ \\
\hline 6 & 1 & 30 & 20 & 6.89 & 65.5 & N/a & $\mathrm{N} / \mathrm{a}$ & 17.13 & 10.24 \\
\hline 7 & 1 & 30 & 25 & 9.59 & 61.6 & N/a & $\mathrm{N} / \mathrm{a}$ & 17.27 & 7.68 \\
\hline 8 & 1 & 35 & 20 & 12.59 & 37.0 & 20 & 0.0 & 15.24 & 2.65 \\
\hline 9 & 2 & 40 & 30 & 13.09 & 56.3 & 20 & 33.3 & 31.16 & 15.75 \\
\hline 10 & 3 & 50 & 35 & 32.92 & 5.9 & 20 & 42.9 & $\mathrm{~N} / \mathrm{a}$ & $\mathrm{N} / \mathrm{a}$ \\
\hline 11 & 3 & 55 & 35 & 30.19 & 13.7 & 20 & 42.9 & N/a & $\mathrm{N} / \mathrm{a}$ \\
\hline 12 & 3 & 55 & 40 & 30.19 & 24.5 & 20 & 50.0 & $\mathrm{~N} / \mathrm{a}$ & $\mathrm{N} / \mathrm{a}$ \\
\hline 13 & 4 & 70 & 25 & 32.78 & 31.1 & 15 & 40.0 & N/a & N/a \\
\hline 14 & 4 & 85 & 15 & 26.38 & 75.9 & 25 & 66.7 & N/a & N/a \\
\hline 15 & 4 & 90 & 15 & 28.09 & 87.3 & 20 & 33.3 & N/a & N/a \\
\hline 16 & 4 & 95 & 15 & 21.95 & 46.4 & 15 & 0.0 & N/a & $\mathrm{N} / \mathrm{a}$ \\
\hline
\end{tabular}

Table 4.37: 24-hour wind speed increase model for Hurricane Karl. 


\begin{tabular}{|c|c|c|c|c|c|c|c|c|}
\hline Date & Time & Model & $\begin{array}{c}\text { Cent. } \\
\text { Int. }\end{array}$ & $\begin{array}{c}\text { 6-hour Pres. } \\
\text { (hPa) }\end{array}$ & $\begin{array}{c}\mathbf{6} \text {-hour } \\
\text { Drop Obs. }\end{array}$ & $\begin{array}{c}\text { Model } \\
\text { (hPa) }\end{array}$ & $\begin{array}{c}\text { CSM } \\
\text { error }\end{array}$ & $\begin{array}{c}\text { Improv. } \\
\text { (hPa) }\end{array}$ \\
\hline $9 / 150 Z$ & 1 & 1 & 1008 & 0 & $\mathbf{0 . 2 6}$ & N/a & N/a & N/a \\
\hline $9 / 156 Z$ & 2 & 1 & 1008 & 0 & $\mathbf{0 . 5 8}$ & N/a & N/a & N/a \\
\hline $9 / 1512 Z$ & 3 & 1 & 1008 & 0 & $\mathbf{0 . 3 8}$ & N/a & N/a & N/a \\
\hline $9 / 1518 Z$ & 4 & 1 & 1008 & 0 & $\mathbf{0 . 5 9}$ & N/a & N/a & N/a \\
\hline $9 / 160 Z$ & 5 & 1 & 1008 & 0 & $\mathbf{0 . 4 5}$ & N/a & 1.53 & -1.08 \\
\hline $9 / 166 Z$ & 6 & 1 & 1008 & 1 & $\mathbf{0 . 7 0}$ & 30.0 & 1.53 & -0.23 \\
\hline $9 / 1612 Z$ & 7 & 1 & 1007 & 2 & $\mathbf{1 . 9 9}$ & 0.2 & 1.53 & -0.52 \\
\hline $9 / 1618 Z$ & 8 & 1 & 1005 & 3 & $\mathbf{2 . 9 5}$ & 1.4 & 2.63 & -0.42 \\
\hline $9 / 170 Z$ & 9 & 2 & 1002 & 5 & $\mathbf{2 . 6 3}$ & 47.3 & 3.08 & 0.45 \\
\hline $9 / 176 Z$ & 10 & 3 & 997 & 3 & $\mathbf{3 . 9 6}$ & 32.1 & N/a & N/a \\
\hline $9 / 1712 Z$ & 11 & 3 & 994 & 2 & $\mathbf{6 . 0 8}$ & 54.1 & N/a & N/a \\
\hline $9 / 1718 Z$ & 12 & 3 & 992 & 8 & $\mathbf{2 . 2 0}$ & 72.5 & N/a & N/a \\
\hline $9 / 180 Z$ & 13 & 4 & 984 & 9 & $\mathbf{7 . 4 4}$ & 17.3 & N/a & N/a \\
\hline $9 / 186 Z$ & 14 & 4 & 975 & 5 & $\mathbf{7 . 0 2}$ & 40.5 & N/a & N/a \\
\hline $9 / 1812 Z$ & 15 & 4 & 970 & 5 & $\mathbf{7 . 3 6}$ & 47.3 & N/a & N/a \\
\hline $9 / 1818 Z$ & 16 & 4 & 965 & 0 & $\mathbf{6 . 8 8}$ & N/a & N/a & N/a \\
\hline
\end{tabular}

Table 4.38: 6-hour pressure drop model for Hurricane Karl. 
Model 3 uses the previous 6-hour wind speed change as a significant variable, but it underestimated the amount the deepening at the onset of the RIP. Similar results appeared for the 6-hour wind speed model (Table 4.39) as the model predicted the shortterm wind speed increases well even with the misclassification during Time Intervals 5-9. This was mostly due to the modest increases leading up to the RIP. The CSM (Model 2) was able to provide slight improvement during Time Intervals 7 and 8 . Model 3 had trouble during Time Interval 12 (onset of the RIP) greatly underestimating the intensification. As with the 6-hour pressure drop model, Model 3 emphasizes the previous 6-hourly wind speed change, and there was none at this time interval. Model 4 seemed to capture the intensification much better as more significant variables are used, as was also evident in the 6-hour pressure drop model. 


\begin{tabular}{|c|c|c|c|c|c|c|c|c|}
\hline Date & $\begin{array}{l}\text { Time } \\
\text { Int. }\end{array}$ & Model & $\begin{array}{l}\text { Max. Sus. } \\
\text { Winds (kts) }\end{array}$ & $\begin{array}{c}\text { 6-hour } \\
\text { Wind } \\
\text { Speed Obs. }\end{array}$ & $\begin{array}{c}\text { 6-hour } \\
\text { Model } \\
\text { (kts) }\end{array}$ & $\%$ error & $\begin{array}{l}\text { CSM } \\
(\mathrm{kts})\end{array}$ & $\begin{array}{c}\text { Improv. } \\
\text { (kts) }\end{array}$ \\
\hline $9 / 150 Z$ & 1 & 1 & 30 & 0 & 1.36 & $\mathrm{~N} / \mathrm{a}$ & $\mathrm{N} / \mathrm{a}$ & $\mathrm{N} / \mathrm{a}$ \\
\hline $9 / 156 Z$ & 2 & 1 & 30 & 0 & 1.36 & $\mathrm{~N} / \mathrm{a}$ & $\mathrm{N} / \mathrm{a}$ & $\mathrm{N} / \mathrm{a}$ \\
\hline $9 / 1512 Z$ & 3 & 1 & 30 & 0 & 1.36 & $\mathrm{~N} / \mathrm{a}$ & $\mathrm{N} / \mathrm{a}$ & $\mathrm{N} / \mathrm{a}$ \\
\hline $9 / 1518 Z$ & 4 & 1 & 30 & 0 & 1.36 & $\mathrm{~N} / \mathrm{a}$ & $\mathrm{N} / \mathrm{a}$ & $\mathrm{N} / \mathrm{a}$ \\
\hline $9 / 160 Z$ & 5 & 1 & 30 & 0 & 1.36 & N/a & 1.74 & -0.38 \\
\hline $9 / 166 Z$ & 6 & 1 & 30 & 0 & 1.36 & $\mathrm{~N} / \mathrm{a}$ & 2.22 & -0.86 \\
\hline $9 / 1612 Z$ & 7 & 1 & 30 & 5 & 1.33 & 73.3 & 3.83 & 2.50 \\
\hline $9 / 1618 Z$ & 8 & 1 & 35 & 5 & 3.59 & 28.1 & 4.62 & 1.03 \\
\hline $9 / 170 Z$ & 9 & 2 & 40 & 10 & 6.02 & 39.7 & 4.99 & -1.03 \\
\hline $9 / 176 Z$ & 10 & 3 & 50 & 5 & 6.43 & 28.7 & $\mathrm{~N} / \mathrm{a}$ & $\mathrm{N} / \mathrm{a}$ \\
\hline $9 / 1712 Z$ & 11 & 3 & 55 & 0 & 4.92 & $\mathrm{~N} / \mathrm{a}$ & $\mathrm{N} / \mathrm{a}$ & $\mathrm{N} / \mathrm{a}$ \\
\hline $9 / 1718 \mathrm{Z}$ & 12 & 3 & 55 & 15 & 3.74 & 75.1 & $\mathrm{~N} / \mathrm{a}$ & $\mathrm{N} / \mathrm{a}$ \\
\hline $9 / 180 \mathrm{Z}$ & 13 & 4 & 70 & 15 & 11.36 & 24.3 & $\mathrm{~N} / \mathrm{a}$ & $\mathrm{N} / \mathrm{a}$ \\
\hline 9/18 6Z & 14 & 4 & 85 & 5 & 8.69 & 74.0 & $\mathrm{~N} / \mathrm{a}$ & $\mathrm{N} / \mathrm{a}$ \\
\hline $9 / 1812 Z$ & 15 & 4 & 90 & 5 & 7.88 & 57.6 & $\mathrm{~N} / \mathrm{a}$ & $\mathrm{N} / \mathrm{a}$ \\
\hline $9 / 1818 Z$ & 16 & 4 & 95 & 0 & 6.79 & $\mathrm{~N} / \mathrm{a}$ & $\mathrm{N} / \mathrm{a}$ & $\mathrm{N} / \mathrm{a}$ \\
\hline
\end{tabular}

Table 4.39: 6-hour wind speed increase model for Hurricane Karl. 


\subsubsection{Hurricane Lisa (2004)}

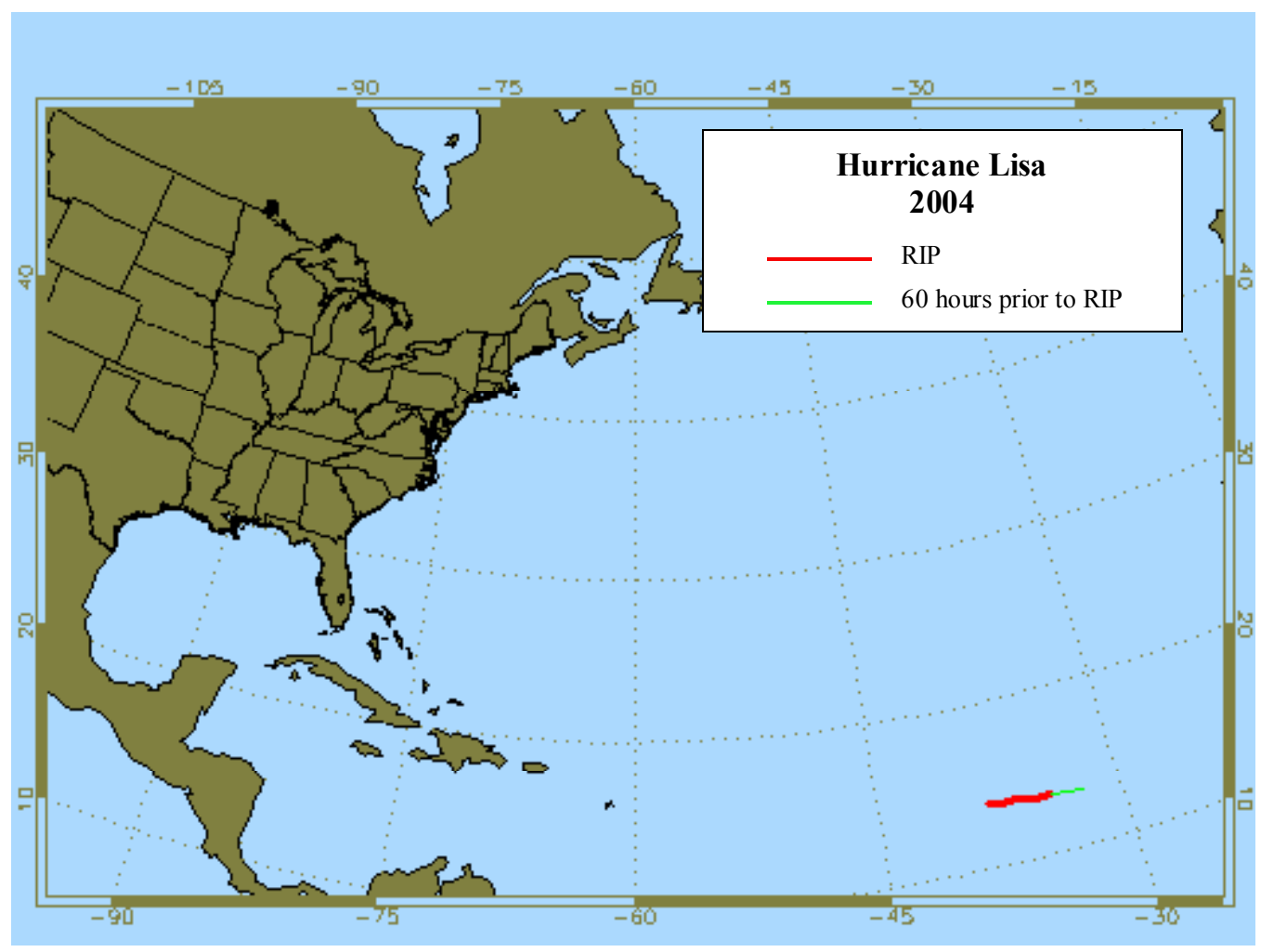

Figure 4.9: Track of Hurricane Lisa (2004).

Hurricane Lisa's track study began at $12 \mathrm{Z}$ September 17 as Lisa was a developing tropical wave off the African coast. Lisa remained nearly stationary and developed very slowly for two days. By $18 Z$ September 19, Lisa had organized into a tropical depression about 450 nautical miles southwest of the Cape Verde Islands. As Lisa began to drift westward, it encountered an unfavorable environment located between Hurricane Karl and another tropical wave. Even though the outflow from Karl created northerly shear, Lisa started to organize rapidly and entered the RIP on September 20. By the end of the 
RIP, Lisa had become a tropical storm but was quickly weakened by the northerly shear from Karl that occurred after the RIP. Lisa eventually became a minimal Category 1 hurricane in the central Atlantic when it was relatively late in its life cycle, 13 days after becoming a tropical depression.

The DFA was able to correctly classify 10 out of the 16 time intervals as a minor hurricane (Time Intervals 3, 4, 6, 11, 15, and 16 were classified as major). The misclassified intervals were mistakenly classified as a major hurricane predominantly because they exhibited very low 850-200 hPa wind shear (around 3-4 $\mathrm{m} \mathrm{s}^{-1}$ ). When the time interval classification was considered, an additional 4 intervals were misclassified making only 6 of the total 16 time intervals correctly classified (Time Intervals 5, 7, 8, and 9 misclassified in addition to the previously mentioned intervals). Lisa exhibited the low 850-200 hPa wind shear characteristics of a major hurricane. However, it also had the low translational speed, low heat potential, and high central pressure characteristics of a minor hurricane which made it difficult to classify.

Of the available percentage errors for the 24-hour pressure model (Table 4.40) only one interval had a high error (Time Interval 16). This interval was misclassified but the interaction with Hurricane Karl created high wind shear after Time Interval 16 which caused the pressure to rise. The CSM (Model 8) did help but it still did not capture the 24-hour pressure rise. The DFA selected Model 1 for Time Intervals 3 and 4 instead of the CSM (Model 5) but it still only missed the observed values by $0.34 \mathrm{hPa}$ and $1.91 \mathrm{hPa}$ respectively. In this case, it only misclassified in terms of type (major/minor) and NOT time interval. Time Intervals 5 and 7 overestimated the amount of deepening because Model 7 was selected instead of the CSM (Model 6). Here, the DFA did not misclassify 


\begin{tabular}{|c|c|c|c|c|c|c|c|c|}
\hline $\begin{array}{l}\text { Date } \\
(2004)\end{array}$ & $\begin{array}{c}\text { Time } \\
\text { Interval }\end{array}$ & Model & $\begin{array}{c}\text { Central } \\
\text { Pressure } \\
(\mathrm{hPa})\end{array}$ & $\begin{array}{c}\text { 24-hour } \\
\text { Obs. }\end{array}$ & $\begin{array}{c}\text { 24-hour } \\
\text { Press } \\
\text { Model } \\
\text { (hPa) }\end{array}$ & $\%$ error & $\begin{array}{c}\text { Correct } \\
\text { Selected } \\
\text { Model } \\
(\mathrm{hPa})\end{array}$ & $\begin{array}{c}\text { Improv. } \\
(\mathrm{hPa})\end{array}$ \\
\hline $9 / 1712 Z$ & 1 & 5 & 1004 & 0 & -0.13 & $\mathrm{~N} / \mathrm{a}$ & $\mathrm{N} / \mathrm{a}$ & $\mathrm{N} / \mathrm{a}$ \\
\hline $9 / 1718 \mathrm{Z}$ & 2 & 5 & 1004 & 0 & 0.02 & $\mathrm{~N} / \mathrm{a}$ & $\mathrm{N} / \mathrm{a}$ & $\mathrm{N} / \mathrm{a}$ \\
\hline $9 / 180 Z$ & 3 & 1 & 1004 & 0 & 0.34 & $\mathrm{~N} / \mathrm{a}$ & -0.37 & -0.03 \\
\hline $9 / 186 Z$ & 4 & 1 & 1004 & 0 & 1.91 & $\mathrm{~N} / \mathrm{a}$ & -0.27 & 1.64 \\
\hline $9 / 1812 Z$ & 5 & 7 & 1004 & 0 & 10.83 & $\mathrm{~N} / \mathrm{a}$ & 2.04 & 8.79 \\
\hline $9 / 1818 Z$ & 6 & 1 & 1004 & 0 & 2.68 & $\mathrm{~N} / \mathrm{a}$ & 3.45 & -0.77 \\
\hline 9/19 0Z & 7 & 7 & 1004 & 0 & 10.91 & $\mathrm{~N} / \mathrm{a}$ & -0.05 & 10.86 \\
\hline $9 / 196 Z$ & 8 & 5 & 1004 & 0 & 0.18 & $\mathrm{~N} / \mathrm{a}$ & 1.88 & -1.70 \\
\hline $9 / 1912 Z$ & 9 & 6 & 1004 & 2 & 1.98 & 0.9 & 11.37 & -9.35 \\
\hline $9 / 1918 Z$ & 10 & 7 & 1004 & 7 & 11.27 & 61.1 & $\mathrm{~N} / \mathrm{a}$ & $\mathrm{N} / \mathrm{a}$ \\
\hline $9 / 200 \mathrm{Z}$ & 11 & 1 & 1004 & 10 & 4.85 & 51.4 & 10.27 & 4.88 \\
\hline $9 / 206 \mathrm{Z}$ & 12 & 7 & 1004 & 14 & 10.79 & 22.9 & $\mathrm{~N} / \mathrm{a}$ & $\mathrm{N} / \mathrm{a}$ \\
\hline $9 / 2012 Z$ & 13 & 8 & 1002 & 12 & 14.64 & 22.1 & $\mathrm{~N} / \mathrm{a}$ & $\mathrm{N} / \mathrm{a}$ \\
\hline $9 / 2018 Z$ & 14 & 8 & 997 & 7 & 10.29 & 47.1 & $\mathrm{~N} / \mathrm{a}$ & $\mathrm{N} / \mathrm{a}$ \\
\hline $9 / 210 Z$ & 15 & 2 & 994 & 0 & 7.26 & $\mathrm{~N} / \mathrm{a}$ & 9.28 & -2.02 \\
\hline $9 / 216 Z$ & 16 & 3 & 990 & -7 & 26.19 & 474.2 & 14.85 & 11.34 \\
\hline
\end{tabular}

Table 4.40: 24-hour pressure drop model for Hurricane Lisa. 
in terms of type but by time interval, causing it to miss the observed value by approximately $10 \mathrm{hPa}$. The hurricane type misclassifications did not prove as detrimental as the time misclassifications. During Time Intervals 10,12,13, and 14 when the correct model was selected, it was able to forecast the intensification within $5 \mathrm{hPa}$. At the onset of the RIP, Model 7 emphasizes the relative humidity at $850 \mathrm{hPa}$ and $925 \mathrm{hPa}$. In particular, the $850 \mathrm{hPa}$ relative humidity was increasing causing the model to forecast further deepening. Model 8 (Time Intervals 13 and 14) considered the 850-100 $\mathrm{hPa}$ shear which was higher than the $850-200 \mathrm{hPa}$ shear, and captured some of the outflow from Hurricane Karl.

Since Lisa entered its RIP early in its life cycle, the NHC did not issue its official 24-hour wind speed increase forecast (Table 4.41) until Time Interval 10. Therefore comparisons between the model output and the NHC are available for only 7 time intervals. The model was more accurate on only 2 of the 7 intervals. Time Intervals 10 and 12 (Model 7), which were classified correctly, were more accurate than the NHC and had the CSM (Model 7) been used at Time Interval 11, it would have been more accurate as well. Model 7 is an aggressive model with a high constant in the regression equation and has a strong negative wind speed coefficient. Since the wind speed at this interval was low, it predicted a fairly strong increase in the wind speeds over the next 24 hours which closely correspond to the observations. However, Model 8 tended to overestimate the amount of strengthening during Time Intervals 13 and 14. Model 8 has positive coefficients with MPI and heat potential and since Lisa had a relatively high MPI (over $900 \mathrm{hPa}$ ) and moderate heat potential (approximately $20 \mathrm{~kJ} \mathrm{~cm}^{-2}$ ), it predicted moderate strengthening. The misclassified intervals (Time Intervals 11, 15 and 16) had the highest 


\begin{tabular}{|c|c|c|c|c|c|c|c|c|c|}
\hline $\begin{array}{c}\text { Time } \\
\text { Int. }\end{array}$ & Model & $\begin{array}{l}\text { Max. } \\
\text { Sus. } \\
\text { Wind } \\
\text { (kts) }\end{array}$ & $\begin{array}{c}\text { 24-hour } \\
\text { Obs. }\end{array}$ & $\begin{array}{c}\text { 24-hour } \\
\text { Model } \\
\text { (kts) }\end{array}$ & $\%$ error & $\begin{array}{c}\text { NHC } \\
24 \text { hour } \\
\text { For. }\end{array}$ & $\begin{array}{c}\text { NHC } \\
\% \\
\text { error }\end{array}$ & $\begin{array}{l}\text { CSM } \\
(\mathrm{kts})\end{array}$ & $\begin{array}{c}\text { Improv. } \\
\text { (kts) }\end{array}$ \\
\hline 1 & 5 & 30 & 0 & 1.88 & N/a & N/a & $\mathrm{N} / \mathrm{a}$ & $\mathrm{N} / \mathrm{a}$ & N/a \\
\hline 2 & 5 & 30 & 0 & 2.03 & $\mathrm{~N} / \mathrm{a}$ & N/a & $\mathrm{N} / \mathrm{a}$ & $\mathrm{N} / \mathrm{a}$ & N/a \\
\hline 3 & 1 & 30 & 0 & 7.46 & $\mathrm{~N} / \mathrm{a}$ & $\mathrm{N} / \mathrm{a}$ & $\mathrm{N} / \mathrm{a}$ & 2.18 & 5.28 \\
\hline 4 & 1 & 30 & 0 & 7.61 & $\mathrm{~N} / \mathrm{a}$ & N/a & $\mathrm{N} / \mathrm{a}$ & 2.33 & 5.28 \\
\hline 5 & 7 & 30 & 0 & 21.94 & $\mathrm{~N} / \mathrm{a}$ & $\mathrm{N} / \mathrm{a}$ & $\mathrm{N} / \mathrm{a}$ & 4.06 & 17.88 \\
\hline 6 & 1 & 30 & 0 & 8.13 & $\mathrm{~N} / \mathrm{a}$ & N/a & $\mathrm{N} / \mathrm{a}$ & 3.62 & 4.51 \\
\hline 7 & 7 & 30 & 0 & 24.17 & N/a & N/a & $\mathrm{N} / \mathrm{a}$ & 3.30 & 20.87 \\
\hline 8 & 5 & 30 & 0 & 2.93 & N/a & $\mathrm{N} / \mathrm{a}$ & $\mathrm{N} / \mathrm{a}$ & 2.17 & 0.76 \\
\hline 9 & 6 & 30 & 10 & 2.63 & 73.7 & N/a & $\mathrm{N} / \mathrm{a}$ & 25.31 & -7.94 \\
\hline 10 & 7 & 30 & 20 & 24.63 & 23.2 & 10 & 50.0 & $\mathrm{~N} / \mathrm{a}$ & $\mathrm{N} / \mathrm{a}$ \\
\hline 11 & 1 & 30 & 25 & 9.69 & 61.2 & 10 & 60.0 & 23.32 & 13.63 \\
\hline 12 & 7 & 30 & 30 & 20.62 & 31.2 & 10 & 66.7 & $\mathrm{~N} / \mathrm{a}$ & $\mathrm{N} / \mathrm{a}$ \\
\hline 13 & 8 & 40 & 20 & 27.83 & 39.2 & 15 & 25.0 & $\mathrm{~N} / \mathrm{a}$ & N/a \\
\hline 14 & 8 & 50 & 10 & 20.83 & 108.3 & 15 & 50.0 & $\mathrm{~N} / \mathrm{a}$ & N/a \\
\hline 15 & 2 & 55 & 0 & 8.95 & N/a & 0 & $\mathrm{~N} / \mathrm{a}$ & 20.98 & -12.03 \\
\hline 16 & 3 & 60 & -10 & 36.57 & 465.7 & 0 & 100 & 17.77 & 18.80 \\
\hline
\end{tabular}

Table 4.41: 24-hour wind speed increase model for Hurricane Lisa. 
errors and the CSM particularly during Time Intervals 11 and 16 would have provided substantial improvement.

The 6-hourly pressure drop model (Table 4.42) exhibited very low percentage errors primarily due to very low observed values. All available percentage errors were lower than approximately $50 \%$. The majority of the misclassified intervals occurred prior to Time Interval 11 when the observed pressure was stable. Therefore even misclassified models were able to predict the pressure, but when the pressure started to drop (after Time Interval 12), the correct model was used and it was able to predict the short term pressure decrease within approximately $2 \mathrm{hPa}$. As with the 6-hour wind speed model (Table 4.43), prior to Time Interval 12, there was no change in the wind speed allowing the model to easily forecast the persistent conditions. At the onset of the RIP, Model 7 did underestimate the wind speed because it only considered two significant variables, primarily the 6-hour wind speed change. Since it did not change in the previous 6 hours, it forecasted a modest change. However, beginning at Time Interval 13 when Model 8 was correctly used, it was more accurate because it considers 3 other significant variables in addition to the 6-hour wind speed change. 


\begin{tabular}{|c|c|c|c|c|c|c|c|c|}
\hline Date & Time & Model & $\begin{array}{c}\text { Cent. } \\
\text { Int. }\end{array}$ & $\begin{array}{c}\text { 6-hour Pres. } \\
\text { (hPa) }\end{array}$ & $\begin{array}{c}\mathbf{6} \text {-hour } \\
\text { Drop Obs. }\end{array}$ & $\begin{array}{c}\text { Model } \\
\text { error }\end{array}$ & $\begin{array}{c}\text { CSM } \\
\text { (hPa) }\end{array}$ & $\begin{array}{c}\text { Improv. } \\
\text { (hPa) }\end{array}$ \\
\hline $9 / 1712 \mathrm{Z}$ & 1 & 5 & 1004 & 0 & $\mathbf{0 . 0 8}$ & N/a & N/a & N/a \\
\hline $9 / 1718 Z$ & 2 & 5 & 1004 & 0 & $\mathbf{0 . 0 8}$ & N/a & N/a & N/a \\
\hline $9 / 180 Z$ & 3 & 1 & 1004 & 0 & $\mathbf{0 . 0 2}$ & N/a & 0.08 & -0.06 \\
\hline $9 / 186 Z$ & 4 & 1 & 1004 & 0 & $\mathbf{0 . 2 9}$ & N/a & 0.08 & 0.21 \\
\hline $9 / 1812 Z$ & 5 & 7 & 1004 & 0 & $\mathbf{1 . 0 1}$ & N/a & 0.46 & 0.55 \\
\hline $9 / 1818 Z$ & 6 & 1 & 1004 & 0 & $\mathbf{0 . 4 5}$ & N/a & 0.46 & -0.01 \\
\hline $9 / 190 Z$ & 7 & 7 & 1004 & 0 & $\mathbf{0 . 4 4}$ & N/a & 0.46 & -0.02 \\
\hline $9 / 196 Z$ & 8 & 5 & 1004 & 0 & $\mathbf{0 . 0 8}$ & N/a & 0.46 & -0.38 \\
\hline $9 / 1912 Z$ & 9 & 6 & 1004 & 0 & $\mathbf{0 . 4 6}$ & N/a & 0.93 & -0.47 \\
\hline $9 / 1918 Z$ & 10 & 7 & 1004 & 0 & $\mathbf{1 . 0 7}$ & N/a & N/a & N/a \\
\hline $9 / 200 Z$ & 11 & 1 & 1004 & 0 & $\mathbf{1 . 2 6}$ & N/a & 1.05 & 0.21 \\
\hline $9 / 206 Z$ & 12 & 7 & 1004 & 2 & $\mathbf{0 . 9 9}$ & 50.4 & N/a & N/a \\
\hline $9 / 2012 Z$ & 13 & 8 & 1002 & 5 & $\mathbf{3 . 8 1}$ & 23.7 & N/a & N/a \\
\hline $9 / 2018 Z$ & 14 & 8 & 997 & 3 & $\mathbf{2 . 9 7}$ & 0.9 & N/a & N/a \\
\hline $9 / 210 Z$ & 15 & 2 & 994 & 4 & $\mathbf{2 . 6 3}$ & 34.1 & 2.44 & -0.19 \\
\hline $9 / 216 Z$ & 16 & 3 & 990 & 0 & $\mathbf{3 . 0 2}$ & N/a & 4.01 & -0.99 \\
\hline
\end{tabular}

Table 4.42: 6-hour pressure drop model for Hurricane Lisa. 


\begin{tabular}{|c|c|c|c|c|c|c|c|c|}
\hline Date & $\begin{array}{l}\text { Time } \\
\text { Int. }\end{array}$ & Model & $\begin{array}{l}\text { Max. Sus. } \\
\text { Winds (kts) }\end{array}$ & $\begin{array}{c}\text { 6-hour } \\
\text { Wind } \\
\text { Speed Obs. }\end{array}$ & $\begin{array}{c}\text { 6-hour } \\
\text { Model } \\
\text { (kts) }\end{array}$ & $\%$ error & $\begin{array}{l}\text { CSM } \\
\text { (kts) }\end{array}$ & $\begin{array}{c}\text { Improv. } \\
\text { (kts) }\end{array}$ \\
\hline $9 / 1712 Z$ & 1 & 5 & 30 & 0 & 0.27 & $\mathrm{~N} / \mathrm{a}$ & N/a & $\mathrm{N} / \mathrm{a}$ \\
\hline $9 / 1718 Z$ & 2 & 5 & 30 & 0 & 0.27 & $\mathrm{~N} / \mathrm{a}$ & $\mathrm{N} / \mathrm{a}$ & $\mathrm{N} / \mathrm{a}$ \\
\hline $9 / 180 Z$ & 3 & 1 & 30 & 0 & 1.20 & $\mathrm{~N} / \mathrm{a}$ & 0.27 & 0.93 \\
\hline $9 / 186 Z$ & 4 & 1 & 30 & 0 & 1.20 & $\mathrm{~N} / \mathrm{a}$ & 0.27 & 0.93 \\
\hline $9 / 1812 Z$ & 5 & 7 & 30 & 0 & 3.02 & N/a & 0.97 & 2.05 \\
\hline $9 / 1818 \mathrm{Z}$ & 6 & 1 & 30 & 0 & 1.20 & $\mathrm{~N} / \mathrm{a}$ & 0.53 & 0.67 \\
\hline 9/19 0Z & 7 & 7 & 30 & 0 & 3.02 & $\mathrm{~N} / \mathrm{a}$ & 0.82 & 2.20 \\
\hline $9 / 196 Z$ & 8 & 5 & 30 & 0 & 0.27 & $\mathrm{~N} / \mathrm{a}$ & 0.53 & -0.26 \\
\hline $9 / 1912 Z$ & 9 & 6 & 30 & 0 & 0.90 & $\mathrm{~N} / \mathrm{a}$ & 3.02 & -2.12 \\
\hline $9 / 1918 Z$ & 10 & 7 & 30 & 0 & 3.02 & $\mathrm{~N} / \mathrm{a}$ & $\mathrm{N} / \mathrm{a}$ & $\mathrm{N} / \mathrm{a}$ \\
\hline $9 / 200 Z$ & 11 & 1 & 30 & 0 & 1.21 & N/a & 3.01 & -1.80 \\
\hline $9 / 206 Z$ & 12 & 7 & 30 & 10 & 3.01 & 69.9 & N/a & $\mathrm{N} / \mathrm{a}$ \\
\hline $9 / 2012 Z$ & 13 & 8 & 40 & 10 & 10.36 & 3.7 & $\mathrm{~N} / \mathrm{a}$ & $\mathrm{N} / \mathrm{a}$ \\
\hline $9 / 2018 Z$ & 14 & 8 & 50 & 5 & 7.99 & 59.8 & $\mathrm{~N} / \mathrm{a}$ & $\mathrm{N} / \mathrm{a}$ \\
\hline $9 / 210 Z$ & 15 & 2 & 55 & 5 & 4.56 & 8.6 & 5.88 & -0.44 \\
\hline $9 / 216 Z$ & 16 & 3 & 60 & 0 & 6.64 & N/a & 5.05 & 1.59 \\
\hline
\end{tabular}

Table 4.43: 6-hour wind speed increase model for Hurricane Lisa. 


\subsubsection{Hurricane Dennis (2005)}

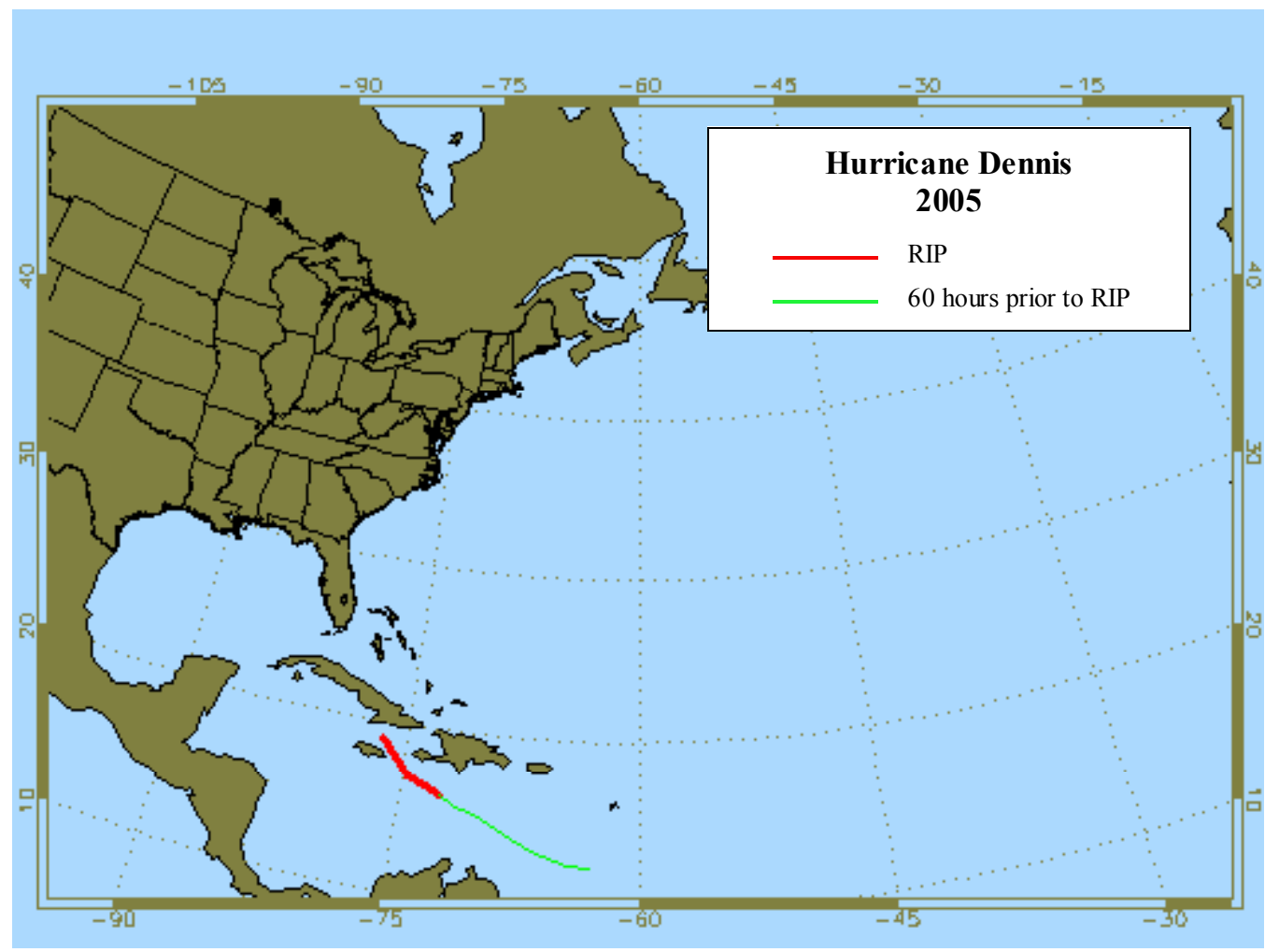

Figure 4.10: Track of Hurricane Dennis (2005).

The period of study for Hurricane Dennis began at $6 \mathrm{Z}$ July 4 when it was moving through the Windward Islands as a tropical disturbance. Convection started to organize and Dennis quickly developed into a tropical depression by $18 \mathrm{Z}$ July 4 as it progressed to the west. By July 5, Dennis started to turn toward the northwest and quickly became a tropical storm. Dennis began to undergo the RIP at 0Z July 7 as a Category 1 hurricane and was a strong Category 3 hurricane (115 knots) at the end of the RIP, but just prior to 
its initial landfall near Punta del Ingles, Cuba, it was a Category 4. Dennis would pass over Cuba and weaken to Category 1 status but would eventually strengthen again to a Category 3 in the Gulf of Mexico before making U.S. landfall near Santa Rosa Island, FL.

The DFA was able to classify 14 of the 16 time intervals correctly as becoming a major hurricane. It classified Time Intervals 1 and 2 as a minor hurricane since it was poorly organized at the time with a high central pressure of $1010 \mathrm{hPa}$ and high ambient surface pressure near $1015 \mathrm{hPa}$. The DFA at least used the correct time classification with these two time intervals even though the incorrect type was selected. Of the remaining 14 correctly selected time intervals, the DFA only misclassified 4 time classifications (Time Intervals 5, 11, 12, and 15). At Time Interval 5, the DFA tended to retain Model 1 instead of using Model 2 because the central pressure still remained high at $1009 \mathrm{hPa}$. During Time Intervals 11 and 12, the DFA selected Model 2 and Model 1 respectively instead of Model 3 primarily because the $850-200 \mathrm{hPa}$ wind shear increased sharply to values more indicative of days before the RIP instead of just prior to the onset.

The 24-hour pressure model (Table 4.44) predicted the pressure with low percentage errors at all of the time intervals, although the highest errors were at the misclassified time intervals. Time Intervals 1 and 2 were misclassified in terms of type and not time classification, therefore using Model 5 instead of Model 1. However the DFA selected model was more accurate than the CSM because as stated earlier, Dennis had a high central pressure and ambient pressure. The major hurricane model (Model 1) factored the high central pressure but it also factored the high core heat potential which caused it to overestimate the amount of deepening. The minor hurricane model (Model 


\begin{tabular}{|c|c|c|c|c|c|c|c|c|}
\hline $\begin{array}{l}\text { Date } \\
(2005)\end{array}$ & $\begin{array}{c}\text { Time } \\
\text { Interval }\end{array}$ & Model & $\begin{array}{c}\text { Central } \\
\text { Pressure } \\
(\mathrm{hPa})\end{array}$ & $\begin{array}{c}\text { 24-hour } \\
\text { Obs. }\end{array}$ & $\begin{array}{c}\text { 24-hour } \\
\text { Press } \\
\text { Model } \\
\text { (hPa) }\end{array}$ & $\%$ error & $\begin{array}{c}\text { Correct } \\
\text { Selected } \\
\text { Model } \\
(\mathrm{hPa})\end{array}$ & $\begin{array}{c}\text { Improv. } \\
(\mathrm{hPa})\end{array}$ \\
\hline $7 / 46 Z$ & 1 & 5 & 1010 & 0 & 0.67 & $\mathrm{~N} / \mathrm{a}$ & 6.14 & -5.47 \\
\hline $7 / 412 Z$ & 2 & 5 & 1010 & 1 & 0.45 & 54.7 & 5.57 & -4.02 \\
\hline $7 / 418 Z$ & 3 & 1 & 1010 & 4 & 5.55 & 38.8 & $\mathrm{~N} / \mathrm{a}$ & $\mathrm{N} / \mathrm{a}$ \\
\hline $7 / 50 Z$ & 4 & 1 & 1010 & 5 & 6.11 & 22.3 & $\mathrm{~N} / \mathrm{a}$ & $\mathrm{N} / \mathrm{a}$ \\
\hline $7 / 56 \mathrm{Z}$ & 5 & 1 & 1009 & 10 & 6.61 & 33.8 & 10.07 & 3.32 \\
\hline $7 / 512 Z$ & 6 & 2 & 1006 & 15 & 11.01 & 26.6 & $\mathrm{~N} / \mathrm{a}$ & $\mathrm{N} / \mathrm{a}$ \\
\hline $7 / 518 Z$ & 7 & 2 & 1005 & 15 & 11.15 & 25.6 & $\mathrm{~N} / \mathrm{a}$ & $\mathrm{N} / \mathrm{a}$ \\
\hline $7 / 60 \mathrm{Z}$ & 8 & 2 & 1000 & 18 & 12.57 & 30.1 & $\mathrm{~N} / \mathrm{a}$ & $\mathrm{N} / \mathrm{a}$ \\
\hline $7 / 66 \mathrm{Z}$ & 9 & 3 & 994 & 20 & 26.57 & 32.9 & $\mathrm{~N} / \mathrm{a}$ & $\mathrm{N} / \mathrm{a}$ \\
\hline $7 / 612 Z$ & 10 & 3 & 991 & 24 & 26.62 & 10.9 & $\mathrm{~N} / \mathrm{a}$ & $\mathrm{N} / \mathrm{a}$ \\
\hline $7 / 618 Z$ & 11 & 2 & 987 & 23 & 10.90 & 52.6 & 30.08 & 5.02 \\
\hline $7 / 70 Z$ & 12 & 1 & 980 & 30 & 12.34 & 58.9 & 29.82 & 17.48 \\
\hline $7 / 76 \mathrm{Z}$ & 13 & 4 & 970 & 30 & 27.17 & 9.4 & N/a & N/a \\
\hline $7 / 712 Z$ & 14 & 4 & 968 & 20 & 15.47 & 22.6 & $\mathrm{~N} / \mathrm{a}$ & $\mathrm{N} / \mathrm{a}$ \\
\hline $7 / 718 Z$ & 15 & 3 & 657 & 30 & 35.51 & 18.4 & 11.67 & -12.82 \\
\hline $7 / 80 \mathrm{Z}$ & 16 & 4 & 650 & 8 & 5.01 & 37.3 & $\mathrm{~N} / \mathrm{a}$ & $\mathrm{N} / \mathrm{a}$ \\
\hline
\end{tabular}

Table 4.44: 24-hour pressure drop model for Hurricane Dennis. 
5), which primarily factored the high pressure in the attained MPI and the previous 6hour wind speed change, (previous 6-hour wind speed change was 0 ), allowed it to predict a modest change in the pressure, which was much closer to the observations. Time Interval 5 used Model 1 instead of the CSM Model 2 because of the high central pressure. The selected model was within $4 \mathrm{hPa}$ but the CSM (Model 2) was within 0.1 hPa. In fact, Model 2 was very accurate as a correctly selected model (Time Intervals 58) predicting within $6 \mathrm{hPa}$, since it factored the low $850-500 \mathrm{hPa}$ wind shear (less than 3 $\mathrm{m} \mathrm{s}^{-1}$ ), the high SSTs (more than $301 \mathrm{~K}$ ), and low MPI (less than $900 \mathrm{hPa}$ ). Model 3 also did well during Time Intervals 9-10 and as the CSM during Time Intervals 11-12 since it considered the extremely high core heat potential $\left(\right.$ more than $70 \mathrm{~kJ} \mathrm{~cm}^{-2}$ ), and the increasing wind speed. This allowed it to predict the intensification much more aggressively than Model 2 and ultimately be very accurate. Model 3 was able to forecast future 24-hour pressure drop at the onset of the RIP within $1 \mathrm{hPa}$. Model 4 was also very respectable as a selected model since it considered the high heat potential predicting the deepening within $5 \mathrm{hPa}$.

Of the 12 time intervals where comparisons were available for the 24-hour wind speed increase (Table 4.45), the DFA selected model was able to outperform the NHC forecasts on 7 time intervals. On the majority of the 5 time intervals that were not more accurate, the NHC forecasts were within 3 knots of the model forecasts (Time Intervals 6 , 8,11 , and 14). Therefore even when the NHC was technically more accurate, it was usually by small margins. Two of the misclassified intervals (Time Intervals 11 and 12) would have been improved by using the CSM (Model 3). Six hours before the onset of the RIP, the CSM was within 3 knots of the observations and at the onset of the RIP, the 


\begin{tabular}{|c|c|c|c|c|c|c|c|c|c|}
\hline $\begin{array}{c}\text { Time } \\
\text { Int. }\end{array}$ & Model & $\begin{array}{l}\text { Max. } \\
\text { Sus. } \\
\text { Wind } \\
\text { (kts) }\end{array}$ & $\begin{array}{c}\text { 24-hour } \\
\text { Obs. }\end{array}$ & $\begin{array}{c}\text { 24-hour } \\
\text { Model } \\
\text { (kts) }\end{array}$ & $\%$ error & $\begin{array}{c}\text { NHC } \\
24 \text { hour } \\
\text { For. }\end{array}$ & $\begin{array}{c}\text { NHC } \\
\% \\
\text { error }\end{array}$ & $\begin{array}{l}\text { CSM } \\
\text { (kts) }\end{array}$ & $\begin{array}{c}\text { Improv. } \\
\text { (kts) }\end{array}$ \\
\hline 1 & 5 & 30 & 0 & 2.48 & $\mathrm{~N} / \mathrm{a}$ & $\mathrm{N} / \mathrm{a}$ & $\mathrm{N} / \mathrm{a}$ & 14.57 & -12.09 \\
\hline 2 & 5 & 30 & 0 & 2.63 & $\mathrm{~N} / \mathrm{a}$ & N/a & $\mathrm{N} / \mathrm{a}$ & 15.45 & -12.82 \\
\hline 3 & 1 & 30 & 5 & 13.07 & 161.5 & $\mathrm{~N} / \mathrm{a}$ & $\mathrm{N} / \mathrm{a}$ & $\mathrm{N} / \mathrm{a}$ & $\mathrm{N} / \mathrm{a}$ \\
\hline 4 & 1 & 30 & 5 & 13.44 & 169.0 & $\mathrm{~N} / \mathrm{a}$ & $\mathrm{N} / \mathrm{a}$ & N/a & N/a \\
\hline 5 & 1 & 30 & 15 & 12.86 & 14.2 & 5 & 66.7 & 10.52 & -2.34 \\
\hline 6 & 2 & 35 & 25 & 17.84 & 28.6 & 20 & 20.0 & $\mathrm{~N} / \mathrm{a}$ & $\mathrm{N} / \mathrm{a}$ \\
\hline 7 & 2 & 35 & 25 & 22.27 & 10.9 & 15 & 40.0 & N/a & $\mathrm{N} / \mathrm{a}$ \\
\hline 8 & 2 & 45 & 20 & 20.27 & 1.4 & 20 & 0.0 & $\mathrm{~N} / \mathrm{a}$ & $\mathrm{N} / \mathrm{a}$ \\
\hline 9 & 3 & 55 & 30 & 32.81 & 9.4 & 25 & 16.7 & N/a & N/a \\
\hline 10 & 3 & 60 & 25 & 28.13 & 12.5 & 15 & 40.0 & $\mathrm{~N} / \mathrm{a}$ & $\mathrm{N} / \mathrm{a}$ \\
\hline 11 & 2 & 55 & 30 & 14.83 & 50.6 & 15 & 50.0 & 32.98 & 12.19 \\
\hline 12 & 1 & 75 & 45 & 13.99 & 68.9 & 25 & 44.4 & 33.64 & 19.65 \\
\hline 13 & 4 & 80 & 40 & 28.66 & 28.3 & 20 & 50.0 & $\mathrm{~N} / \mathrm{a}$ & $\mathrm{N} / \mathrm{a}$ \\
\hline 14 & 4 & 90 & 35 & 19.82 & 43.3 & 20 & 42.9 & $\mathrm{~N} / \mathrm{a}$ & N/a \\
\hline 15 & 3 & 100 & 40 & 33.23 & 16.9 & 10 & 75.0 & 9.92 & -23.31 \\
\hline 16 & 4 & 115 & 15 & 2.85 & 81.0 & -5 & 133 & N/a & $\mathrm{N} / \mathrm{a}$ \\
\hline
\end{tabular}

Table 4.45: 24-hour wind speed increase model for Hurricane Dennis. 
CSM was within 12 knots. This was more accurate than the NHC by more than 8 knots. Model 3 in particular did better than the NHC because of the low MPI (less than $890 \mathrm{hPa}$ ) that was considered, which allowed Model 3 to forecast a dramatic increase in wind speed. The SSTs were very warm (above $301 \mathrm{~K}$ ) which caused the MPI to drop and the NHC underestimated this rapid intensification. Most notably, the selected model (Model 3) during Time Interval 15 was more accurate by 23 knots than the NHC. Even though it was technically misclassified, the DFA noted the very high SSTs (above $302 \mathrm{~K}$ ) and the extremely low MPI (approximately $870 \mathrm{hPa}$ ) which is more typical of the time period just prior to the onset of the RIP. Therefore Model 3 predicted the intensification very well while the CSM (Model 4) was more consistent with the NHC forecast.

The 6-hour pressure drop model (Table 4.46) had percentage errors all less than $100 \%$ with the exception of Time Interval 13. The highest errors occurred around the onset of the RIP because two of the intervals were misclassified. As with the 24-hour models, the CSM (Model 3) would have improved the forecast. However, in this model it considered the very high core heat potential $\left(75 \mathrm{~kJ} \mathrm{~cm}^{-2}\right)$. It is interesting to note that in Time Interval 13, Model 4 overestimated the short-term deepening but it would rapidly deepen in just 12 hours. The 6-hour wind speed model (Table 4.47) also had low errors except around the onset of the RIP. The misclassified intervals (Time Intervals 11 and 12) had high errors, but the CSM (Model 3) did not provide much improvement because this model did not consider any thermodynamic variables. Model 4 also did not look at these variables such as the heat potential or the MPI, which may have caused it to have a larger error at Time Interval 13. 


\begin{tabular}{|c|c|c|c|c|c|c|c|c|}
\hline Date & $\begin{array}{l}\text { Time } \\
\text { Int. }\end{array}$ & Model & $\begin{array}{c}\text { Cent. } \\
\text { Pressure } \\
(\mathrm{hPa})\end{array}$ & $\begin{array}{l}\text { 6-hour Pres. } \\
\text { Drop Obs. }\end{array}$ & $\begin{array}{l}\text { 6-hour } \\
\text { Model } \\
\text { (hPa) }\end{array}$ & $\begin{array}{l}\% \\
\text { error }\end{array}$ & $\begin{array}{l}\text { CSM } \\
(\mathrm{hPa})\end{array}$ & $\begin{array}{l}\text { Improv. } \\
(\mathrm{hPa})\end{array}$ \\
\hline $7 / 46 Z$ & 1 & 5 & 1010 & 0 & 0.08 & $\mathrm{~N} / \mathrm{a}$ & 0.65 & -0.57 \\
\hline $7 / 412 Z$ & 2 & 5 & 1010 & 0 & 0.08 & $\mathrm{~N} / \mathrm{a}$ & 0.53 & -0.45 \\
\hline $7 / 418 Z$ & 3 & 1 & 1010 & 0 & 0.53 & $\mathrm{~N} / \mathrm{a}$ & $\mathrm{N} / \mathrm{a}$ & $\mathrm{N} / \mathrm{a}$ \\
\hline $7 / 50 Z$ & 4 & 1 & 1010 & 1 & 0.64 & 35.3 & $\mathrm{~N} / \mathrm{a}$ & $\mathrm{N} / \mathrm{a}$ \\
\hline $7 / 56 Z$ & 5 & 1 & 1009 & 3 & 0.78 & 73.9 & 1.53 & 0.75 \\
\hline $7 / 512 Z$ & 6 & 2 & 1006 & 1 & 1.53 & 53.1 & $\mathrm{~N} / \mathrm{a}$ & $\mathrm{N} / \mathrm{a}$ \\
\hline $7 / 518 \mathrm{Z}$ & 7 & 2 & 1005 & 5 & 2.63 & 47.3 & $\mathrm{~N} / \mathrm{a}$ & $\mathrm{N} / \mathrm{a}$ \\
\hline $7 / 60 Z$ & 8 & 2 & 1000 & 6 & 1.53 & 74.5 & $\mathrm{~N} / \mathrm{a}$ & $\mathrm{N} / \mathrm{a}$ \\
\hline $7 / 66 Z$ & 9 & 3 & 994 & 3 & 5.14 & 71.5 & $\mathrm{~N} / \mathrm{a}$ & $\mathrm{N} / \mathrm{a}$ \\
\hline $7 / 612 Z$ & 10 & 3 & 991 & 4 & 5.35 & 33.9 & $\mathrm{~N} / \mathrm{a}$ & $\mathrm{N} / \mathrm{a}$ \\
\hline $7 / 618 Z$ & 11 & 2 & 987 & 7 & 2.63 & 62.3 & 4.64 & 2.01 \\
\hline $7 / 70 Z$ & 12 & 1 & 980 & 10 & 1.54 & 84.6 & 2.89 & 1.35 \\
\hline $7 / 76 Z$ & 13 & 4 & 970 & 2 & 12.35 & 517.9 & $\mathrm{~N} / \mathrm{a}$ & $\mathrm{N} / \mathrm{a}$ \\
\hline $7 / 712 Z$ & 14 & 4 & 968 & 11 & 9.56 & 13.0 & $\mathrm{~N} / \mathrm{a}$ & $\mathrm{N} / \mathrm{a}$ \\
\hline $7 / 718 Z$ & 15 & 3 & 657 & 7 & 5.75 & 17.8 & 7.05 & 1.20 \\
\hline $7 / 80 Z$ & 16 & 4 & 650 & 0 & 9.40 & $\mathrm{~N} / \mathrm{a}$ & $\mathrm{N} / \mathrm{a}$ & $\mathrm{N} / \mathrm{a}$ \\
\hline
\end{tabular}

Table 4.46: 6-hour pressure drop model for Hurricane Dennis. 


\begin{tabular}{|c|c|c|c|c|c|c|c|c|}
\hline Date & $\begin{array}{l}\text { Time } \\
\text { Int. }\end{array}$ & Model & $\begin{array}{l}\text { Max. Sus. } \\
\text { Winds (kts) }\end{array}$ & $\begin{array}{c}\text { 6-hour } \\
\text { Wind } \\
\text { Speed Obs. }\end{array}$ & $\begin{array}{c}\text { 6-hour } \\
\text { Model } \\
\text { (kts) }\end{array}$ & $\%$ error & $\begin{array}{l}\text { CSM } \\
\text { (kts) }\end{array}$ & $\begin{array}{c}\text { Improv. } \\
\text { (kts) }\end{array}$ \\
\hline $7 / 46 Z$ & 1 & 5 & 30 & 0 & 0.27 & $\mathrm{~N} / \mathrm{a}$ & 2.61 & -2.34 \\
\hline $7 / 412 Z$ & 2 & 5 & 30 & 0 & 0.27 & $\mathrm{~N} / \mathrm{a}$ & 2.61 & -2.34 \\
\hline $7 / 418 Z$ & 3 & 1 & 30 & 0 & 2.61 & $\mathrm{~N} / \mathrm{a}$ & $\mathrm{N} / \mathrm{a}$ & $\mathrm{N} / \mathrm{a}$ \\
\hline $7 / 50 Z$ & 4 & 1 & 30 & 0 & 2.61 & $\mathrm{~N} / \mathrm{a}$ & $\mathrm{N} / \mathrm{a}$ & $\mathrm{N} / \mathrm{a}$ \\
\hline $7 / 56 Z$ & 5 & 1 & 30 & 0 & 2.56 & $\mathrm{~N} / \mathrm{a}$ & 4.42 & -1.86 \\
\hline $7 / 512 Z$ & 6 & 2 & 35 & 5 & 2.29 & 54.1 & $\mathrm{~N} / \mathrm{a}$ & $\mathrm{N} / \mathrm{a}$ \\
\hline $7 / 518 Z$ & 7 & 2 & 35 & 0 & 4.14 & $\mathrm{~N} / \mathrm{a}$ & $\mathrm{N} / \mathrm{a}$ & N/a \\
\hline $7 / 60 Z$ & 8 & 2 & 45 & 10 & 4.04 & 59.5 & $\mathrm{~N} / \mathrm{a}$ & $\mathrm{N} / \mathrm{a}$ \\
\hline $7 / 66 Z$ & 9 & 3 & 55 & 10 & 7.55 & 24.4 & $\mathrm{~N} / \mathrm{a}$ & $\mathrm{N} / \mathrm{a}$ \\
\hline $7 / 612 Z$ & 10 & 3 & 60 & 5 & 6.80 & 36.0 & $\mathrm{~N} / \mathrm{a}$ & $\mathrm{N} / \mathrm{a}$ \\
\hline $7 / 618 Z$ & 11 & 2 & 55 & -5 & 4.18 & 183.7 & 6.22 & -2.04 \\
\hline $7 / 70 Z$ & 12 & 1 & 75 & 20 & 0.76 & 96.2 & 4.09 & 3.33 \\
\hline $7 / 76 Z$ & 13 & 4 & 80 & 5 & 11.89 & 137.9 & $\mathrm{~N} / \mathrm{a}$ & $\mathrm{N} / \mathrm{a}$ \\
\hline $7 / 712 \mathrm{Z}$ & 14 & 4 & 90 & 10 & 11.30 & 13.1 & $\mathrm{~N} / \mathrm{a}$ & $\mathrm{N} / \mathrm{a}$ \\
\hline $7 / 718 Z$ & 15 & 3 & 100 & 10 & 7.25 & 4.5 & 9.54 & 2.29 \\
\hline $7 / 80 \mathrm{Z}$ & 16 & 4 & 115 & 15 & 8.96 & 40.3 & $\mathrm{~N} / \mathrm{a}$ & $\mathrm{N} / \mathrm{a}$ \\
\hline
\end{tabular}

Table 4.47: 6-hour wind speed increase model for Hurricane Dennis. 


\subsubsection{Hurricane Emily (2005)}

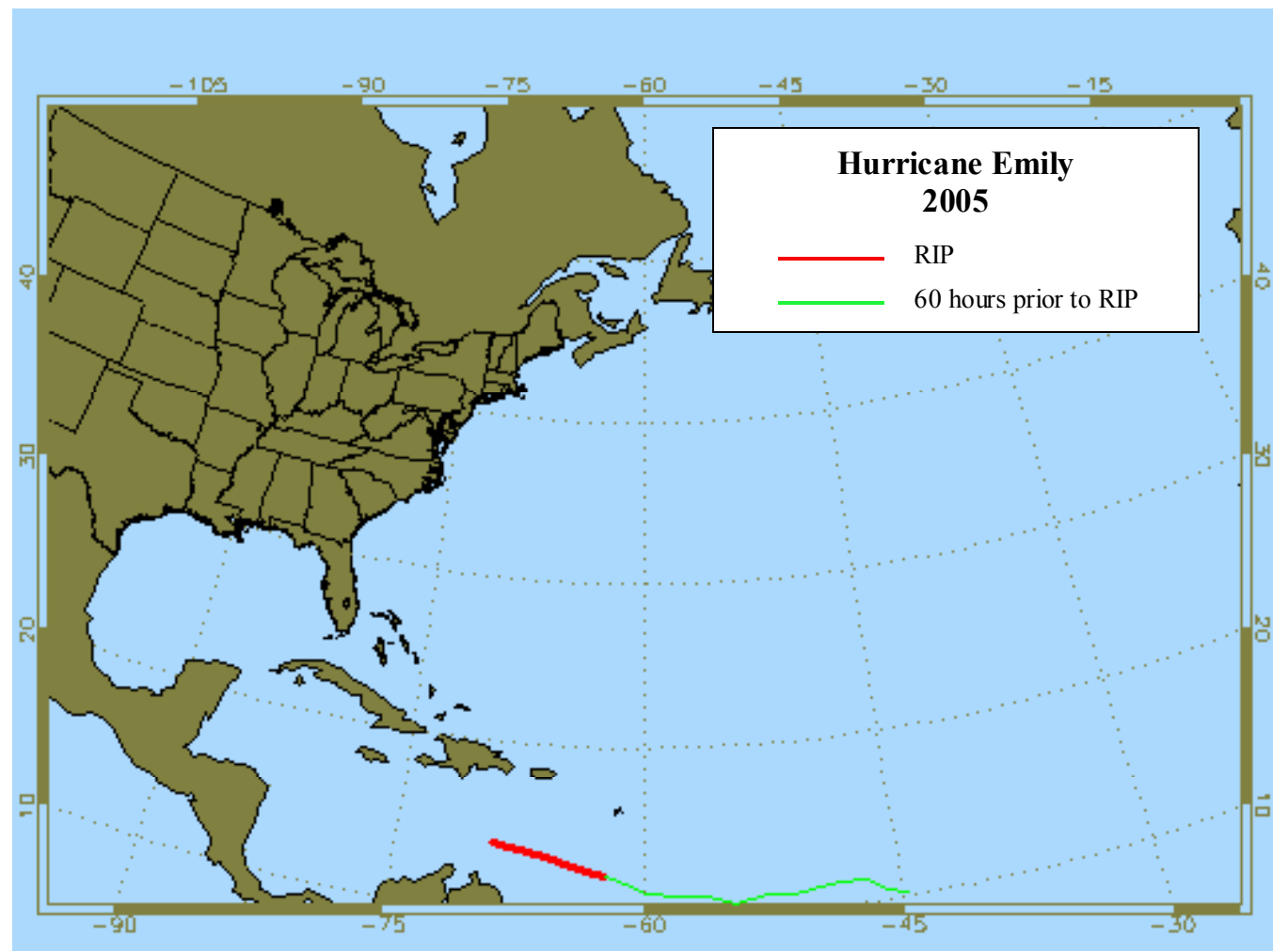

Figure 4.11: Track of Hurricane Emily (2005).

The study for Hurricane Emily began at $12 \mathrm{Z}$ on July 11 when it was a tropical depression about 1000 miles east of the Windward Islands. Emily started to move westward but modest easterly shear kept it from developing rapidly. The system was not well defined but nevertheless became a tropical storm at $0 \mathrm{Z}$ July 12 . As the translational speed started to increase, the wind shear also increased, which caused Emily to temporarily weaken early on July 13 . By $0 Z$ July 14 , the shear had weakened substantially and Emily started to strengthen again, officially becoming a Category 1 at 
the onset of the RIP. Emily strengthened to a strong Category 3 hurricane (115 knots) by the end of the RIP as it turned to the northwest and entered the Caribbean Sea. Over the next few days, Emily would shift between Category 4 and Category 5 status as it underwent several eyewall replacement cycles. The center made landfall on the Yucatan peninsula and made a secondary landfall near San Fernando, Mexico as a Category 3 hurricane.

All 16 time intervals were correctly classified by the DFA as eventually becoming a major hurricane. However, the DFA did misclassify 4 intervals according to the relationship to its RIP. Three of the misclassifications (Time Intervals 6, 9, and 10) occurred because of the high shear that was present which caused the DFA to select a model when the hurricane was much further from its RIP. The other misclassification at Time Interval 13 (using Model 3 instead of Model 4) is not completely understood especially since the central pressure at this time was $976 \mathrm{hPa}$, which is generally lower than the average pressure at the onset of the RIP.

The 24-hour pressure drop model (Table 4.48) had two distinct periods where it had errors of prediction, Time Intervals 5-7 and 13-16. During Time Intervals 5-7, the DFA selected models and the CSM both overestimated the amount of deepening. They failed to capture the temporary weakening caused by the high translational speed (between 7-10 $\mathrm{m} \mathrm{s}^{-1}$ ) and some mid-level dry air. Model 2 predicts intensification based on low level wind shear, MPI, and SSTs and therefore missed the governing factors responsible for the temporary weakening. However, after the temporary weakening (Time Intervals 8-12) the selected DFA had low percentage errors and the CSM (Model 3 


\begin{tabular}{|c|c|c|c|c|c|c|c|c|}
\hline $\begin{array}{l}\text { Date } \\
(2005)\end{array}$ & $\begin{array}{c}\text { Time } \\
\text { Interval }\end{array}$ & Model & $\begin{array}{c}\text { Central } \\
\text { Pressure } \\
(\mathrm{hPa})\end{array}$ & $\begin{array}{c}\text { 24-hour } \\
\text { Obs. }\end{array}$ & $\begin{array}{c}\text { 24-hour } \\
\text { Press } \\
\text { Model } \\
\text { (hPa) }\end{array}$ & $\%$ error & $\begin{array}{c}\text { Correct } \\
\text { Selected } \\
\text { Model } \\
(\mathrm{hPa})\end{array}$ & $\begin{array}{c}\text { Improv. } \\
(\mathrm{hPa})\end{array}$ \\
\hline $7 / 1112 Z$ & 1 & 1 & 1008 & 8 & 7.49 & 6.4 & $\mathrm{~N} / \mathrm{a}$ & $\mathrm{N} / \mathrm{a}$ \\
\hline $7 / 1118 \mathrm{Z}$ & 2 & 1 & 1008 & 8 & 8.70 & 8.9 & $\mathrm{~N} / \mathrm{a}$ & $\mathrm{N} / \mathrm{a}$ \\
\hline $7 / 120 Z$ & 3 & 1 & 1003 & 6 & 7.77 & 29.6 & $\mathrm{~N} / \mathrm{a}$ & $\mathrm{N} / \mathrm{a}$ \\
\hline $7 / 126 Z$ & 4 & 1 & 1003 & 6 & 10.42 & 73.8 & $\mathrm{~N} / \mathrm{a}$ & $\mathrm{N} / \mathrm{a}$ \\
\hline $7 / 1212 Z$ & 5 & 2 & 1000 & -3 & 11.34 & 478.2 & $\mathrm{~N} / \mathrm{a}$ & $\mathrm{N} / \mathrm{a}$ \\
\hline $7 / 1218 Z$ & 6 & 1 & 1000 & -3 & 11.65 & 488.6 & 12.28 & -0.63 \\
\hline $7 / 130 \mathrm{Z}$ & 7 & 2 & 997 & 5 & 12.31 & 146.2 & $\mathrm{~N} / \mathrm{a}$ & $\mathrm{N} / \mathrm{a}$ \\
\hline $7 / 136 Z$ & 8 & 2 & 997 & 6 & 11.15 & 86.0 & $\mathrm{~N} / \mathrm{a}$ & $\mathrm{N} / \mathrm{a}$ \\
\hline $7 / 1312 Z$ & 9 & 1 & 1003 & 27 & 12.08 & 55.2 & 25.82 & 13.90 \\
\hline $7 / 1318 Z$ & 10 & 1 & 1003 & 35 & $\overline{12.76}$ & 63.5 & 24.10 & 11.34 \\
\hline $7 / 140 Z$ & 11 & 3 & 992 & 35 & 30.40 & 13.1 & $\mathrm{~N} / \mathrm{a}$ & $\mathrm{N} / \mathrm{a}$ \\
\hline $7 / 146 Z$ & 12 & 3 & 991 & 39 & 30.96 & 20.6 & $\mathrm{~N} / \mathrm{a}$ & $\mathrm{N} / \mathrm{a}$ \\
\hline $7 / 1412 Z$ & 13 & 3 & 976 & 8 & 30.60 & 282.5 & 9.82 & 20.78 \\
\hline $7 / 1418 Z$ & 14 & 4 & 968 & -1 & 0.77 & 177.8 & $\mathrm{~N} / \mathrm{a}$ & $\mathrm{N} / \mathrm{a}$ \\
\hline $7 / 150 Z$ & 15 & 4 & 957 & 3 & -0.91 & 130.5 & $\mathrm{~N} / \mathrm{a}$ & $\mathrm{N} / \mathrm{a}$ \\
\hline $7 / 156 Z$ & 16 & 4 & 952 & 2 & -5.87 & 393.5 & $\mathrm{~N} / \mathrm{a}$ & $\mathrm{N} / \mathrm{a}$ \\
\hline
\end{tabular}

Table 4.48: 24-hour pressure drop model for Hurricane Emily. 
during Time Intervals 9 and 10) added accuracy to the forecast by factoring the high core heat potential. Shortly before the onset and at the onset of the RIP (Time Intervals 11 and 12), the selected model was within 5 and $9 \mathrm{hPa}$ respectively of the observations. The model was predicting a $960 \mathrm{hPa}$ hurricane when Emily actually reached $952 \mathrm{hPa}$ in 24 hours. Time Interval 13 (DFA selected Model 3) was misclassified and continued to predict an approximate $30 \mathrm{hPa}$ deepening, forecasting a $946 \mathrm{hPa}$ hurricane. The CSM (Model 4) forecasted a $10 \mathrm{hPa}$ deepening, close to the observed value of $8 \mathrm{hPa}$. Shortly after the end of the RIP, Emily was starting eyewall replacement cycles, causing it to weaken after the rapid intensification.

The 24-hour wind speed model (Table 4.49) also had low errors with the exception of Time Intervals 5-6, when high translational speed, mid-level dry air, and moderate shear were taking place, and Time Intervals 15-16, which could not take into account the eyewall replacement cycle that occurred outside of the time of study. The DFA selected model was more accurate than the NHC for 11 of the 16 time intervals. The 5 exceptions occurred from Time Intervals 3-5, even though the NHC was only slightly better (less than 5 knots), and Time Intervals 15 and 16, which were affected by the eyewall replacement cycles. Between Time Intervals 7-10, the selected model was slightly better than the NHC, however, the CSM (Model 3) added greater accuracy during Intervals 9 and 10 since it considered the very low MPI (approximately $880 \mathrm{hPa}$ ). It improved on the selected model by 15 knots and on the NHC forecast by 17-20 knots. By factoring the high SST in the MPI, the CSM was much closer to forecasting the rapid intensification as seen in Time Intervals 11-13. During these intervals, the model 


\begin{tabular}{|c|c|c|c|c|c|c|c|c|c|}
\hline $\begin{array}{c}\text { Time } \\
\text { Int. }\end{array}$ & Model & $\begin{array}{l}\text { Max. } \\
\text { Sus. } \\
\text { Wind } \\
\text { (kts) }\end{array}$ & $\begin{array}{c}\text { 24-hour } \\
\text { Obs. }\end{array}$ & $\begin{array}{c}\text { 24-hour } \\
\text { Model } \\
\text { (kts) }\end{array}$ & $\%$ error & $\begin{array}{c}\text { NHC } \\
24 \text { hour } \\
\text { For. }\end{array}$ & $\begin{array}{c}\text { NHC } \\
\% \\
\text { error }\end{array}$ & $\begin{array}{l}\text { CSM } \\
(\mathrm{kts})\end{array}$ & $\begin{array}{c}\text { Improv. } \\
(\mathrm{kts})\end{array}$ \\
\hline 1 & 1 & 30 & 15 & 14.49 & 3.3 & 10 & 33.3 & $\mathrm{~N} / \mathrm{a}$ & $\mathrm{N} / \mathrm{a}$ \\
\hline 2 & 1 & 30 & 15 & 14.01 & 6.6 & 10 & 33.3 & $\mathrm{~N} / \mathrm{a}$ & N/a \\
\hline 3 & 1 & 40 & 10 & 18.91 & 89.1 & 15 & 50.0 & $\mathrm{~N} / \mathrm{a}$ & $\mathrm{N} / \mathrm{a}$ \\
\hline 4 & 1 & 40 & 10 & 15.89 & 59.0 & 15 & 50.0 & $\mathrm{~N} / \mathrm{a}$ & N/a \\
\hline 5 & 2 & 45 & 5 & 19.76 & 295.3 & 15 & 200 & $\mathrm{~N} / \mathrm{a}$ & $\mathrm{N} / \mathrm{a}$ \\
\hline 6 & 1 & 45 & 5 & 17.37 & 247.6 & 20 & 300 & 18.98 & -1.61 \\
\hline 7 & 2 & 50 & 30 & 19.44 & 35.2 & 15 & 50.0 & $\mathrm{~N} / \mathrm{a}$ & $\mathrm{N} / \mathrm{a}$ \\
\hline 8 & 2 & 50 & 30 & 18.80 & 37.3 & 15 & 50.0 & $\mathrm{~N} / \mathrm{a}$ & $\mathrm{N} / \mathrm{a}$ \\
\hline 9 & 1 & 50 & 35 & 16.79 & 52.0 & 15 & 57.1 & 37.47 & 15.74 \\
\hline 10 & 1 & 50 & 50 & 17.12 & 65.8 & 15 & 70.0 & 32.24 & 15.12 \\
\hline 11 & 3 & 80 & 30 & 31.93 & 6.5 & 10 & 66.7 & $\mathrm{~N} / \mathrm{a}$ & $\mathrm{N} / \mathrm{a}$ \\
\hline 12 & 3 & 80 & 35 & 33.92 & 3.1 & 10 & 71.4 & $\mathrm{~N} / \mathrm{a}$ & $\mathrm{N} / \mathrm{a}$ \\
\hline 13 & 3 & 85 & 25 & 32.76 & 31.1 & 15 & 40.0 & 6.77 & -10.47 \\
\hline 14 & 4 & 100 & -10 & -10.09 & 0.9 & 15 & 250 & N/a & N/a \\
\hline 15 & 4 & 110 & 5 & 30.41 & 508.4 & 5 & 0.0 & N/a & $\mathrm{N} / \mathrm{a}$ \\
\hline 16 & 4 & 115 & 5 & 29.92 & 498.6 & 0 & 100 & $\mathrm{~N} / \mathrm{a}$ & $\mathrm{N} / \mathrm{a}$ \\
\hline
\end{tabular}

Table 4.49: 24-hour wind speed increase model for Hurricane Emily. 
forecasted within 2, 2, and 8 knots, respectively, whereas the NHC forecasted within 20, 25 , and 10 knots, respectively.

As for the 6-hour pressure model (Table 4.50), the highest percentage errors occurred during Time Interval 8, which consistently did not consider some of the inhibiting factors, Time Interval 11, which overestimated the deepening due the high core heat potential, and Time Interval 16 because of the previously mentioned eyewall replacement. The high "spike" in core heat potential (over $60 \mathrm{~kJ} \mathrm{~cm}^{-2}$ ) that occurred in Time Interval 11 did not cause the pressure to drop rapidly until 12 hours later, indicating a lag response to the core heat potential. The 6-hour wind speed increase model (Table 4.51) did capture the modest intensification prior to Time Interval 10 but, unfortunately, Models 3 and 4 did not consider some of the key thermodynamic factors such as heat potential and SST that caused Emily to rapidly intensify. Models 3 and 4 tended to greatly underestimate the intensification with the exception of Time Interval 11. Here, Model 3 used the previous 6-hour wind speed change, and since it had increased 30 knots in the previous 6 hours, it overestimated in this case. 


\begin{tabular}{|c|c|c|c|c|c|c|c|c|}
\hline Date & $\begin{array}{l}\text { Time } \\
\text { Int. }\end{array}$ & Model & $\begin{array}{c}\text { Cent. } \\
\text { Pressure } \\
(\mathrm{hPa})\end{array}$ & $\begin{array}{c}\text { 6-hour Pres. } \\
\text { Drop Obs. }\end{array}$ & $\begin{array}{c}\text { 6-hour } \\
\text { Model } \\
\text { (hPa) }\end{array}$ & $\begin{array}{l}\% \\
\text { error }\end{array}$ & $\begin{array}{l}\text { CSM } \\
\text { (hPa) }\end{array}$ & $\begin{array}{l}\text { Improv. } \\
(\mathrm{hPa})\end{array}$ \\
\hline $7 / 1112 Z$ & 1 & 1 & 1008 & 0 & 1.55 & $\mathrm{~N} / \mathrm{a}$ & $\mathrm{N} / \mathrm{a}$ & $\mathrm{N} / \mathrm{a}$ \\
\hline $7 / 1118 Z$ & 2 & 1 & 1008 & 5 & 1.80 & 64.0 & $\mathrm{~N} / \mathrm{a}$ & $\mathrm{N} / \mathrm{a}$ \\
\hline $7 / 120 Z$ & 3 & 1 & 1003 & 0 & 3.05 & $\mathrm{~N} / \mathrm{a}$ & $\mathrm{N} / \mathrm{a}$ & $\mathrm{N} / \mathrm{a}$ \\
\hline $7 / 126 \mathrm{Z}$ & 4 & 1 & 1003 & 3 & 2.32 & 22.6 & $\mathrm{~N} / \mathrm{a}$ & N/a \\
\hline $7 / 1212 Z$ & 5 & 2 & 1000 & 0 & 2.63 & $\mathrm{~N} / \mathrm{a}$ & $\mathrm{N} / \mathrm{a}$ & $\mathrm{N} / \mathrm{a}$ \\
\hline $7 / 1218 Z$ & 6 & 1 & 1000 & 3 & 2.32 & 22.6 & 1.53 & -0.79 \\
\hline $7 / 130 \mathrm{Z}$ & 7 & 2 & 997 & 0 & 2.63 & $\mathrm{~N} / \mathrm{a}$ & $\mathrm{N} / \mathrm{a}$ & $\mathrm{N} / \mathrm{a}$ \\
\hline $7 / 136 Z$ & 8 & 2 & 997 & -6 & 1.53 & 125.5 & $\mathrm{~N} / \mathrm{a}$ & $\mathrm{N} / \mathrm{a}$ \\
\hline $7 / 1312 Z$ & 9 & 1 & 1003 & 0 & 2.77 & N/a & 3.26 & -0.49 \\
\hline $7 / 1318 Z$ & 10 & 1 & 1003 & 11 & 2.73 & 75.1 & 3.40 & 0.67 \\
\hline $7 / 140 Z$ & 11 & 3 & 992 & 1 & 8.90 & 790.0 & $\mathrm{~N} / \mathrm{a}$ & $\mathrm{N} / \mathrm{a}$ \\
\hline $7 / 146 Z$ & 12 & 3 & 991 & 15 & 3.36 & 77.6 & $\mathrm{~N} / \mathrm{a}$ & $\mathrm{N} / \mathrm{a}$ \\
\hline $7 / 1412 Z$ & 13 & 3 & 976 & 8 & 4.17 & 47.8 & 8.40 & 3.43 \\
\hline $7 / 1418 Z$ & 14 & 4 & 968 & 11 & 6.17 & 43.9 & $\mathrm{~N} / \mathrm{a}$ & $\mathrm{N} / \mathrm{a}$ \\
\hline $7 / 150 Z$ & 15 & 4 & 957 & -5 & 7.22 & 244.4 & $\mathrm{~N} / \mathrm{a}$ & $\mathrm{N} / \mathrm{a}$ \\
\hline $7 / 156 Z$ & 16 & 4 & 952 & -16 & 9.83 & 234.8 & $\mathrm{~N} / \mathrm{a}$ & $\mathrm{N} / \mathrm{a}$ \\
\hline
\end{tabular}

Table 4.50: 6-hour pressure drop model for Hurricane Emily. 


\begin{tabular}{|c|c|c|c|c|c|c|c|c|}
\hline Date & $\begin{array}{l}\text { Time } \\
\text { Int. }\end{array}$ & Model & $\begin{array}{l}\text { Max. Sus. } \\
\text { Winds (kts) }\end{array}$ & $\begin{array}{c}\text { 6-hour } \\
\text { Wind } \\
\text { Speed Obs. }\end{array}$ & $\begin{array}{c}\text { 6-hour } \\
\text { Model } \\
\text { (kts) }\end{array}$ & $\%$ error & $\begin{array}{l}\text { CSM } \\
(\mathrm{kts})\end{array}$ & $\begin{array}{c}\text { Improv. } \\
(\mathrm{kts})\end{array}$ \\
\hline $7 / 1112 Z$ & 1 & 1 & 30 & 0 & 2.19 & $\mathrm{~N} / \mathrm{a}$ & $\mathrm{N} / \mathrm{a}$ & $\mathrm{N} / \mathrm{a}$ \\
\hline $7 / 1118 Z$ & 2 & 1 & 30 & 10 & 2.23 & 77.6 & $\mathrm{~N} / \mathrm{a}$ & $\mathrm{N} / \mathrm{a}$ \\
\hline $7 / 120 Z$ & 3 & 1 & 40 & 0 & 6.64 & $\mathrm{~N} / \mathrm{a}$ & $\mathrm{N} / \mathrm{a}$ & $\mathrm{N} / \mathrm{a}$ \\
\hline $7 / 126 Z$ & 4 & 1 & 40 & 5 & 2.32 & 53.5 & $\mathrm{~N} / \mathrm{a}$ & $\mathrm{N} / \mathrm{a}$ \\
\hline $7 / 1212 Z$ & 5 & 2 & 45 & 0 & 3.82 & $\mathrm{~N} / \mathrm{a}$ & N/a & $\mathrm{N} / \mathrm{a}$ \\
\hline $7 / 1218 Z$ & 6 & 1 & 45 & 5 & 2.81 & 43.8 & 4.41 & 1.60 \\
\hline $7 / 130 \mathrm{Z}$ & 7 & 2 & 50 & 0 & 2.92 & $\mathrm{~N} / \mathrm{a}$ & $\mathrm{N} / \mathrm{a}$ & $\mathrm{N} / \mathrm{a}$ \\
\hline $7 / 136 Z$ & 8 & 2 & 50 & 0 & 2.29 & $\mathrm{~N} / \mathrm{a}$ & $\mathrm{N} / \mathrm{a}$ & $\mathrm{N} / \mathrm{a}$ \\
\hline $7 / 1312 Z$ & 9 & 1 & 50 & 0 & 2.46 & N/a & 5.16 & -2.70 \\
\hline $7 / 1318 Z$ & 10 & 1 & 50 & 30 & 2.61 & 91.3 & 4.58 & 1.97 \\
\hline $7 / 140 Z$ & 11 & 3 & 80 & 0 & 11.78 & $\mathrm{~N} / \mathrm{a}$ & $\mathrm{N} / \mathrm{a}$ & $\mathrm{N} / \mathrm{a}$ \\
\hline $7 / 146 Z$ & 12 & 3 & 80 & 5 & 4.90 & 1.8 & $\mathrm{~N} / \mathrm{a}$ & $\mathrm{N} / \mathrm{a}$ \\
\hline $7 / 1412 Z$ & 13 & 3 & 85 & 15 & 5.85 & 61.0 & 11.29 & 5.44 \\
\hline $7 / 1418 Z$ & 14 & 4 & 100 & 10 & 9.77 & 2.2 & $\mathrm{~N} / \mathrm{a}$ & $\mathrm{N} / \mathrm{a}$ \\
\hline $7 / 150 Z$ & 15 & 4 & 110 & 5 & 8.63 & 72.8 & $\mathrm{~N} / \mathrm{a}$ & $\mathrm{N} / \mathrm{a}$ \\
\hline $7 / 156 Z$ & 16 & 4 & 115 & -5 & 7.98 & 259.6 & $\mathrm{~N} / \mathrm{a}$ & $\mathrm{N} / \mathrm{a}$ \\
\hline
\end{tabular}

Table 4.51: 6-hour wind speed increase model for Hurricane Emily. 


\subsubsection{Hurricane Irene (2005)}

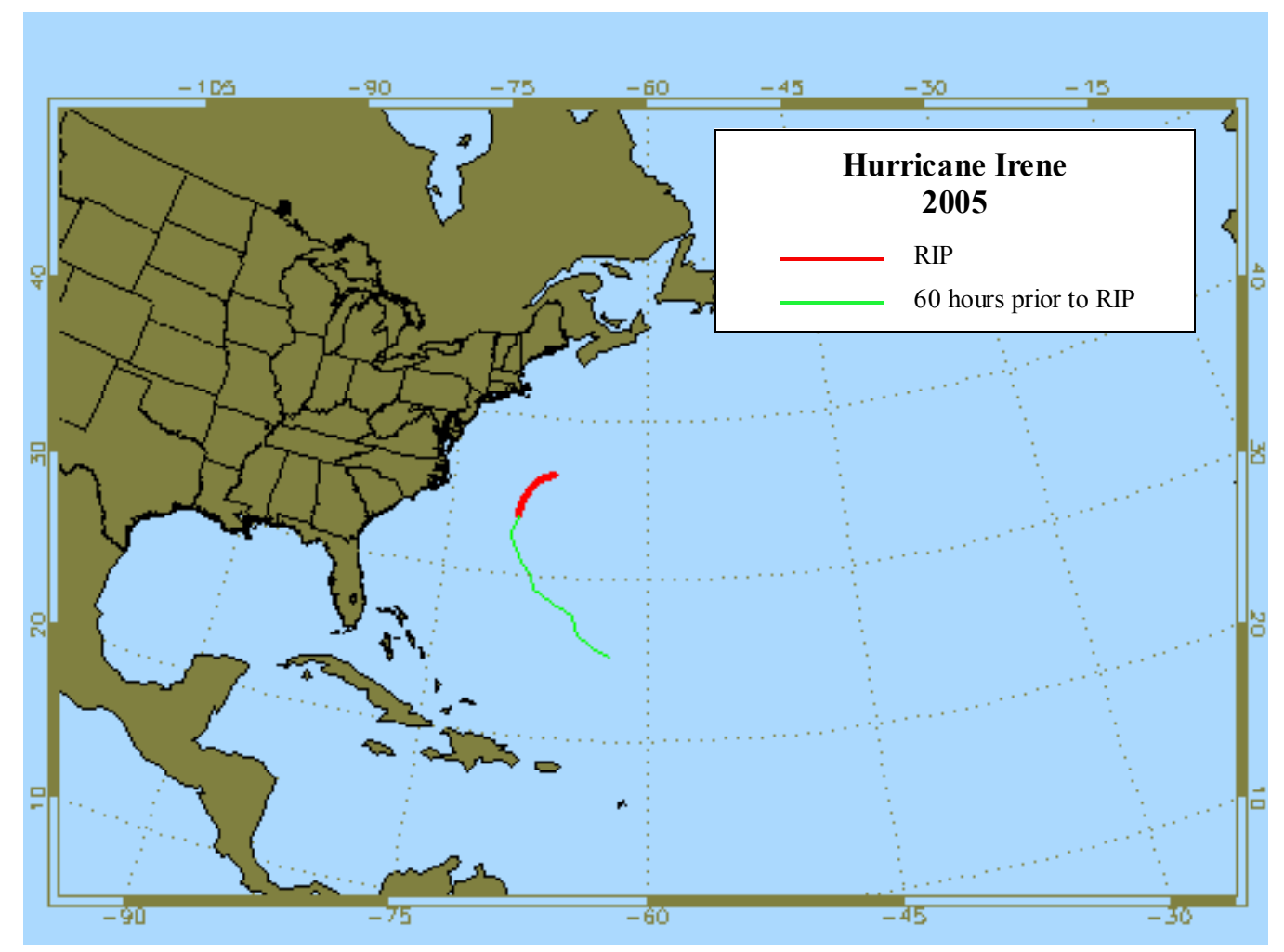

Figure 4.12: Track of Hurricane Irene (2005).

The study for Irene began at $12 \mathrm{Z}$ August 11 when it was approximately 300 miles northeast of the Leeward Islands and already at tropical storm strength. The vertical shear was low allowing convection to develop as Irene started to turn toward the northwest. As it moved toward the northwest, Irene moved around a ridge located near Bermuda, which also caused the vertical shear to relax, permitting Irene to further intensify. The intensification was very slow leading to the RIP since the core heat 
potential was very low $\left(10 \mathrm{~kJ} \mathrm{~cm}^{-2}\right)$. Irene, as a tropical storm, continued to move between Bermuda and the North Carolina Outer Banks and entered the RIP at $6 \mathrm{Z}$ on August 14. It reached hurricane strength just 12 hours later and was a strong Category 1 hurricane at the end of the RIP. Irene then turned toward the northeast but would only attain Category 2 status as it progressed into the North Atlantic.

The DFA misclassified all 16 time intervals classifying all intervals as a major hurricane, when it only became a minor hurricane. Irene possessed some of the characteristics of eventual major hurricanes including low vertical wind shear and initial high heat potential. However, Irene was moving rapidly to the north, and as it started to re-curve to the northeast, it quickly encountered the unfavorable cooler waters of the North Atlantic. Had it not encountered the cooler waters shortly after the RIP, Irene might have had time to become a minimal major hurricane.

Even though it was the wrong model (Table 4.52), Model 1 predicted the 24-hour pressure drop fairly well (Time Intervals 1 and 3). The CSM (Model 5) was slightly more accurate. When Model 2 was selected (Time Intervals 2 and 4-6), it did not perform as well as the CSM for the respective intervals. Both Model 5 and Model 6 would have been better predictors because they considered some of the inhibiting factors that kept Irene from rapidly intensifying, including the translational speed and the wind shear. However, one of the key differences between the major hurricane and minor hurricane model is the coefficient for the SST. For the major Model 2, the SST coefficient was strongly positive whereas it was strongly negative for the minor Model 6. Therefore the two models produced different results for these time intervals when the 


\begin{tabular}{|c|c|c|c|c|c|c|c|c|}
\hline $\begin{array}{l}\text { Date } \\
(2005)\end{array}$ & $\begin{array}{c}\text { Time } \\
\text { Interval }\end{array}$ & Model & $\begin{array}{c}\text { Central } \\
\text { Pressure } \\
(\mathrm{hPa})\end{array}$ & $\begin{array}{c}\text { 24-hour } \\
\text { Obs. }\end{array}$ & $\begin{array}{c}\text { 24-hour } \\
\text { Press } \\
\text { Model } \\
\text { (hPa) }\end{array}$ & $\%$ error & $\begin{array}{c}\text { Correct } \\
\text { Selected } \\
\text { Model } \\
(\mathrm{hPa})\end{array}$ & $\begin{array}{c}\text { Improv. } \\
(\mathrm{hPa})\end{array}$ \\
\hline $8 / 1112 Z$ & 1 & 1 & 1000 & 6 & 4.52 & 24.6 & 6.01 & 1.47 \\
\hline $8 / 1118 \mathrm{Z}$ & 2 & 2 & 1000 & 3 & 11.61 & 287.1 & 5.97 & 5.64 \\
\hline $8 / 120 Z$ & 3 & 1 & 1000 & 9 & 3.67 & 59.2 & 5.84 & 2.17 \\
\hline $8 / 126 Z$ & 4 & 2 & 997 & 0 & 12.16 & $\mathrm{~N} / \mathrm{a}$ & 7.19 & 4.97 \\
\hline $8 / 1212 Z$ & 5 & 2 & 994 & -3 & 11.17 & 472.5 & 2.18 & 8.99 \\
\hline $8 / 1218 Z$ & 6 & 2 & 997 & -2 & 11.36 & 668.3 & 1.11 & 10.25 \\
\hline $8 / 130 Z$ & 7 & 3 & 991 & -6 & 12.57 & 309.7 & 2.18 & 10.39 \\
\hline $8 / 136 Z$ & 8 & 3 & 997 & -2 & 11.26 & 663.5 & 1.73 & 9.53 \\
\hline $8 / 1312 Z$ & 9 & 3 & 997 & -2 & 11.01 & 650.5 & 12.41 & -1.40 \\
\hline $8 / 1318 Z$ & 10 & 3 & 999 & 7 & 10.62 & 51.8 & 12.57 & -1.95 \\
\hline $8 / 140 Z$ & 11 & 3 & 997 & 8 & 10.69 & 33.7 & 12.84 & -2.15 \\
\hline $8 / 146 Z$ & 12 & 3 & 999 & 14 & 10.35 & 26.1 & 13.40 & 3.05 \\
\hline $8 / 1412 Z$ & 13 & 3 & 999 & 14 & 9.26 & 33.8 & 2.06 & -7.20 \\
\hline $8 / 1418 Z$ & 14 & 3 & 992 & 12 & 9.99 & 16.7 & 6.14 & -3.85 \\
\hline $8 / 150 Z$ & 15 & 4 & 989 & 9 & 19.62 & 118.1 & 3.12 & 4.74 \\
\hline $8 / 156 Z$ & 16 & 4 & 985 & 2 & 15.04 & 652.4 & 2.75 & 12.29 \\
\hline
\end{tabular}

Table 4.52: 24-hour pressure drop model for Hurricane Irene. 
SST was very high at $302 \mathrm{~K}$. Model 3, which factors core heat potential, was selected for Time Intervals 7-14 but it did not do well during intervals 7-9, when the core heat potential was low. It produced large errors because major hurricanes do not occur when heat potential values are that low. But when the core heat potential increased (Time Intervals 10-14), the error was much lower. The CSM (Time Intervals 10-14) did not provide significant improvement when the core heat potential increased to values more representative of major hurricanes. The selected model during Time Intervals 15 and 16 produced an unrealistic result because Model 4 factored the current heat potential, which was high at the end of the RIP but rapidly decreased due to the colder water.

For the 24-hour wind speed increase (Table 4.53), the selected DFA models were only able to predict 7 of the 16 intervals more accurately than the NHC (Time Intervals 36 and 12-14). Had the CSM been used in all time intervals, it would have predicted 10 out of the 16 intervals more accurately than the NHC. The major model still performed well when Irene was intensifying fairly rapidly, as can be seen from Time Intervals 3-6 and 12-14. This was when the heat potential was high and representative of major hurricanes. But when the heat potential decreased dramatically, the intensification lessened and the selected model produced large errors. Here, the CSM minor models improved the prediction significantly and outperformed the NHC. The selected DFA model (Model 4) produced a greatly exaggerated result in Time Interval 15 and 16 because of the high heat potential (positive coefficient) and low wind speed (negative coefficient) exhibited.

As with the previous types of models, the short-term 6-hour pressure drop model (Table 4.54) forecasted well when the pressure dropped. However, when the pressure 


\begin{tabular}{|c|c|c|c|c|c|c|c|c|c|}
\hline $\begin{array}{c}\text { Time } \\
\text { Int. }\end{array}$ & Model & $\begin{array}{l}\text { Max. } \\
\text { Sus. } \\
\text { Wind } \\
\text { (kts) }\end{array}$ & $\begin{array}{c}\text { 24-hour } \\
\text { Obs. }\end{array}$ & $\begin{array}{c}\text { 24-hour } \\
\text { Model } \\
\text { (kts) }\end{array}$ & $\%$ error & $\begin{array}{c}\text { NHC } \\
24 \text { hour } \\
\text { For. }\end{array}$ & $\begin{array}{c}\text { NHC } \\
\% \\
\text { error }\end{array}$ & $\begin{array}{l}\text { CSM } \\
\text { (kts) }\end{array}$ & $\begin{array}{c}\text { Improv. } \\
\text { (kts) }\end{array}$ \\
\hline 1 & 1 & 45 & 10 & 18.34 & 83.5 & 15 & 50.0 & 7.13 & 5.47 \\
\hline 2 & 2 & 45 & 15 & 8.72 & 41.8 & 15 & 0.0 & 7.28 & -1.44 \\
\hline 3 & 1 & 45 & 15 & 14.24 & 5.0 & 10 & 33.3 & 7.43 & -6.81 \\
\hline 4 & 2 & 50 & 10 & 11.14 & 11.4 & 15 & 50.0 & 11.71 & -0.57 \\
\hline 5 & 2 & 55 & 5 & 14.04 & 180.8 & 20 & 300 & 7.52 & 6.52 \\
\hline 6 & 2 & 60 & 0 & 2.92 & $\mathrm{~N} / \mathrm{a}$ & 15 & $\mathrm{~N} / \mathrm{a}$ & 0.98 & 1.94 \\
\hline 7 & 3 & 60 & 0 & 21.84 & N/a & 10 & $\mathrm{~N} / \mathrm{a}$ & 5.70 & 16.14 \\
\hline 8 & 3 & 60 & -5 & 18.84 & 476.8 & 5 & 200 & 2.62 & 16.22 \\
\hline 9 & 3 & 60 & -5 & 17.89 & 457.9 & 5 & 200 & 11.31 & 6.58 \\
\hline 10 & 3 & 60 & 0 & 17.21 & N/a & 5 & $\mathrm{~N} / \mathrm{a}$ & 10.98 & 6.23 \\
\hline 11 & 3 & 60 & 10 & 16.00 & 60.1 & 5 & 50.0 & 9.43 & 5.43 \\
\hline 12 & 3 & 55 & 20 & 16.63 & 16.8 & 5 & 75.0 & 10.37 & -6.26 \\
\hline 13 & 3 & 55 & 20 & 13.65 & 31.7 & 5 & 75.0 & 10.50 & -3.15 \\
\hline 14 & 3 & 60 & 20 & 13.14 & 34.3 & 5 & 75.0 & 10.30 & -2.84 \\
\hline 15 & 4 & 70 & 10 & 67.82 & 578.2 & 0 & 100 & -1.07 & 46.75 \\
\hline 16 & 4 & 75 & 0 & 68.90 & N/a & 0 & $\mathrm{~N} / \mathrm{a}$ & -1.03 & 67.87 \\
\hline
\end{tabular}

Table 4.53: 24-hour wind speed increase model for Hurricane Irene. 


\begin{tabular}{|c|c|c|c|c|c|c|c|c|}
\hline Date & $\begin{array}{l}\text { Time } \\
\text { Int. }\end{array}$ & Model & $\begin{array}{c}\text { Cent. } \\
\text { Pressure } \\
(\mathrm{hPa})\end{array}$ & $\begin{array}{c}\text { 6-hour Pres. } \\
\text { Drop Obs. }\end{array}$ & $\begin{array}{l}\text { 6-hour } \\
\text { Model } \\
\text { (hPa) }\end{array}$ & $\begin{array}{l}\% \\
\text { error }\end{array}$ & $\begin{array}{l}\text { CSM } \\
\text { (hPa) }\end{array}$ & $\begin{array}{l}\text { Improv. } \\
(\mathrm{hPa})\end{array}$ \\
\hline $8 / 1112 Z$ & 1 & 1 & 1000 & 0 & 4.25 & $\mathrm{~N} / \mathrm{a}$ & 1.21 & 3.04 \\
\hline $8 / 1118 Z$ & 2 & 2 & 1000 & 0 & 4.84 & $\mathrm{~N} / \mathrm{a}$ & 0.95 & 3.89 \\
\hline $8 / 120 Z$ & 3 & 1 & 1000 & 3 & 2.92 & 2.6 & 0.83 & -2.09 \\
\hline $8 / 126 \mathrm{Z}$ & 4 & 2 & 997 & 3 & 4.84 & 61.3 & 1.45 & 0.29 \\
\hline $8 / 1212 Z$ & 5 & 2 & 994 & -3 & 5.95 & 298.3 & 0.93 & 5.02 \\
\hline $8 / 1218 Z$ & 6 & 2 & 997 & 6 & 4.84 & 19.3 & 0.93 & -3.91 \\
\hline $8 / 130 Z$ & 7 & 3 & 991 & -6 & 3.76 & 162.6 & 0.46 & 3.30 \\
\hline $8 / 136 Z$ & 8 & 3 & 997 & 0 & 2.93 & $\mathrm{~N} / \mathrm{a}$ & 0.46 & 2.47 \\
\hline $8 / 1312 Z$ & 9 & 3 & 997 & -2 & 2.99 & 249.5 & 1.52 & 0.51 \\
\hline $8 / 1318 Z$ & 10 & 3 & 999 & 2 & 3.08 & 54.0 & 1.59 & 0.47 \\
\hline $8 / 140 Z$ & 11 & 3 & 997 & -2 & 3.23 & 261.5 & 1.48 & 1.75 \\
\hline $8 / 146 Z$ & 12 & 3 & 999 & 0 & 3.34 & $\mathrm{~N} / \mathrm{a}$ & 0.89 & 2.45 \\
\hline $8 / 1412 Z$ & 13 & 3 & 999 & 7 & 3.46 & 50.5 & 2.97 & -0.49 \\
\hline $8 / 1418 Z$ & 14 & 3 & 992 & 3 & 3.45 & 15.0 & 3.78 & -0.33 \\
\hline $8 / 150 Z$ & 15 & 4 & 989 & 4 & 5.27 & 31.7 & 3.80 & 1.07 \\
\hline $8 / 156 Z$ & 16 & 4 & 985 & 2 & 0.83 & 58.5 & 3.76 & -0.59 \\
\hline
\end{tabular}

Table 4.54: 6-hour pressure drop model for Hurricane Irene. 
actually increased, the selected DFA model overestimated the decrease of the pressure. The CSM, utilizing the minor hurricane model, was more accurate for reasons similar to those stated earlier. In addition, the minor hurricane model factored the previous 6-hour wind speed change and since the wind speed changed very little, it forecasted a modest change. The DFA selected major models had higher positive coefficients on the wind speed change which caused them to forecast more intensification. The 6-hour wind speed increase model (Table 4.55) was helped by the fact the wind speeds did not change much between intervals. This helped produce low errors despite using the major hurricane models. However, the CSM for minor hurricanes did help in the majority of the time intervals (12 of the 16). The greatest improvement occurred during Time Intervals 15 and 16 (Model 8) which factored the wind speed at these intervals that happened to be low at the end of the RIP. The low wind speed was much more representative of a minor hurricane than a major hurricane. 


\begin{tabular}{|c|c|c|c|c|c|c|c|c|}
\hline Date & $\begin{array}{l}\text { Time } \\
\text { Int. }\end{array}$ & Model & $\begin{array}{l}\text { Max. Sus. } \\
\text { Winds (kts) }\end{array}$ & $\begin{array}{c}\text { 6-hour } \\
\text { Wind } \\
\text { Speed Obs. }\end{array}$ & $\begin{array}{c}\text { 6-hour } \\
\text { Model } \\
\text { (kts) }\end{array}$ & $\%$ error & $\begin{array}{l}\text { CSM } \\
(\mathrm{kts})\end{array}$ & $\begin{array}{c}\text { Improv. } \\
(\mathrm{kts})\end{array}$ \\
\hline $8 / 1112 Z$ & 1 & 1 & 45 & 0 & 8.02 & $\mathrm{~N} / \mathrm{a}$ & 2.95 & 5.07 \\
\hline $8 / 1118 Z$ & 2 & 2 & 45 & 0 & 5.86 & $\mathrm{~N} / \mathrm{a}$ & 2.34 & 3.52 \\
\hline $8 / 120 \mathrm{Z}$ & 3 & 1 & 45 & 5 & 5.98 & 19.7 & 2.06 & -1.96 \\
\hline $8 / 126 Z$ & 4 & 2 & 50 & 5 & 4.94 & 1.1 & 3.60 & -1.34 \\
\hline $8 / 1212 Z$ & 5 & 2 & 55 & 5 & 6.71 & 34.3 & 2.48 & -0.81 \\
\hline $8 / 1218 Z$ & 6 & 2 & 60 & 0 & 6.00 & $\mathrm{~N} / \mathrm{a}$ & -0.50 & 5.50 \\
\hline $8 / 130 \mathrm{Z}$ & 7 & 3 & 60 & 0 & 6.02 & $\mathrm{~N} / \mathrm{a}$ & 0.00 & 6.02 \\
\hline $8 / 136 Z$ & 8 & 3 & 60 & 0 & 4.43 & $\mathrm{~N} / \mathrm{a}$ & -1.83 & 2.60 \\
\hline $8 / 1312 Z$ & 9 & 3 & 60 & 0 & 4.38 & $\mathrm{~N} / \mathrm{a}$ & 1.37 & 3.01 \\
\hline $8 / 1318 Z$ & 10 & 3 & 60 & 0 & 4.27 & $\mathrm{~N} / \mathrm{a}$ & 1.32 & 2.95 \\
\hline $8 / 140 Z$ & 11 & 3 & 60 & -5 & 4.23 & 184.6 & 1.24 & 2.99 \\
\hline $8 / 146 Z$ & 12 & 3 & 55 & 0 & 4.43 & $\mathrm{~N} / \mathrm{a}$ & -0.64 & 3.79 \\
\hline $8 / 1412 Z$ & 13 & 3 & 55 & 5 & 4.08 & 18.4 & 3.63 & -0.45 \\
\hline $8 / 1418 Z$ & 14 & 3 & 60 & 10 & 4.06 & 59.4 & 4.55 & 0.49 \\
\hline $8 / 150 Z$ & 15 & 4 & 70 & 5 & 15.54 & 210.9 & 2.74 & 8.28 \\
\hline $8 / 156 Z$ & 16 & 4 & 75 & 0 & 15.64 & $\mathrm{~N} / \mathrm{a}$ & 0.87 & 14.77 \\
\hline
\end{tabular}

Table 4.55: 6-hour wind speed increase model for Hurricane Irene. 


\subsubsection{Hurricane Katrina (2005)}

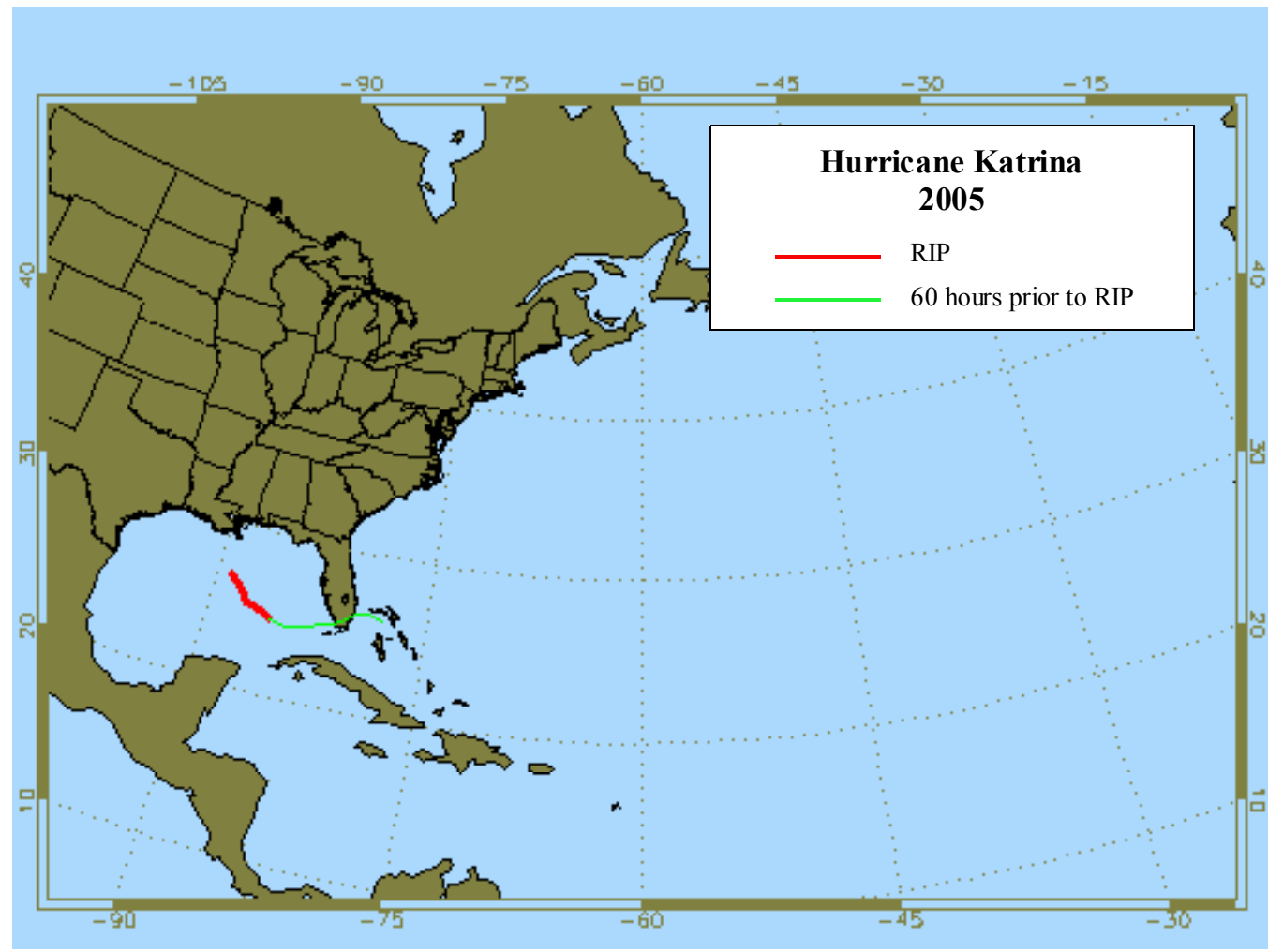

Figure 4.13: Track of Hurricane Katrina (2005).

Katrina's track study began at $0 Z$ on August 25 when it was just west of the central Bahamas. At this point, Katrina was a tropical storm and headed toward South Florida because a strong upper level ridge located over the northern Gulf of Mexico steered it to the south. Initially, Katrina generated deep convection due to the low wind shear and abundant heat potential. This caused Katrina to reach hurricane status around 
$21 Z$ August 25 or just 2 hours prior to landfall along the southeastern Florida coast. Katrina passed over South Florida as a Category 1 hurricane but started to develop an asymmetric pattern due to the northerly shear. Nevertheless, Katrina did not weaken as much as anticipated, remaining a strong tropical storm on the southwest coast of Florida near 5Z August 26. When Katrina reemerged over the Gulf of Mexico, it intensified quickly to Category 1 strength at $6 \mathrm{Z}$ August 26.

Katrina was now located underneath an upper level high pressure which helped create low wind shear and good outflow. Combined with the incredibly high heat potential in the Gulf, Katrina intensified extremely rapidly. At the onset of the RIP at $18 \mathrm{Z}$ August 27, Katrina was already a Category 3 hurricane. By the end of the RIP, 24 hours later, Katrina had achieved Category 5 status with winds of 145 knots and a central pressure of $902 \mathrm{hPa}$, at the time the third lowest recorded pressure in the Atlantic basin. Katrina would eventually weaken to Category 3 strength just before making landfall within 24 hours near the Louisiana and Mississippi border.

The DFA was able to correctly classify all 16 time intervals as becoming a major hurricane beginning with Time Interval 1 when it was still a tropical storm and at least 18 hours from achieving hurricane status. Katrina exhibited all of the classic characteristics of becoming a major hurricane, including very low $850-200 \mathrm{hPa}$ vertical wind shear and the unusually high heat potential that was in the Gulf of Mexico. A warm core ring located in the central Gulf had extraordinary heat potential values over $100 \mathrm{~kJ} \mathrm{~cm}^{-2}$. Passing over the warm core ring helped transform Katrina into a massive Category 5 hurricane, which likely would not have occurred without the effect of the warm core ring. The DFA was not as accurate selecting the time interval with respect to the RIP. It 
correctly classified only 5 of the 16 intervals because Katrina had such an unusually low pressure leading up to the RIP. The DFA classified it only 6 hours away from the RIP when Katrina had a central pressure of $965 \mathrm{hPa}$ at Time Interval 9. However, it did not officially start the RIP until Time Interval 12 when the central pressure was $945 \mathrm{hPa}$. This very low pressure leading up to the RIP caused the DFA to predict it was closer to the RIP than it actually was. Therefore Model 1 was not selected at all, Model 2 was selected for the Time Intervals 1 and 2, Model 3 was selected for Time Intervals 3-9, and Model 4 was selected to be used from Time Interval 10-16.

Table 4.56 shows the 24-hour pressure drop model; overall, it had low percentage errors despite the abundance of misclassifications. Usually Model 2 is not an aggressive model, but during Time Intervals 1 and 2, it forecasted moderate deepening because of the high SSTs (more than $303 \mathrm{~K}$ ) and the extremely low MPI (approximately $850 \mathrm{hPa}$ ). It was more accurate than the CSM (Model 1) because it factored these variables. Model 3 was selected to be used from Time Interval 3-9 and was very aggressive because of the consideration of the core heat potential and the current wind speed. The core heat potential during this period ranged from $40-70 \mathrm{~kJ} \mathrm{~cm}^{-2}$ and the wind speed was fairly high (50-90 knots). Even though these intervals were mostly misclassified, these intervals had characteristics of hurricanes that were very close to the RIP. In fact, Katrina went through a "secondary" rapid intensification before undergoing the primary RIP, which likely caused the DFA to select the models it did. Since it was going through the secondary rapid intensification during these time intervals, Model 3 was very accurate and more accurate than the CSM. At Time Interval 9, the DFA selected model was 


\begin{tabular}{|c|c|c|c|c|c|c|c|c|}
\hline $\begin{array}{l}\text { Date } \\
(2005)\end{array}$ & $\begin{array}{c}\text { Time } \\
\text { Interval }\end{array}$ & Model & $\begin{array}{c}\text { Central } \\
\text { Pressure } \\
(\mathrm{hPa})\end{array}$ & $\begin{array}{c}\text { 24-hour } \\
\text { Obs. }\end{array}$ & $\begin{array}{l}\text { 24-hour } \\
\text { Press } \\
\text { Model } \\
\text { (hPa) }\end{array}$ & $\%$ error & $\begin{array}{c}\text { Correct } \\
\text { Selected } \\
\text { Model } \\
(\mathrm{hPa})\end{array}$ & $\begin{array}{c}\text { Improv. } \\
(\mathrm{hPa})\end{array}$ \\
\hline $8 / 250 Z$ & 1 & 2 & 1001 & 17 & $\overline{15.05}$ & 11.4 & 8.75 & -6.30 \\
\hline $8 / 256 Z$ & 2 & 2 & 1000 & 13 & 14.36 & 10.5 & 7.81 & -3.83 \\
\hline $8 / 2512 Z$ & 3 & 3 & 997 & 16 & 25.55 & 59.7 & 7.30 & 0.85 \\
\hline $8 / 2518 Z$ & 4 & 3 & 985 & 20 & 27.65 & 38.3 & 6.14 & -6.21 \\
\hline $8 / 260 Z$ & 5 & 3 & 984 & 19 & 25.49 & 34.2 & 15.46 & 2.95 \\
\hline $8 / 266 Z$ & 6 & 3 & 987 & 42 & 24.65 & 41.3 & 15.40 & -9.25 \\
\hline $8 / 2612 Z$ & 7 & 3 & 981 & 41 & 26.25 & 36.0 & 13.70 & -12.55 \\
\hline $8 / 2618 Z$ & 8 & 3 & 965 & 20 & 31.64 & 58.2 & 14.14 & 5.78 \\
\hline $8 / 270 Z$ & 9 & 3 & 965 & 26 & 32.48 & 25.0 & $\mathrm{~N} / \mathrm{a}$ & $\mathrm{N} / \mathrm{a}$ \\
\hline $8 / 276 Z$ & 10 & 4 & 945 & 10 & 7.67 & 23.3 & 34.90 & -22.57 \\
\hline $8 / 2712 Z$ & 11 & 4 & 940 & 33 & 7.83 & 76.3 & 35.21 & 22.96 \\
\hline $8 / 2718 \mathrm{Z}$ & 12 & 4 & 945 & 43 & 11.06 & 74.3 & 35.11 & 24.05 \\
\hline $8 / 280 Z$ & 13 & 4 & 939 & 35 & 5.34 & 84.7 & $\mathrm{~N} / \mathrm{a}$ & $\mathrm{N} / \mathrm{a}$ \\
\hline $8 / 286 Z$ & 14 & 4 & 935 & 20 & -6.27 & 131.4 & $\mathrm{~N} / \mathrm{a}$ & $\mathrm{N} / \mathrm{a}$ \\
\hline $8 / 2812 Z$ & 15 & 4 & 907 & -20 & -19.04 & 4.8 & $\mathrm{~N} / \mathrm{a}$ & $\mathrm{N} / \mathrm{a}$ \\
\hline $8 / 2818 Z$ & 16 & 4 & 902 & -58 & -29.36 & 49.4 & $\mathrm{~N} / \mathrm{a}$ & $\mathrm{N} / \mathrm{a}$ \\
\hline
\end{tabular}

Table 4.56: 24-hour pressure drop model for Hurricane Katrina. 
forecasting a hurricane with an approximate pressure of $933 \mathrm{hPa}$ in 24 hours, whereas the observed pressure was $939 \mathrm{hPa}$. Time Intervals 10-12 were also misclassified and Model 4 was selected to be used instead of the CSM (Model 3). Model 4 greatly underestimated the intensification because of the variables that had negative coefficients, which included MSLP, longitude, and translational speed. The CSM (Model 3) would have continued to forecast rapid intensification because of the high core heat potential and wind speed. It was interesting to note that the CSM would have predicted a 24 hour pressure of approximately $905 \mathrm{hPa}$ and $910 \mathrm{hPa}$ at Time Intervals 11 and 12 respectively. This proved to be very accurate as Katrina eventually had an incredibly low central pressure of $902 \mathrm{hPa}$ at the end of the RIP. Model 4 continued to struggle with Time Intervals 14 and 16, especially Time Interval 16, because Katrina was within 24 hours of making landfall and these models do not consider inland decay.

The DFA-selected 24-hour wind speed model (Table 4.57) was able to outperform the NHC forecasts on 6 of the 16 time intervals. The intervals where it performed the best were Time Intervals 3-7 and 15. Even with the misclassifications, Model 3 was able to forecast the rapid intensification because of the extraordinarily low MPI (below 850 $\mathrm{hPa}$ created by the high SSTs (above $303 \mathrm{~K}$ ) throughout the period. This allowed the model to forecast this "secondary" intensification leading up to the RIP and predict the intensification much better than the NHC. The NHC forecasted a weakening (Time Intervals 3-5) as it passed over South Florida, however both the selected DFA and the CSM suggested otherwise. Since Katrina passed over the Everglades, it did not weaken as it would have if it had passed over drier, more rugged terrain. Model 3 was especially able to capture the rapid intensification, predicting an increase of approximately 40 knots 


\begin{tabular}{|c|c|c|c|c|c|c|c|c|c|}
\hline $\begin{array}{c}\text { Time } \\
\text { Int. }\end{array}$ & Model & $\begin{array}{l}\text { Max. } \\
\text { Sus. } \\
\text { Wind } \\
\text { (kts) }\end{array}$ & $\begin{array}{c}\text { 24-hour } \\
\text { Obs. }\end{array}$ & $\begin{array}{c}\text { 24-hour } \\
\text { Model } \\
\text { (kts) }\end{array}$ & $\%$ error & $\begin{array}{c}\text { NHC } \\
24 \text { hour } \\
\text { For. }\end{array}$ & $\begin{array}{c}\text { NHC } \\
\% \\
\text { error }\end{array}$ & $\begin{array}{l}\text { CSM } \\
\text { (kts) }\end{array}$ & $\begin{array}{c}\text { Improv. } \\
\text { (kts) }\end{array}$ \\
\hline 1 & 2 & 45 & 20 & 22.68 & 13.4 & 20 & 0.0 & 12.16 & -5.16 \\
\hline 2 & 2 & 45 & 20 & 18.98 & 5.1 & 20 & 0.0 & 12.79 & -6.19 \\
\hline 3 & 3 & 50 & 20 & 39.57 & 97.9 & -5 & 125 & 14.98 & 14.55 \\
\hline 4 & 3 & 65 & 20 & 39.53 & 97.7 & -25 & 225 & 18.65 & 18.18 \\
\hline 5 & 3 & 65 & 25 & 40.15 & 60.6 & -10 & 140 & 21.48 & 11.63 \\
\hline 6 & 3 & 65 & 35 & 39.96 & 14.2 & 10 & 71.4 & 17.67 & -12.37 \\
\hline 7 & 3 & 70 & 30 & 39.74 & 32.5 & 10 & 66.7 & 14.73 & -5.53 \\
\hline 8 & 3 & 85 & 15 & 40.26 & 168.4 & 10 & 33.3 & 12.85 & 23.11 \\
\hline 9 & 3 & 90 & 10 & 40.98 & 309.9 & 25 & 150 & N/a & N/a \\
\hline 10 & 4 & 100 & 25 & 10.61 & 57.5 & 15 & 40.0 & 39.67 & -5.28 \\
\hline 11 & 4 & 100 & 50 & 13.86 & 72.3 & 15 & 70.0 & 40.77 & 26.91 \\
\hline 12 & 4 & 100 & 45 & 13.25 & 70.5 & 15 & 66.7 & 39.93 & 26.68 \\
\hline 13 & 4 & 100 & 40 & 7.82 & 80.4 & 20 & 50.0 & $\mathrm{~N} / \mathrm{a}$ & $\mathrm{N} / \mathrm{a}$ \\
\hline 14 & 4 & 125 & 5 & -20.57 & 511.5 & 10 & 100 & N/a & N/a \\
\hline 15 & 4 & 150 & -40 & -33.12 & 17.2 & -10 & 75.0 & N/a & N/a \\
\hline 16 & 4 & 145 & -80 & -38.61 & 51.7 & -85 & 6.3 & N/a & $\mathrm{N} / \mathrm{a}$ \\
\hline
\end{tabular}

Table 4.57: 24-hour wind speed increase model for Hurricane Katrina. 
after Katrina reemerged in the Gulf (Time Intervals 6-7), whereas the NHC only predicted a 10 knot increase. It is interesting to note that during Time Intervals 8 and 9 , the selected model continued to predict a rapid intensification but it did not start until about 18 hours later. At these intervals, the heat potential exhibited a significant increase but there was a slight lag response before the extreme rapid intensification took place. For that reason, the CSM (Model 2) performed better during Time Interval 8 because it did not factor the SST as does Model 3. From Time Intervals 10-16, the DFA selected Model 4 to be used, even though the RIP had not quite started yet. This was because the wind speed was already so high, the central pressure was low, and Katrina had gone through a tremendous amount of intensification that the DFA analyzed that the RIP was in progress. Model 4 did consider the high heat potential; however, this model also considered the high wind speed, longitude and translational speed, all of which have negative coefficients that predict less intensification. The most intriguing aspect was 6hours before and the onset of the RIP (Time Intervals 11 and 12), when the selected DFA model and the NHC forecasted similar wind speeds. However, the CSM (Model 3) predicted an approximate 40 knot increase, basically forecasting a 140 knot hurricane within 24 hours. Katrina eventually achieved wind speeds of 150 knots. Therefore, the CSM only missed the observed value by approximately 10 knots whereas the NHC prediction of 115 knots at the same intervals missed by 35 knots. In summary, the selected DFA models performed well despite the misclassifications until Time Interval 8, but the CSM would have helped on 3 more intervals afterward.

Model 2 for the 6-hour pressure drop (Table 4.58) performed well for the misclassified intervals because of the modest pressure drop, but Model 3 had more 


\begin{tabular}{|c|c|c|c|c|c|c|c|c|}
\hline Date & $\begin{array}{l}\text { Time } \\
\text { Int. }\end{array}$ & Model & $\begin{array}{c}\text { Cent. } \\
\text { Pressure } \\
(\mathrm{hPa})\end{array}$ & $\begin{array}{l}\text { 6-hour Pres. } \\
\text { Drop Obs. }\end{array}$ & $\begin{array}{l}\text { 6-hour } \\
\text { Model } \\
\text { (hPa) }\end{array}$ & $\begin{array}{l}\% \\
\text { error }\end{array}$ & $\begin{array}{l}\text { CSM } \\
(\mathrm{hPa})\end{array}$ & $\begin{array}{c}\text { Improv. } \\
\text { (hPa) }\end{array}$ \\
\hline $8 / 250 Z$ & 1 & 2 & 1001 & 1 & 1.53 & 53.1 & 2.53 & -1.00 \\
\hline $8 / 256 Z$ & 2 & 2 & 1000 & 3 & 1.53 & 49.0 & 2.31 & 0.78 \\
\hline $8 / 2512 Z$ & 3 & 3 & 997 & 12 & 4.14 & 65.5 & 2.85 & -1.29 \\
\hline $8 / 2518 Z$ & 4 & 3 & 985 & 1 & 5.59 & 459.4 & 4.29 & 1.30 \\
\hline $8 / 260 Z$ & 5 & 3 & 984 & -3 & 2.48 & 182.7 & 1.53 & 0.95 \\
\hline $8 / 266 Z$ & 6 & 3 & 987 & 6 & 2.34 & 60.9 & 1.53 & -0.81 \\
\hline $8 / 2612 Z$ & 7 & 3 & 981 & 16 & 3.80 & 76.2 & 2.63 & -1.17 \\
\hline $8 / 2618 Z$ & 8 & 3 & 965 & 0 & 6.25 & N/a & 4.84 & 1.41 \\
\hline $8 / 270 Z$ & 9 & 3 & 965 & 20 & 4.66 & 76.7 & $\mathrm{~N} / \mathrm{a}$ & $\mathrm{N} / \mathrm{a}$ \\
\hline $8 / 276 Z$ & 10 & 4 & 945 & 5 & 11.06 & 121.3 & 5.76 & 5.30 \\
\hline $8 / 2712 Z$ & 11 & 4 & 940 & -5 & 12.22 & 344.4 & 4.01 & 8.21 \\
\hline $8 / 2718 Z$ & 12 & 4 & 945 & 6 & 10.52 & 75.4 & 4.20 & 2.72 \\
\hline $8 / 280 Z$ & 13 & 4 & 939 & 4 & 9.21 & 130.3 & $\mathrm{~N} / \mathrm{a}$ & $\mathrm{N} / \mathrm{a}$ \\
\hline $8 / 286 Z$ & 14 & 4 & 935 & 28 & 7.57 & 73.0 & $\mathrm{~N} / \mathrm{a}$ & $\mathrm{N} / \mathrm{a}$ \\
\hline $8 / 2812 Z$ & 15 & 4 & 907 & 5 & 4.84 & 3.0 & $\mathrm{~N} / \mathrm{a}$ & N/a \\
\hline $8 / 2818 Z$ & 16 & 4 & 902 & -2 & 5.25 & 362.7 & $\mathrm{~N} / \mathrm{a}$ & $\mathrm{N} / \mathrm{a}$ \\
\hline
\end{tabular}

Table 4.58: 6-hour pressure drop model for Hurricane Katrina. 
problems. Even though Model 3 considered the extremely high core heat potential, the parameter was not weighted enough and the results predominantly underestimated the deepening. Unfortunately, the CSM did not offer much improvement either. But the CSM did offer improvement beginning at Time Interval 8, as it did with the 24-hour models. Here, the CSM (Model 3) was better suited because it did factor the core heat potential whereas the selected Model 4 does not. Model 4 did struggle with the prediction of Katrina, especially Time Interval 14, because of the omission of core heat potential. Similar findings occurred with the 6-hour wind speed model (Table 4.59) as Model 2 and Model 3 performed best because of the weighting of the previous 6-hour wind speed change variable and was able to forecast with low percentage error. Again, Model 4 struggled because of the omission of the core heat potential and the CSM (Model 3) would have improved Time Intervals 10-12 because of the previous 6-hour wind speed change variable. 


\begin{tabular}{|c|c|c|c|c|c|c|c|c|}
\hline Date & $\begin{array}{l}\text { Time } \\
\text { Int. }\end{array}$ & Model & $\begin{array}{l}\text { Max. Sus. } \\
\text { Winds (kts) }\end{array}$ & $\begin{array}{c}\text { 6-hour } \\
\text { Wind } \\
\text { Speed Obs. }\end{array}$ & $\begin{array}{c}\text { 6-hour } \\
\text { Model } \\
\text { (kts) }\end{array}$ & $\%$ error & $\begin{array}{l}\text { CSM } \\
(\mathrm{kts})\end{array}$ & $\begin{array}{c}\text { Improv. } \\
\text { (kts) }\end{array}$ \\
\hline $8 / 250 Z$ & 1 & 2 & 45 & 0 & 3.67 & $\mathrm{~N} / \mathrm{a}$ & 2.41 & 1.26 \\
\hline $8 / 256 Z$ & 2 & 2 & 45 & 5 & 3.38 & 32.4 & 2.45 & -0.93 \\
\hline $8 / 2512 Z$ & 3 & 3 & 50 & 15 & 6.05 & 59.6 & 4.69 & -1.36 \\
\hline $8 / 2518 Z$ & 4 & 3 & 65 & 0 & 8.53 & $\mathrm{~N} / \mathrm{a}$ & 8.83 & -0.30 \\
\hline $8 / 260 Z$ & 5 & 3 & 65 & 0 & 4.72 & $\mathrm{~N} / \mathrm{a}$ & 3.66 & 1.06 \\
\hline $8 / 266 Z$ & 6 & 3 & 65 & 5 & 4.67 & 6.5 & 3.48 & -1.19 \\
\hline $8 / 2612 Z$ & 7 & 3 & 70 & 15 & 5.60 & 62.6 & 4.36 & -1.24 \\
\hline $8 / 2618 Z$ & 8 & 3 & 85 & 5 & 8.15 & 63.2 & 6.40 & 1.75 \\
\hline $8 / 270 Z$ & 9 & 3 & 90 & 10 & 5.55 & 44.4 & $\mathrm{~N} / \mathrm{a}$ & N/a \\
\hline $8 / 276 Z$ & 10 & 4 & 100 & 0 & 6.92 & $\mathrm{~N} / \mathrm{a}$ & 6.74 & 0.18 \\
\hline $8 / 2712 Z$ & 11 & 4 & 100 & 0 & 5.98 & $\mathrm{~N} / \mathrm{a}$ & 4.44 & 1.54 \\
\hline $8 / 2718 Z$ & 12 & 4 & 100 & 0 & 7.01 & $\mathrm{~N} / \mathrm{a}$ & 4.32 & 2.69 \\
\hline $8 / 280 Z$ & 13 & 4 & 100 & 25 & 5.95 & 76.2 & $\mathrm{~N} / \mathrm{a}$ & $\mathrm{N} / \mathrm{a}$ \\
\hline $8 / 286 Z$ & 14 & 4 & 125 & 25 & 2.77 & 88.9 & $\mathrm{~N} / \mathrm{a}$ & $\mathrm{N} / \mathrm{a}$ \\
\hline $8 / 2812 Z$ & 15 & 4 & 150 & -5 & -0.34 & 93.1 & $\mathrm{~N} / \mathrm{a}$ & $\mathrm{N} / \mathrm{a}$ \\
\hline $8 / 2818 Z$ & 16 & 4 & 145 & -5 & -0.04 & 99.1 & $\mathrm{~N} / \mathrm{a}$ & $\mathrm{N} / \mathrm{a}$ \\
\hline
\end{tabular}

Table 4.59: 6-hour wind speed increase model for Hurricane Katrina. 


\section{CHAPTER 5}

\section{CONCLUSION}

The overall performance of the procedures developed to predict RIPs can be evaluated by looking at the average error for each model. Table 5.1 shows the average error (in $\mathrm{hPa}$ ) for each 24-hour pressure reduction model, both for when the DFA selected the model to be used and when it should have selected the CSM. When the DFA selected Models 1-4, the errors were 4.45, 7.46, 9.70, and $12.06 \mathrm{hPa}$, respectively. There was a gradual increase in error from Model 1 to 4 simply because the magnitude of the error increases as the intensity of the hurricane increases. When Model 1 was applied, the hurricane was generally more than 48 hours from the RIP and not very intense.

However, by the time Model 4 was applied, the hurricane was in the RIP and usually intense, making the prediction very difficult. Had these models been correctly selected, the average error would have decreased for all four of these major hurricane models. The CSM for Model 3 improved the DFA selection by approximately $4 \mathrm{hPa}$. Models 5-8 had lower average errors ranging between 1 and $8 \mathrm{hPa}$. These errors were lower than Models 1-4 because Models 5-8 were for minor hurricanes and minor hurricanes do not intensify as rapidly or as much making them easier to forecast. The CSM generally provided improvement except for Model 5, where the error slightly increased and Model 8, where 


\begin{tabular}{|c|c|c|}
\hline & DFA Selected & CSM \\
\hline Model 1 & 4.45 & 3.80 \\
\hline Model 2 & 7.46 & 5.63 \\
\hline Model 3 & 9.70 & 5.80 \\
\hline Model 4 & 12.06 & 10.22 \\
\hline Model 5 & 1.66 & 1.83 \\
\hline Model 6 & 6.58 & 3.11 \\
\hline Model 7 & 7.81 & 5.64 \\
\hline Model 8 & 7.03 & 8.20 \\
\hline Average & 7.33 & 5.85 \\
\hline
\end{tabular}

Table 5.1: Average error for 24-h pressure drop models in hPa. 
the error increased by $1 \mathrm{hPa}$. This slight increase in error by the CSM was largely due to one point during Hurricane Lisa where the CSM missed the forecast by over $20 \mathrm{hPa}$. It forecasted a decrease in pressure, however, Lisa was interacting with Hurricane Karl which caused increased shear that made Lisa weaken. The overall error for the 24-hour pressure models was $7.33 \mathrm{hPa}$ as a DFA selected model and only $5.85 \mathrm{hPa}$ if the CSM would have been used. This shows that the DFA selected models were accurate considering the error was low and that these particular hurricanes were not easy to forecast since many rapidly intensified. Since the CSM had an even lower error, it shows that this method is very promising and future studies should concentrate on improving the DFA selection process.

Considering that the official NHC forecast is more accurate on average at the 24hour forecast period than current models used as forecasting guidance by the NHC, it is important to show that the regression models can improve upon their predictions. Table 5.2 shows the summary of average errors (in knots) for the 24-hour wind speed increase models and also shows the average 24-hour forecast error by the NHC for the same storms at the same time intervals. When the DFA selected Model 1, the average error was 7.95 knots which was lower than the NHC by almost 2 knots. If Model 1 was selected correctly for all time intervals, it would have improved upon the error by an additional 1 knot. Model 2 as the DFA selected model had a slightly higher error (11.3 knots) than the NHC (9.06 knots). However, the CSM for Model 2 (7.83 knots) would have improved upon the DFA by approximately 3.5 knots, and would have been more accurate than the NHC. The primary reason the DFA selected model had a higher error was because during Hurricane Ivan, Model 2 was used too late in the cycle. Ivan had an 


\begin{tabular}{|c|c|c|c|}
\hline & DFA Selected & CSM & NHC \\
\hline Model 1 & 7.95 & 6.95 & 9.72 \\
\hline Model 2 & 11.30 & 7.83 & 9.06 \\
\hline Model 3 & 13.61 & 7.47 & 17.36 \\
\hline Model 4 & 20.06 & 14.79 & 13.47 \\
\hline Model 5 & 2.44 & 2.93 & 3.75 \\
\hline Model 6 & 10.90 & 4.23 & 11.00 \\
\hline Model 7 & 15.11 & 7.67 & 15.00 \\
\hline Model 8 & 16.07 & 11.96 & 10.31 \\
\hline Average & 11.83 & 8.47 & 12.53 \\
\hline
\end{tabular}

Table 5.2: Average error for 24-h wind speed increase models in knots. 
unusually high pressure when it started to undergo the RIP and the DFA overestimated the time to the RIP. This caused unusually high errors that affected the average for Model 2. When Model 3 was selected by the DFA, it improved upon the NHC forecast by approximately 4 knots, but the CSM for Model 3 would have improved upon the NHC forecast by approximately 10 knots. Model 3 was able to provide the most improvement over the NHC, as the NHC often times fails to capture the onset of the RIP. However, Model 4 (both the DFA selected and the CSM) had higher errors than the NHC. The reason was because of the unusually high errors during Hurricanes Irene and Katrina. Model 4 was misclassified during Irene and produced exceptionally high errors, which explains why there is a large difference between the DFA selected and the CSM cases (20.06 knots and 14.79 knots). Also, during Katrina, Model 4 was used when landfall was within 24 hours. Therefore, it was not able to factor the inland decay, which even caused the CSM for Model 4 to produce high errors. Without these cases, Model 4 would have been able to outperform the NHC.

The minor hurricane models (Models 5-8) generally outperformed the NHC as well, as both the DFA selected and the CSM for Models 5 and 6 were more accurate than the NHC. The CSM for Model 6 was particularly better by approximately 7 knots. When the DFA selected Model 7 the error was nearly the same as the NHC at comparable time intervals (15.11 knots and 15 knots). But when the CSM for Model 7 was used, the error was only 7.67 knots, improving upon the error by more than 7 knots. As with the major hurricane model (Model 3), it was able to particularly forecast well near the onset of the RIP. Model 8 had higher errors than the NHC primarily because it was selected to be used during Alex and Gaston. Toward the end of their RIP, these storms were near the 
coastline and "skirted" the coastline within 24 hours, which made Model 8 have high error. In summary, the 24-hour wind speed models forecasted extremely well compared to the NHC with the exceptions of Model 4 and 8 for reasons previously stated. These models had problems since they do not factor landfall and therefore caused them to have higher errors. Overall, the DFA selected models had an average error of 11.83 knots while the NHC had an average error of 12.53 knots. This NHC average error is consistent with other studies, such as Franklin (2005) which observed that the average forecast error for all Atlantic storms was 10.9 knots. However, that study included all storms in the Atlantic and also included the entire track. This caused the average error to be less than the findings here because it included lesser known storms which were not as intense plus it included time periods when the storms were not intensifying rapidly. These weaker storms and other weaker intensification periods are much easier to forecast. The average 24-hour wind speed increase error for the CSM was only 8.47 knots. This was more accurate by 3 knots than the DFA selected models and more accurate by more than 4 knots than the NHC. The DFA method can be more accurate than the NHC leading up to the RIP and the onset of the RIP, but it can be further improved by getting the DFA to select the correct model. A two-tailed t-test was performed on the average errors between the DFA and the NHC, and between the CSM and the NHC, to investigate whether the differences between the models could be by chance. The significance value of 0.310 for the DFA-NHC (Table 5.3), shows that the differences between the DFA and NHC average errors were not significant. However, the significance value of 0.001 for the CSM-NHC, shows that the differences between the CSM and the NHC average errors 
were significant. This further demonstrates that the CSM has great potential to improve upon official NHC 24-hour wind speed forecasts.

\begin{tabular}{|c|c|c|c|c|}
\hline & \multicolumn{2}{|c|}{ Differences } & T Confidence Interval of the & Significance \\
\hline & Minimum & Maximum & & \\
\hline DFA-NHC & -1.03 & 3.24 & 1.09 & .310 \\
\hline CSM-NHC & -4.84 & -1.20 & -3.28 & .001 \\
\hline
\end{tabular}

Table 5.3: T-test of the difference between the average errors of the DFA, CSM, and NHC.

Table 5.4 shows the average errors for the 6-hour pressure drop models which were all lower than the errors for the 24-hour pressure models. This stands to reason because of the shorter forecast period and thus less fluctuation in the pressure allowing for lower forecast errors. The major hurricane models (Models 1-4), when selected by the DFA, produced errors ranging from $1 \mathrm{hPa}$ to less than $8 \mathrm{hPa}$. Average errors increased as the hurricane approached the RIP, since the central pressure fluctuated more. The CSM would have improved nearly all of these models with the only exception being 


\begin{tabular}{|c|c|c|}
\hline & DFA Selected & CSM \\
\hline Model 1 & 1.52 & 1.59 \\
\hline Model 2 & 2.54 & 2.40 \\
\hline Model 3 & 4.63 & 3.20 \\
\hline Model 4 & 7.83 & 6.79 \\
\hline Model 5 & 0.08 & 0.51 \\
\hline Model 6 & 1.44 & 1.34 \\
\hline Model 7 & 1.78 & 2.07 \\
\hline Model 8 & 1.98 & 1.86 \\
\hline Average & 3.13 & 2.86 \\
\hline
\end{tabular}

Table 5.4: Average error for 6-h pressure drop models in $\mathrm{hPa}$. 
Model 1, but this error was only minimally higher at $0.07 \mathrm{hPa}$. For the minor hurricane models (Models 5-8), the average error was lower than for Models 1-4 because of the even lower fluctuation of the pressure. Here, the DFA selected model error ranged between 0 and $2 \mathrm{hPa}$, while the CSM produced nearly the same. Very little difference in the error was produced between the DFA selected model and the CSM because of the small deviations in the short term pressure for minor hurricanes. Overall average error for the DFA selected models was $3.13 \mathrm{hPa}$ while the CSM did provide slight improvement at $2.86 \mathrm{hPa}$.

The average error for the 6-hour wind speed increase models are shown in Table 5.5. Again, the errors were relatively low with ranges for the DFA selected major hurricane models (Models 1-4) between 3 and approximately 9 knots and the minor hurricane models approximately between 0 and 5 knots. The CSM would have provided slight improvement for nearly all models with the exception of Model 5. When Model 5 was selected, a minor hurricane often was in the early stages of development. Therefore, the wind speed usually did not change in the short term which made it easier to forecast and, furthermore, produced very low errors. The average DFA-selected model error was 4.52 knots while the CSM again would have provided improvement producing an error of 3.94 knots.

While the DFA selected models for all four types (Tables 5.1 - 5.2 and 5.4 - 5.5) proved to be beneficial as evidenced by the lower error than the NHC shown in Table 5.2. However, the method can still be improved as the CSM provided substantial improvement for each of the four types. Improvement of the DFA selection process is 


\begin{tabular}{|c|c|c|}
\hline & DFA Selected & CSM \\
\hline Model 1 & 3.86 & 3.67 \\
\hline Model 2 & 3.07 & 2.98 \\
\hline Model 3 & 6.04 & 4.63 \\
\hline Model 4 & 9.11 & 8.44 \\
\hline Model 5 & 0.27 & 0.80 \\
\hline Model 6 & 2.11 & 0.73 \\
\hline Model 7 & 5.11 & 2.55 \\
\hline Model 8 & 4.37 & 2.77 \\
\hline Average & 4.52 & 3.94 \\
\hline
\end{tabular}

Table 5.5: Average error for 6-h wind speed increase models in knots. 
where attention needs to be focused for further research. Adding more case studies, in addition to adding a third group of non-hurricanes, could potentially help improve the DFA selection process. Expanding different forecast periods and the time field beyond the period where the most rapid intensification takes place are also areas for future research. Some hurricanes actually have multiple periods of rapid intensification, as seen with Hurricane Katrina, which can cause forecasting problems. Inland decay needs to also be addressed, because of the higher errors when a hurricane makes landfall within the 24-hour forecast period. The eastern Pacific basin, as well as other basins, needs to be investigated and the models for the basins could then be compared with the Atlantic basin models to see how the intensification factors differ from one basin to another. In conclusion, the DFA selection method has been shown to add skill particularly at the 24hour forecast period in terms of both pressure prediction and, especially, wind speed prediction. The NHC consistently struggles with the aspect of rapid intensification and this method shows considerable promise for improving intensification forecasting. 


\section{BIBLIOGRAPHY}

Bender, M.A., 1997: The effect of relative flow on the asymmetric structure in the interior of hurricanes. J. Atmos. Sci., 54, 703-724.

Black, M. L., R. W. Burpee, and F. D. Marks Jr., 1996: Vertical motion characteristics of tropical cyclones determined with airborne Doppler radial velocities. J. Atmos. Sci., 53, 1887-1909.

Black, J. F. Gamache, F. D. Marks Jr., C. E. Samsury, and H. E. Willoughby, 2002: Eastern Pacific Hurricanes Jimena of 1991 and Olivia of 1994: The effect of vertical shear on structure and intensity. Mon. Wea. Rev., 130, 2291-2312.

Bogner, Paul B., G. Barnes, and J. Franklin, 1999: Conditional Instability and Shear for Six Hurricanes over the Atlantic Ocean. Wea. Forecasting, 15, 192-207.

Bosart, Lance F., et al, 2000: Environmental Influences on the Rapid Intensification of Hurricane Opal over the Gulf of Mexico. Mon. Wea. Rev., 128, 322-352.

Chan, J. C. L., Y. Duan, and L. Shay, 2000: Tropical Cyclone Intensity Change from a Simple Ocean-Atmosphere Coupled Model. J. Atmos. Sci., 58, 154-172.

Changnon, S. A., D. Changnon, E. R. Fosse, D. C. Hoganson, R. J. Roth Sr., and J. M. Totsch, 1997: Effects of recent weather extremes on the insurance industry: Major implications for the atmospheric sciences. Bull. Amer. Meteor. Soc., 78, 425-435.

Charney, J.G. and A. Eliassen, 1964: On the Growth of the Hurricane Depression. $J$. Atmos. Sci., 21, 68-75.

Chen, L., 1995: Tropical cyclone heavy rainfall and damaging winds. Global Perspectives on Tropical Cyclones. WMO Tech. Rep. TCP-38. 
Cione, J. J., and Eric W. Uhlhorn, 2003: Sea Surface Temperature Variability in Hurricanes: Implications with Respect to Intensity Change. Mon. Wea. Rev., 131, 1783-1796.

Corbosiero, K. L., and John Molinari, 2002: The effects of vertical wind shear on the distribution of convection in tropical cyclones. Mon. Wea. Rev., 130, 2110-2122.

Cramer, D., 2003: Advanced Quantitative Data Analysis. Philadelphia: Open University Press, 254 pp.

DeMaria, M., J.-. Baik, and J. Kaplan, 1993: Upper-level eddy angular momentum fluxes and tropical cyclone intensity change. J. Atmos. Sci., 50, 1133-1147.

-------, and John Kaplan, 1994: Sea Surface Temperature and the Maximum Intensity of Atlantic Tropical Cyclones. Journal of Climate, 7, 1324-1334.

------- 1996: The effect of Vertical Shear on Tropical Cyclone Intensity Change. $J$. Atmos. Sci., 53, 2076-2087.

-------, and M. M. Huber, 1998: The effect of vertical shear on tropical cyclone intensity change: An historical perspective. Preprints, Symp. On Tropical Cyclone Intensity Change, Phoenix, AZ, American Meteorological Society, 22-29.

-------, and J. Kaplan, 1999: An Updated Statistical Hurricane Intensity Prediction Scheme (SHIPS) for the Atlantic and Eastern North Pacific Basins. Wea. Forecasting, 14, 326-337.

, and J. Kaplan, 2003: Large-Scale Characteristics of Rapidly Intensifying Tropical Cyclones in the North Atlantic Basin. Wea. Forecasting, 18, 1093-1108.

Dunion, J. P., and Christopher S. Velden, 2004: The Impact of the Saharan Air Layer on Atlantic Tropical Cyclone Activity. Bull. Amer. Meteor. Soc., 85, 353-365.

Elsberry, Russell, and Richard A. Jeffries, 1996: Vertical Wind Shear Influences on Tropical Cyclone Formation and Intensification during TCM-92 and TCM-93. Mon. Wea. Rev, 124, 1374-1387.

Elsner, James, and A. Birol Kara, 1999: Hurricanes of the North Atlantic. Oxford University Press, New York.

Emanuel, Kerry, 1986: An air-sea interaction theory for tropical cyclones. Part I: Steady-state maintenance. J. Atmos. Sci., 43, 585-604.

------, 1988: The maximum intensity of hurricanes. J. Atmos. Sci., 45, 1143-1155. 
------, 1991: The theory of hurricanes. Annu. Rev. Fluid Mech., 23, 179-196.

------, 1999: Thermodynamic Control of Hurricane Intensity. Nature, 14 October 1999: 665-669.

Erickson, C.O., 1974: Use of geostationary-satellite cloud vectors to estimate tropical cyclone intensity. NOAA Tech. Memo. NESS 59, Meteor. Satellite Lab., Washington DC, 37pp.

Fitzpatrick, P. J., 1996: Understanding and Forecasting Tropical Cyclone Intensity Change. Ph.D. Dissertation. Department of Atmospheric Science Paper No. 598. Colorado State University, 346 pp.

Frank, W. M., and Elizabeth A. Ritchie, 2001: Effects of vertical wind shear on the intensity and structure of numerically simulated hurricanes. Mon. Wea. Rev., 129, 2249-2269.

Franklin, J. L., S. J. Ford, S. E. Feuer, and F. D. Marks Jr., 1993: The kinematic structure of Hurricane Gloria (1985) determined fro nested analyses of dropwindsonde and Doppler radar data. Mon. Wea. Rev., 121, 2433-2451.

Franklin, J.L., 2005: 2004 National Hurricane Center Forecast Verification Report. National Hurricane Center. NOAA/NWS/NCEP/Tropical Prediction Center.

Gamache, J. F., F. D. Marks, and F. Roux, 1995: Comparison of three airborne Doppler sampling techniques with airborne in situ wind observations in Hurricane Gustav (1990). J. Atmos. Oceanic Technol., 12, 171-181.

Goni, G. J., S. L. Garzoli, A. J. Roubicek, D. B. Olson and O. B. Brown, 1997: Agulthas ring dynamics from TOPEX/POSEIDON satellite altimeter data, J. Mar. Res., 55, 861-883.

Gray, W. M., 1968: Global view of the origin of tropical disturbances and storms. Mon. Wea. Rev., 96, 669-700.

------, 1975: Tropical cyclone genesis. Dept. of Atmospheric Science Paper No. 323, Colorado State University, Ft. Collins, CO, 121 pp.

-------, 1979: Hurricanes, their formation, structure, and likely role in the tropical circulation. Meteorology over the Tropical Oceans, D. B. Shaw, El., Royal Meteorological Society, 155-218.

Hill, T. \& Lewicki, P. (2006). STATISTICS Methods and Applications. StatSoft, Tulsa, OK.

Holland, Greg J., 1997: The Maximum Potential Intensity of Tropical Cyclones. $J$. Atmos. Sci., 54, 2519-2541. 
Jarvinen, B. R., 1984: A Tropical Cyclone Data Tape for the North Atlantic Basin, 18861983: Contents, Limitations, and Uses. NOAA Technical Memorandum NWS NHC 22.

Jones, S. C., 1995: The evolution of vortices in vertical shear. I: Initially barotropic vortices. Quart. J. Roy. Meteor. Soc., 121, 821-851.

-------, 1998: The dynamics of tropical cyclones in shear: Insight from theory and idealized models. Preprints, Symp. On Tropical Cyclone Intensity Change, Phoenix, AZ, Amer. Meteor. Soc., 30-36.

Kalnay, E. et. al, 1996: The NCEP/NCAR 40-Year Reanalysis Project. Bulletin of the American Meteorological Society, 77, 437-471.

Kaplan, John, and Mark DeMaria, 1999: Climatological and Synoptic Characteristics of Rapidly Intensifying Tropical Cyclones in the North Atlantic Basin. Preprints. $23^{\text {rd }}$ Hurricanes and Tropical Meteorology Conference, Dallas, TX, American Meteorological Society, 592-595.

------, and -------, 2000: Large-Scale Characteristics of Rapidly Intensifying Tropical Cyclones in the North Atlantic Basin, Preprints. 24 Hurricanes and Tropical Meteorology Conference, Ft. Lauderdale, FL, American Meteorological Society, 232-233.

------, and -------, 2002: Estimating the Probability of Rapid Intensification Using the SHIPS Model Output: Some Preliminary Results, Preprints. $25^{\text {th }}$ Hurricanes and Tropical Meteorology Conference, San Diego, CA, American Meteorological Society, 124-125.

Klecka, W. R., (1980): Discriminant Analysis. Sage University Paper series on Quantitative Applications in the Social Sciences, Newberry Park: Sage Publications, Inc.

Knaff, J. A., (2003): Statistical, 5-Day Tropical Cyclone Intensity Forecasts Derived from Climatology and Persistence. Wea. Forecasting, 18, 80-92.

Lauchenbruch, P. A. (1975): Discriminant Analysis. New York: Hafner.

Law, K. T., (2001): An Investigation of Dynamic and Thermodynamic Effects Associated with Rapid Tropical Cyclone Intensification. Thesis: The Ohio State University, $83 \mathrm{pp}$.

Leipper, D. and D. Vogenau. 1972: Hurricane heat potential of the Gulf of Mexico, $J$. Phys. Oceanogr., 2, 218-224. 
Levitus, S., 1984: Annual cycle of temperature and heat storage in the world's ocean. $J$. Phys. Oceanogr., 14, 727-746.

Marks, F. D. Jr., R. A. Houze Jr., and J. F. Gamache, 1992: Dual-aircraft investigation of the inner core of Hurricane Norbert. Part I: Kinematic structure. J. Atmos. Sci., 40, 919-942.

McBride, J. L., and R. Zehr, 1981: Observational analysis of tropical cyclone formation. Part II: Comparison of nondeveloping versus developing systems. J. Atmos. Sci., 38, 1132-1151.

Merrill, Robert T., 1988: Environmental Influences on Hurricane Intensification. $J$. Atmos. Sci., 45, 1678-1687.

Molinari, J., S. Skubis, D. Vollaro, F. Alsheimer, and H. E. Willoughby, 1998: Potential vorticity analysis of tropical cyclone intensification. J. Atmos. Sci.., 55, 26322644.

Montgomery, M. T., and R. J. Kallenbach, 1997: A theory for vortex Rossby waves and its application to spiral bands and intensity changes in hurricanes. Quart. J. Roy. Meteor. Soc., 123, 535-565.

Palmen, E., 1948: On the formation and structure of tropical hurricanes. Geophysica No. 3, 26-38.

Pfeffer, R. L., 1958: Concerning the mechanisms of hurricanes. J. Meteor., 15, 113-119.

Pielke, R. A., Jr., and C. W. Landsea, 1998: Normalized hurricane damages in the United States: 1925-95. Wea. Forecasting, 13, 621-631.

Reasor, P. D., M. T. Montgomery, F. D. Marks Jr., and J. F. Gamache, 2000: Lowwavenumber structure and evolution of the hurricane inner core observed by airborne dual-Doppler radar. Mon. Wea. Rev., 128, 1653-1680.

Riehl, H., and R. J. Shafer, 1944: The recurvature of tropical storms. Journal of Meteorology, 1, $42-54$.

Schade, Lars R., and Kerry A. Emanuel, 1999: The Ocean's Effect on the Intensity of Tropical Cyclones: Results from a Simple Coupled Atmosphere-Ocean Model. J. Atmos. Sci, 56, 642-651.

Shay, L. K, G. Gustavo, P. Black, 2000: Effects of a Warm Oceanic Feature on Hurricane Opal. Mon. Wea. Rev., 128, 1366-1383. 
Simpson, R. H., and H. Riehl, 1958: Mid-tropospheric ventilation as a constraint on hurricane development and maintenance. Proc. Tech. Conf. On Hurricane, Miami Beach, FL, Amer. Meteor. Soc. D4.1-D4.10.

Titley, D. W., and Russell L. Elsberry, 1999: Large intensity changes in tropical cyclones: A case study of Supertyphoon Flo during TCM-90., Mon. Wea. Rev., 128, 3556-3573.

Tuleya, R.E., and Y. Kurihara, 1981: A numerical study of the effects of environmental flow on tropical storm genesis. Mon. Wea. Rev., 109, 2487-2506.

Weightman, R. H., 1919: The West India Hurricane of September, 1919, in light of sounding observations. Mon. Wea. Rev., 47, 717-720.

Wu, Chun-Chieh, and Hsiu-Ju Cheng, 1999: An Observational Study of Environmental Influences on the Intensity Changes of Typhoons Flo and Gene. Mon. Wea. Rev., 127, 3003-3031.

Zehr, R. M., 1992: Tropical cyclogenesis in the western North Pacific. NOAA Tech. Rep. NESDIS 61, Dept. of Commerce, Washington, DC, 181 pp.

-------, 1998: Vertical wind shear and tropical cyclone intensity. Preprints, Symp. On Tropical Cyclone Intensity Change, Phoenix, AZ, American Meteorological Society, 124-126. 
APPENDIX A

TROPICAL CYCLONE TRACKS 


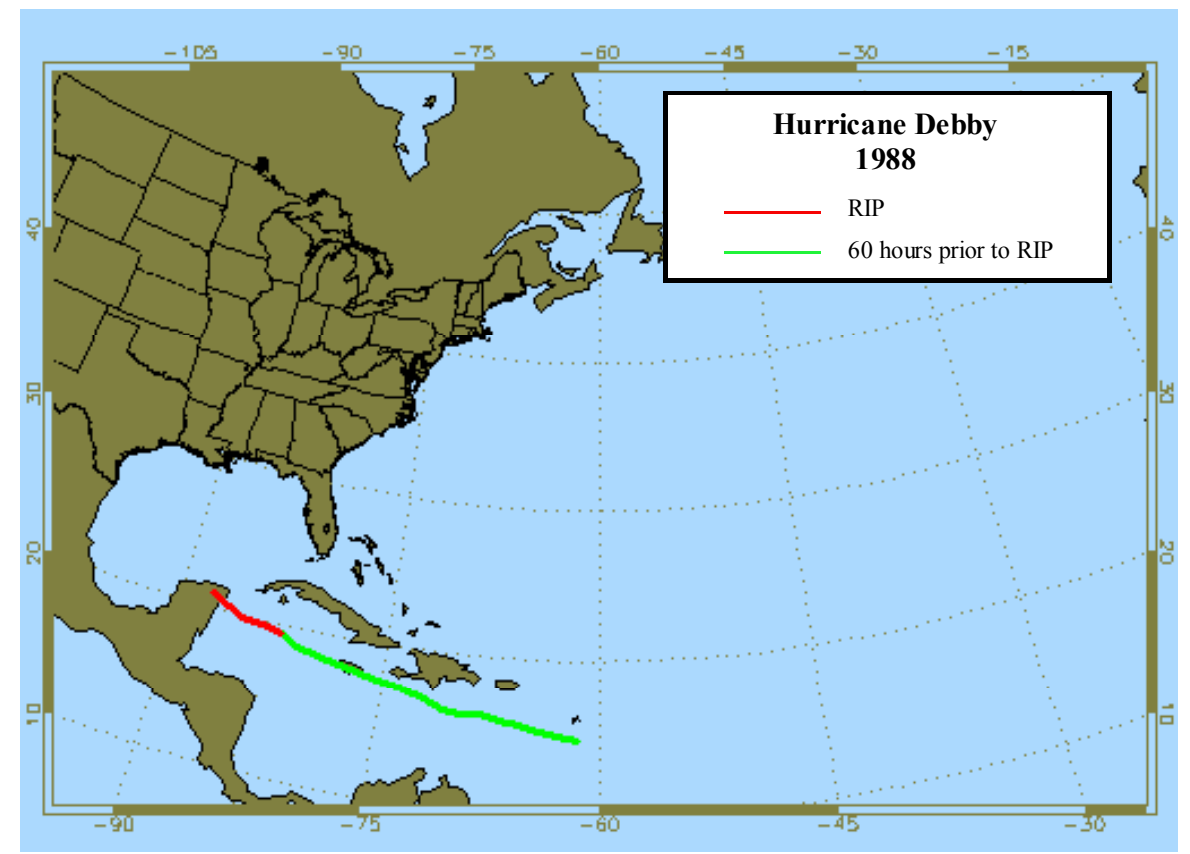

Figure A.1: The figure shows Hurricane Debby's (1988) track prior to and during the RIP.

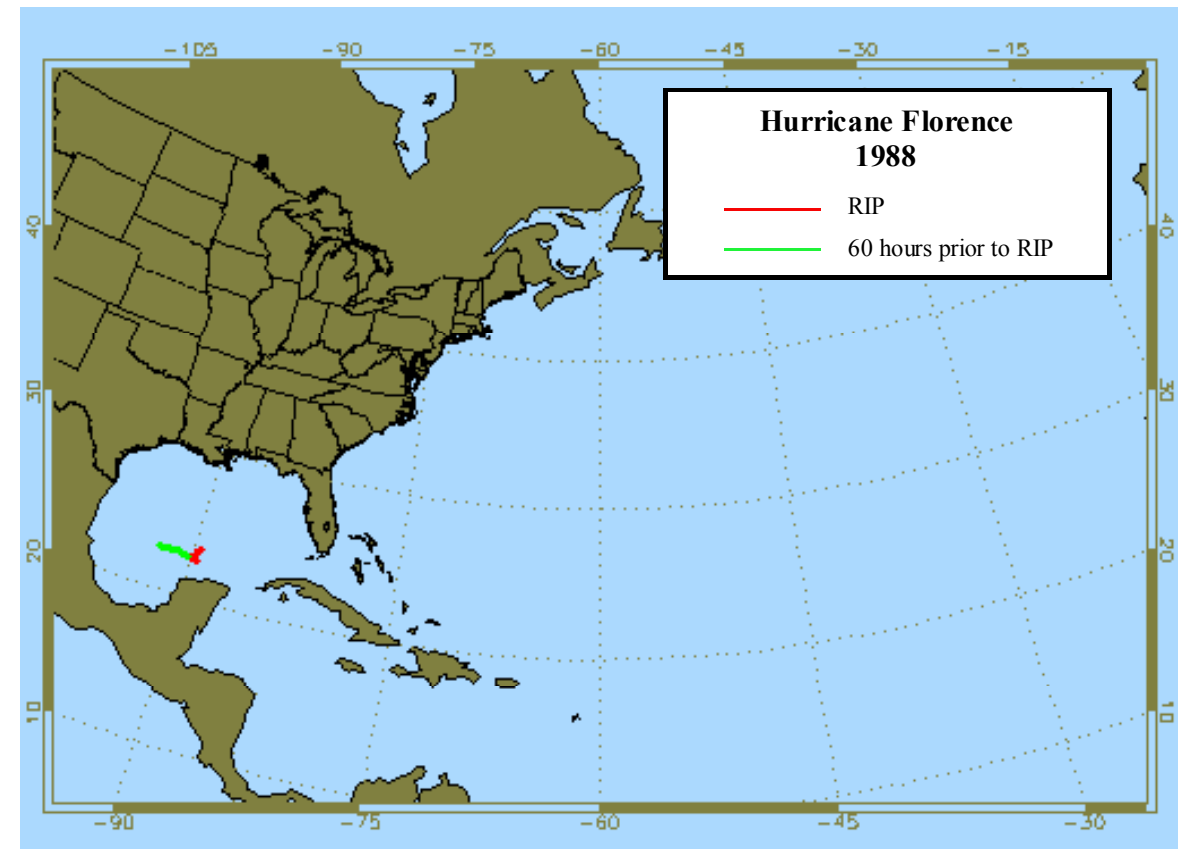

Figure A.2: As in Figure A.1, except for Hurricane Florence (1988). 


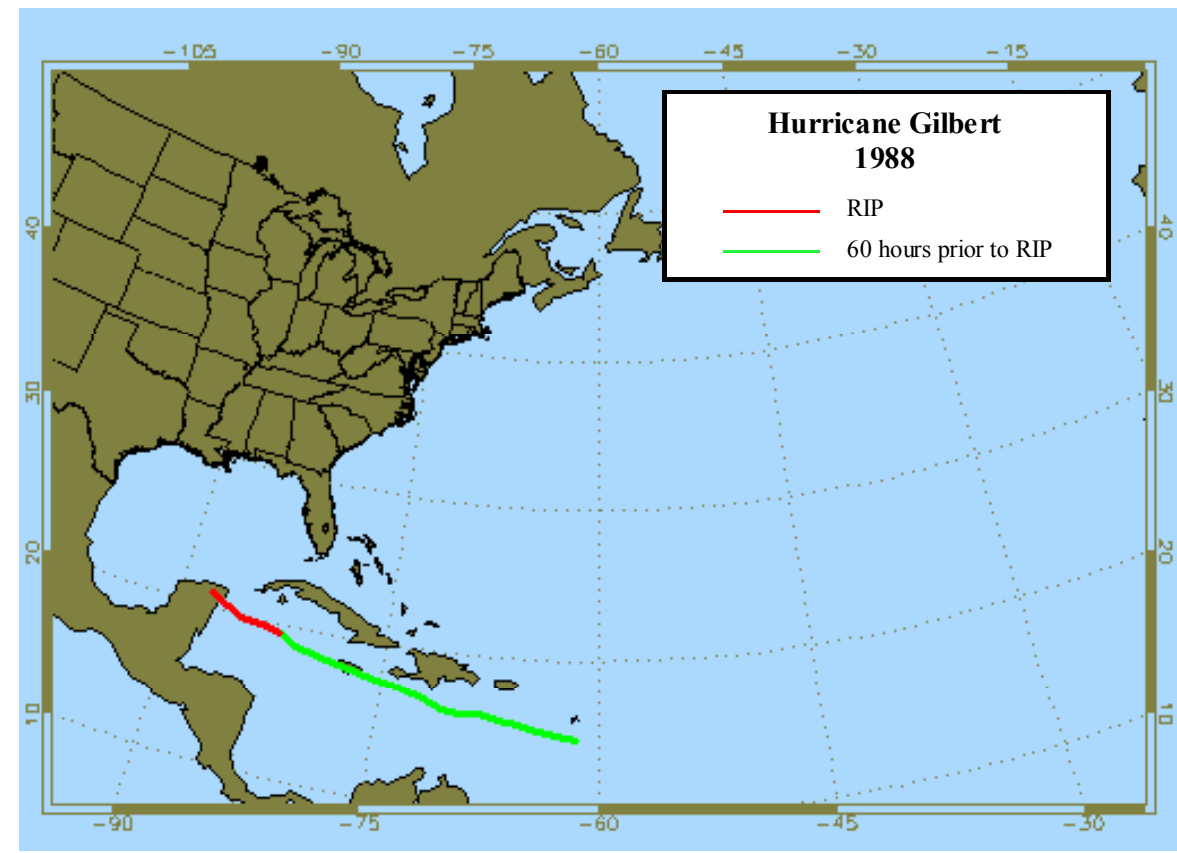

Figure A.3: As in Figure A.1, except for Hurricane Gilbert (1988).

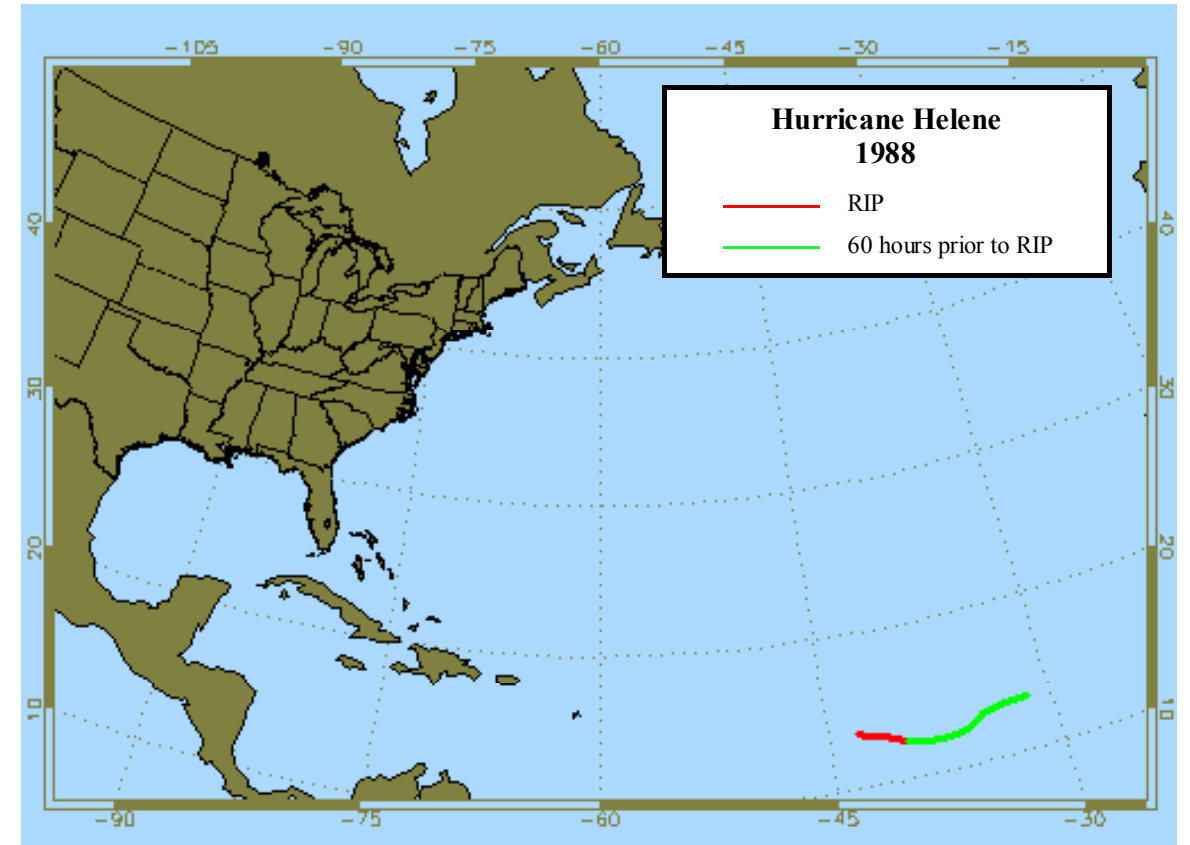

Figure A.4: As in Figure A.1, except for Hurricane Helene (1988). 


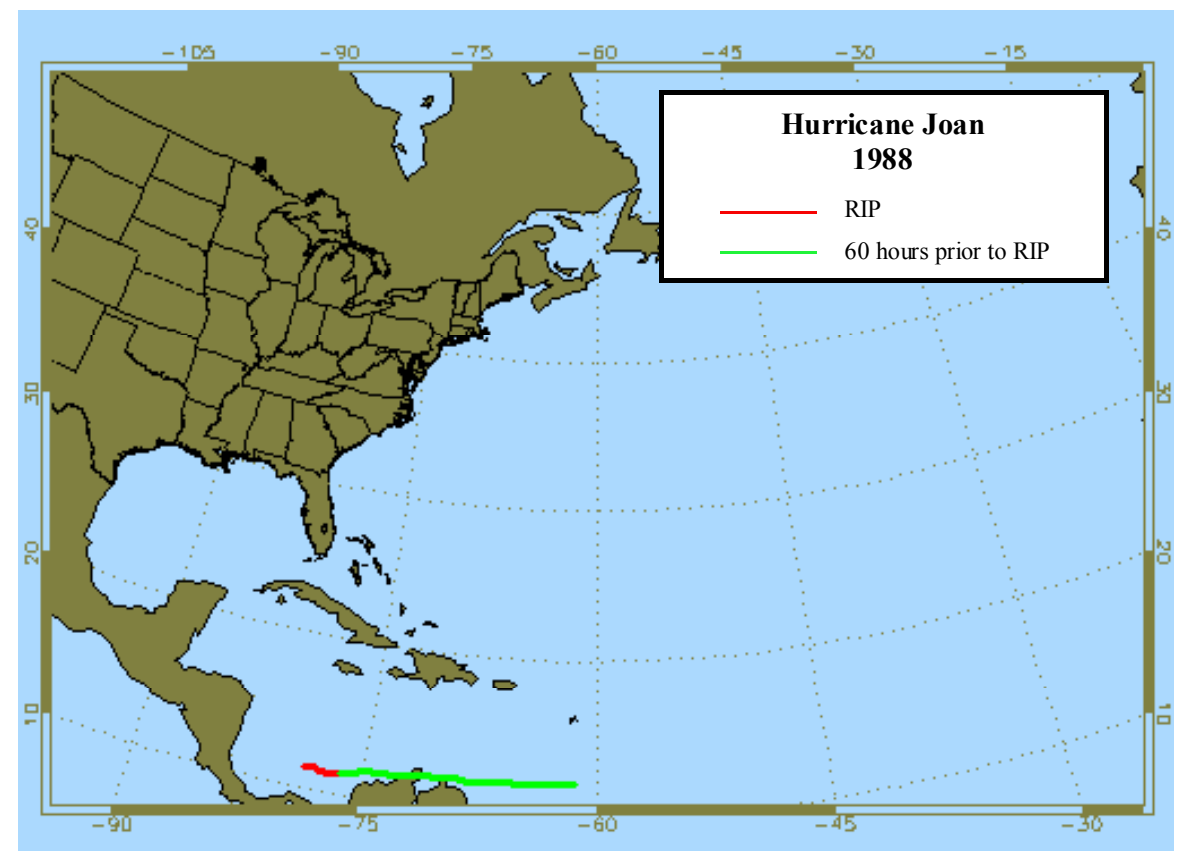

Figure A.5: As in Figure A.1, except for Hurricane Joan (1988).

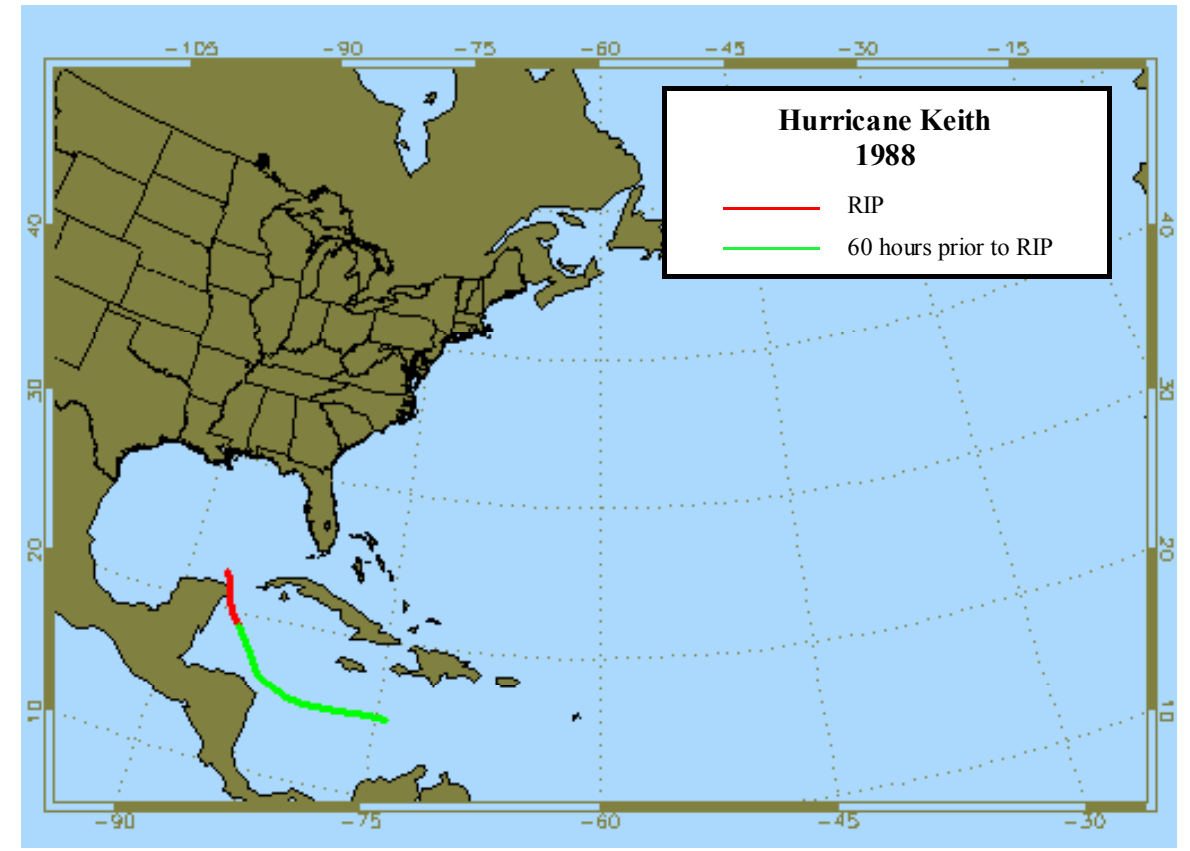

Figure A.6: As in Figure A.1, except for Hurricane Keith (1988). 


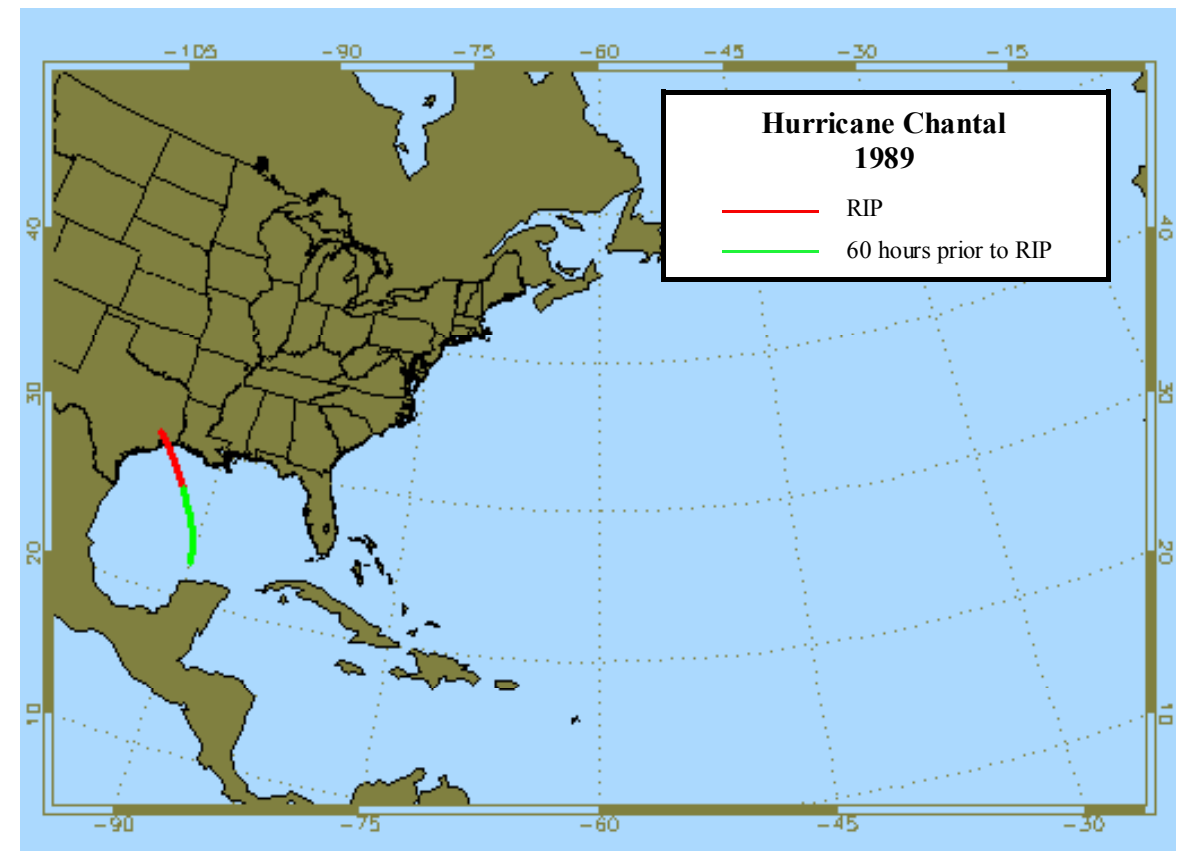

Figure A.7: As in Figure A.1, except for Hurricane Chantal (1989).

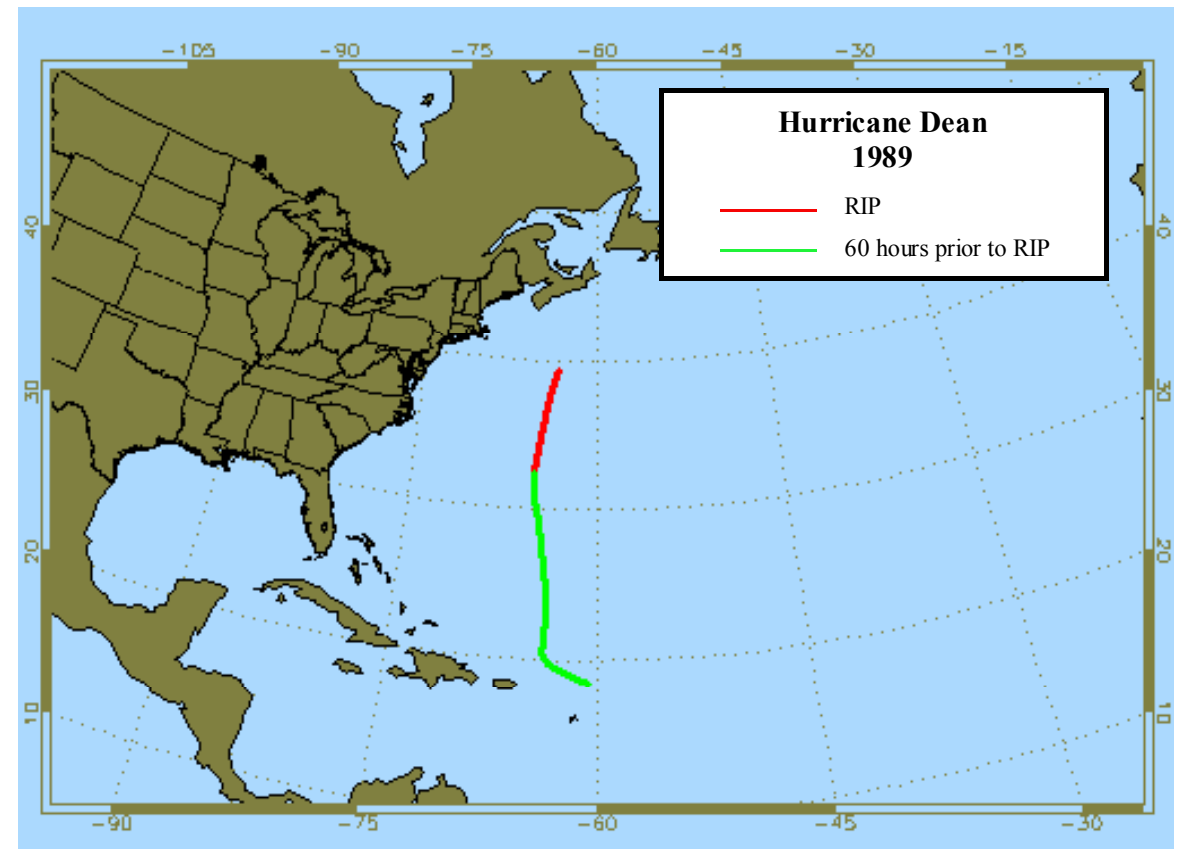

Figure A.8: As in Figure A.1, except for Hurricane Dean (1989). 


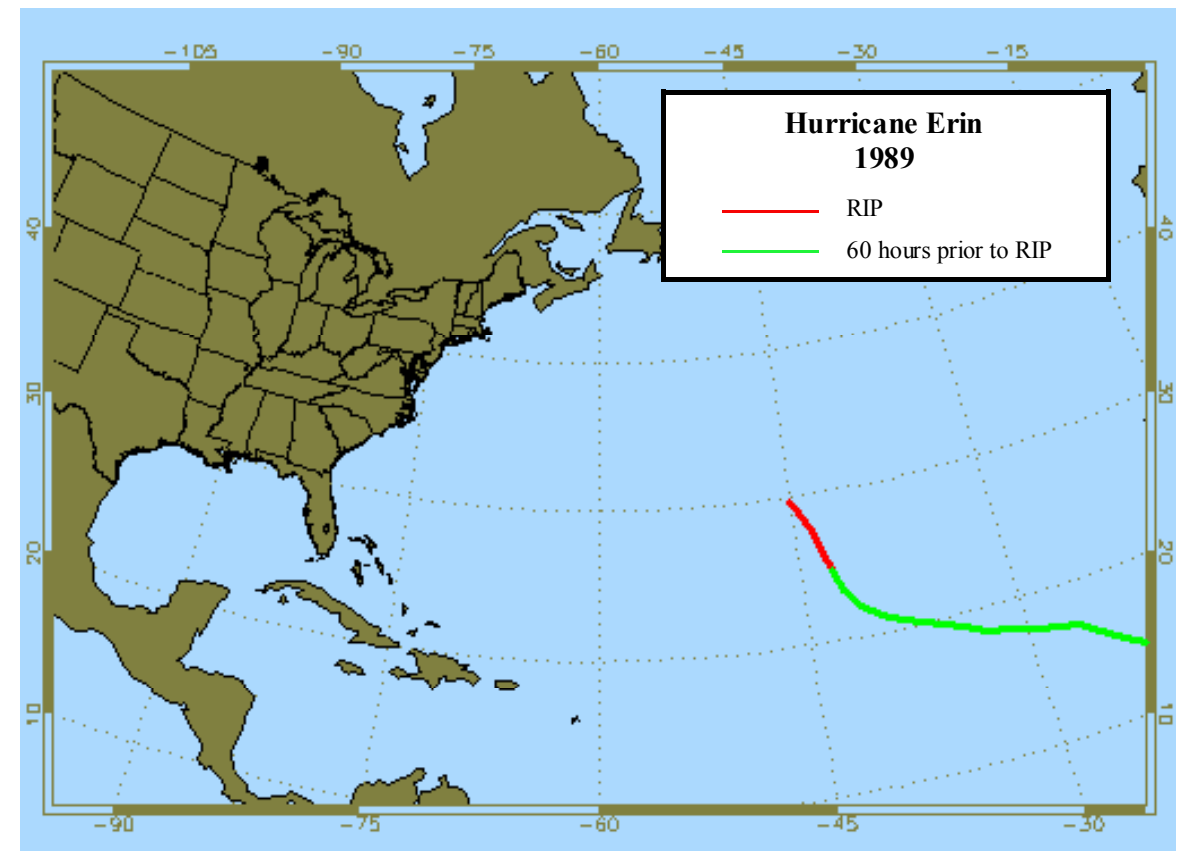

Figure A.9: As in Figure A.1, except for Hurricane Erin (1989).

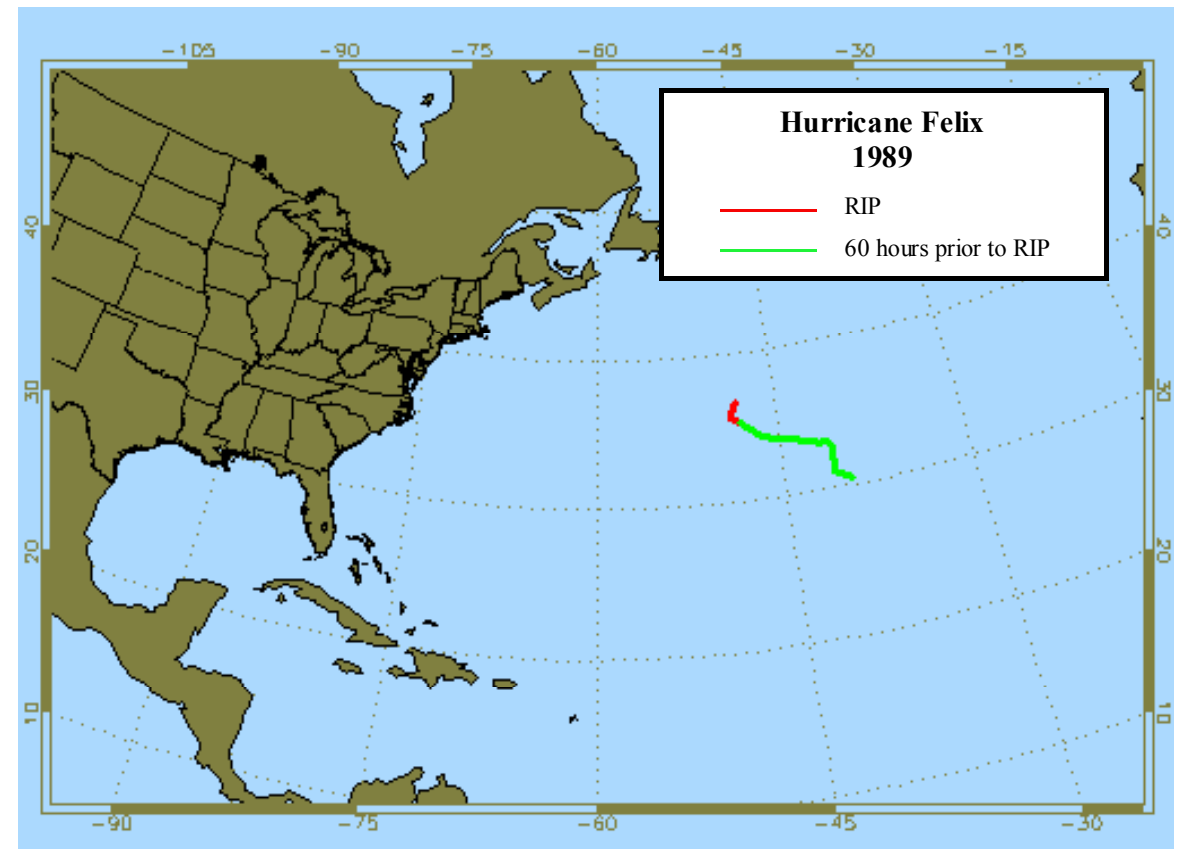

Figure A.10: As in Figure A.1, except for Hurricane Felix (1989). 


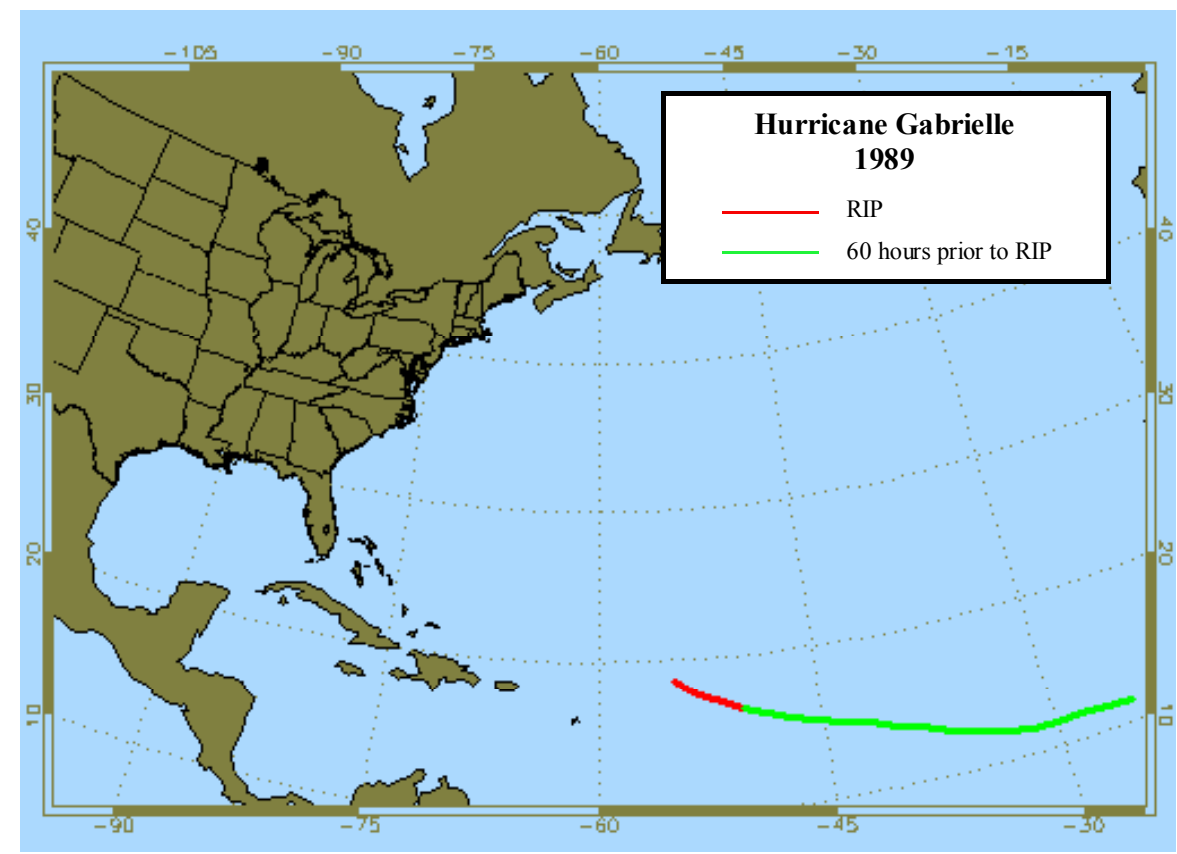

Figure A.11: As in Figure A.1, except for Hurricane Gabrielle (1989).

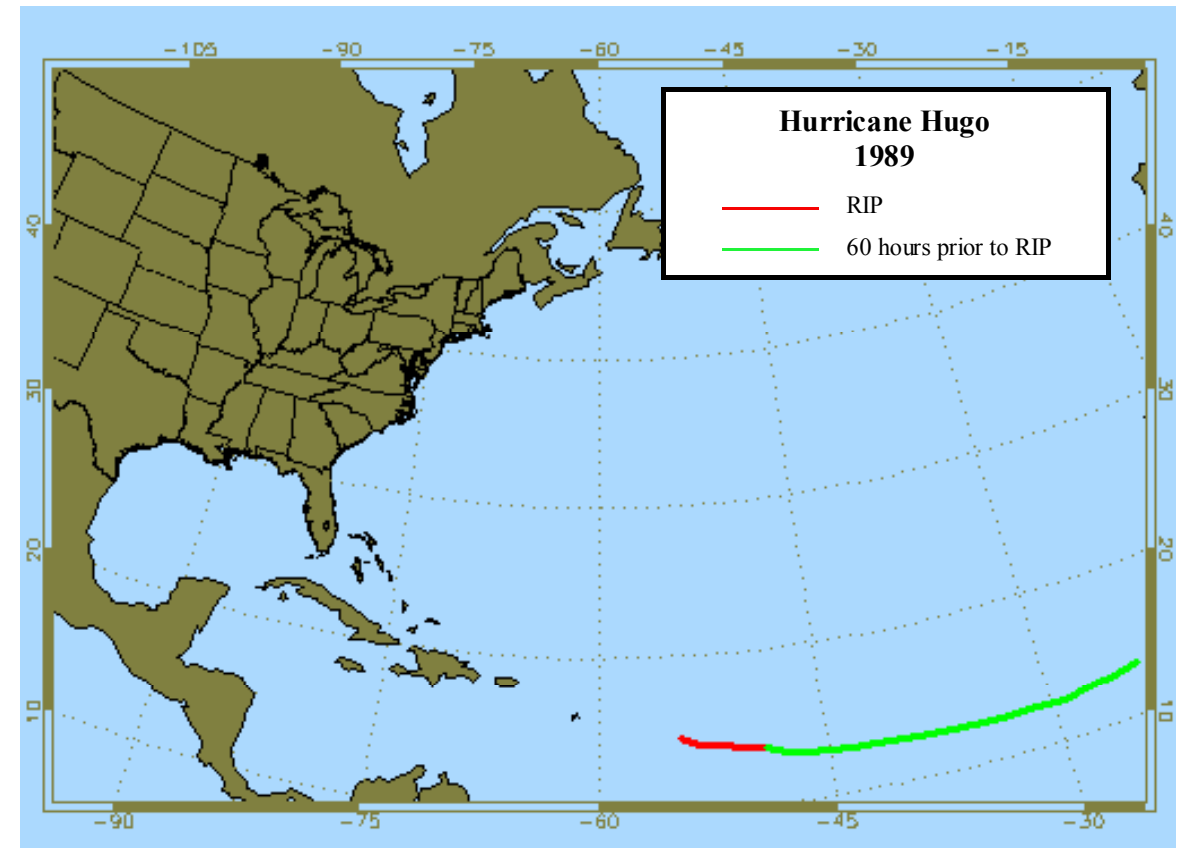

Figure A.12: As in Figure A.1, except for Hurricane Hugo (1989). 


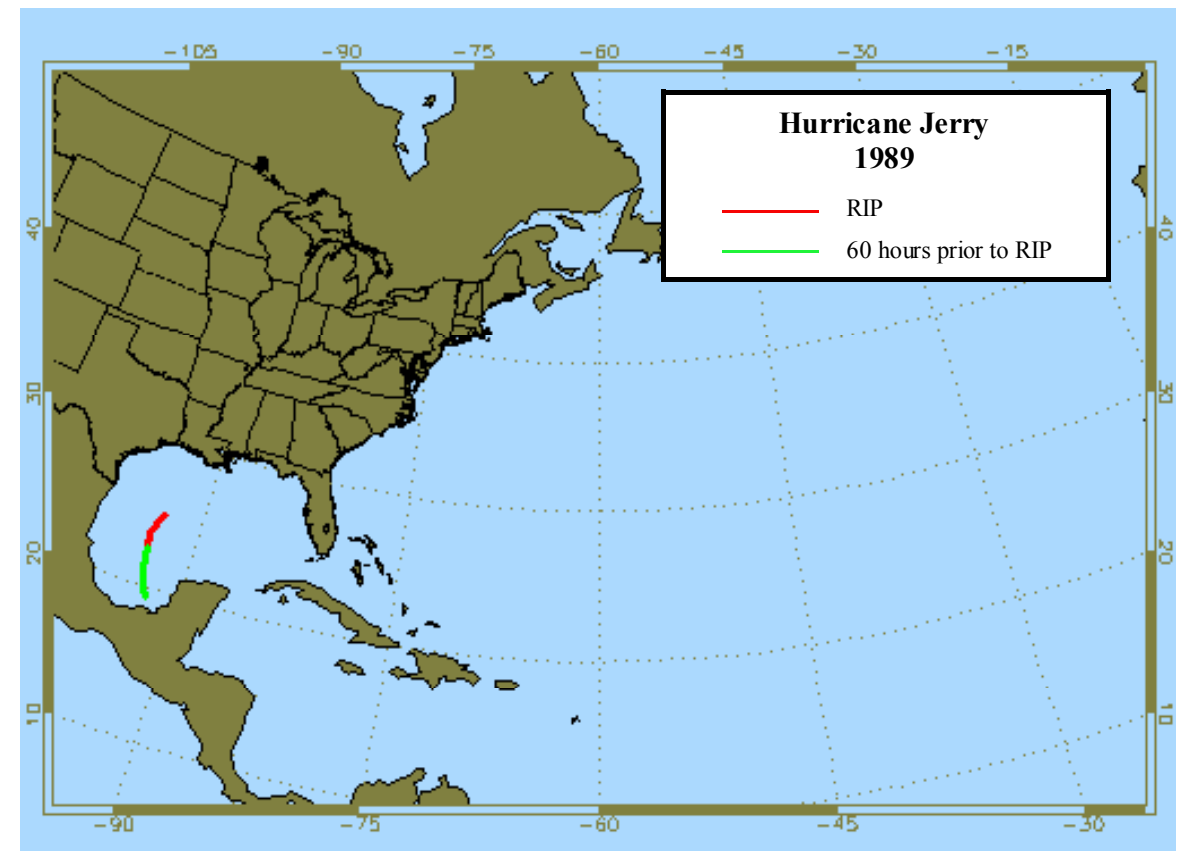

Figure A.13: As in Figure A.1, except for Hurricane Jerry (1989).

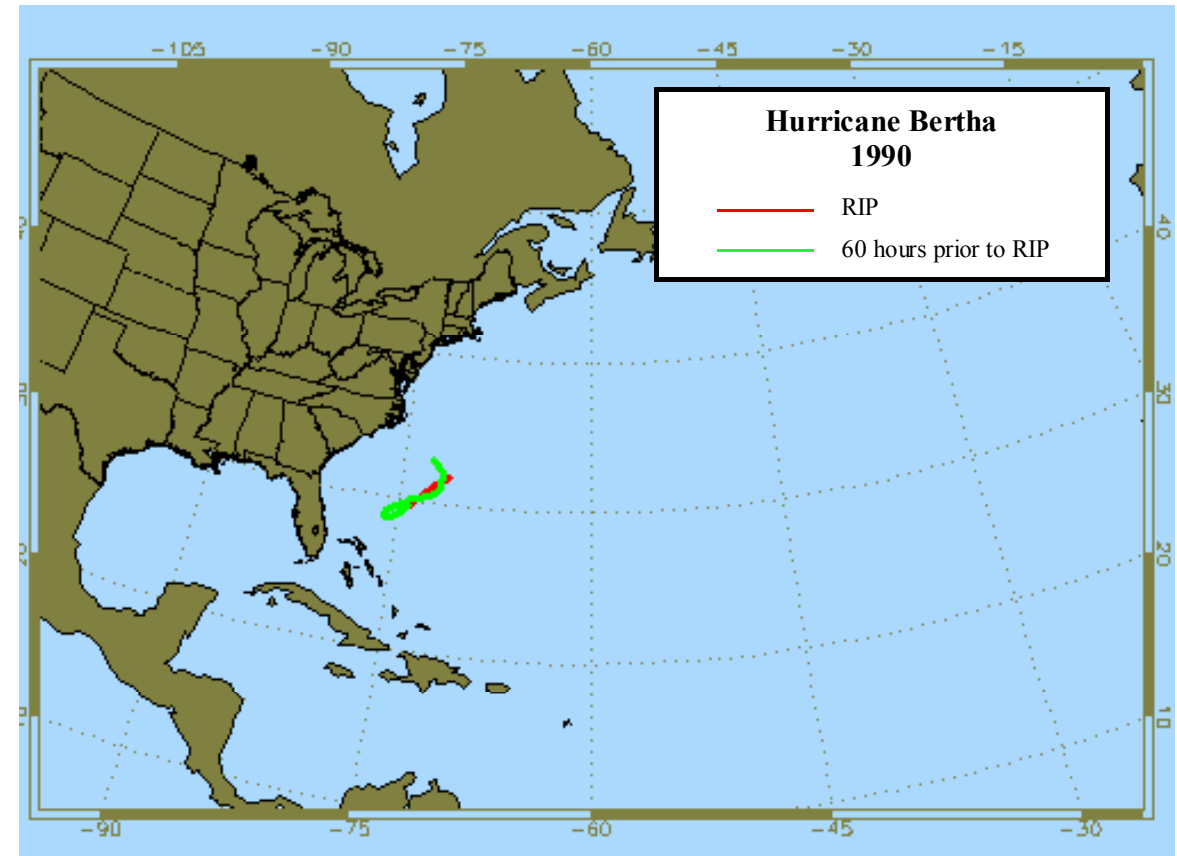

Figure A.14: As in Figure A.1, except for Hurricane Bertha (1990). 


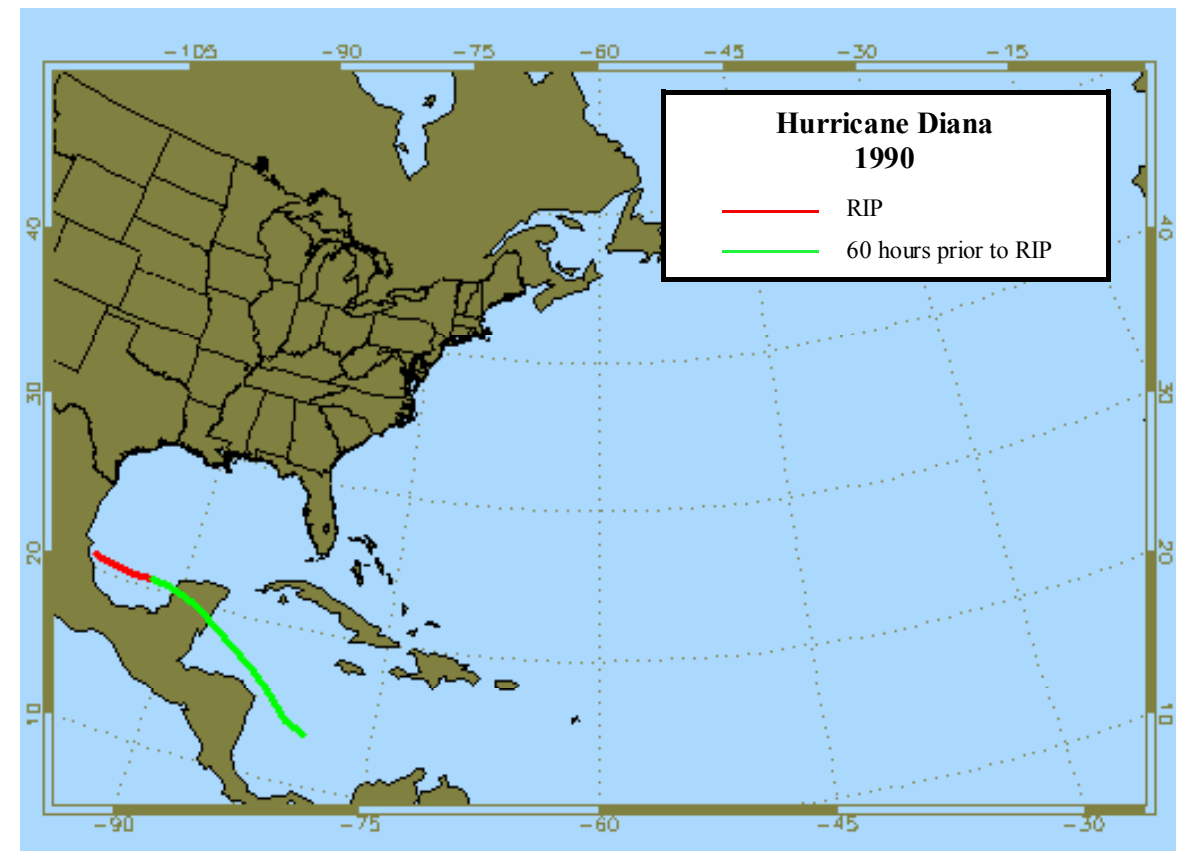

Figure A.15: As in Figure A.1, except for Hurricane Diana (1990).

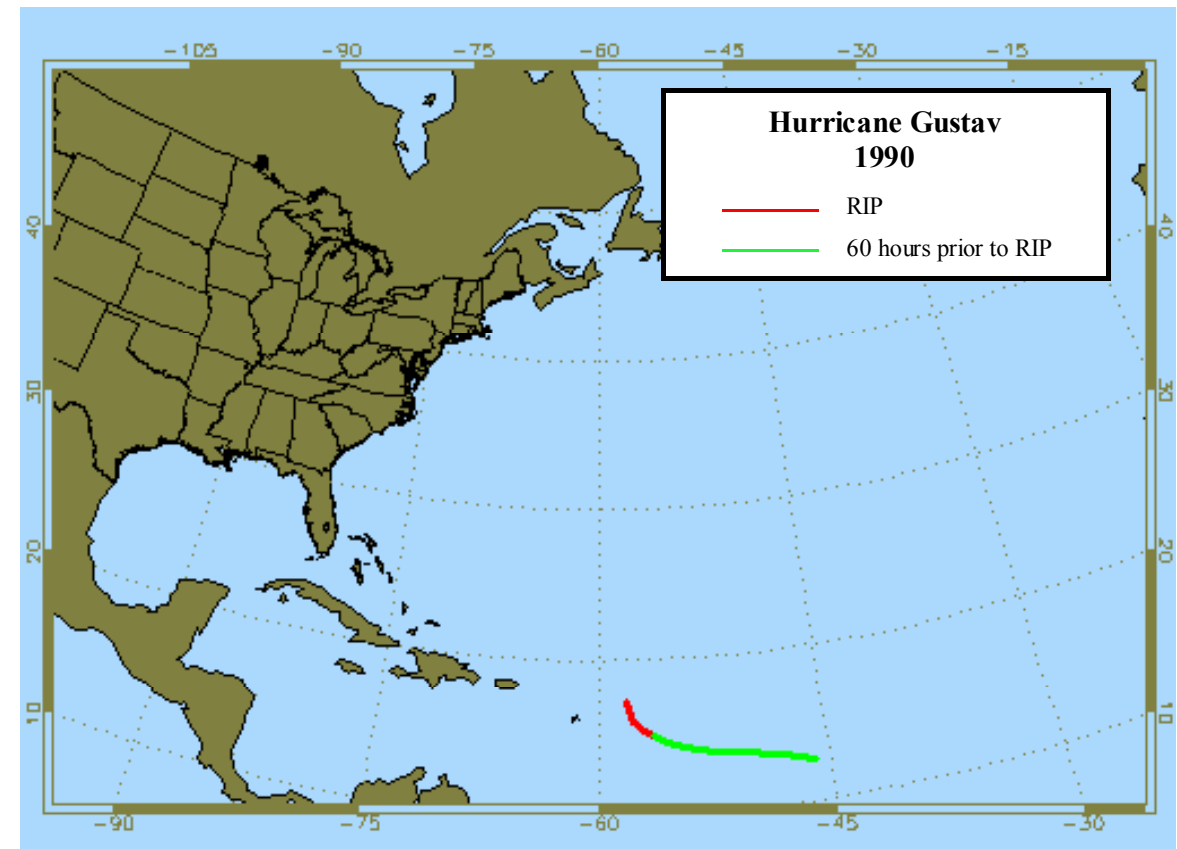

Figure A.16: As in Figure A.1, except for Hurricane Gustav (1990). 


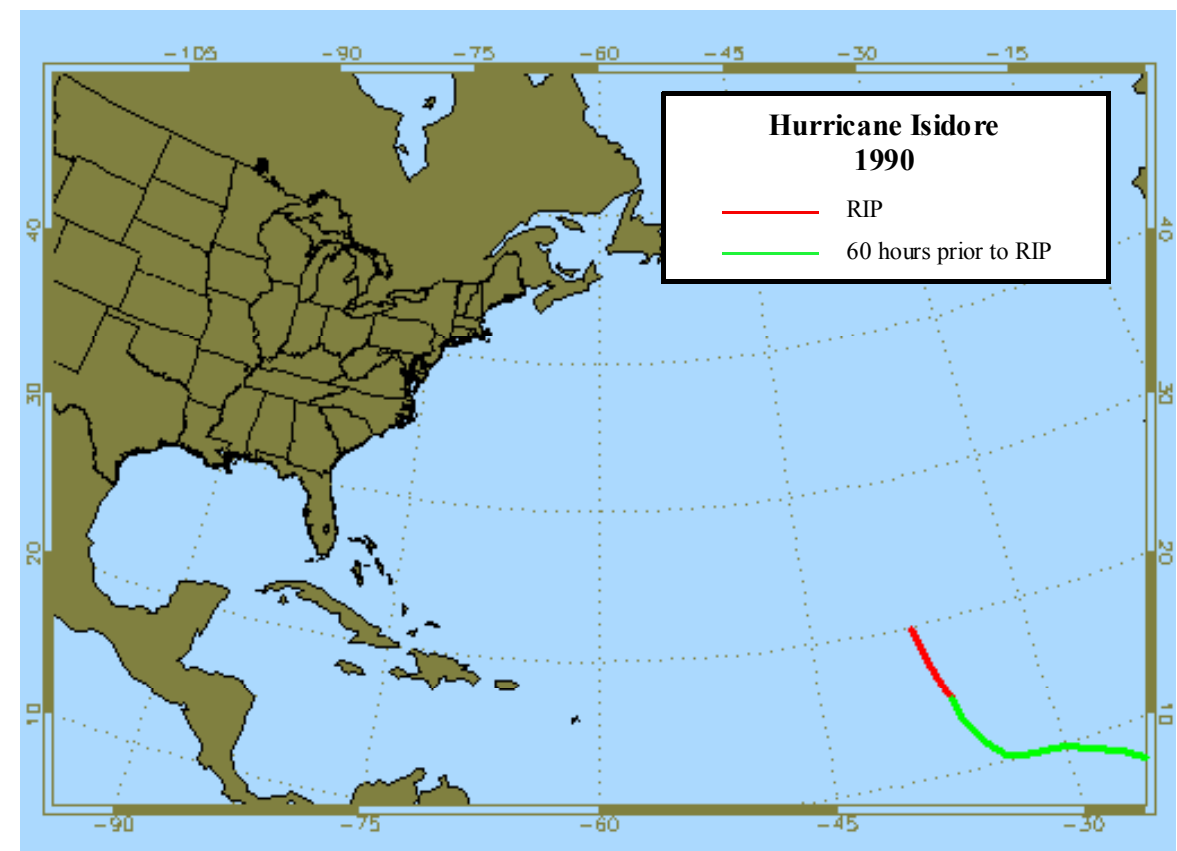

Figure A.17: As in Figure A.1, except for Hurricane Isidore (1990).

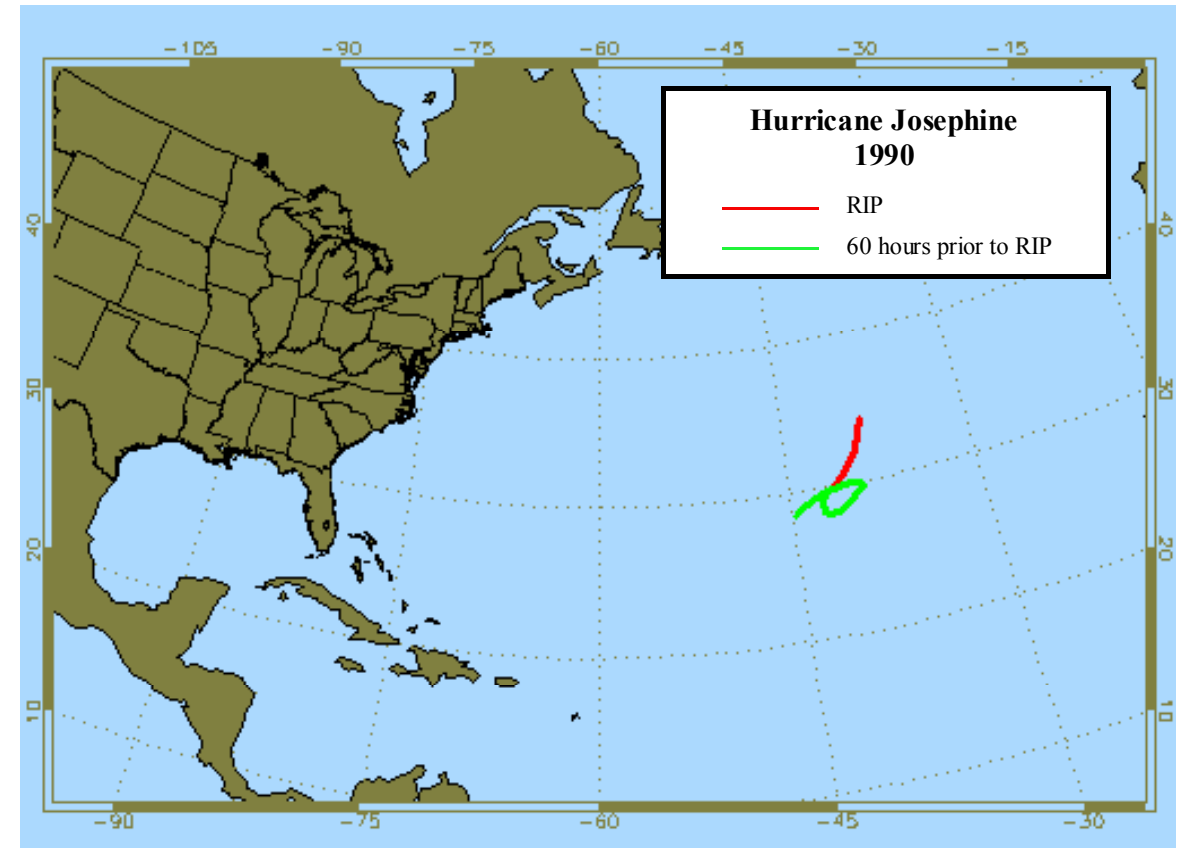

Figure A.18: As in Figure A.1, except for Hurricane Josephine (1990). 


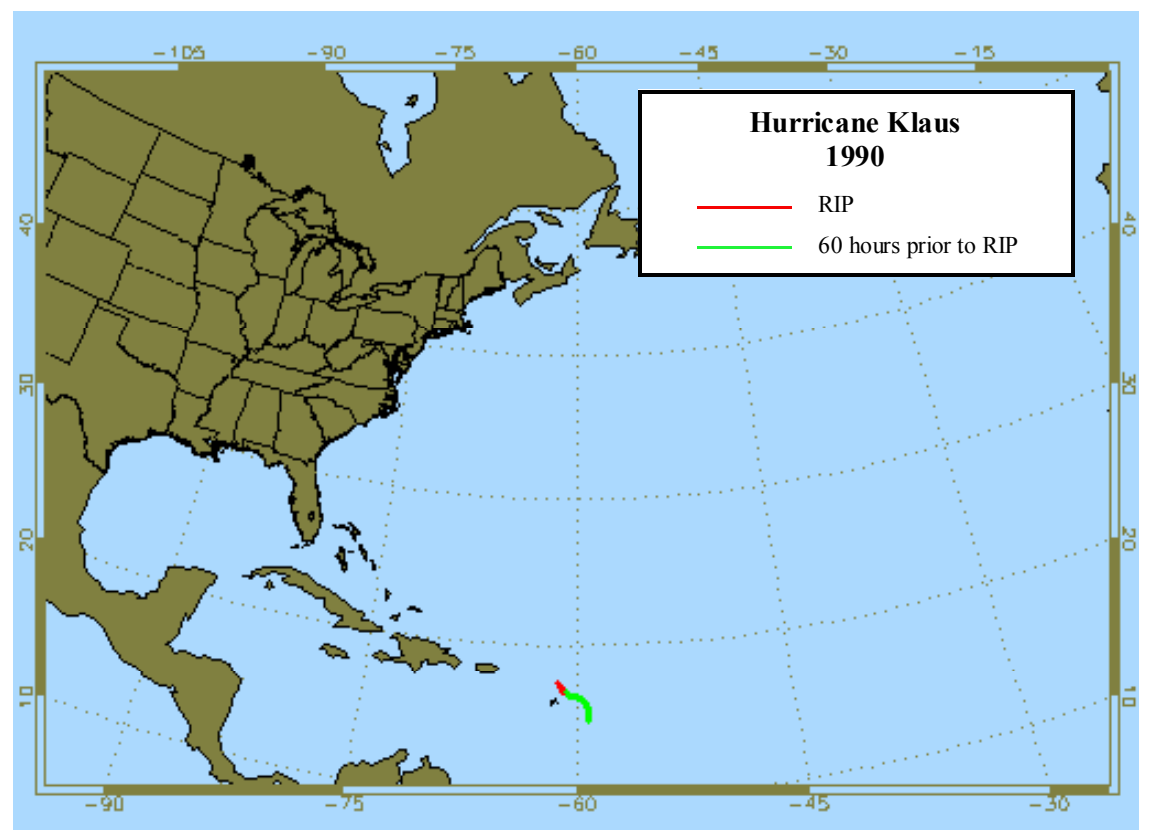

Figure A.19: As in Figure A.1, except for Hurricane Klaus (1990).

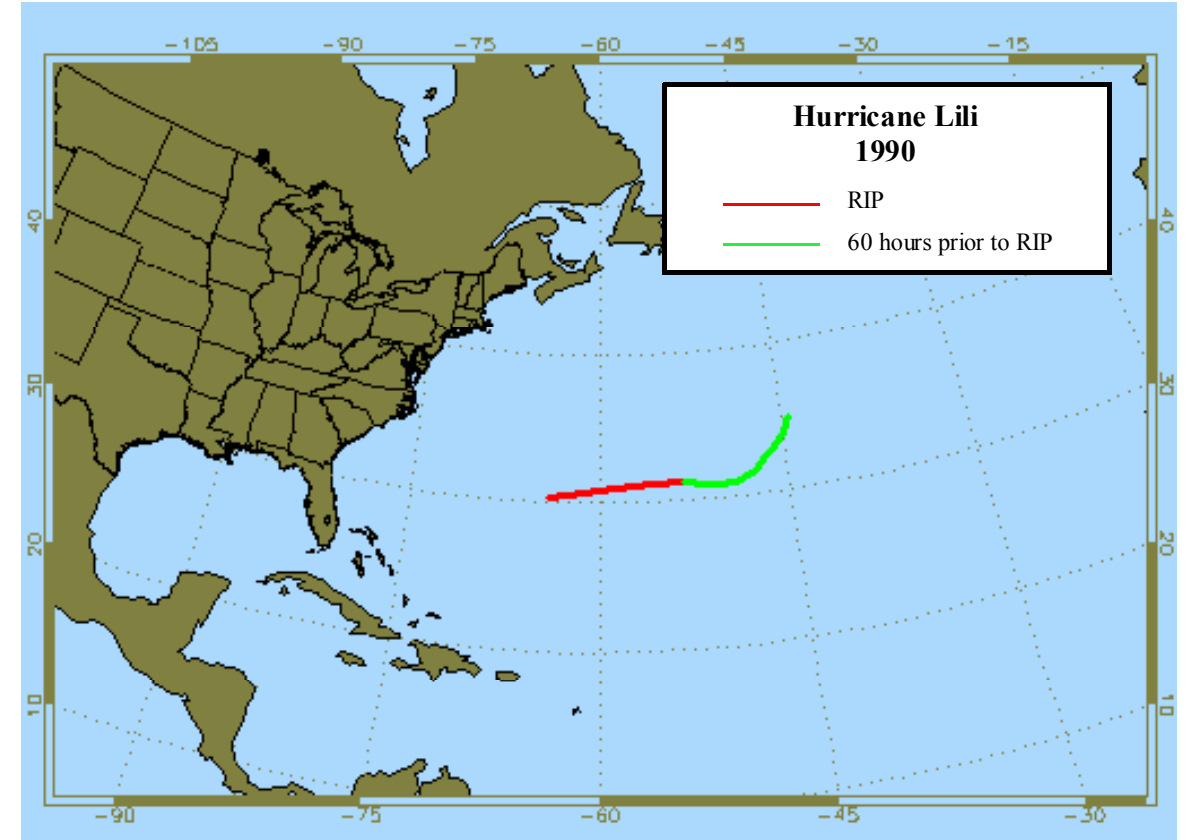

Figure A.20: As in Figure A.1, except for Hurricane Lili (1990). 


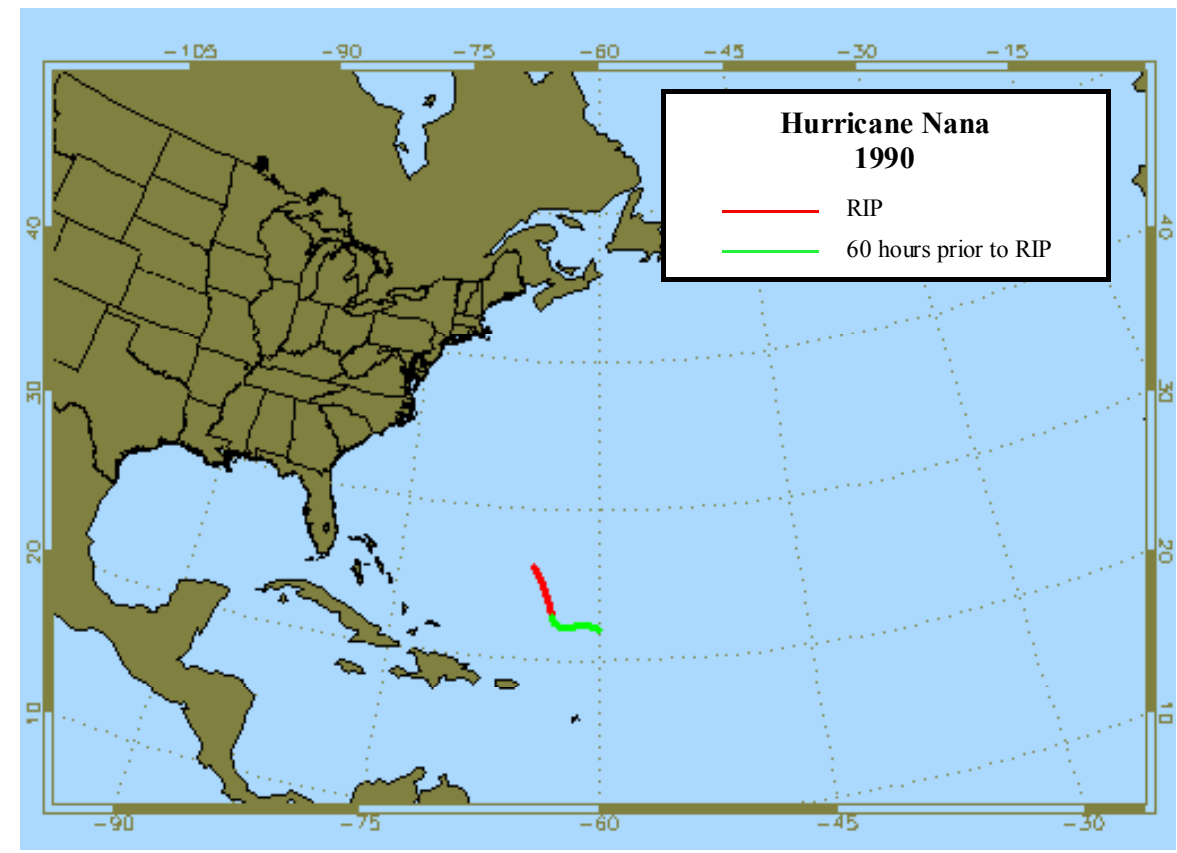

Figure A.21: As in Figure A.1, except for Hurricane Nana (1990).

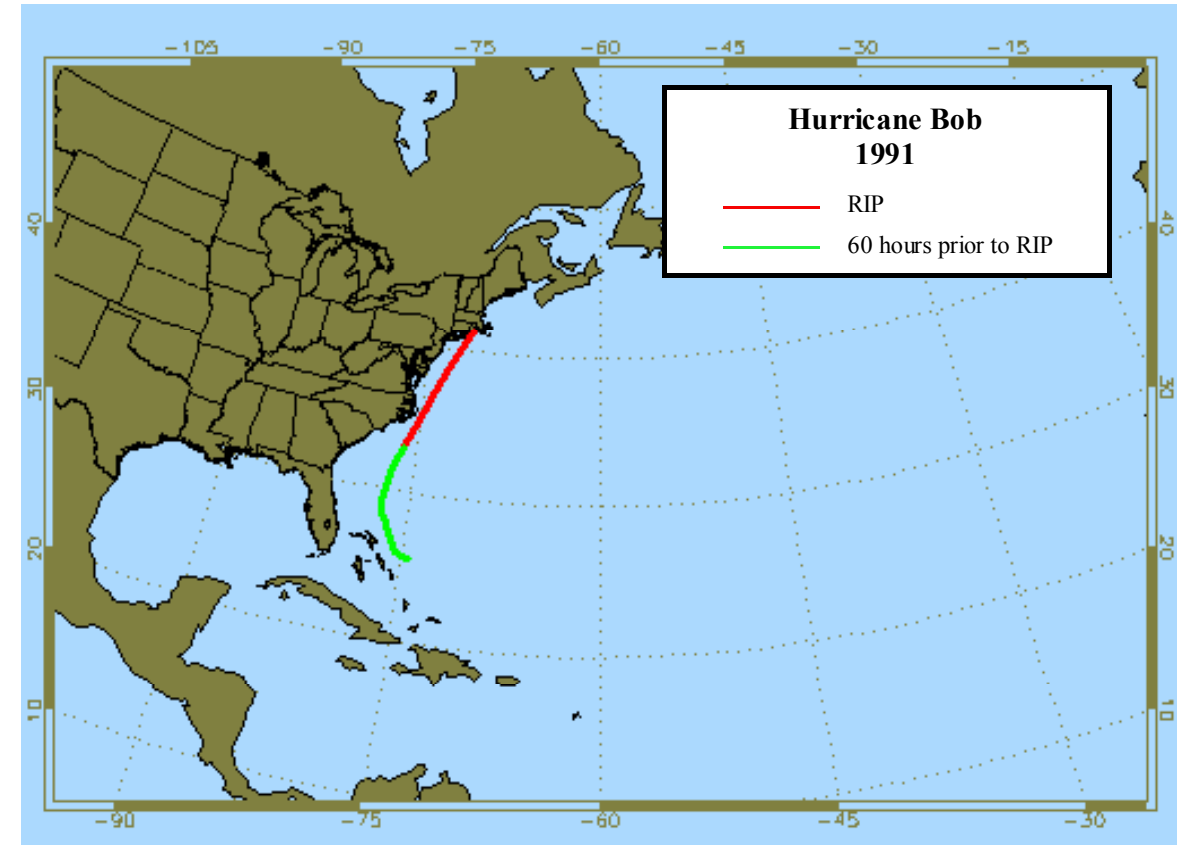

Figure A.22: As in Figure A.1, except for Hurricane Bob (1991). 


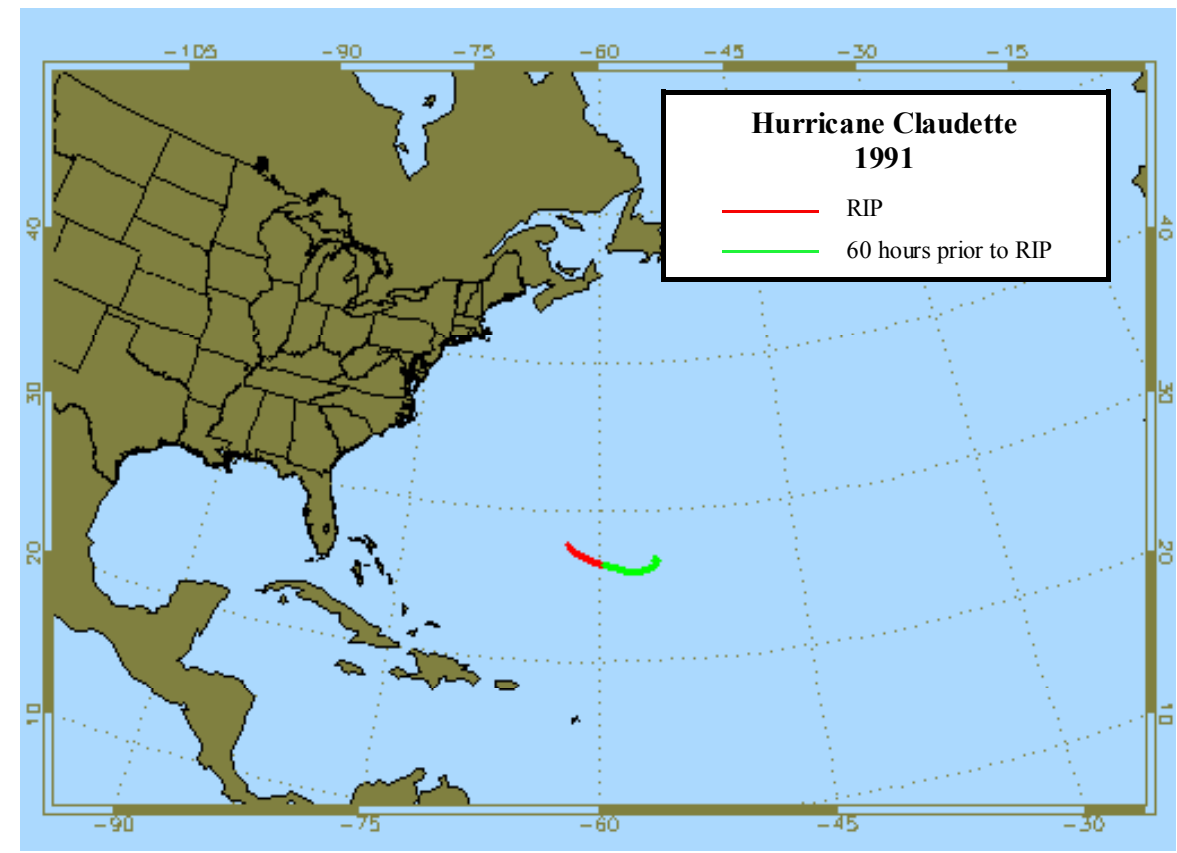

Figure A.23: As in Figure A.1, except for Hurricane Claudette (1991).

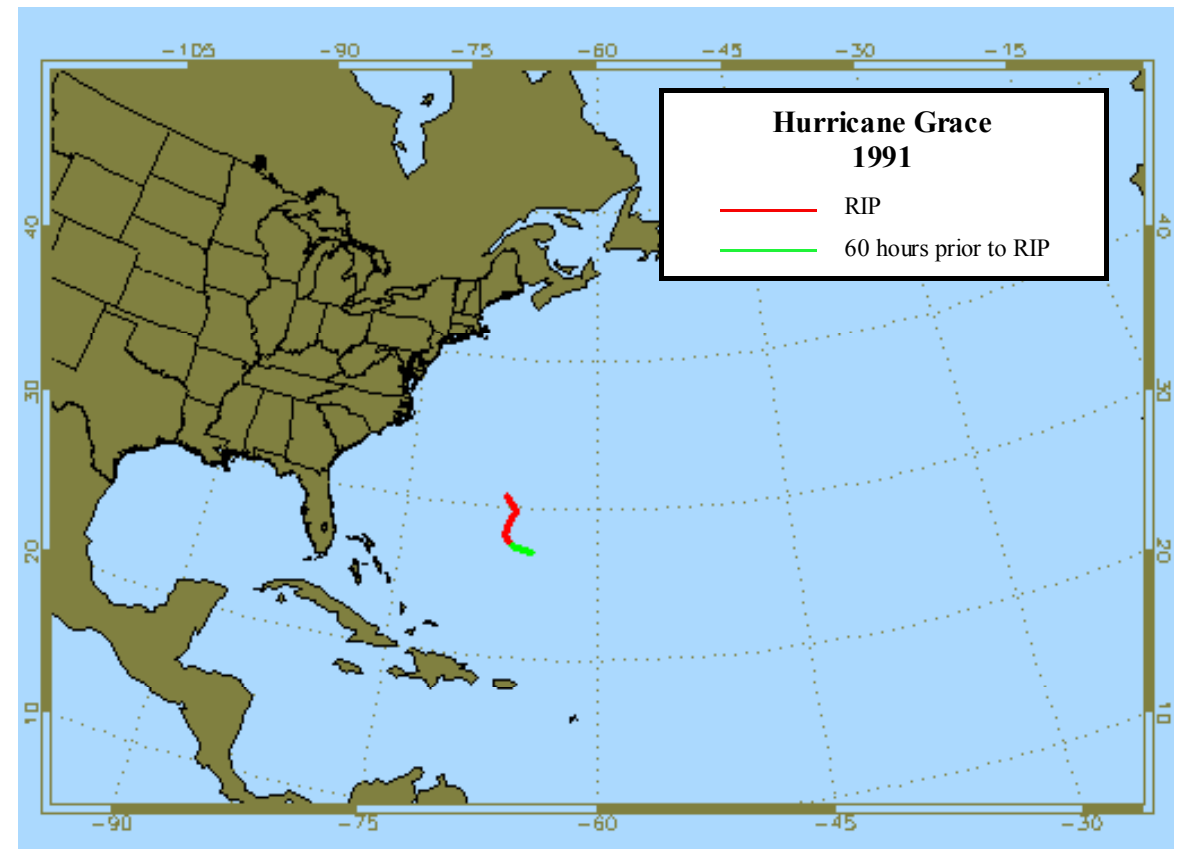

Figure A.24: As in Figure A.1, except for Hurricane Grace (1991). 


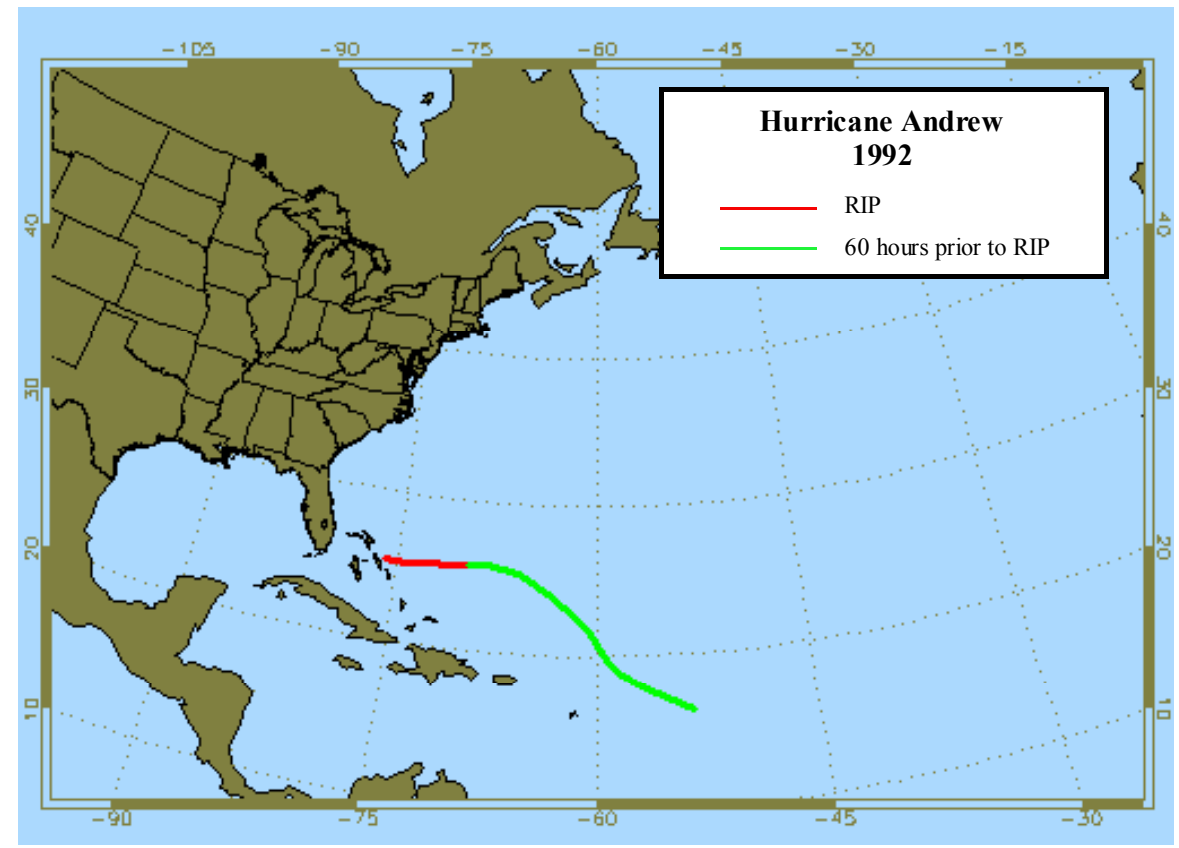

Figure A.25: As in Figure A.1, except for Hurricane Andrew (1992).

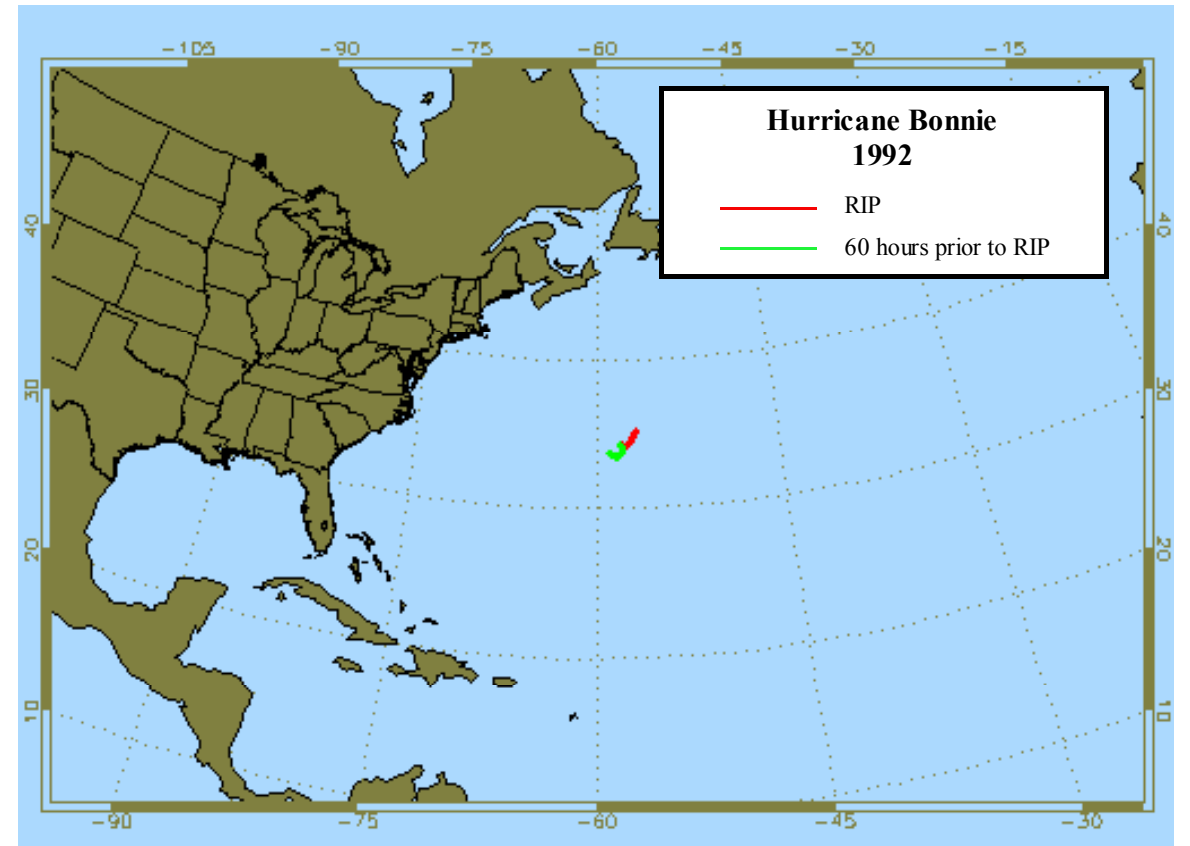

Figure A.26: As in Figure A.1, except for Hurricane Bonnie (1992). 


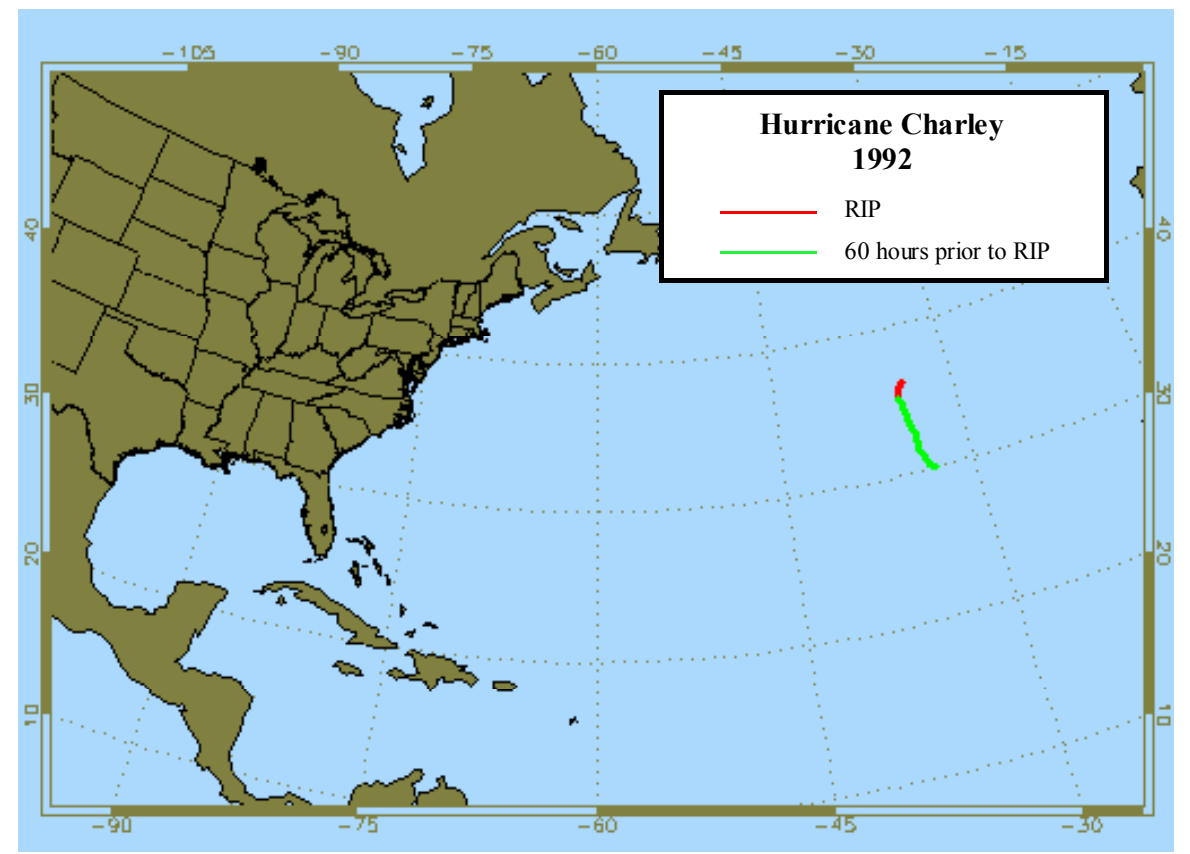

Figure A.27: As in Figure A.1, except for Hurricane Charley (1992).

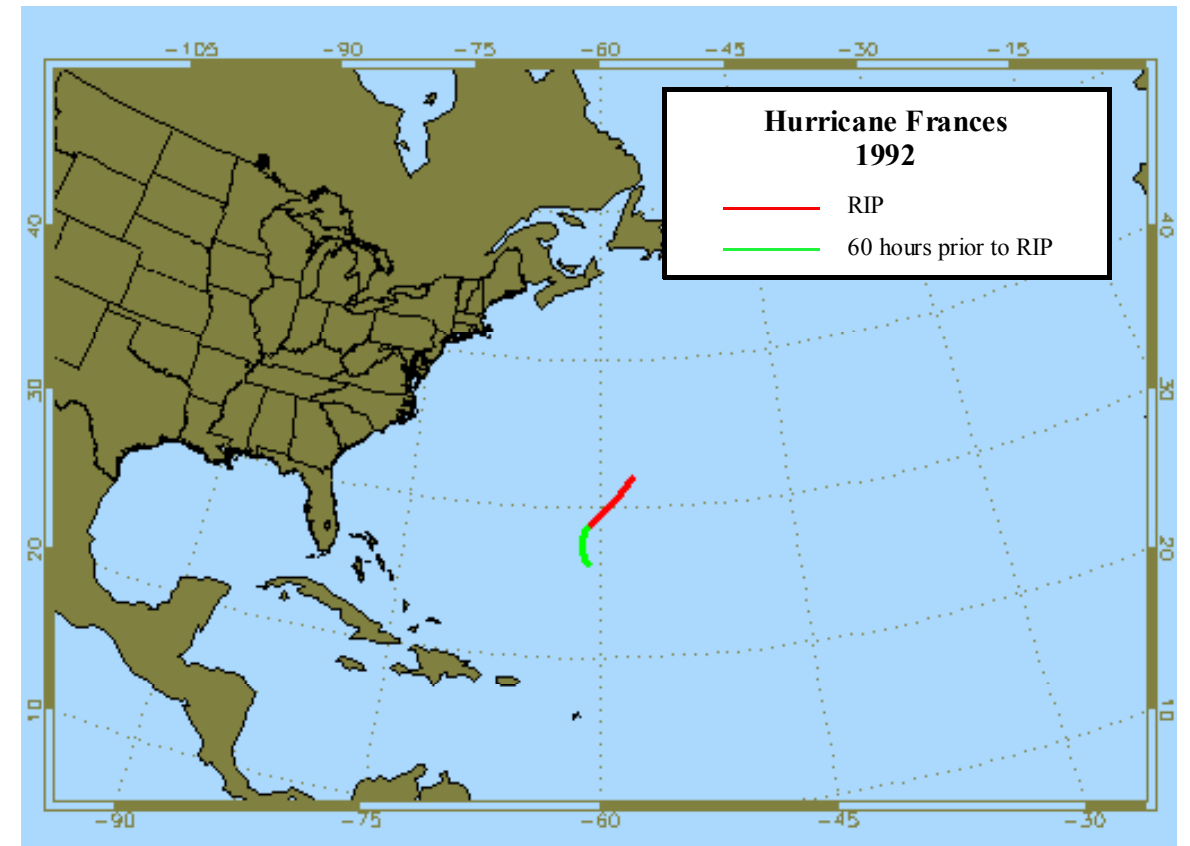

Figure A.28: As in Figure A.1, except for Hurricane Frances (1992). 


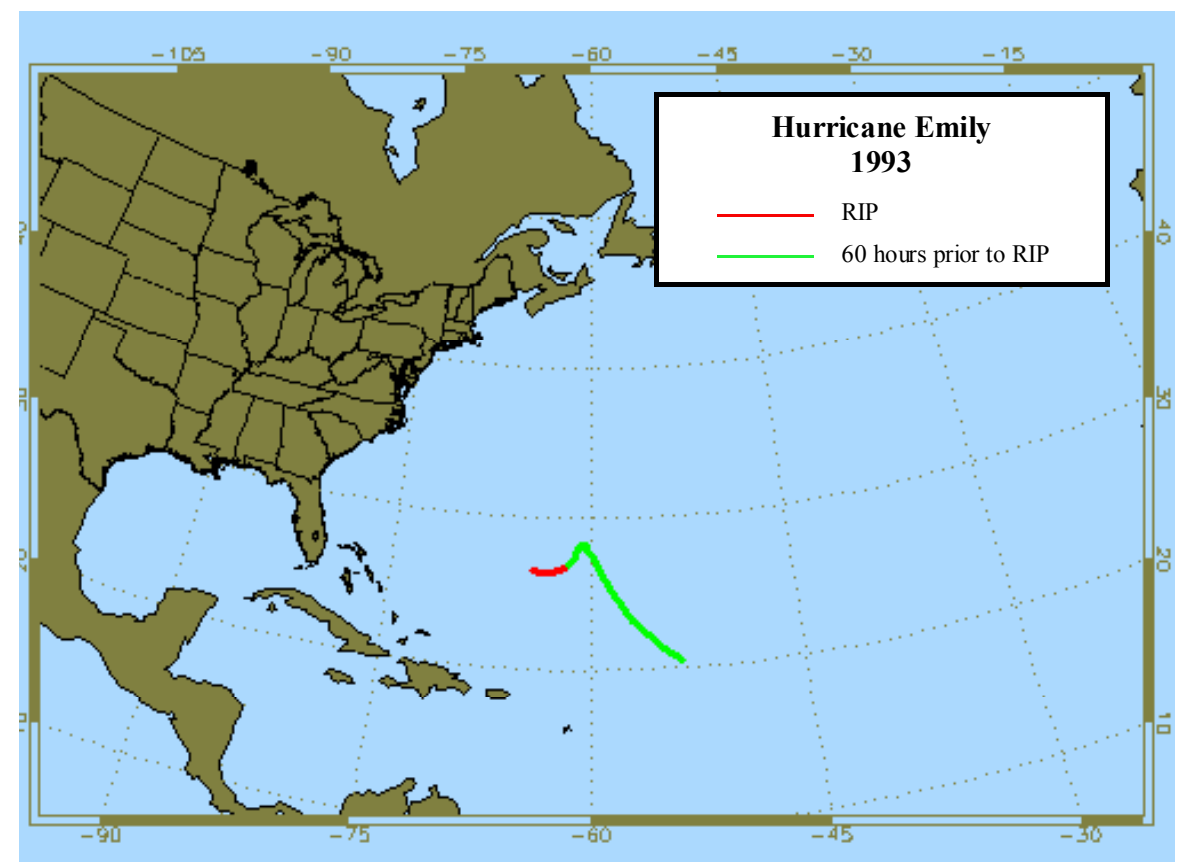

Figure A.29: As in Figure A.1, except for Hurricane Emily (1993).

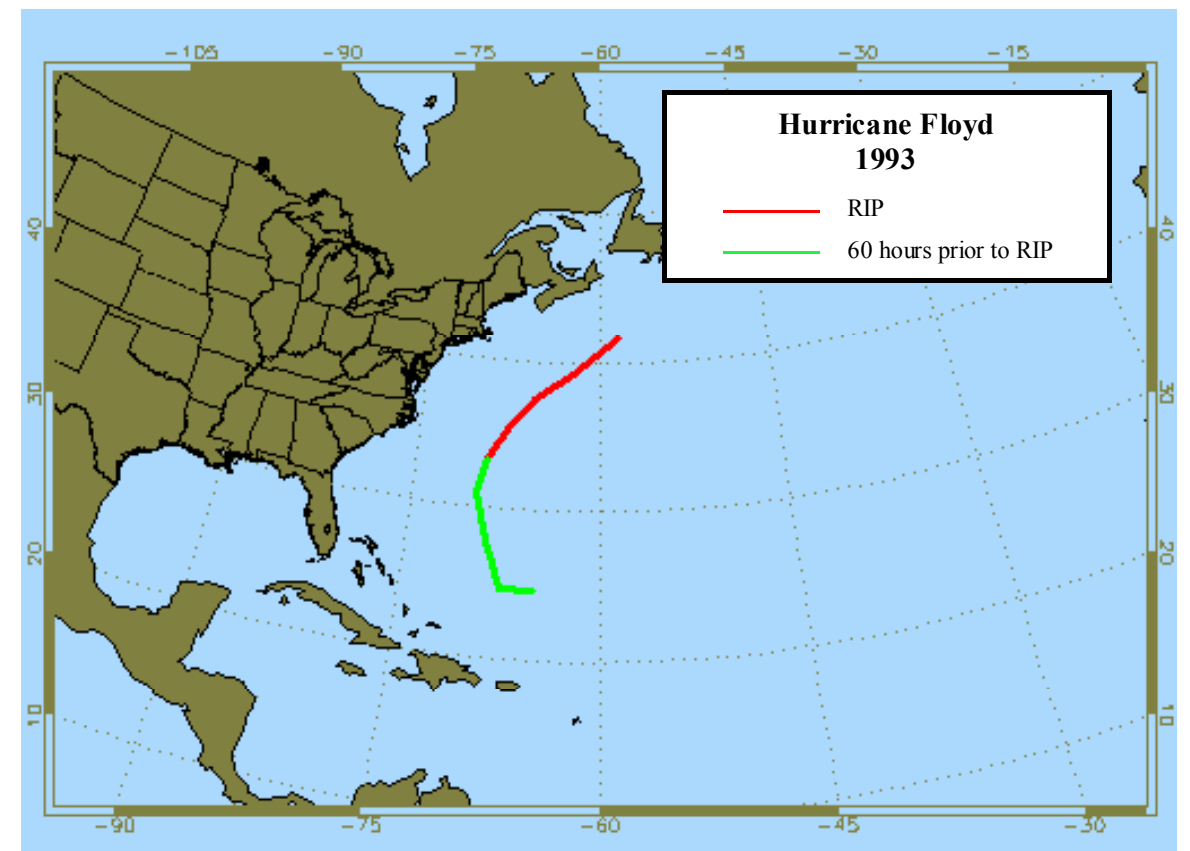

Figure A.30: As in Figure A.1, except for Hurricane Floyd (1993). 


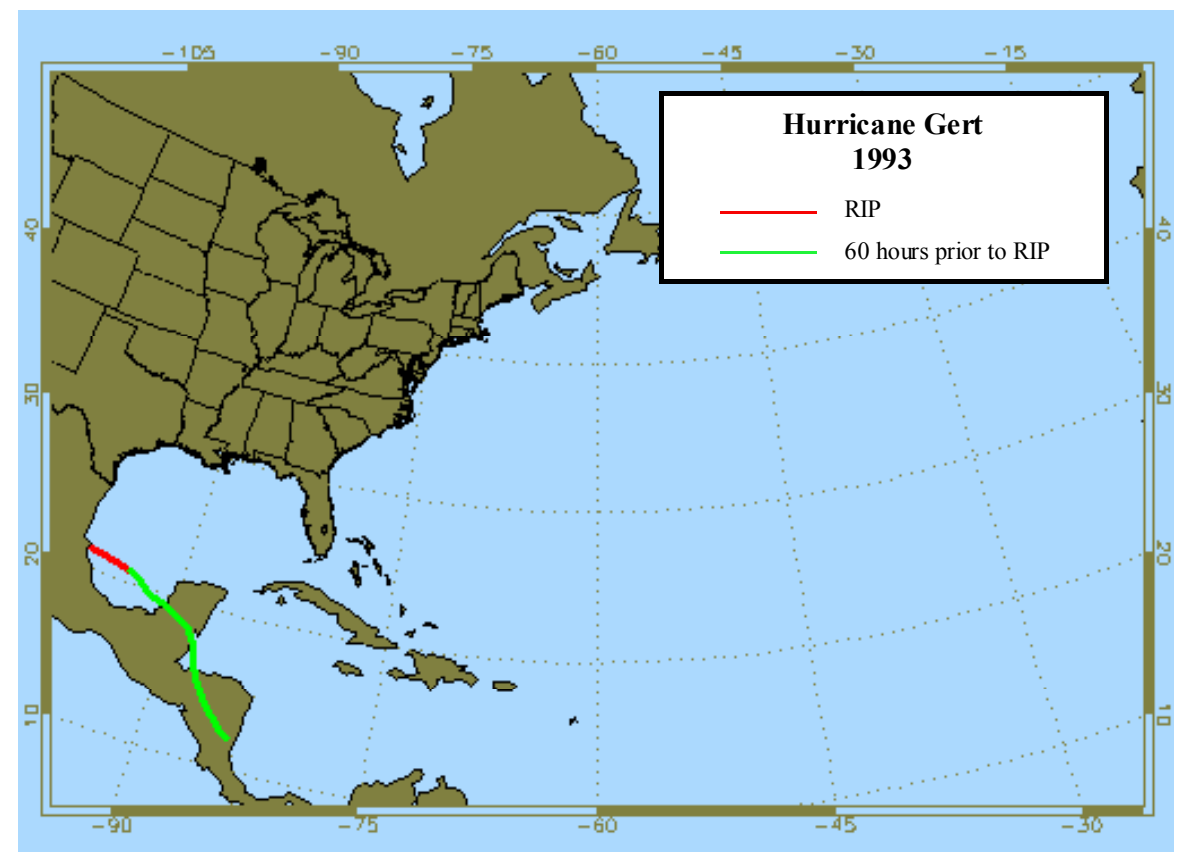

Figure A.31: As in Figure A.1, except for Hurricane Gert (1993).

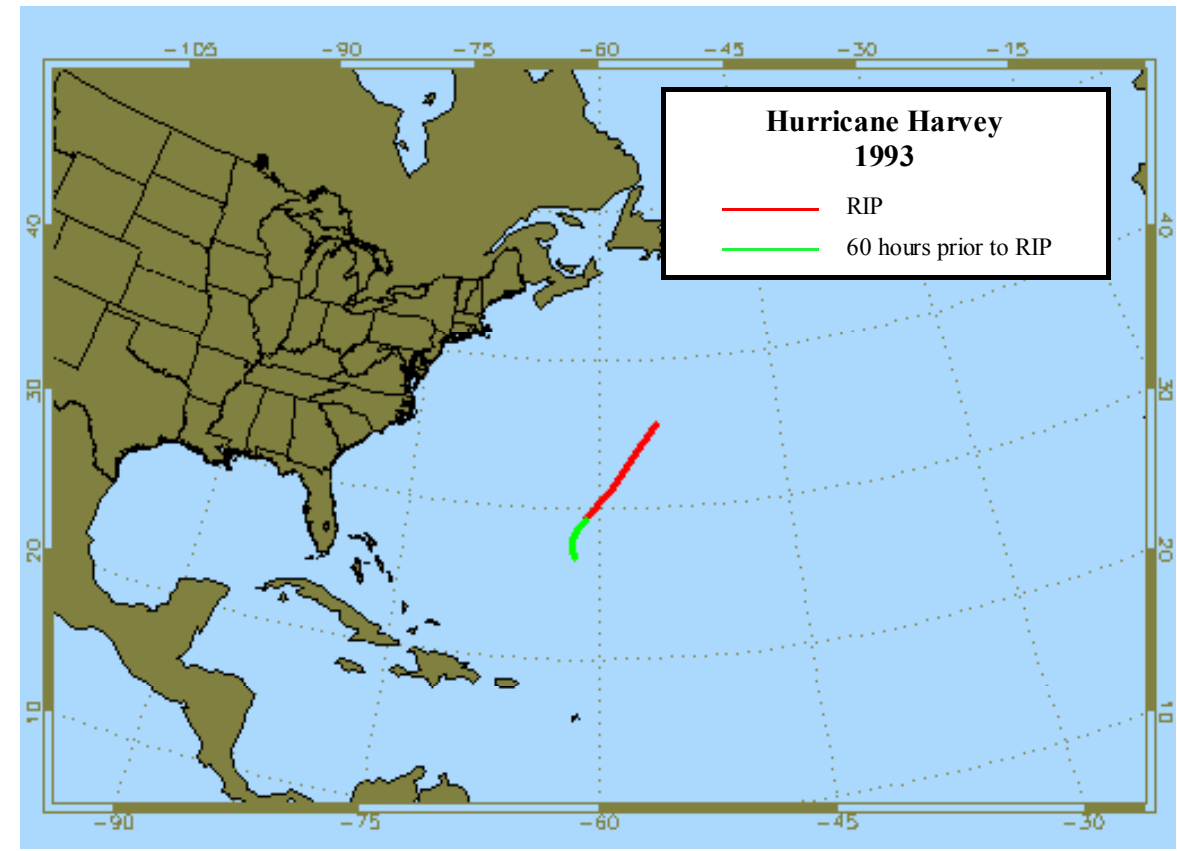

Figure A.32: As in Figure A.1, except for Hurricane Harvey (1993). 


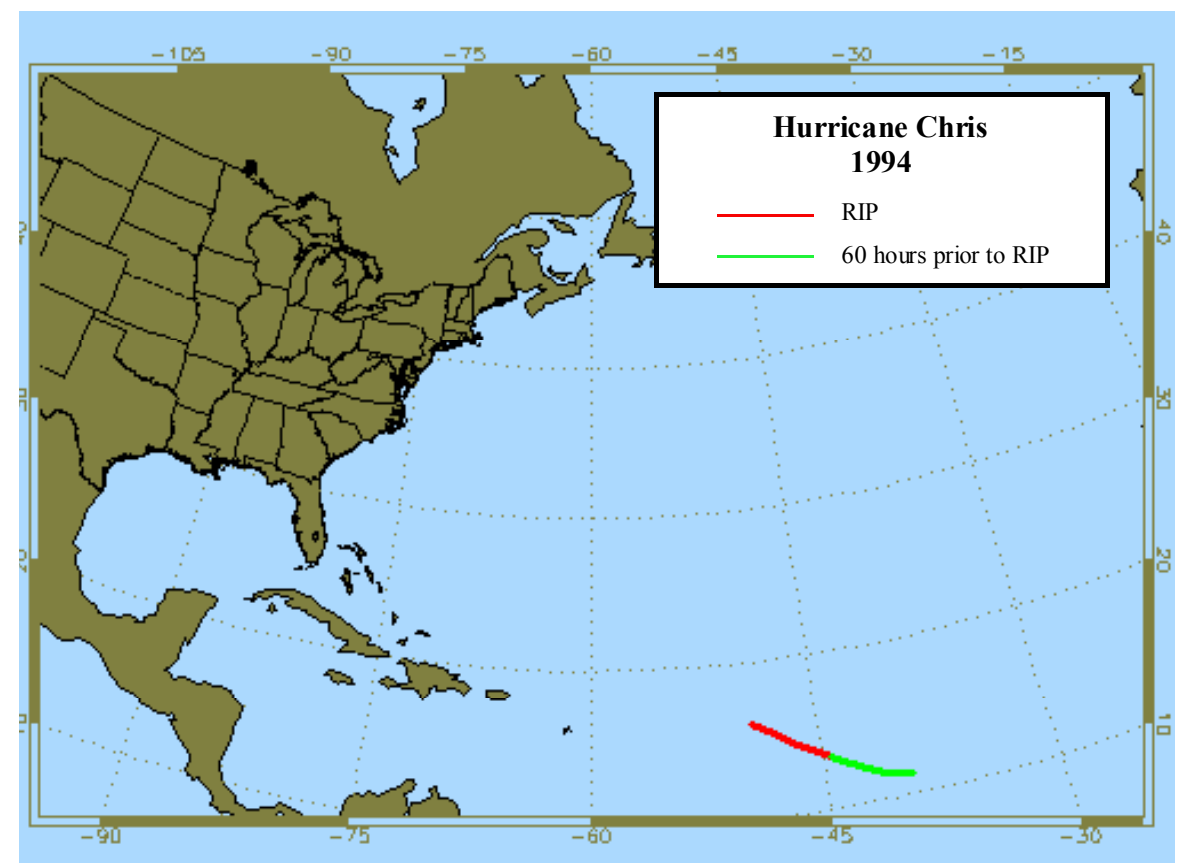

Figure A.33: As in Figure A.1, except for Hurricane Chris (1994).

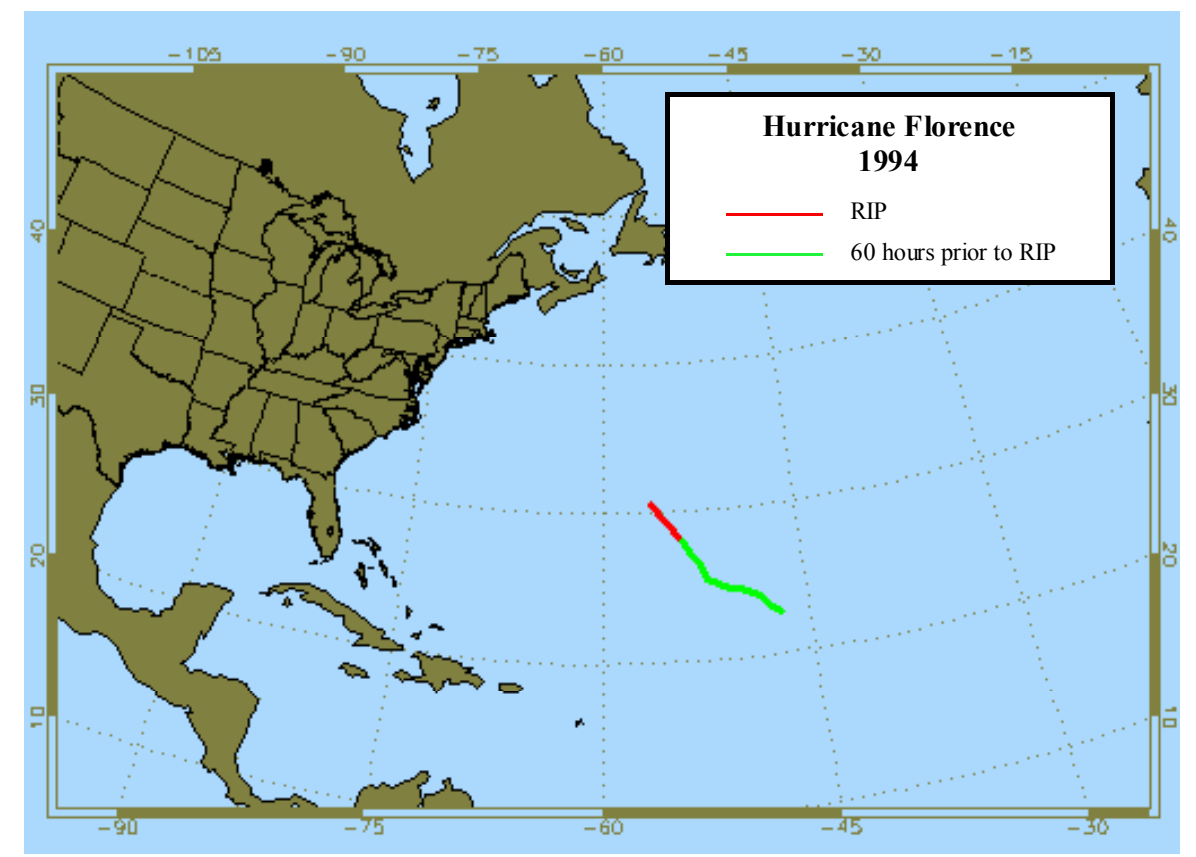

Figure A.34: As in Figure A.1, except for Hurricane Florence (1994). 


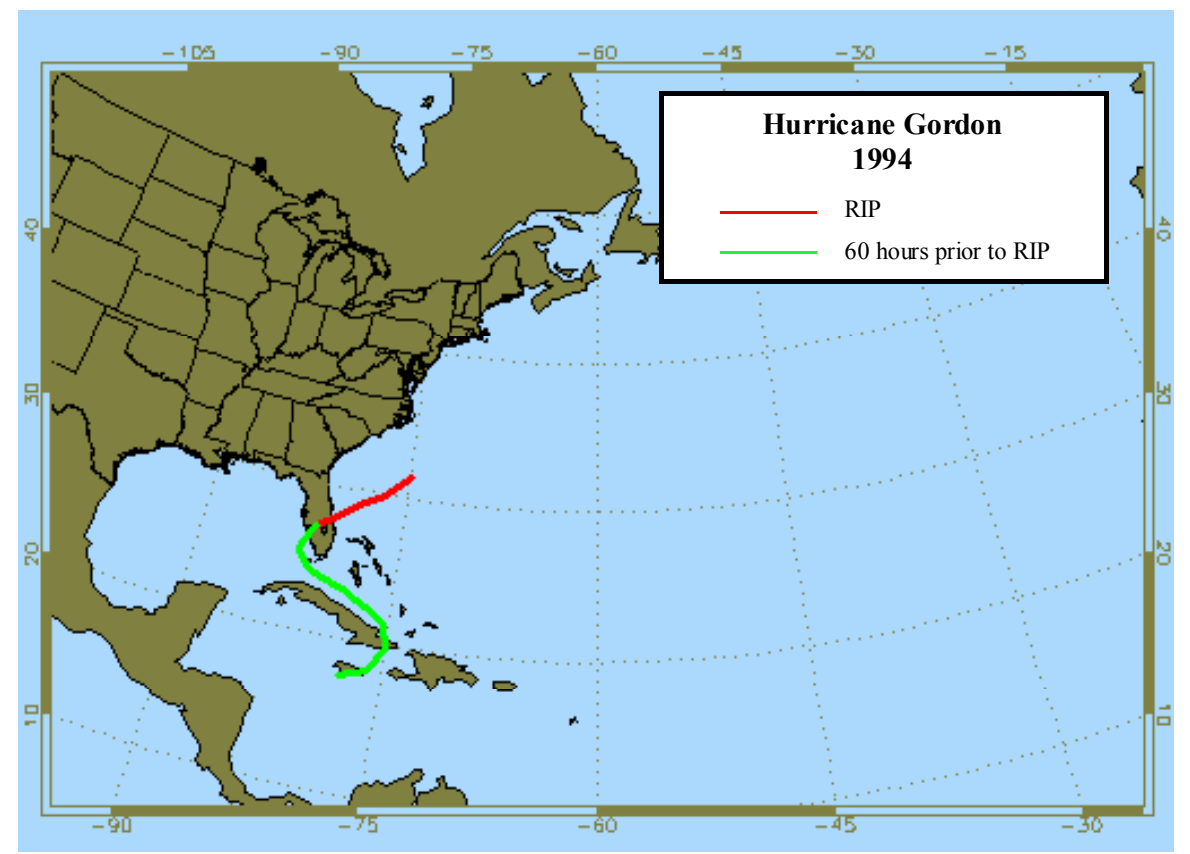

Figure A.35: As in Figure A.1, except for Hurricane Gordon (1994).

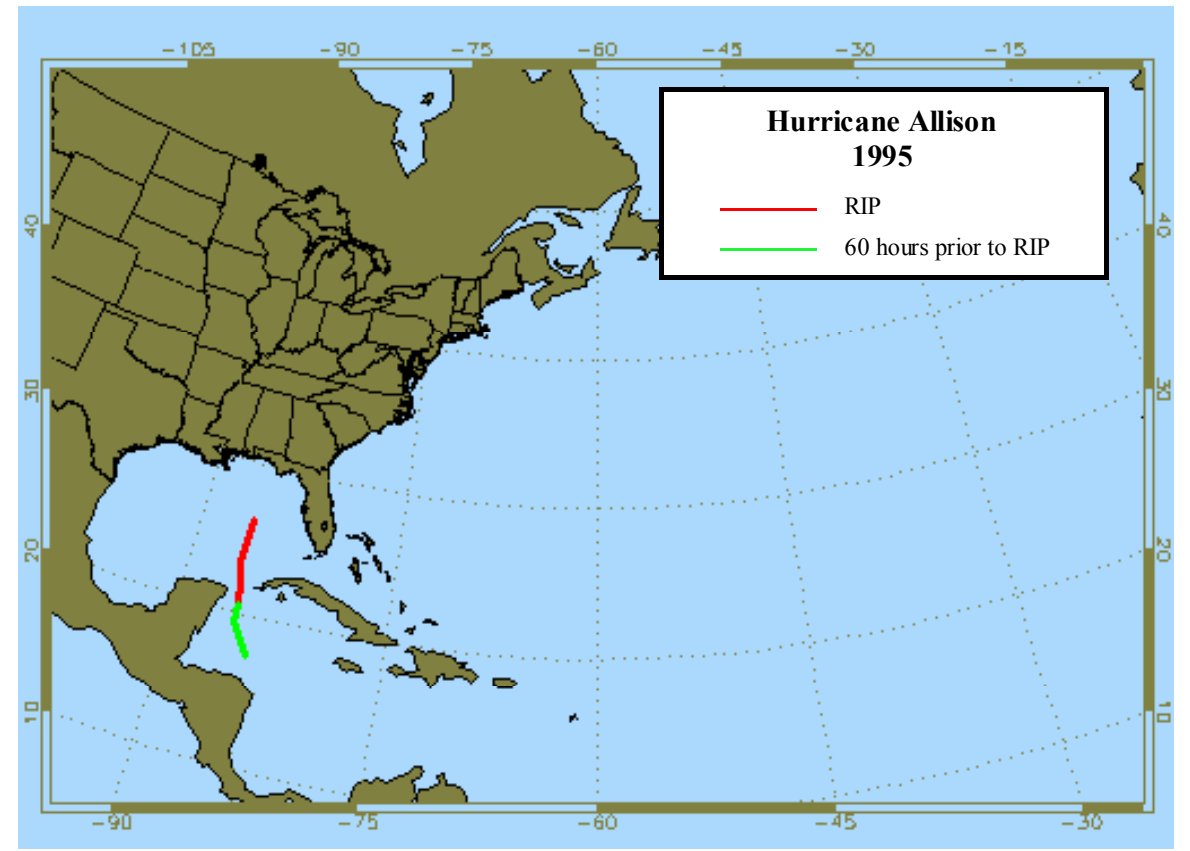

Figure A.36: As in Figure A.1, except for Hurricane Allison (1995). 


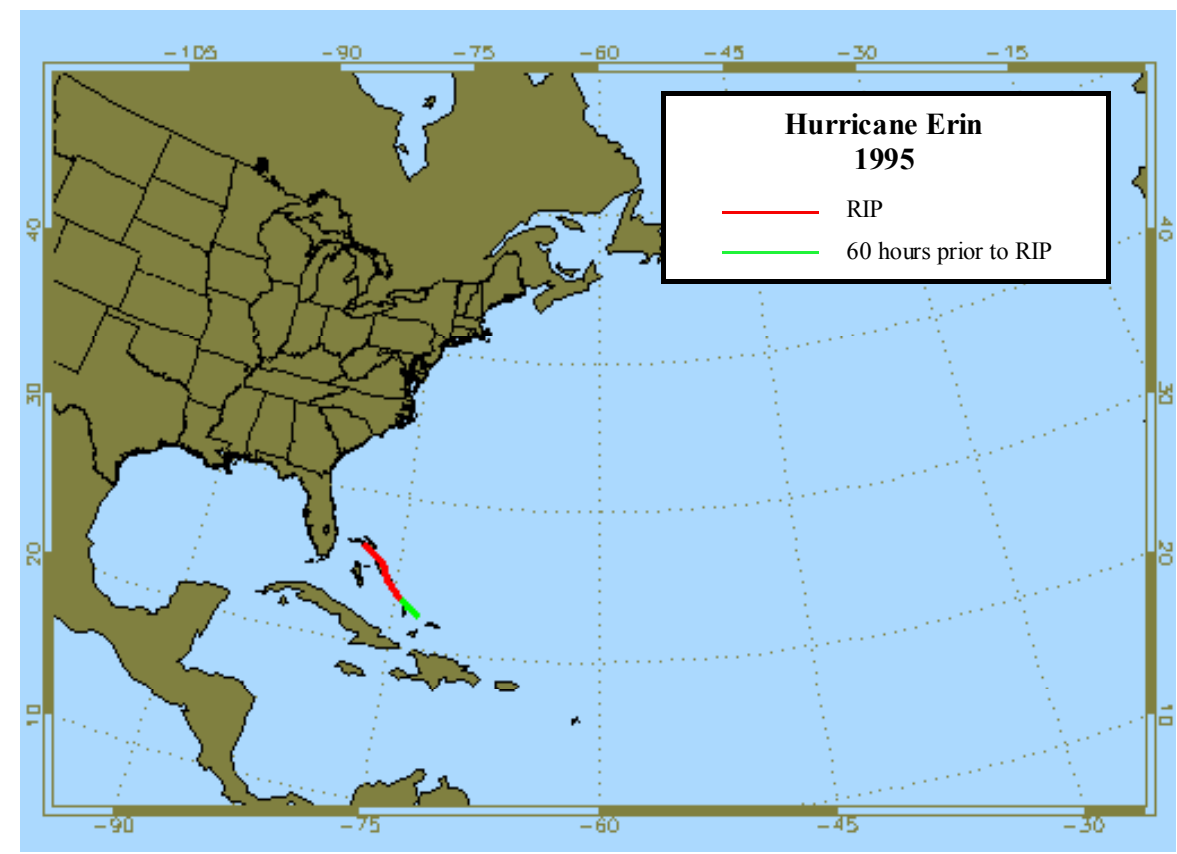

Figure A.37: As in Figure A.1, except for Hurricane Erin (1995).

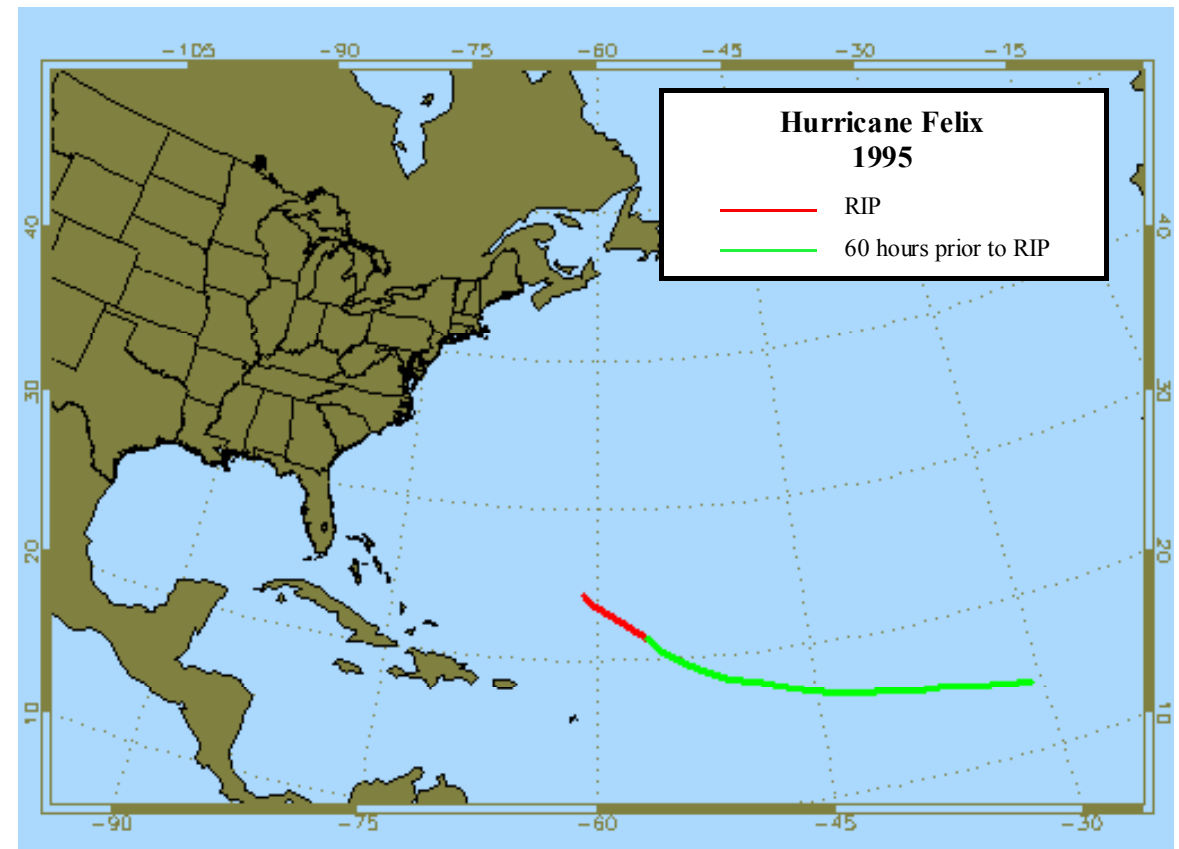

Figure A.38: As in Figure A.1, except for Hurricane Felix (1995). 


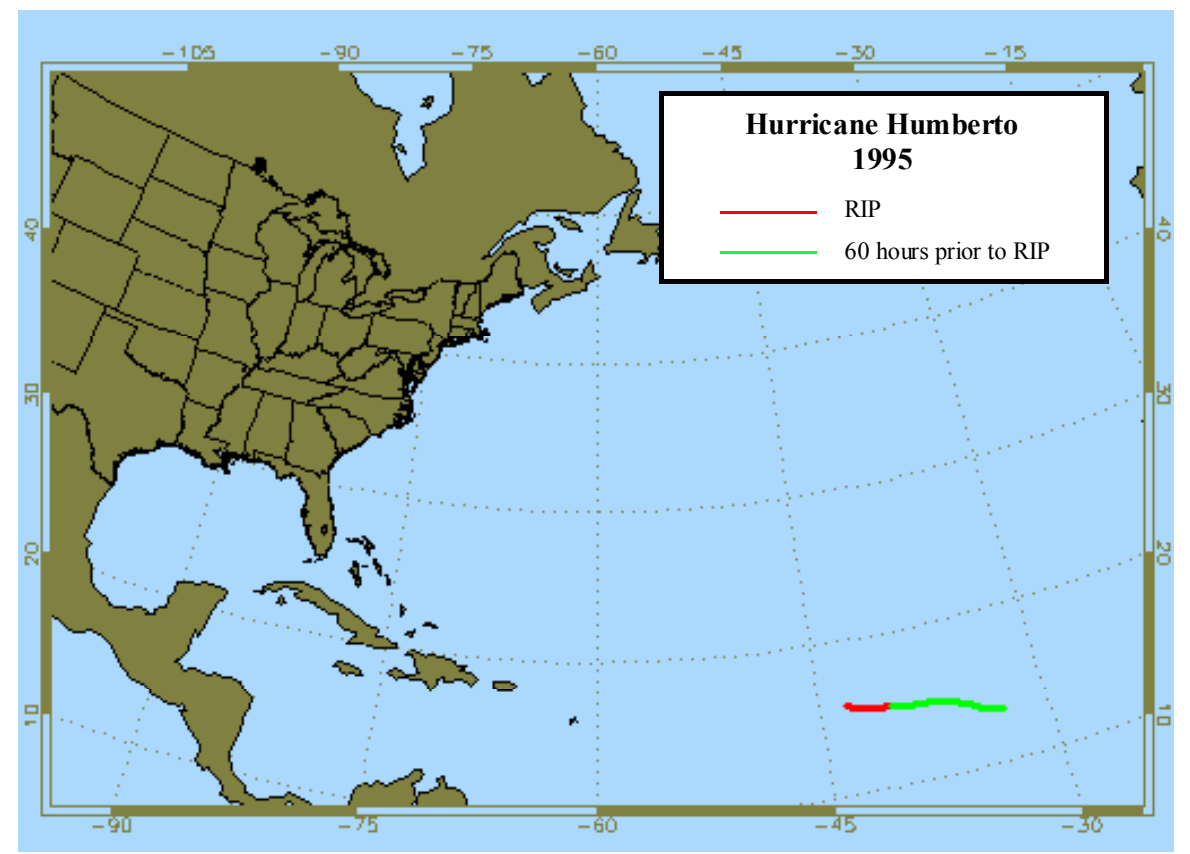

Figure A.39: As in Figure A.1, except for Hurricane Humberto (1995).

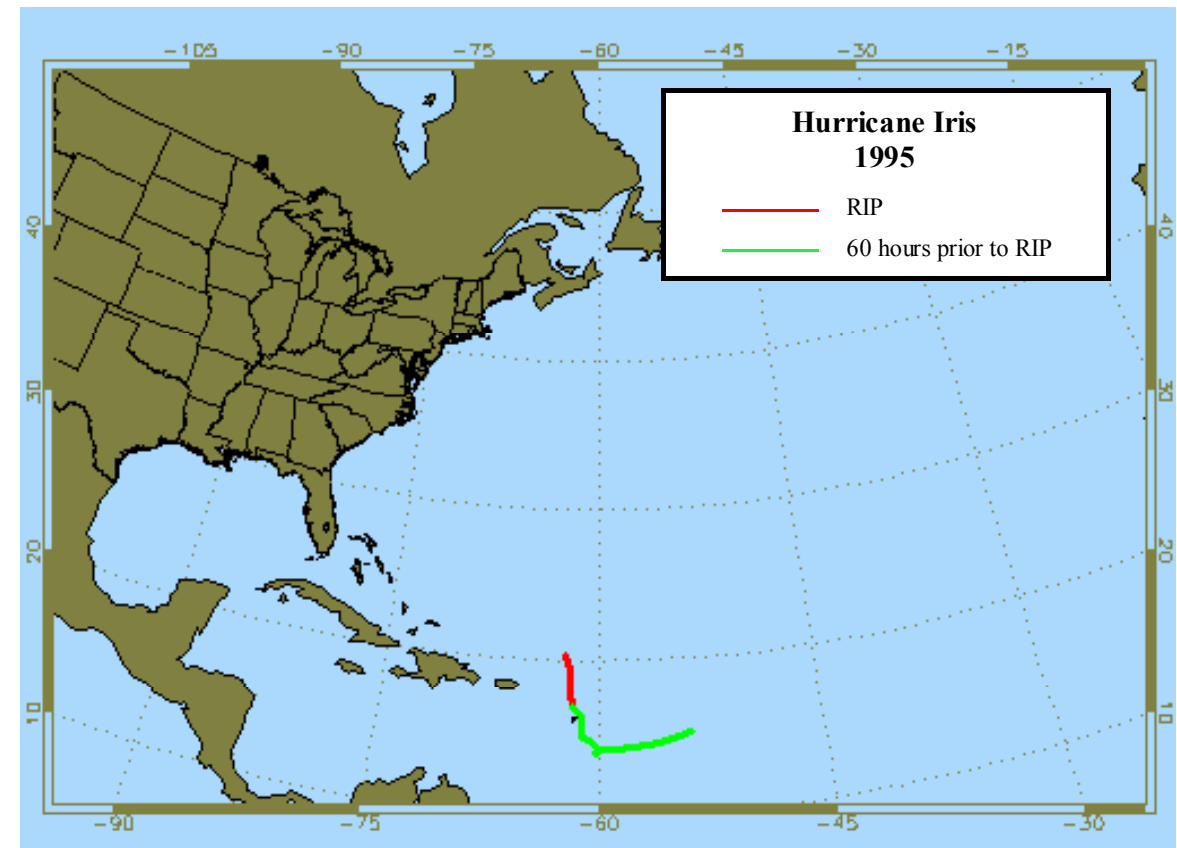

Figure A.40: As in Figure A.1, except for Hurricane Iris (1995). 


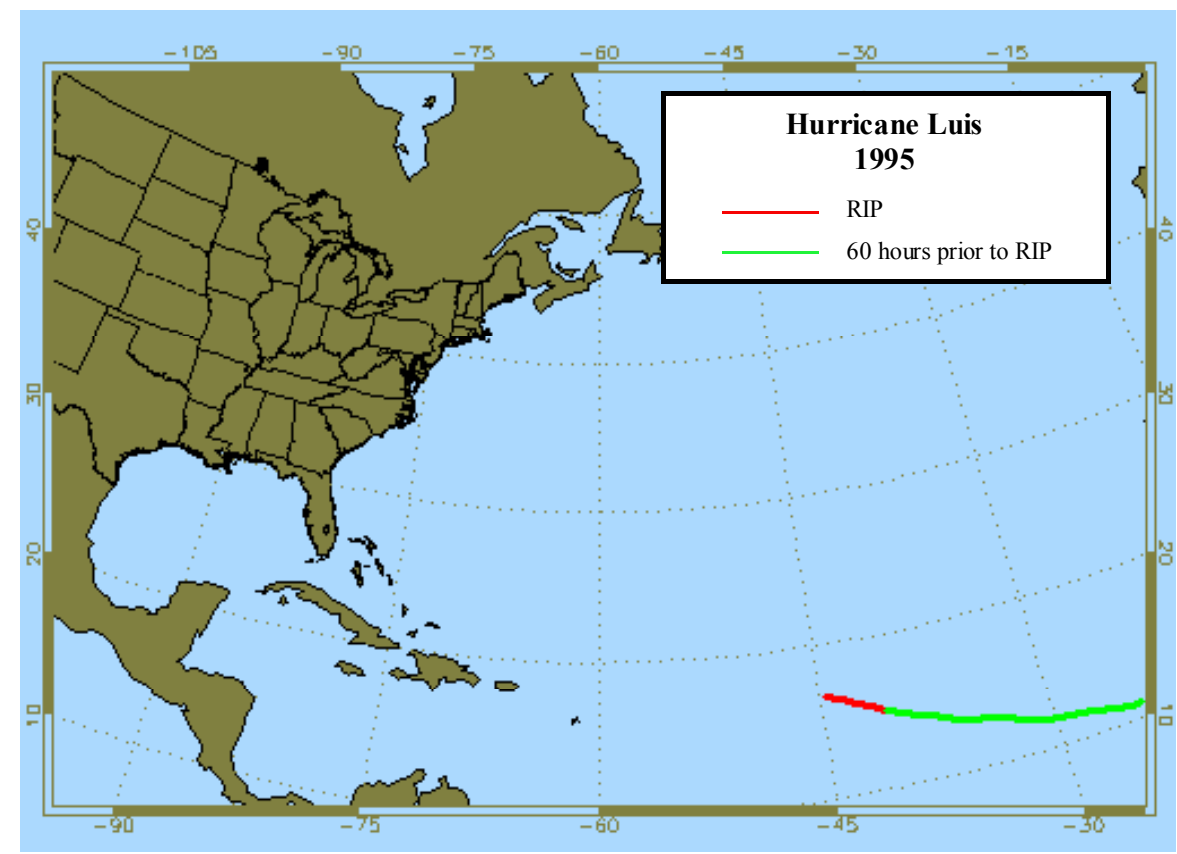

Figure A.41: As in Figure A.1, except for Hurricane Luis (1995).

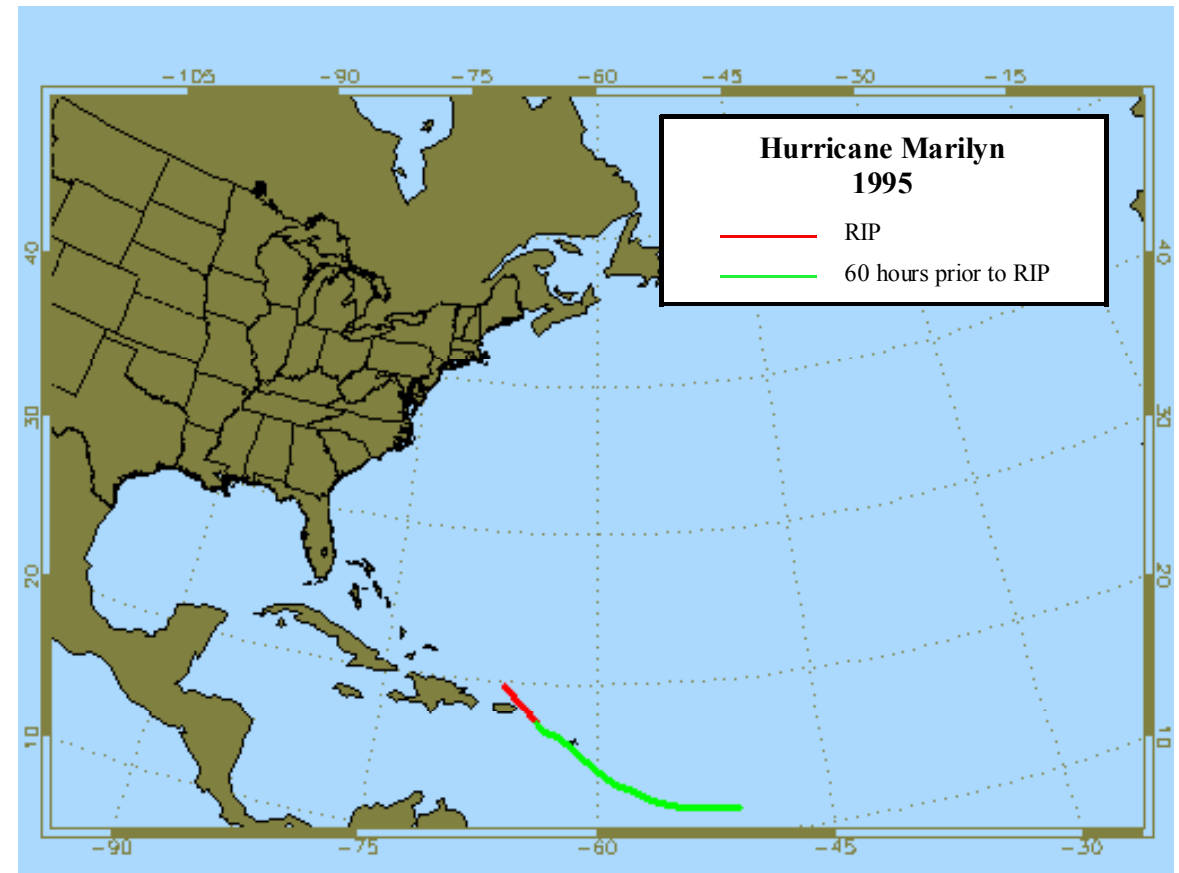

Figure A.42: As in Figure A.1, except for Hurricane Marilyn (1995). 


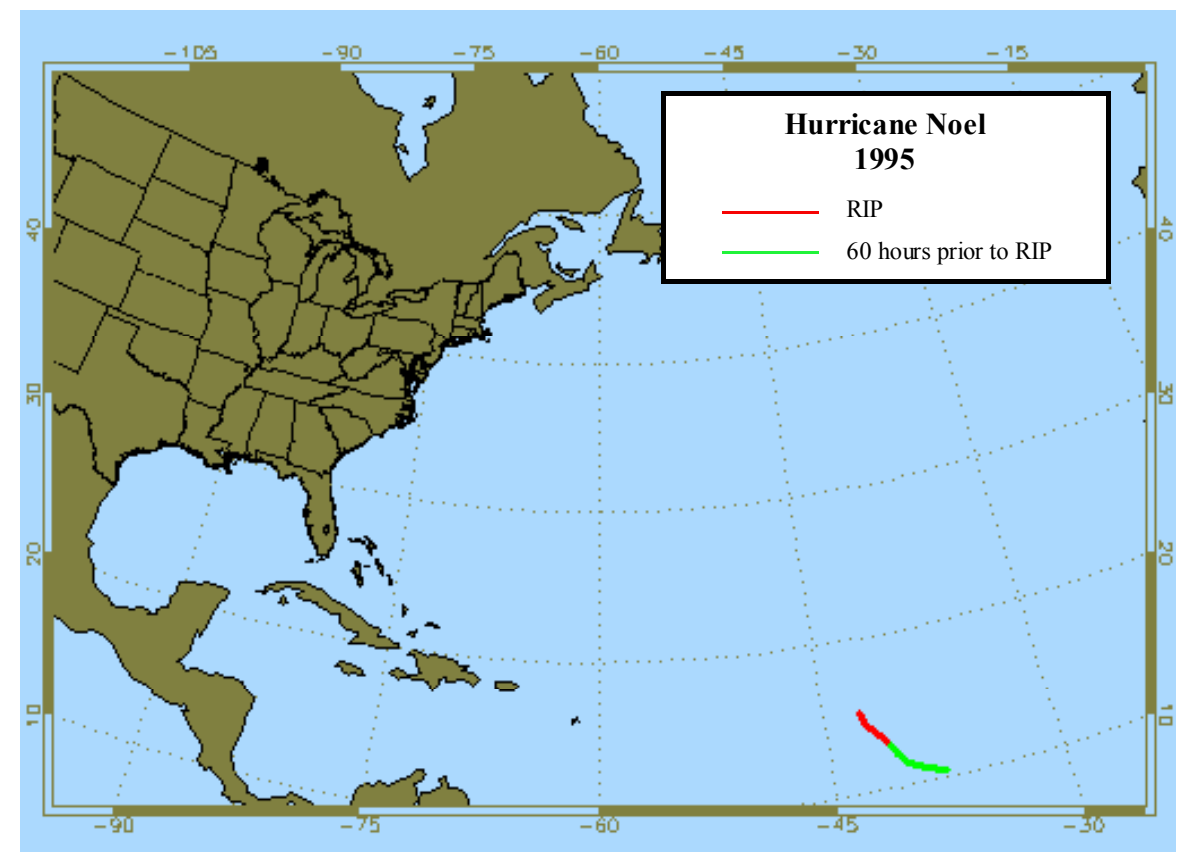

Figure A.43: As in Figure A.1, except for Hurricane Noel (1995).

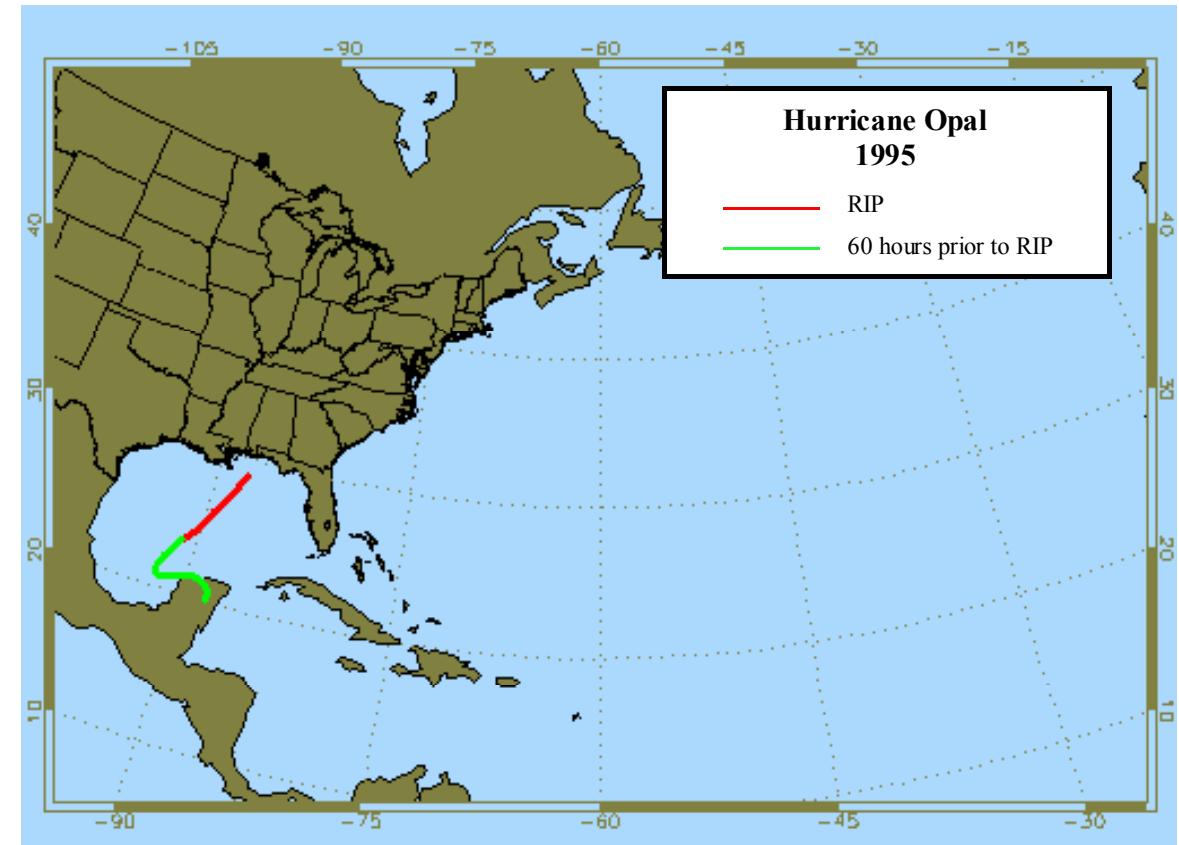

Figure A.44: As in Figure A.1, except for Hurricane Opal (1995). 


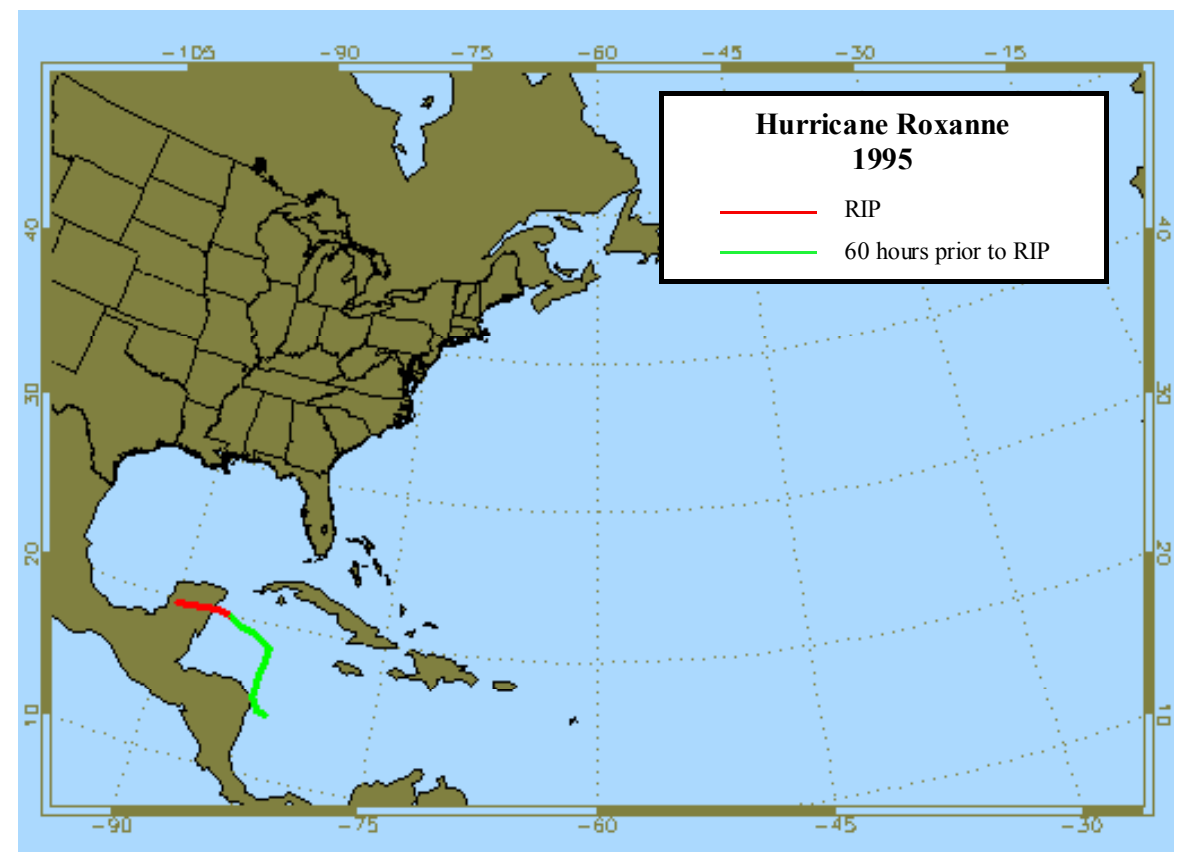

Figure A.45: As in Figure A.1, except for Hurricane Roxanne (1995).

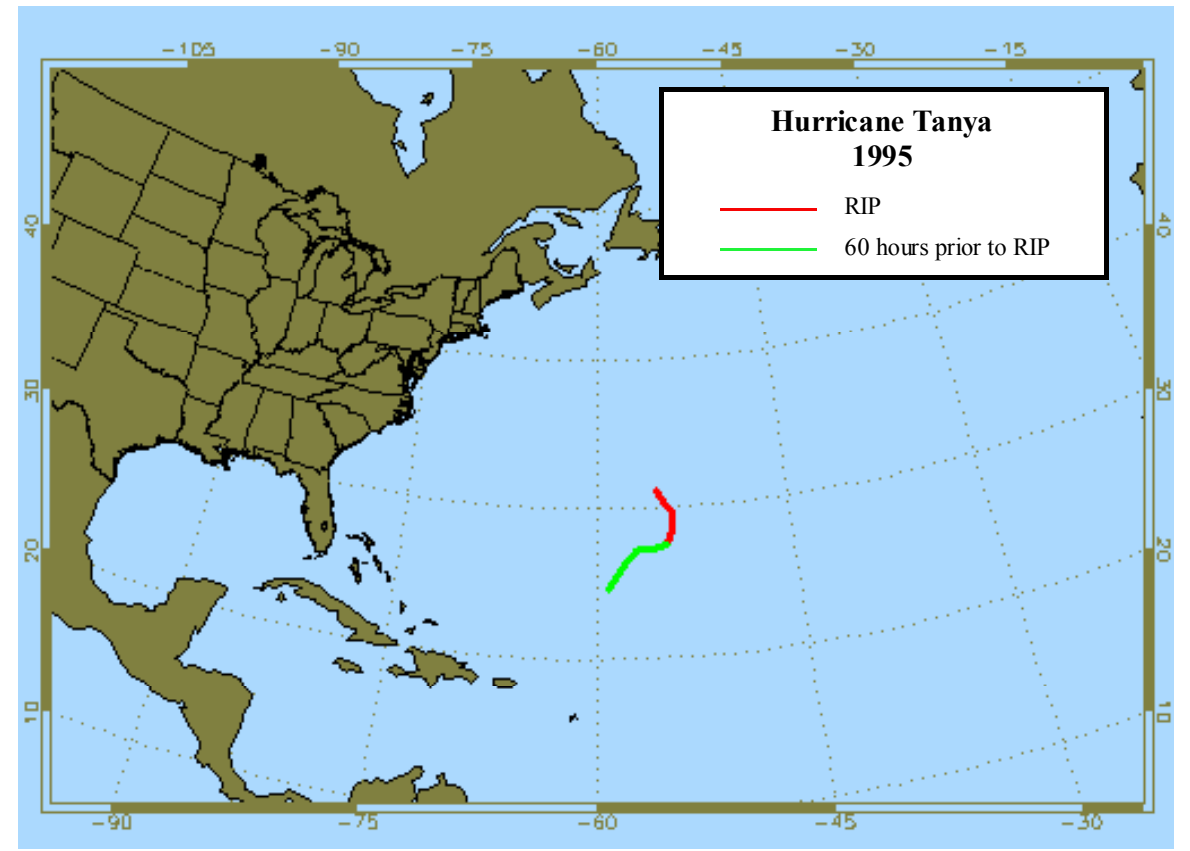

Figure A.46: As in Figure A.1, except for Hurricane Tanya (1995). 


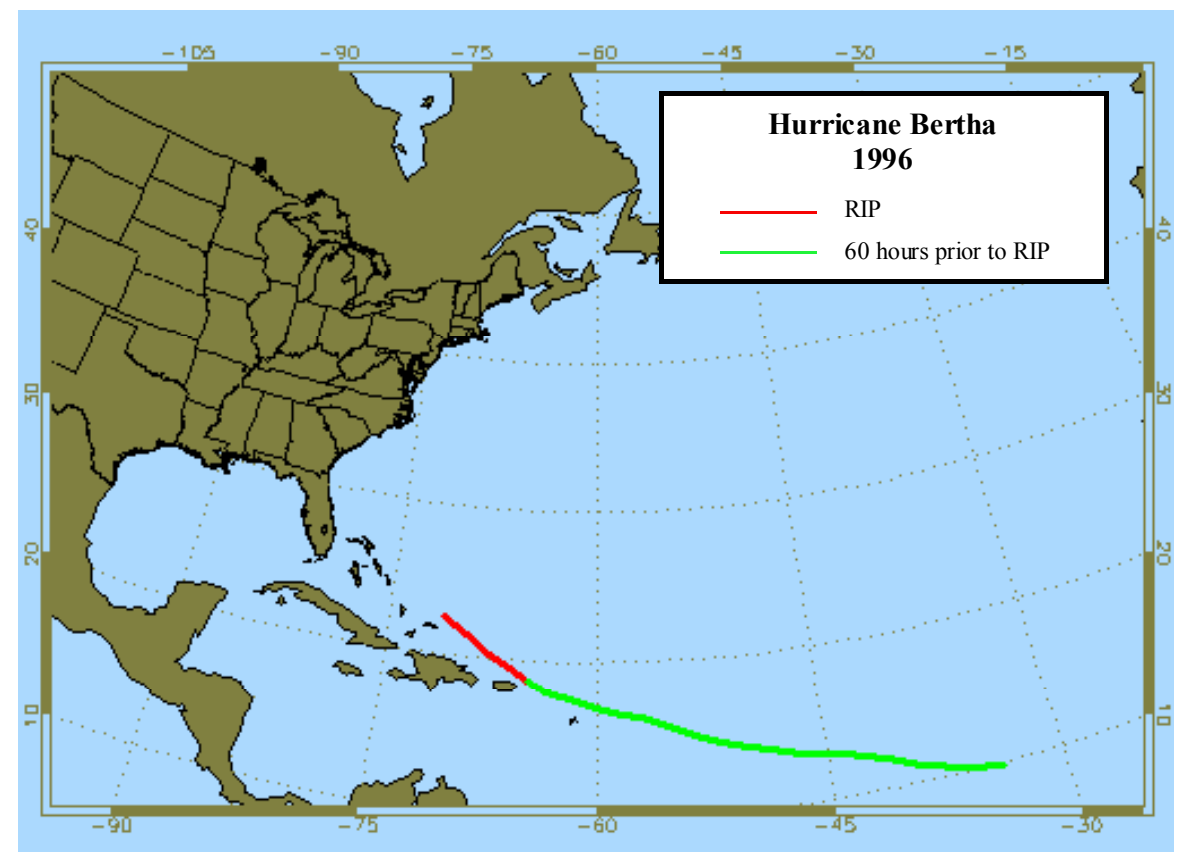

Figure A.47: As in Figure A.1, except for Hurricane Bertha (1996).

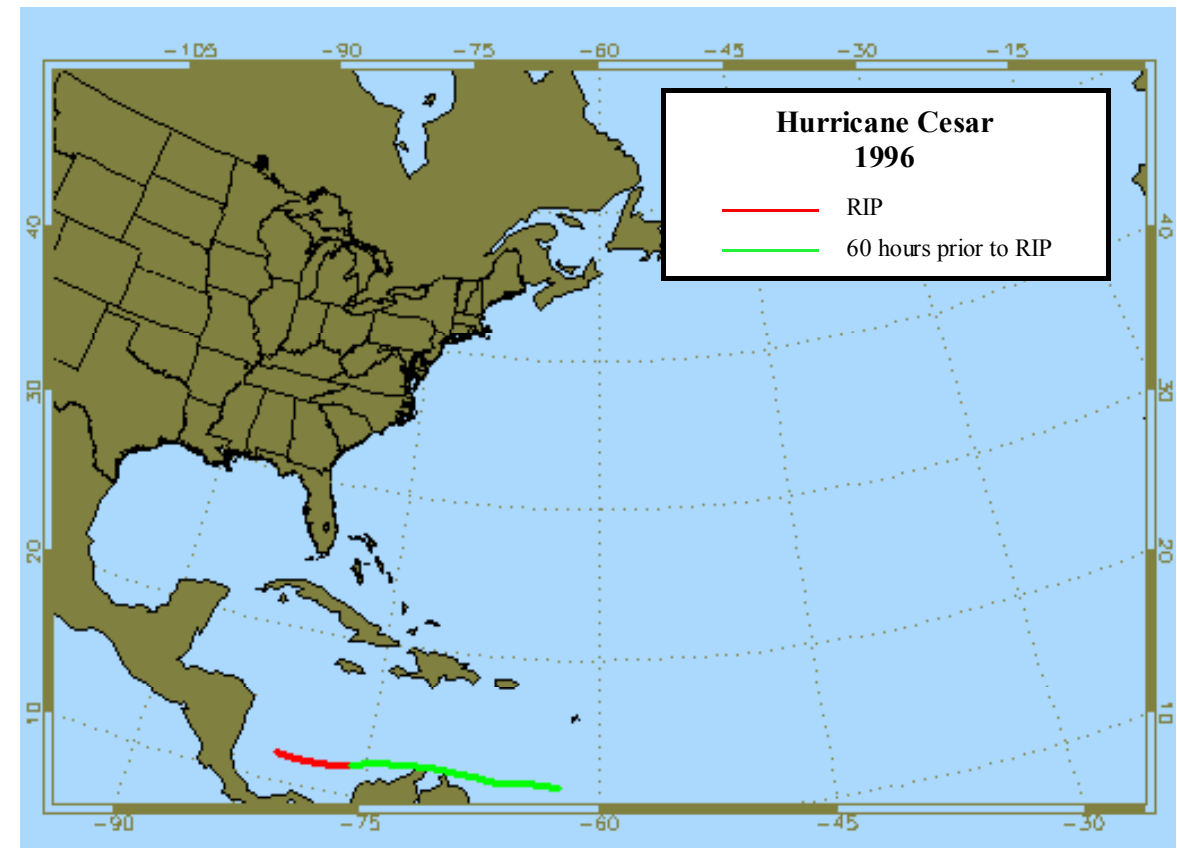

Figure A.48: As in Figure A.1, except for Hurricane Cesar (1996). 


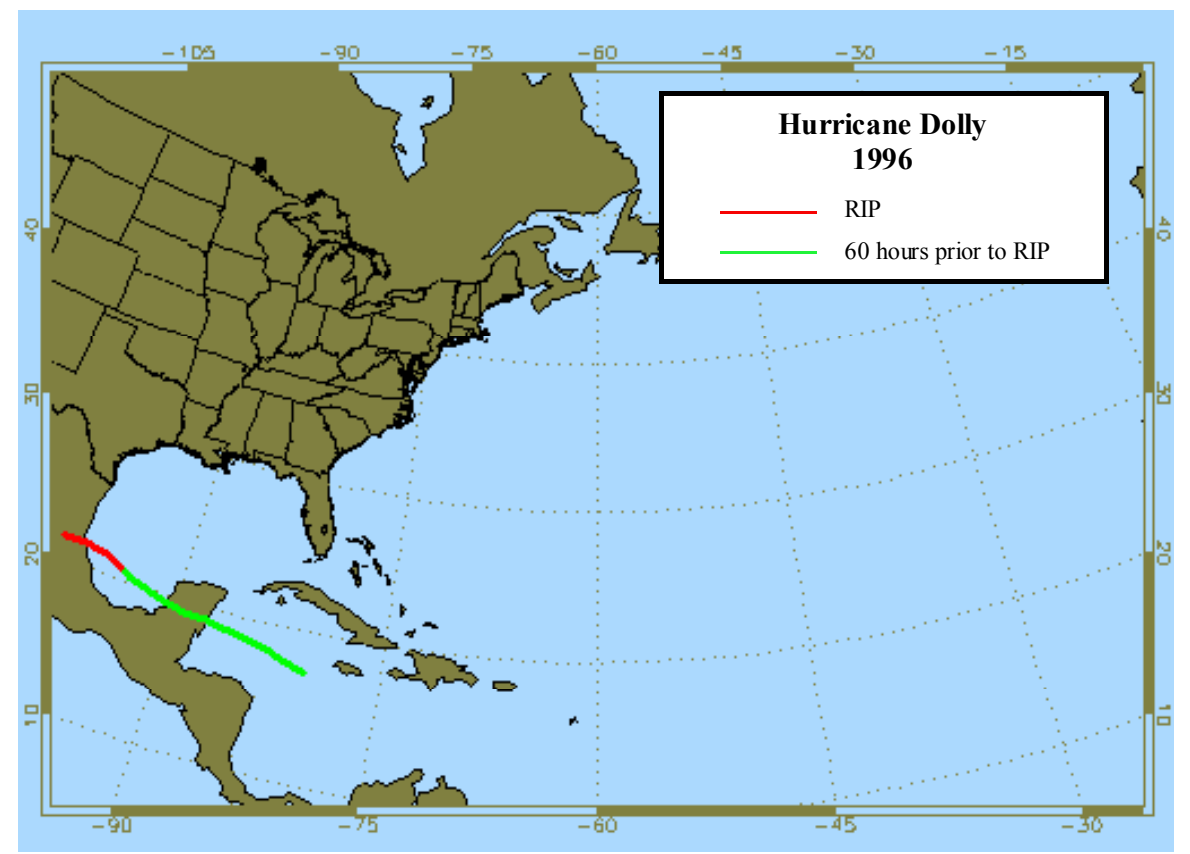

Figure A.49: As in Figure A.1, except for Hurricane Dolly (1996).

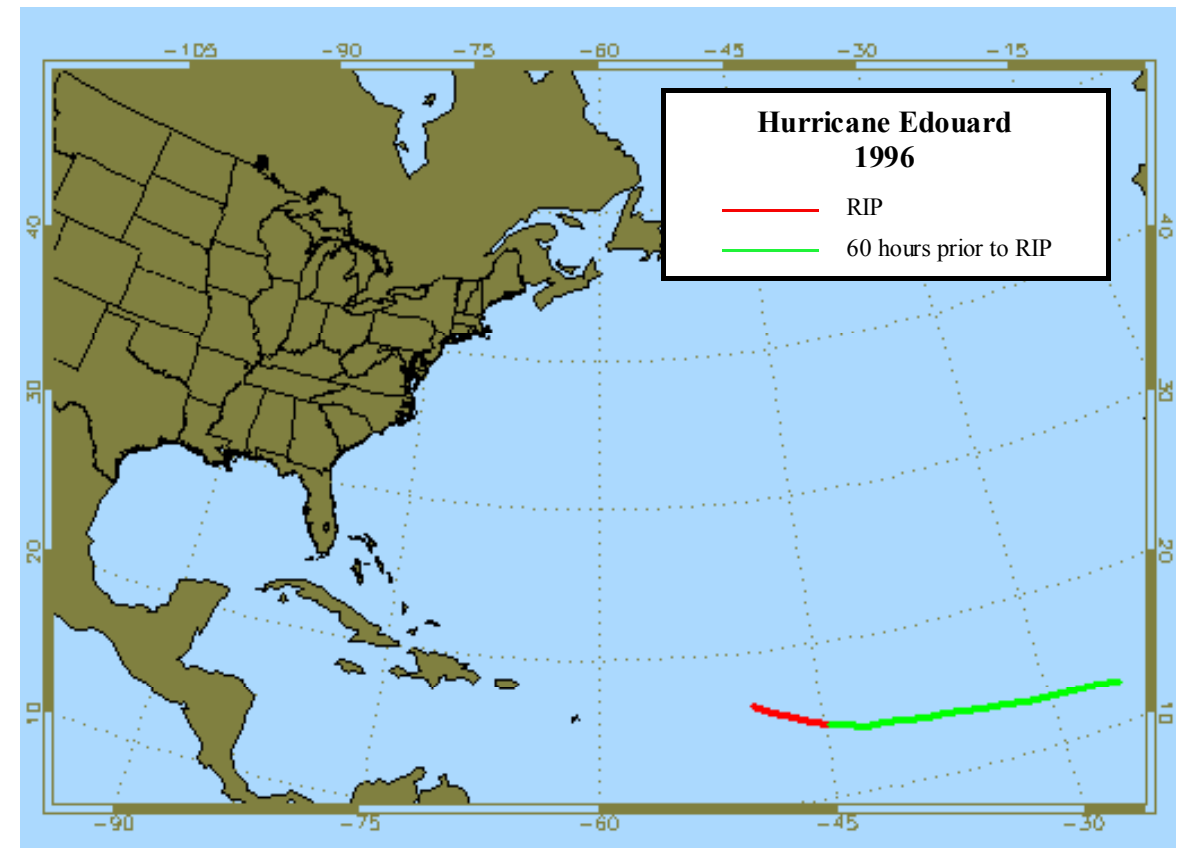

Figure A.50: As in Figure A.1, except for Hurricane Edouard (1996). 


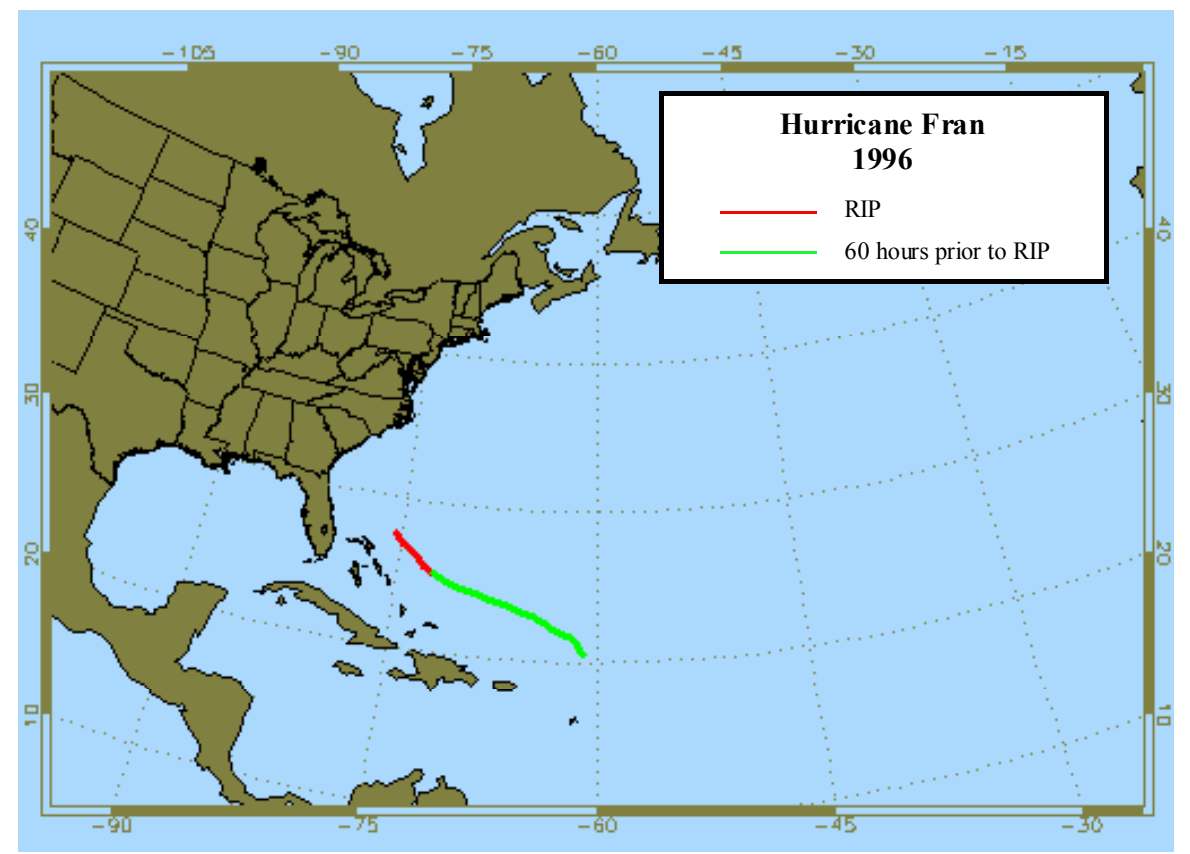

Figure A.51: As in Figure A.1, except for Hurricane Fran (1996).

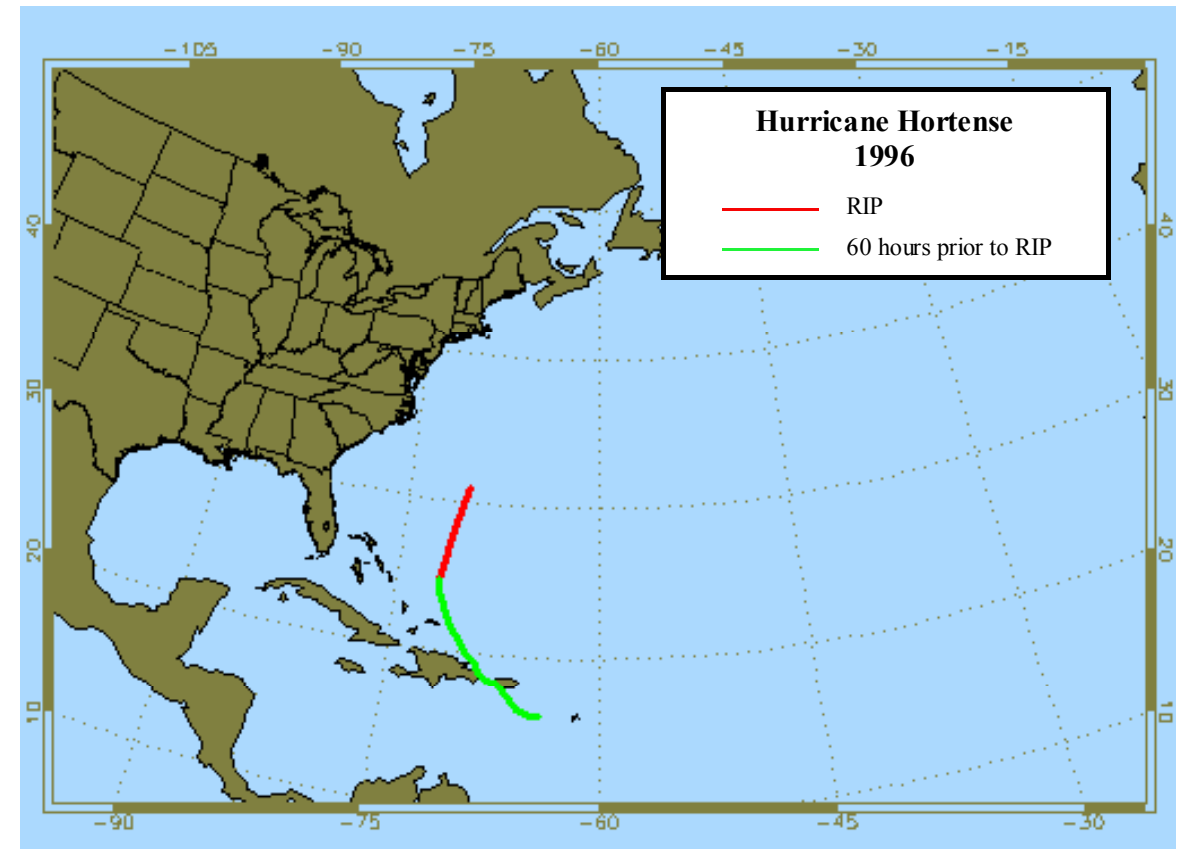

Figure A.52: As in Figure A.1, except for Hurricane Hortense (1996). 


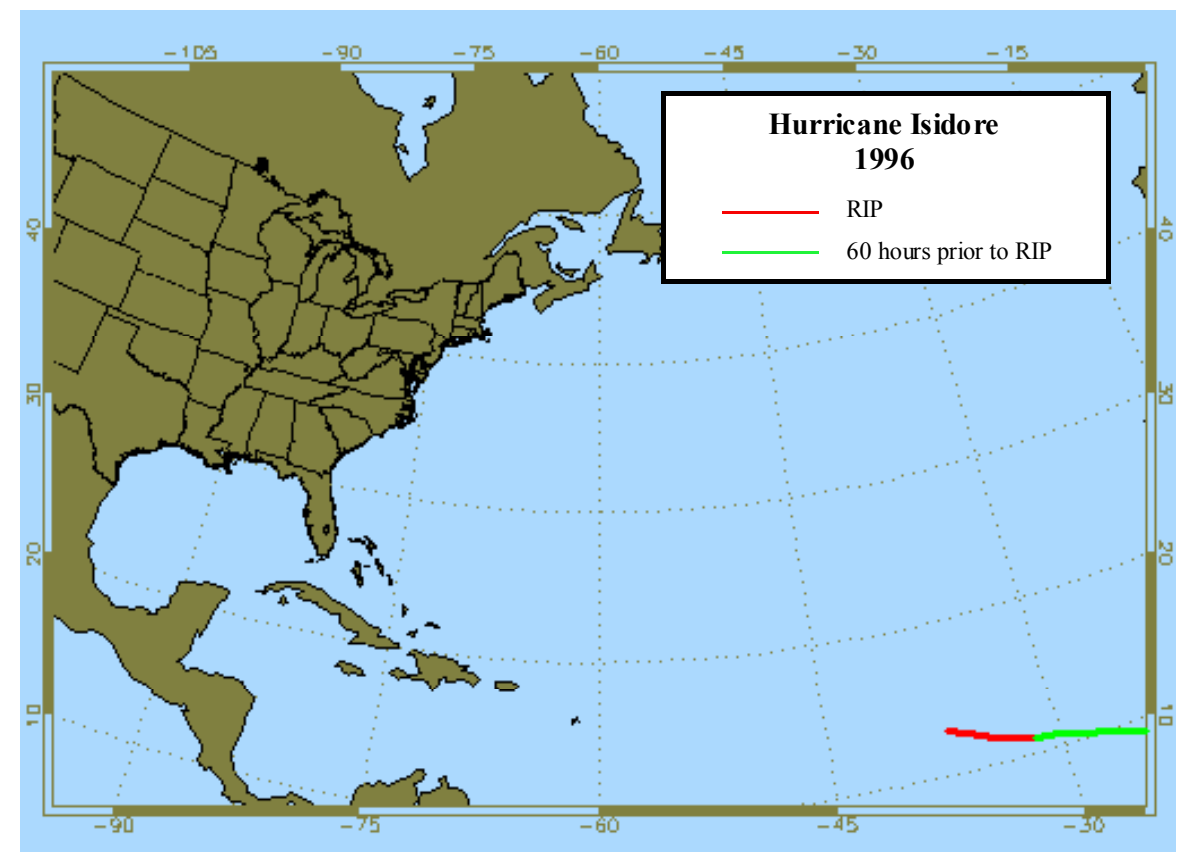

Figure A.53: As in Figure A.1, except for Hurricane Isidore (1996).

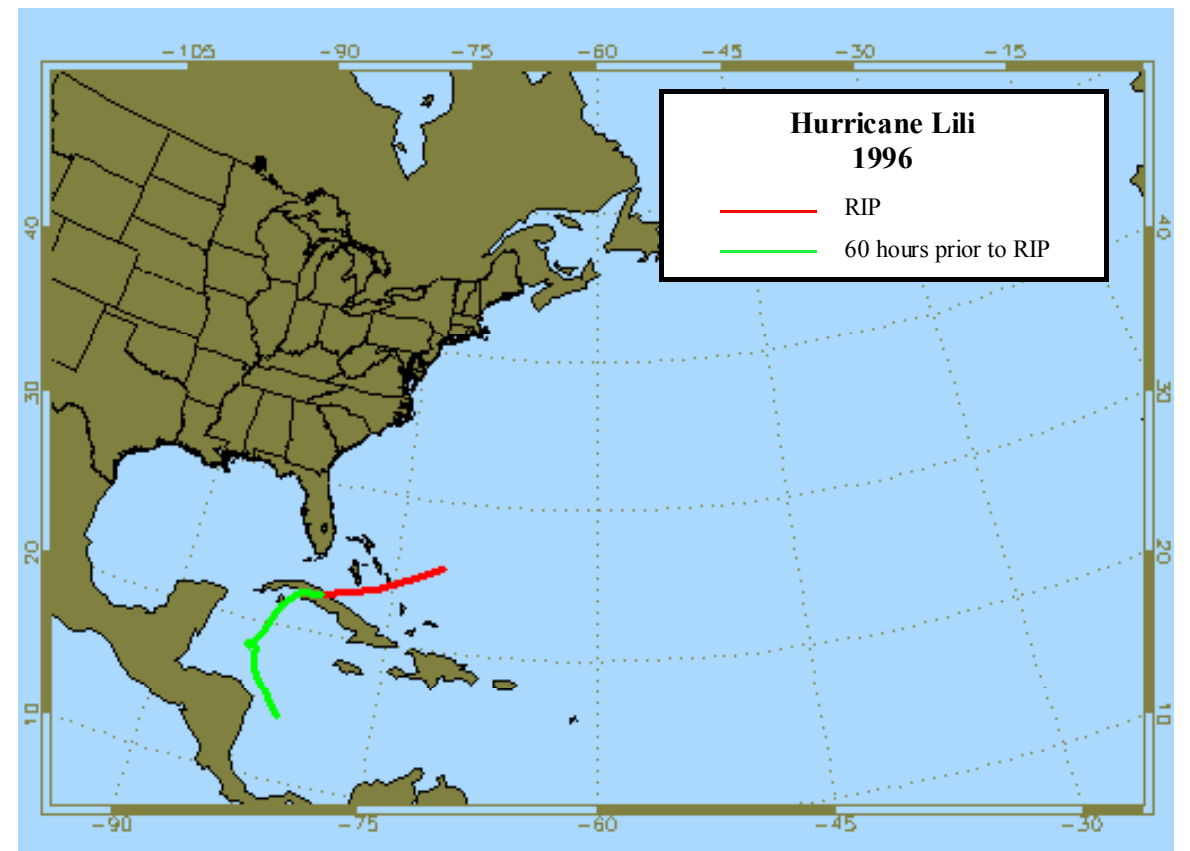

Figure A.54: As in Figure A.1, except for Hurricane Lili (1996). 


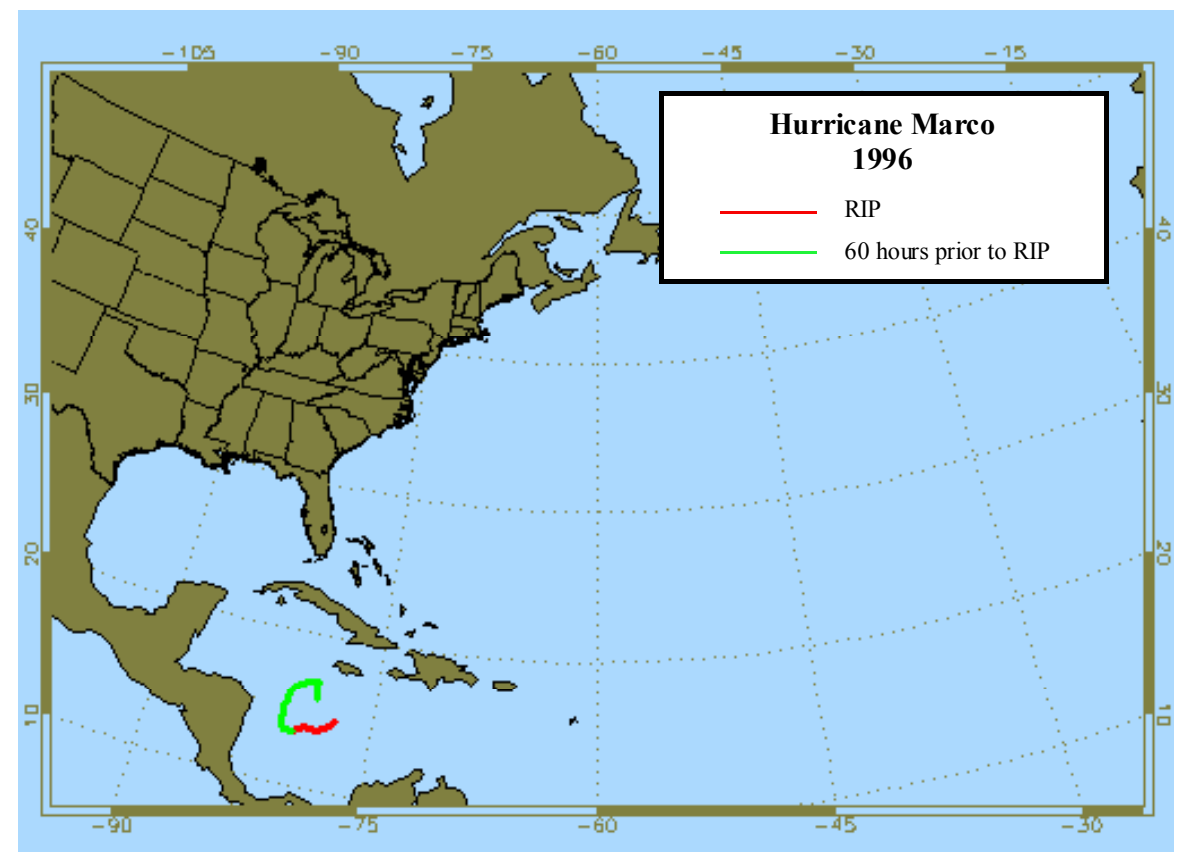

Figure A.55: As in Figure A.1, except for Hurricane Marco (1996).

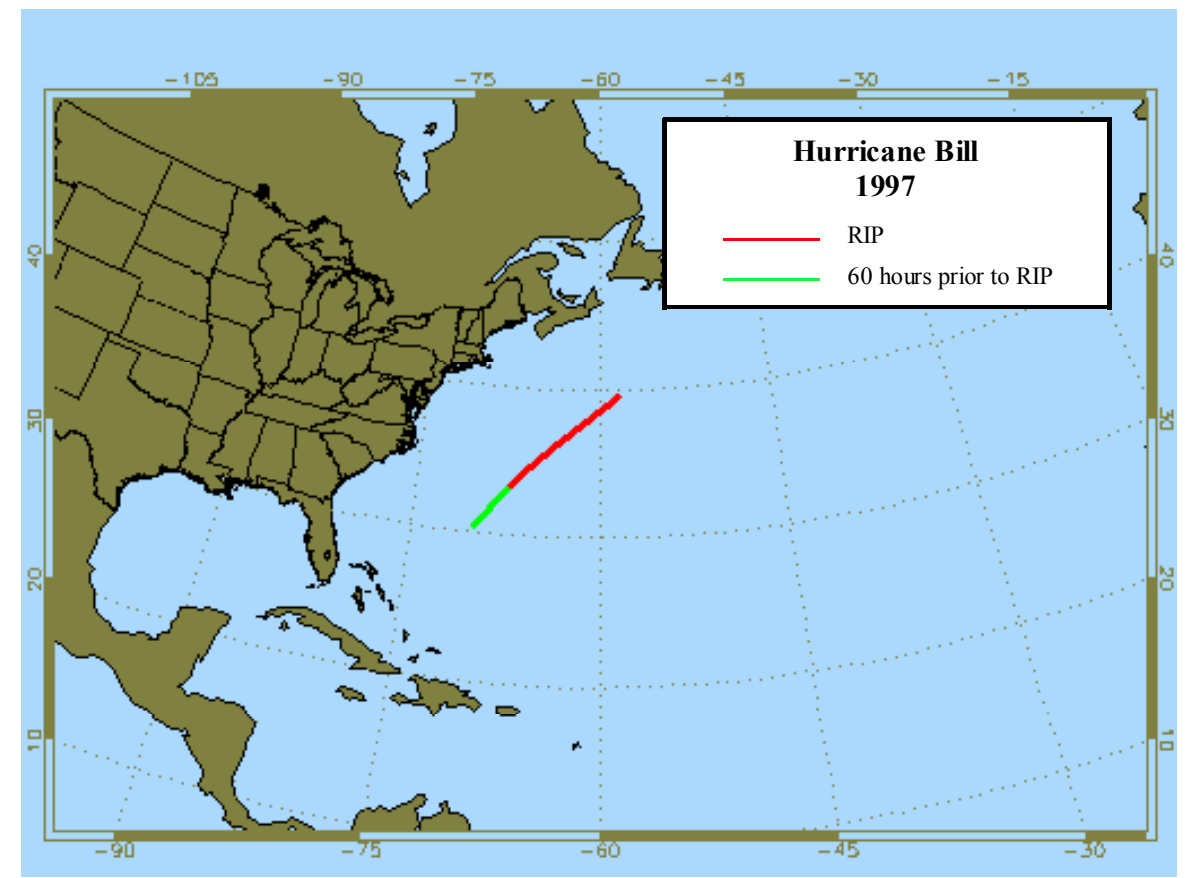

Figure A.56: As in Figure A.1, except for Hurricane Bill (1997). 


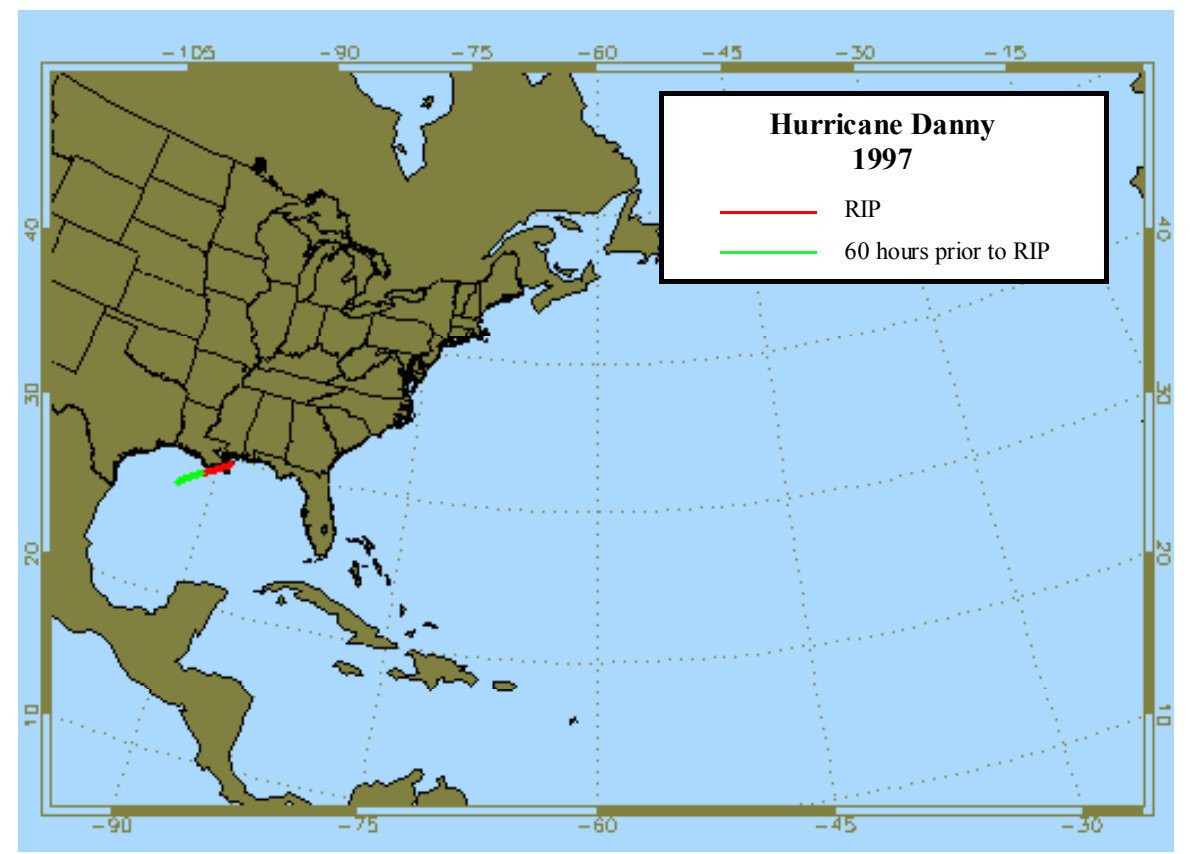

Figure A.57: As in Figure A.1, except for Hurricane Danny (1997).

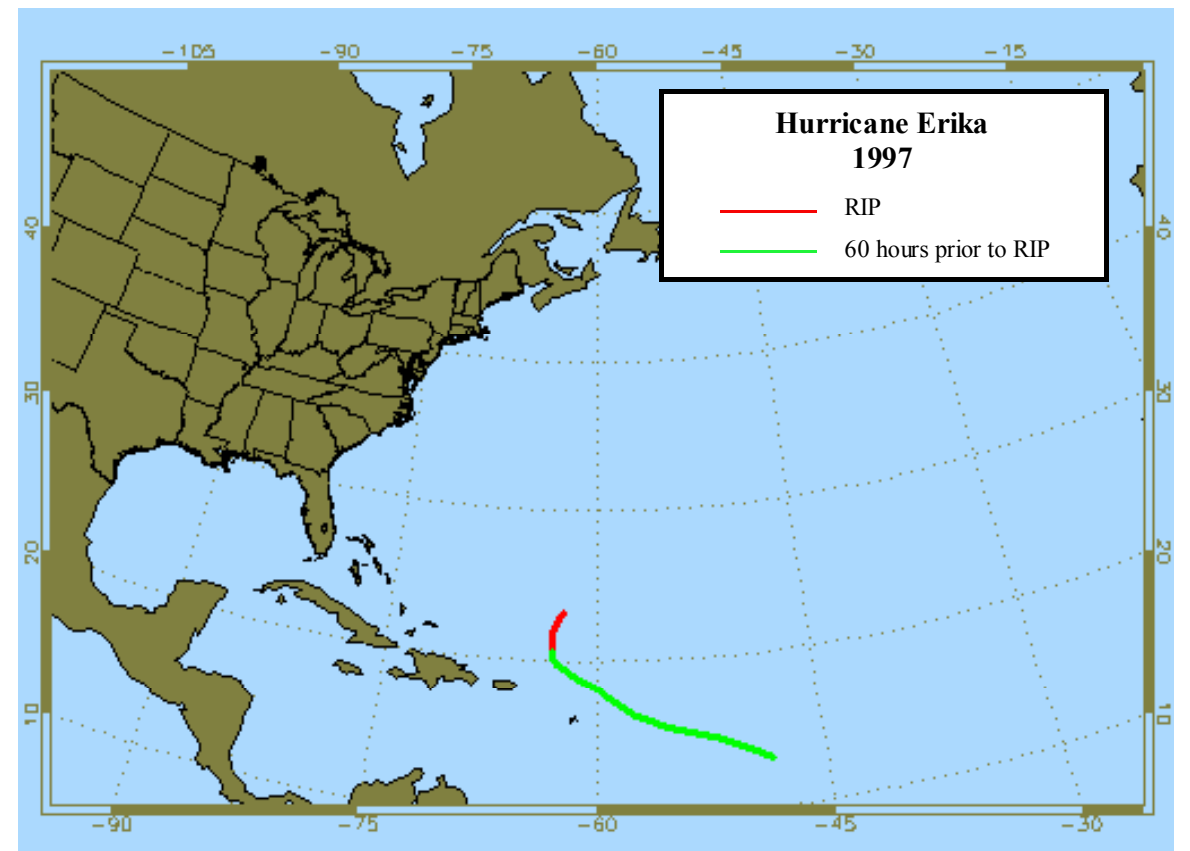

Figure A.58: As in Figure A.1, except for Hurricane Erika (1997). 


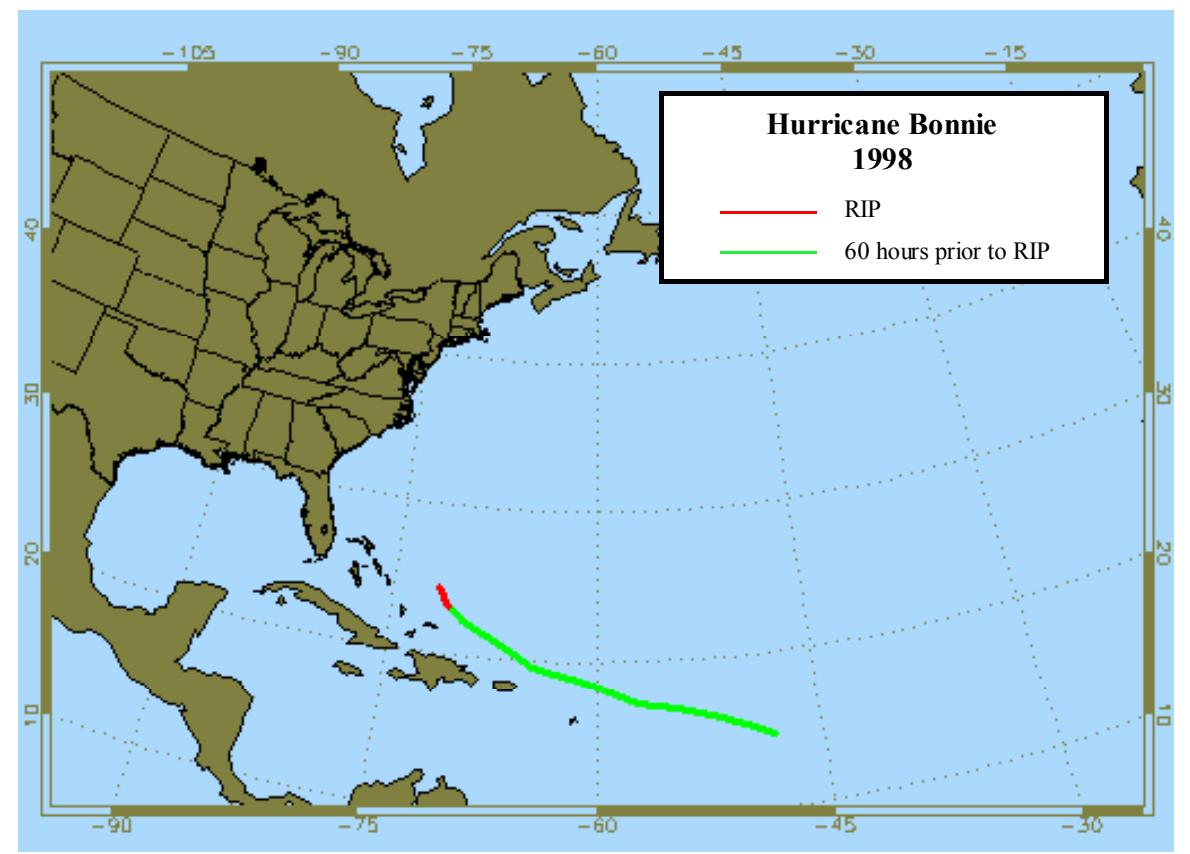

Figure A.59: As in Figure A.1, except for Hurricane Bonnie (1998).

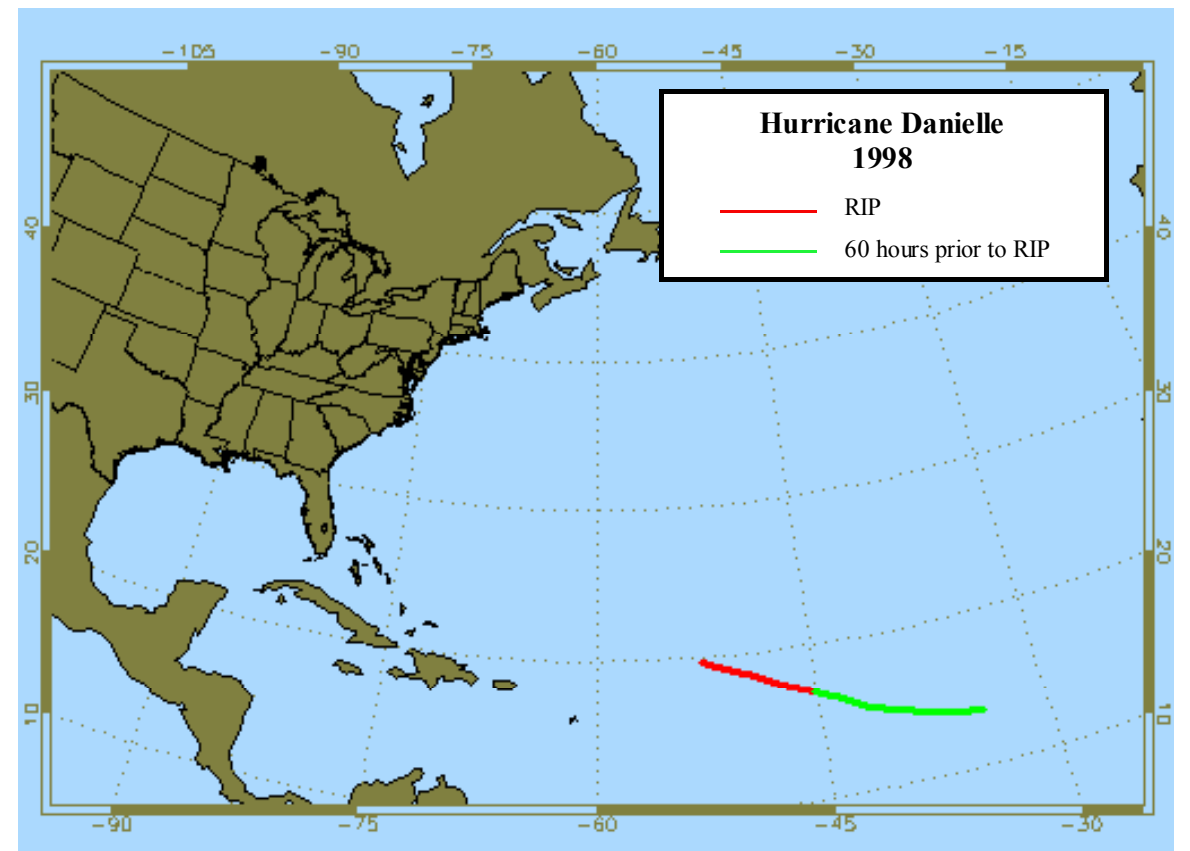

Figure A.60: As in Figure A.1, except for Hurricane Danielle (1998). 


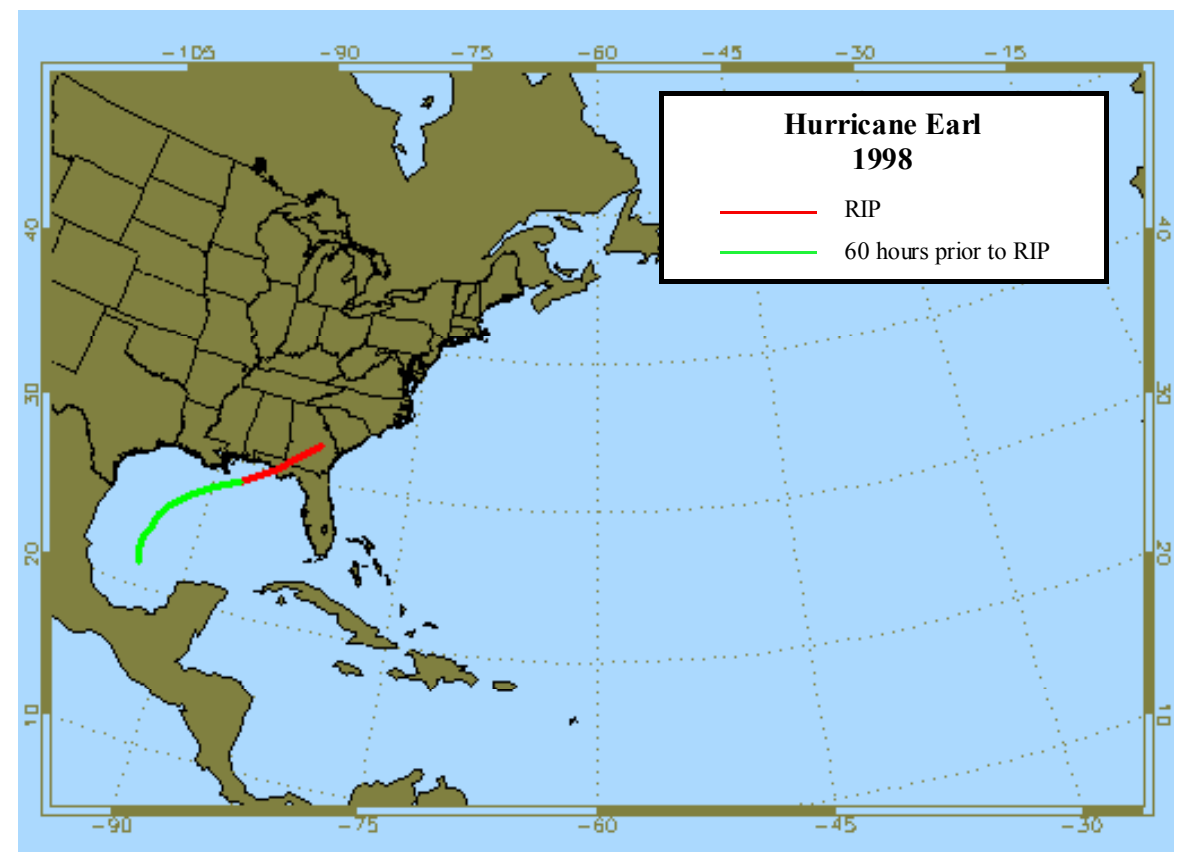

Figure A.61: As in Figure A.1, except for Hurricane Earl (1998).

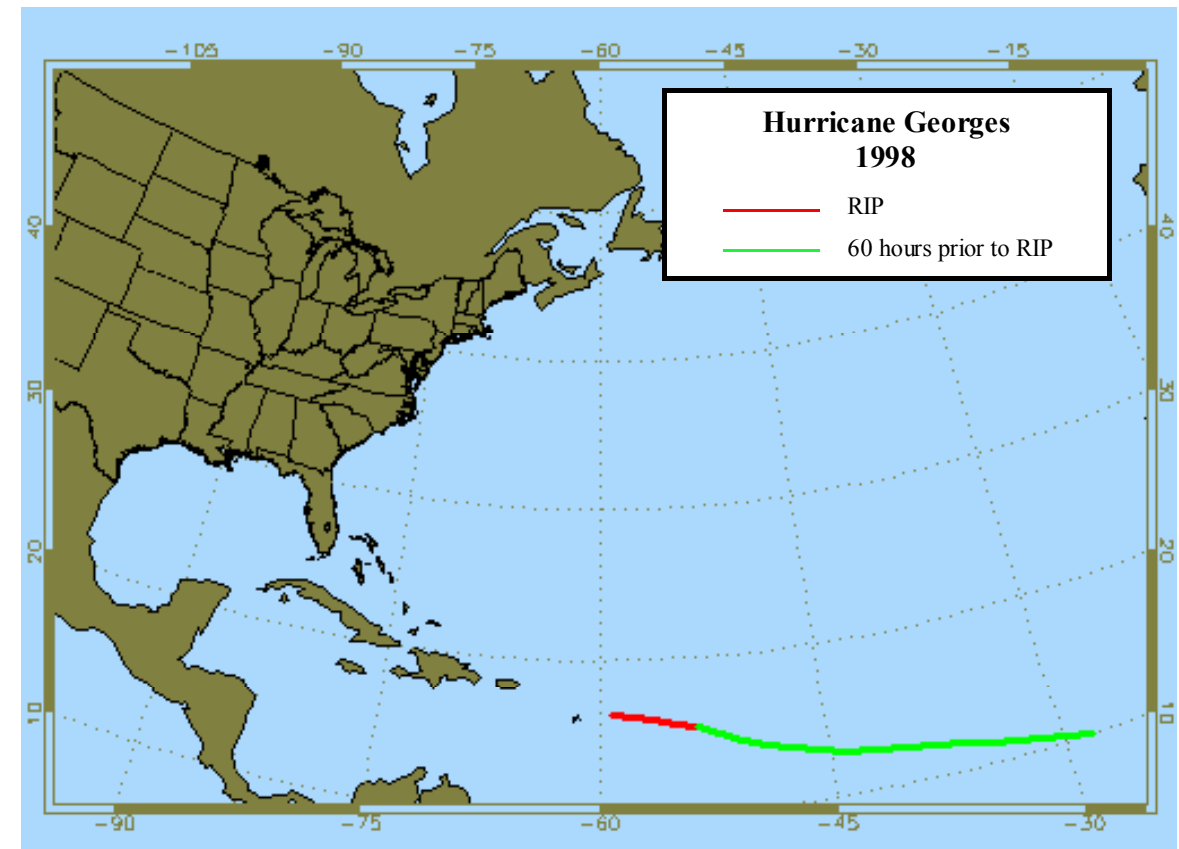

Figure A.62: As in Figure A.1, except for Hurricane Georges (1998). 


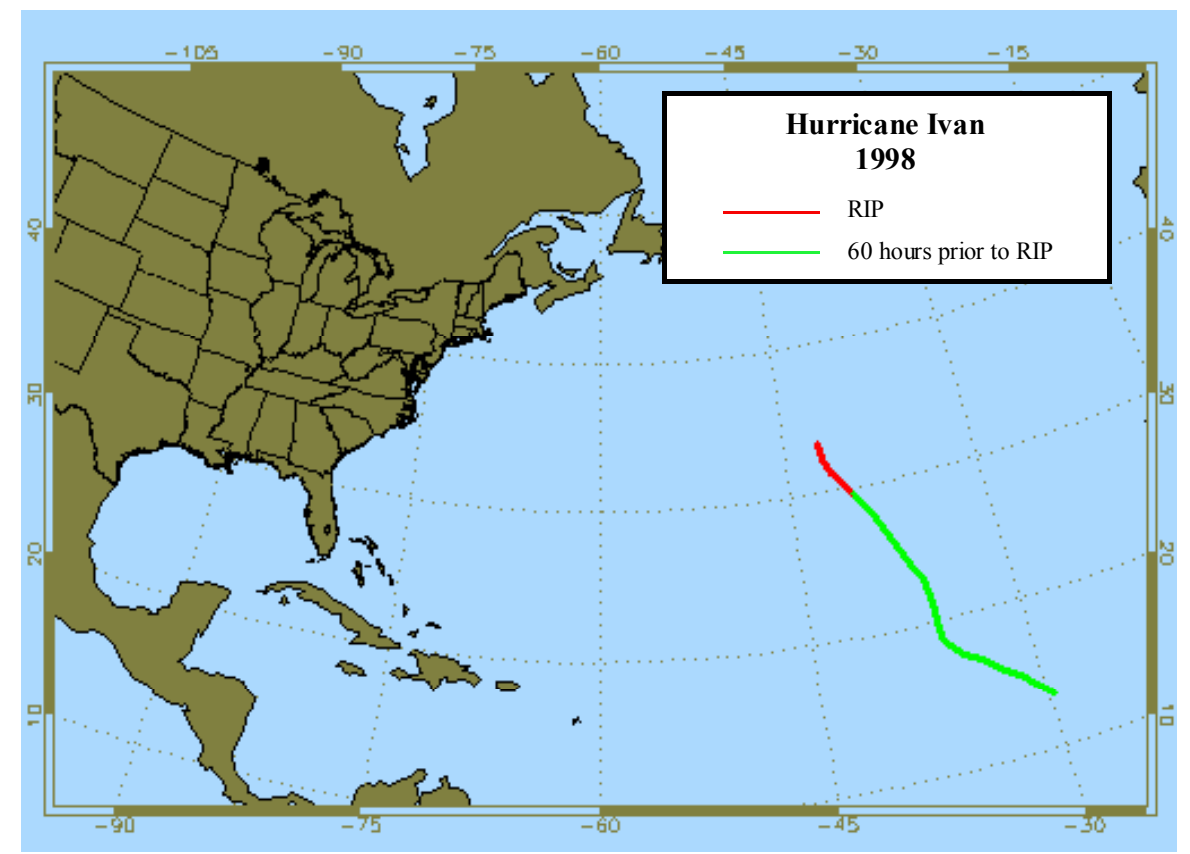

Figure A.63: As in Figure A.1, except for Hurricane Ivan (1998).

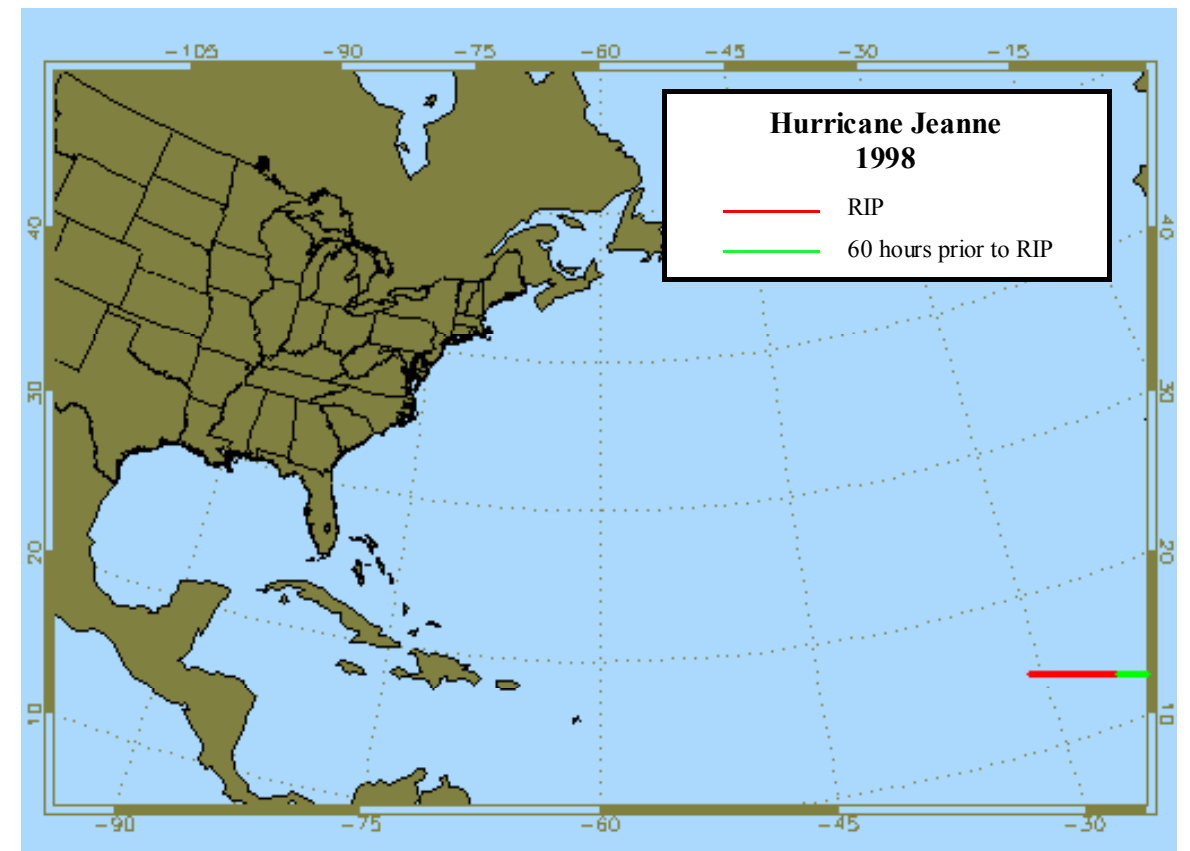

Figure A.64: As in Figure A.1, except for Hurricane Jeanne (1998). 


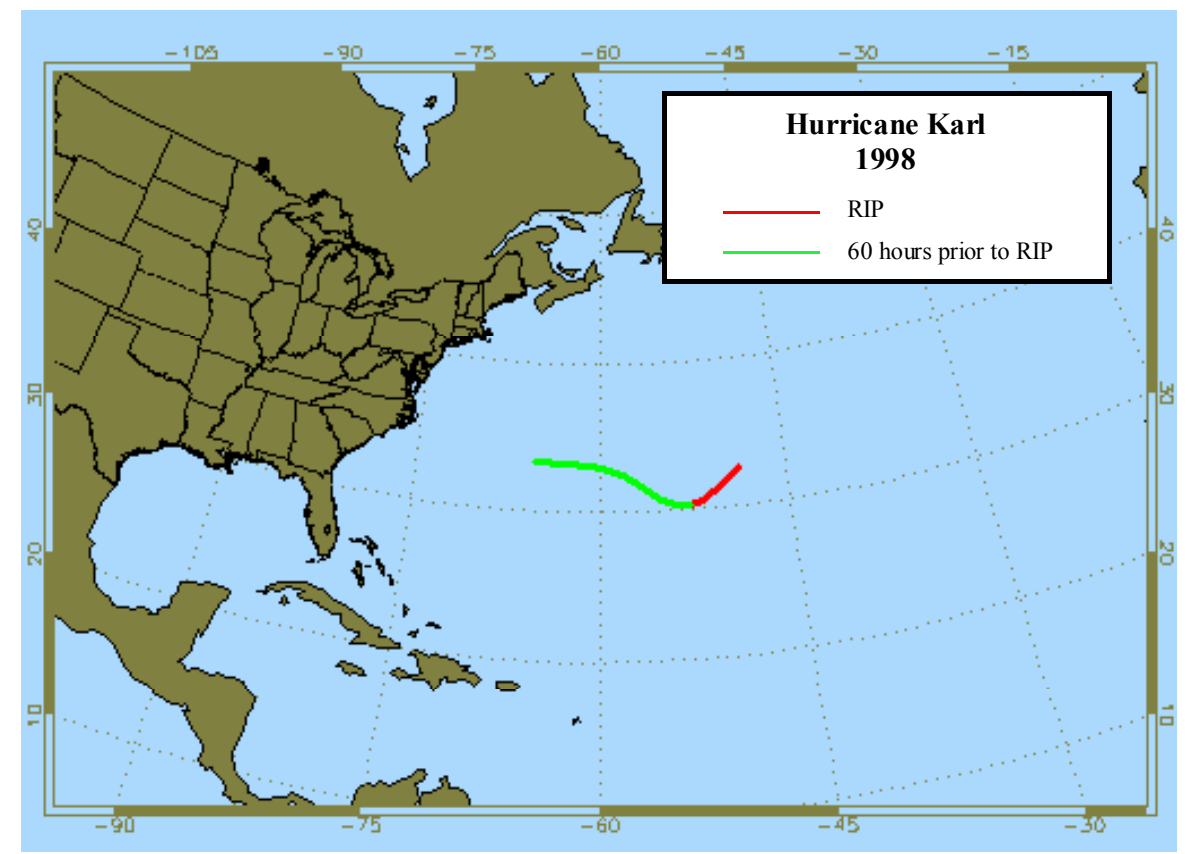

Figure A.65: As in Figure A.1, except for Hurricane Karl (1998).

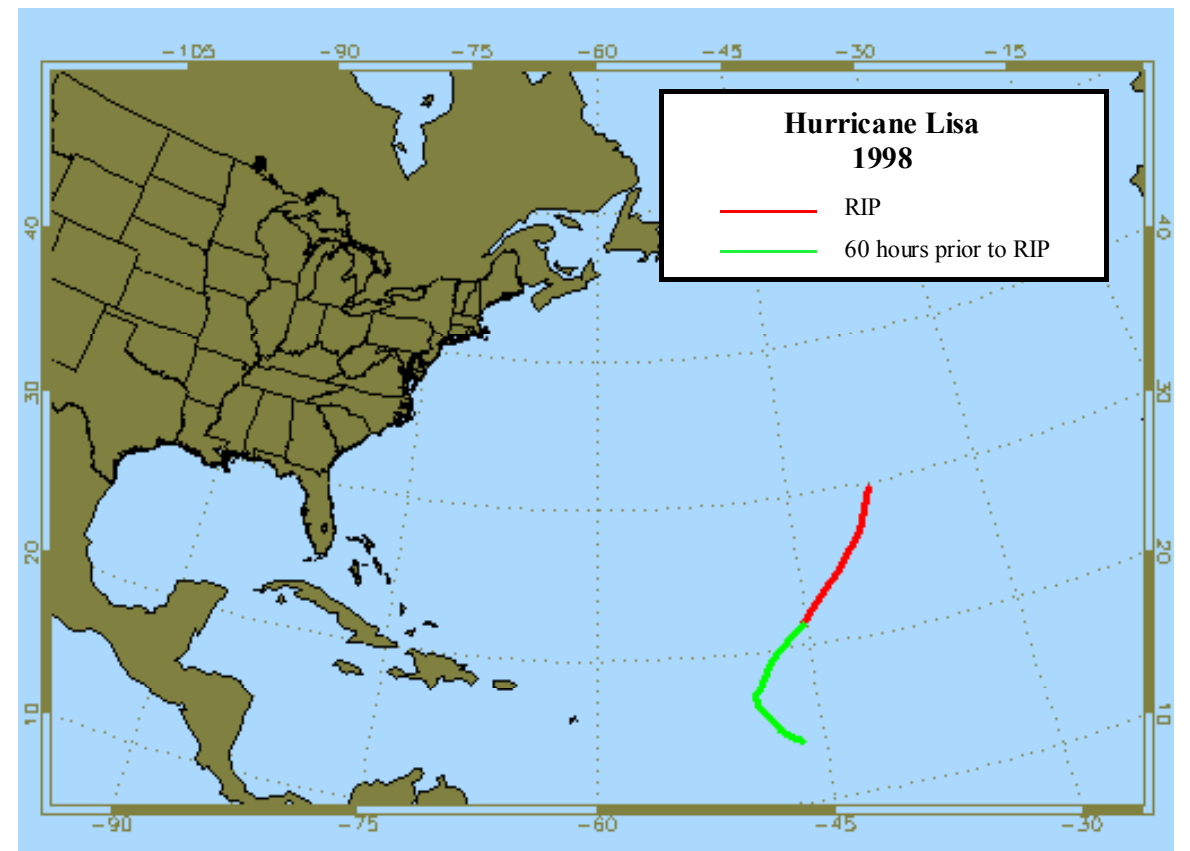

Figure A.66: As in Figure A.1, except for Hurricane Lisa (1998). 


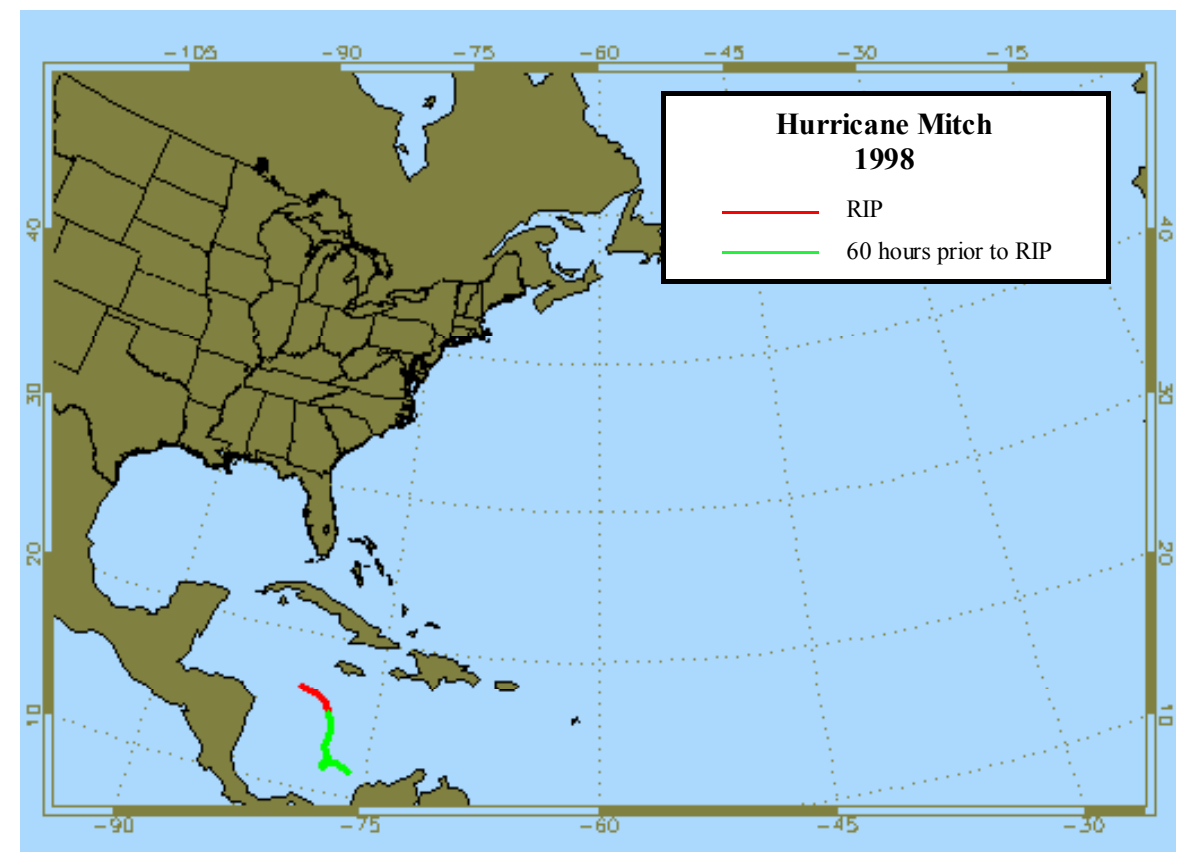

Figure A.67: As in Figure A.1, except for Hurricane Mitch (1998).

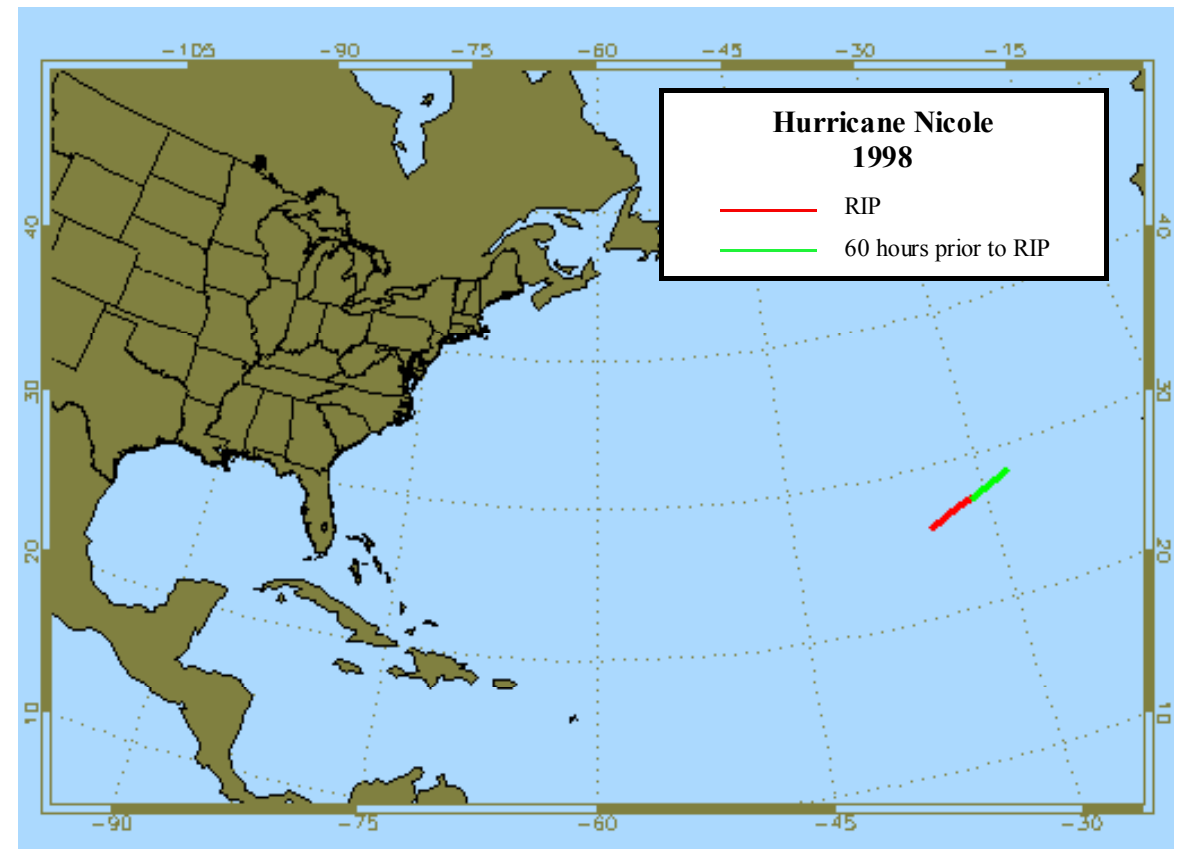

Figure A.68: As in Figure A.1, except for Hurricane Nicole (1998). 


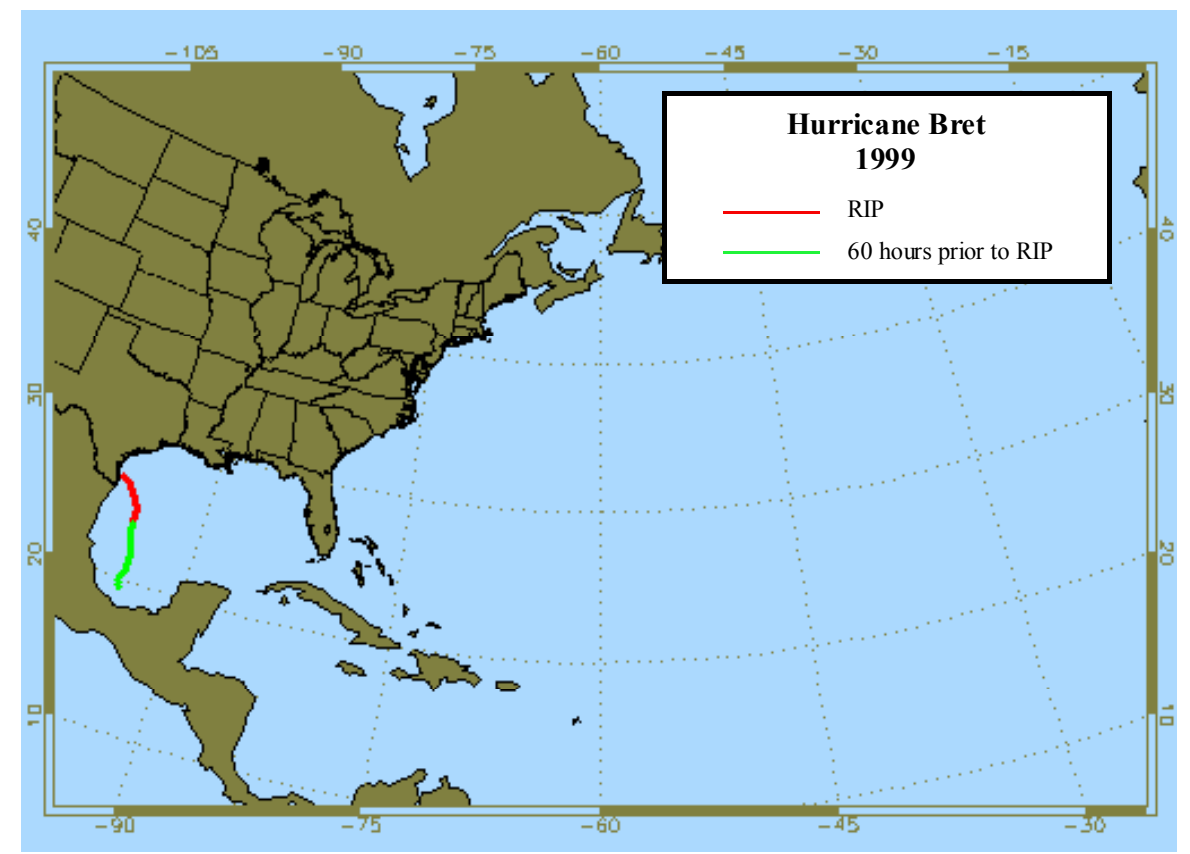

Figure A.69: As in Figure A.1, except for Hurricane Bret (1999).

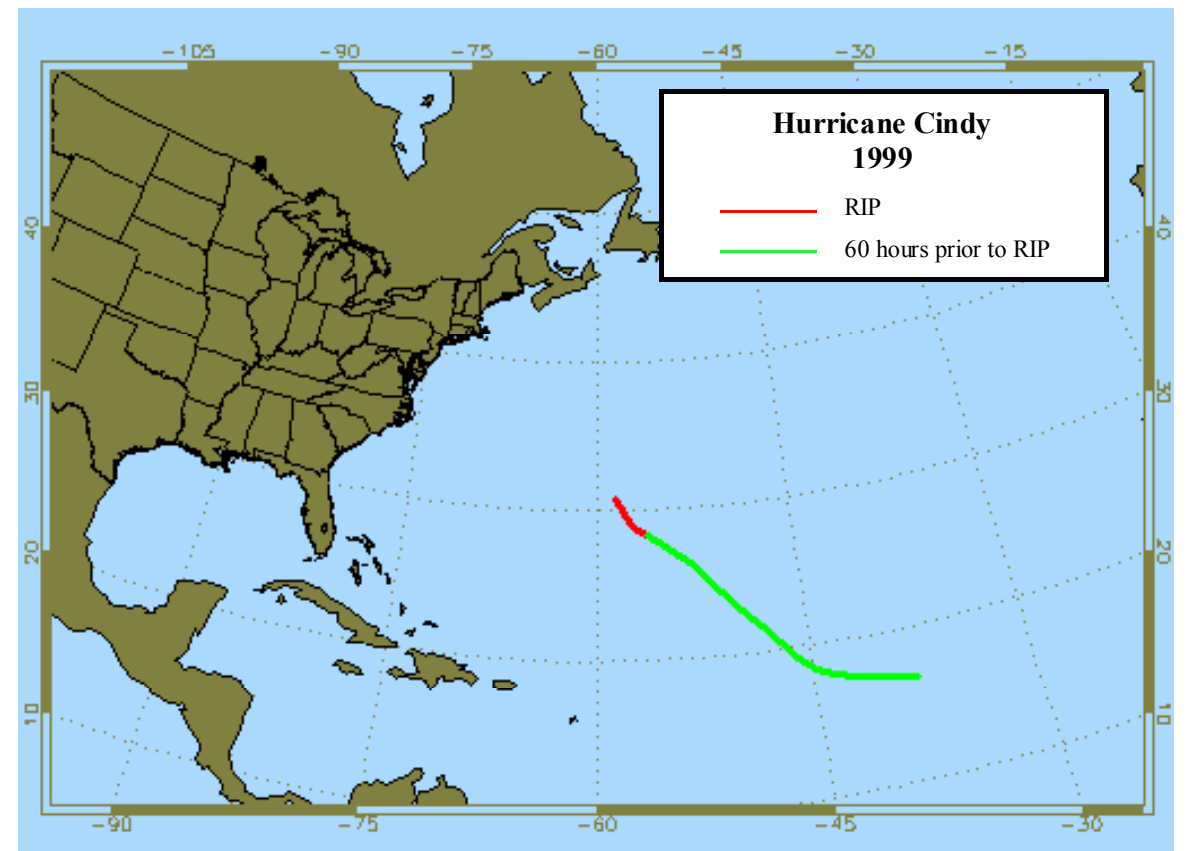

Figure A.70: As in Figure A.1, except for Hurricane Cindy (1999). 


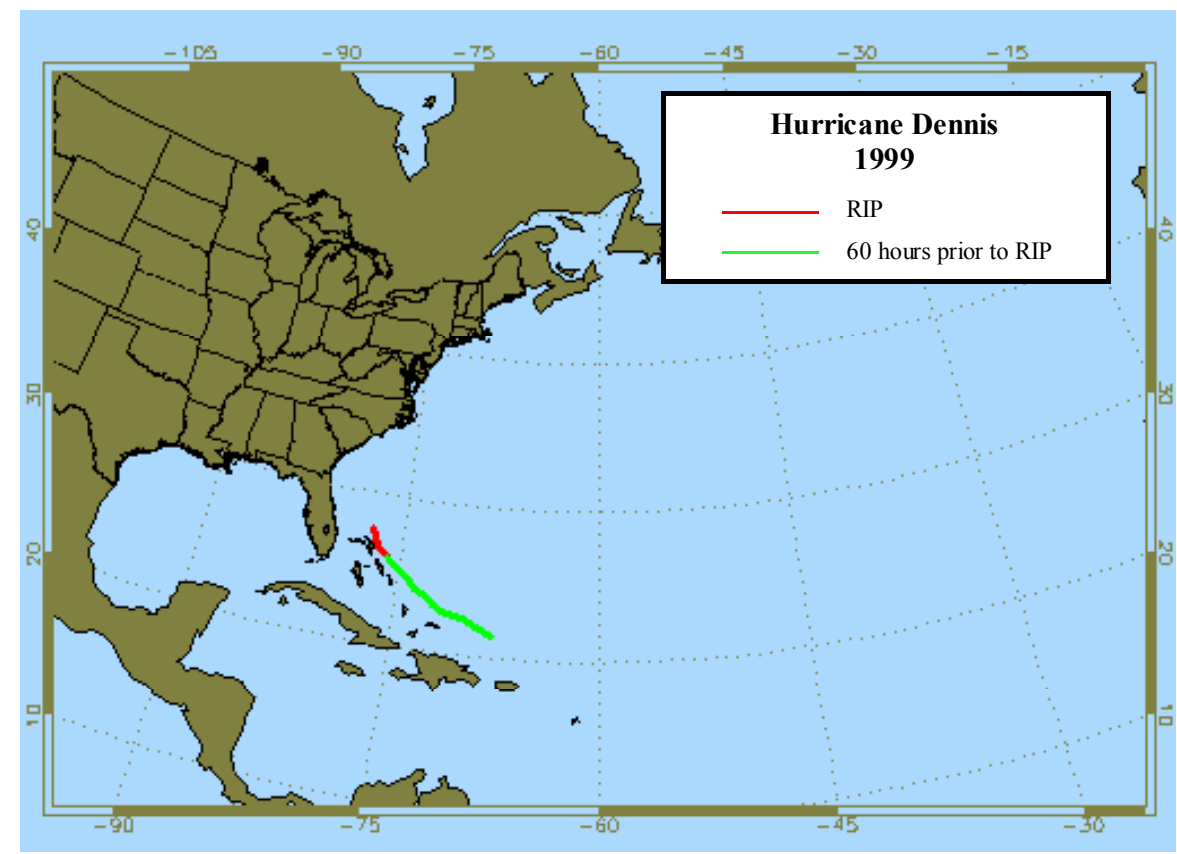

Figure A.71: As in Figure A.1, except for Hurricane Dennis (1999).

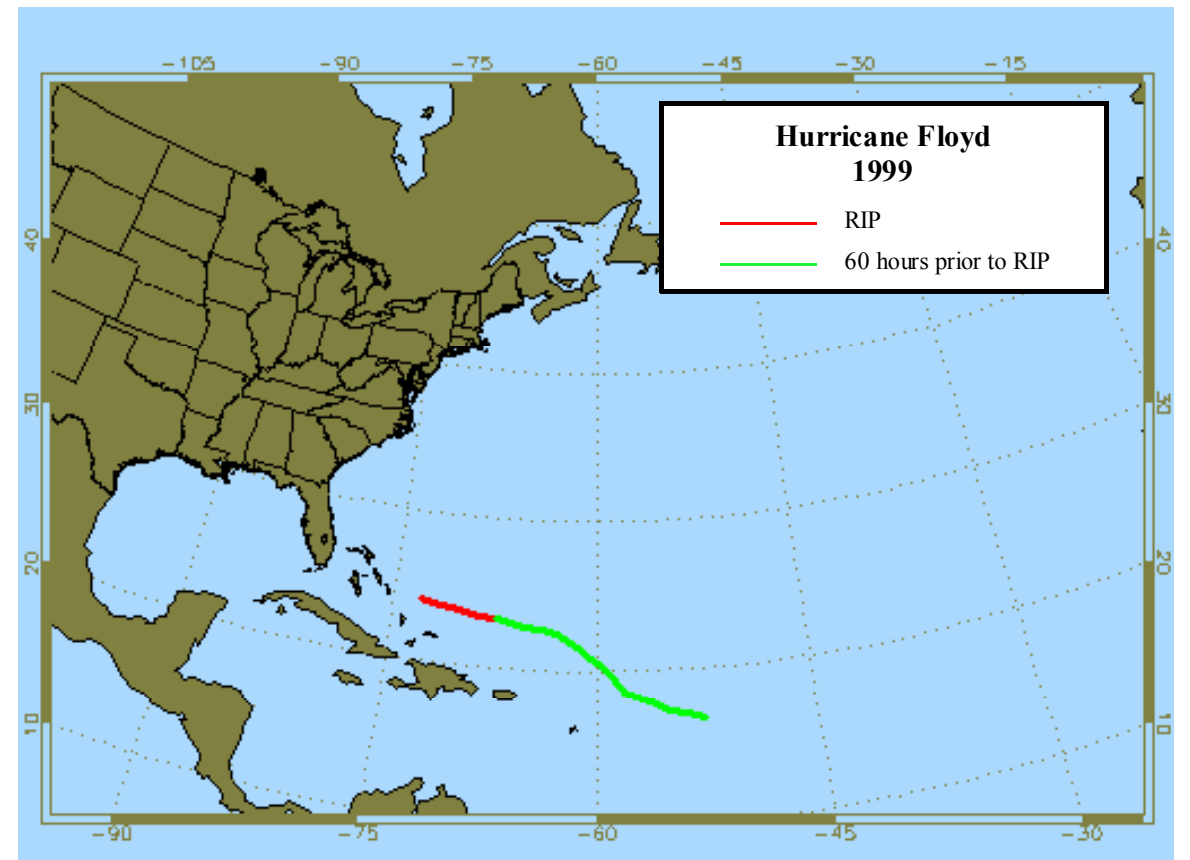

Figure A.72: As in Figure A.1, except for Hurricane Floyd (1999). 


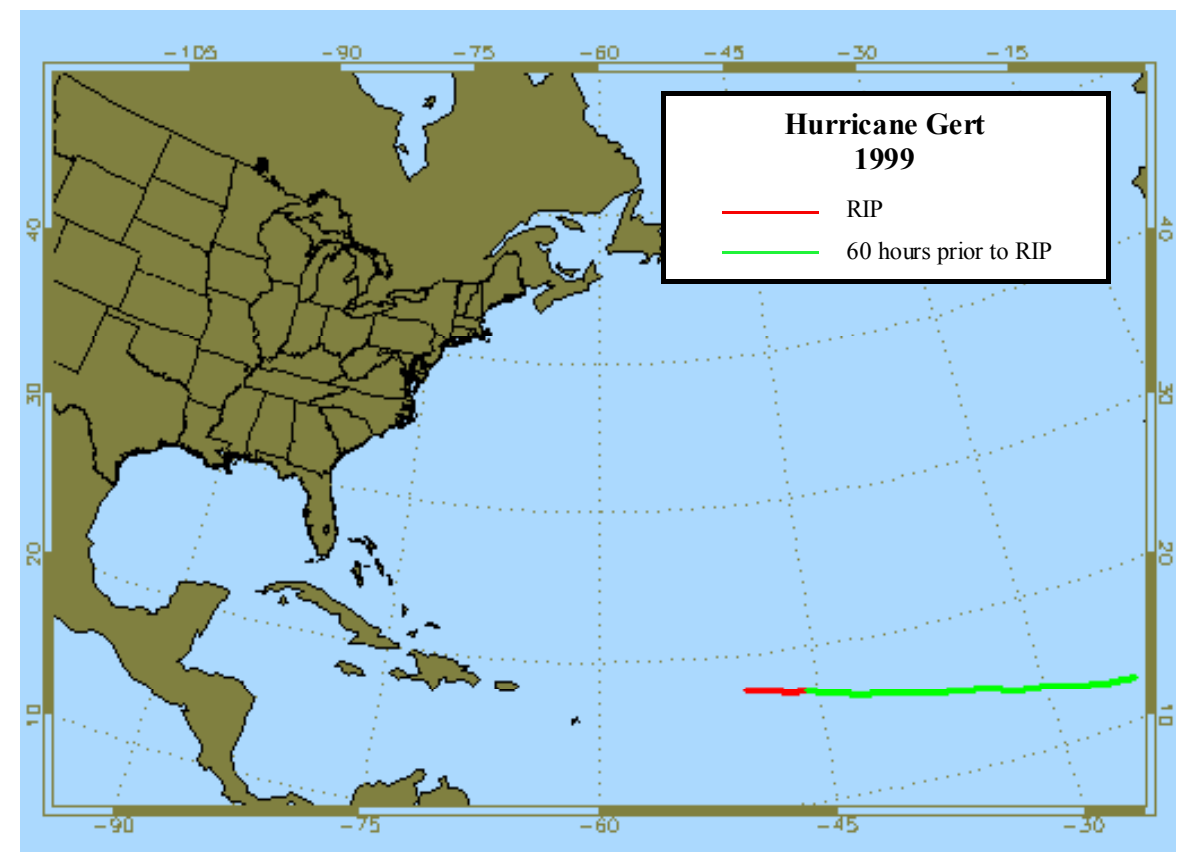

Figure A.73: As in Figure A.1, except for Hurricane Gert (1999).

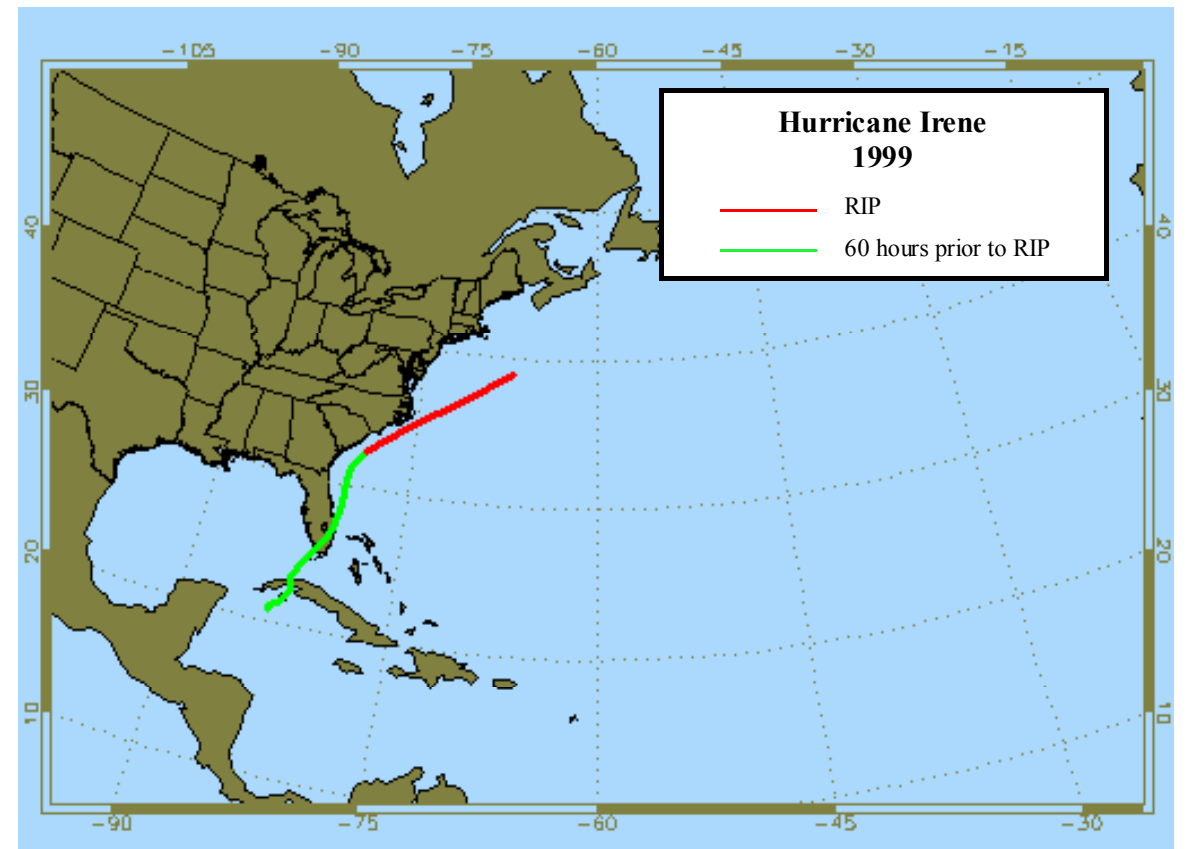

Figure A.74: As in Figure A.1, except for Hurricane Irene (1999). 


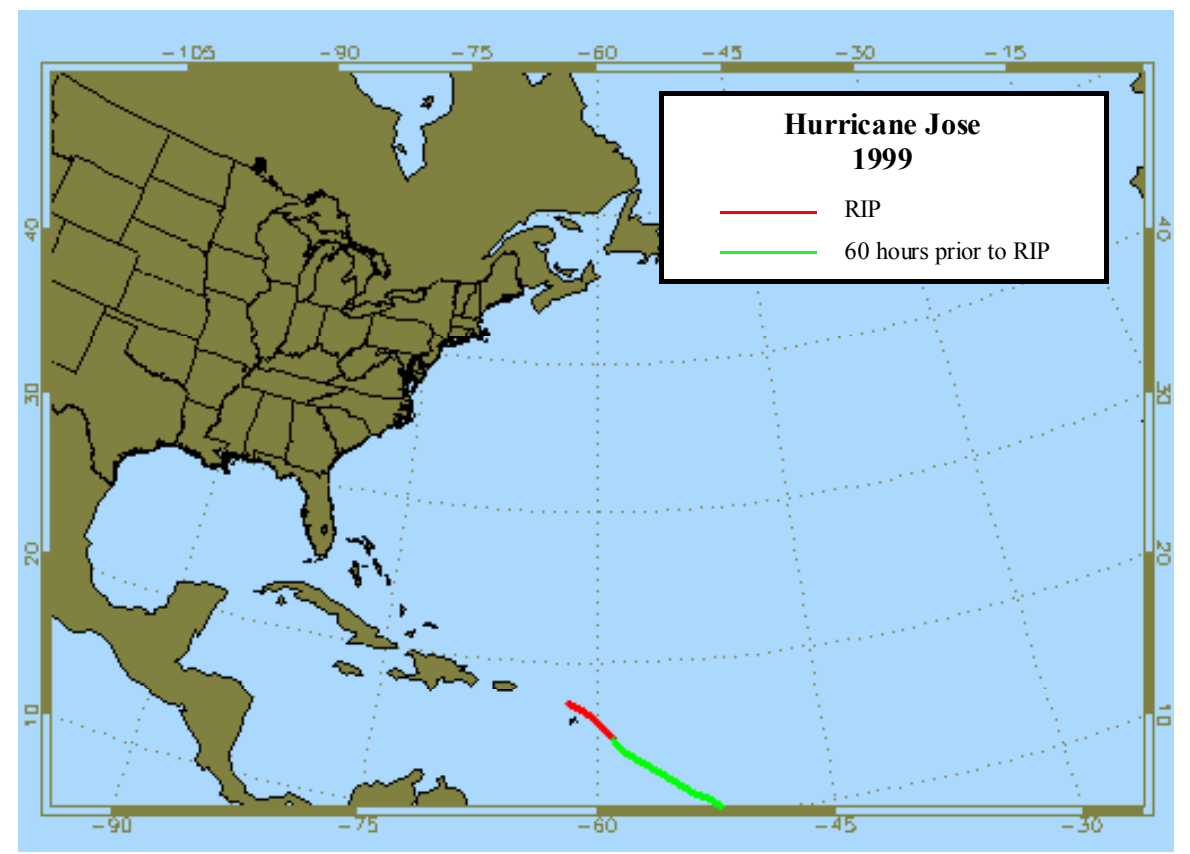

Figure A.75: As in Figure A.1, except for Hurricane Jose (1999).

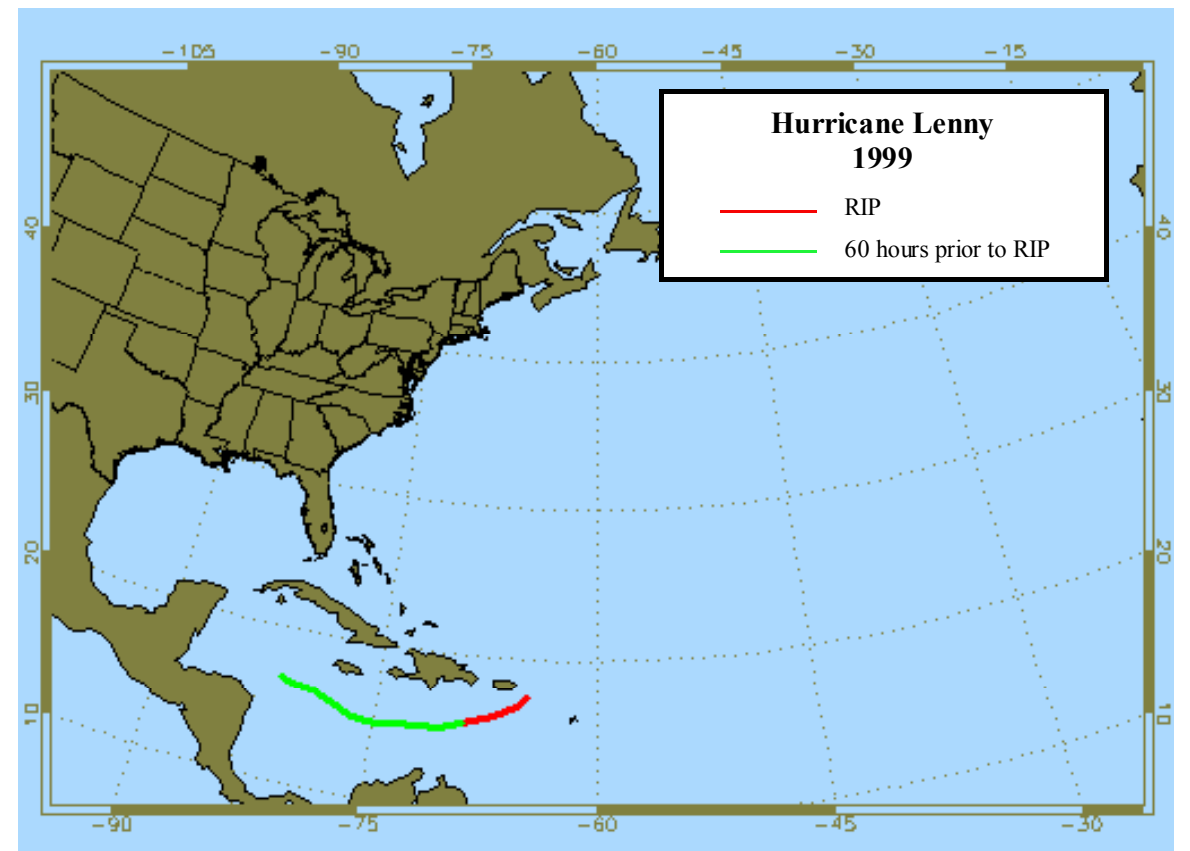

Figure A.76: As in Figure A.1, except for Hurricane Lenny (1999). 


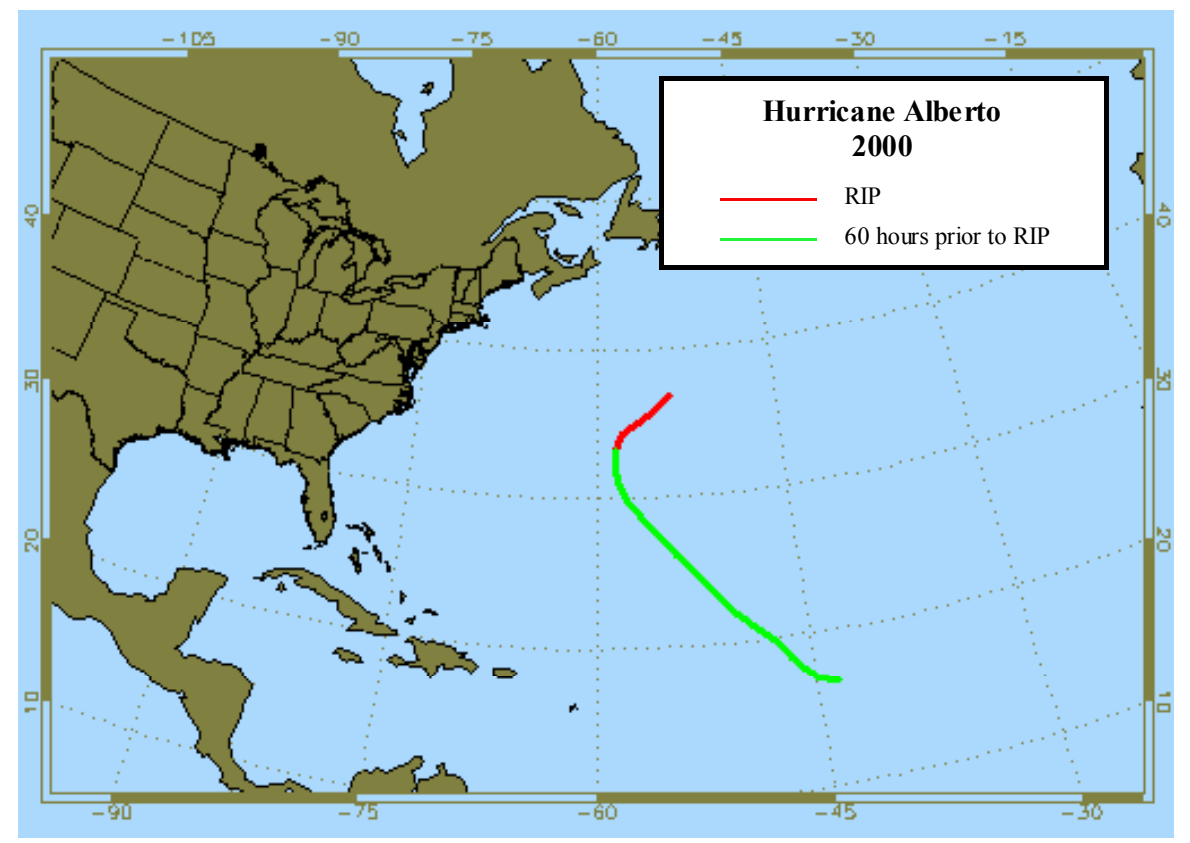

Figure A.77: As in Figure A.1, except for Hurricane Alberto (2000).

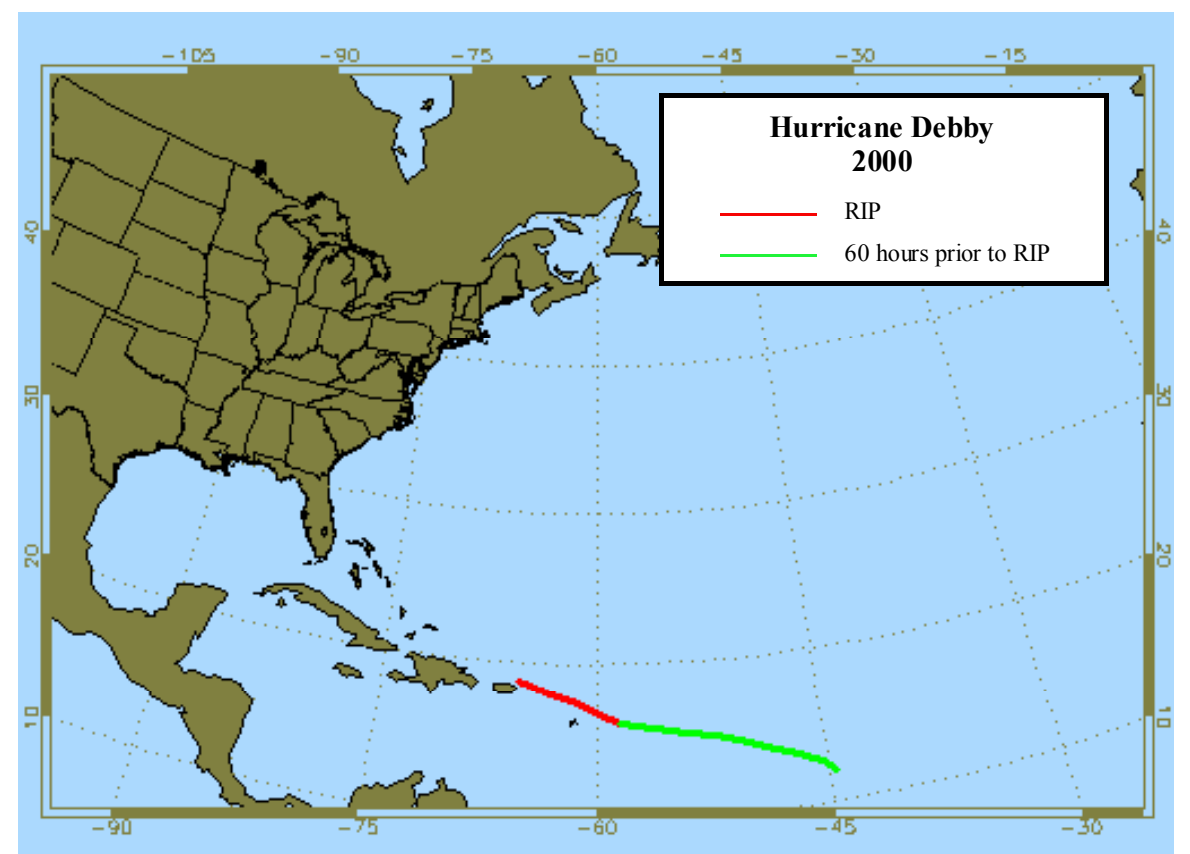

Figure A.78: As in Figure A.1, except for Hurricane Debby (2000). 


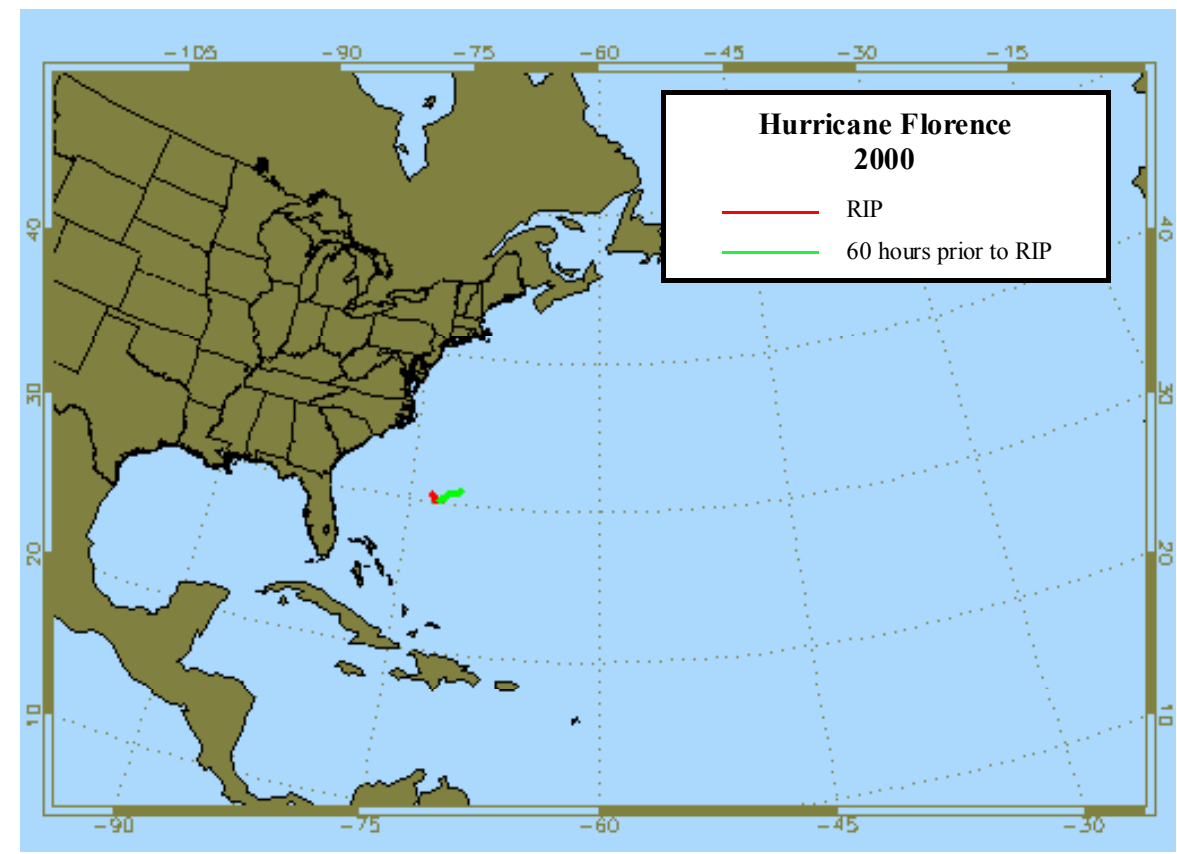

Figure A.79: As in Figure A.1, except for Hurricane Florence (2000).

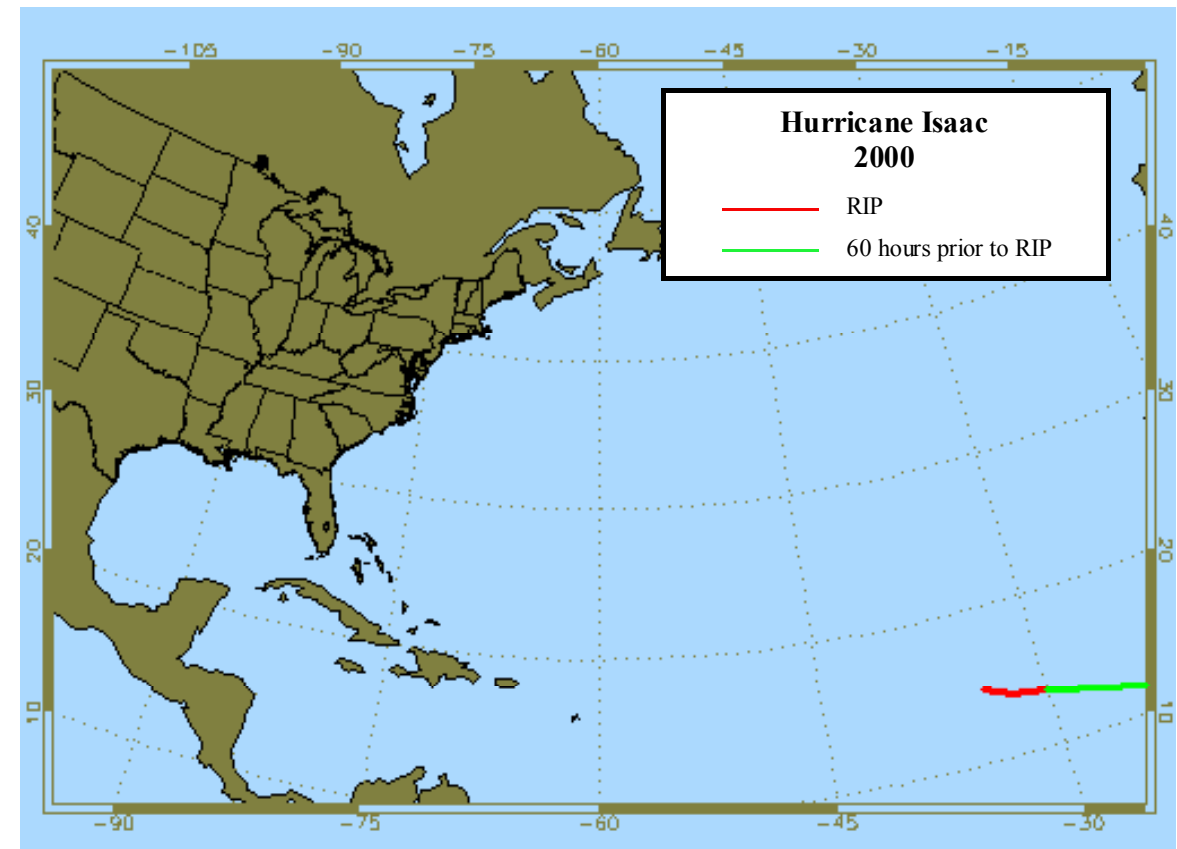

Figure A.80: As in Figure A.1, except for Hurricane Isaac (2000). 


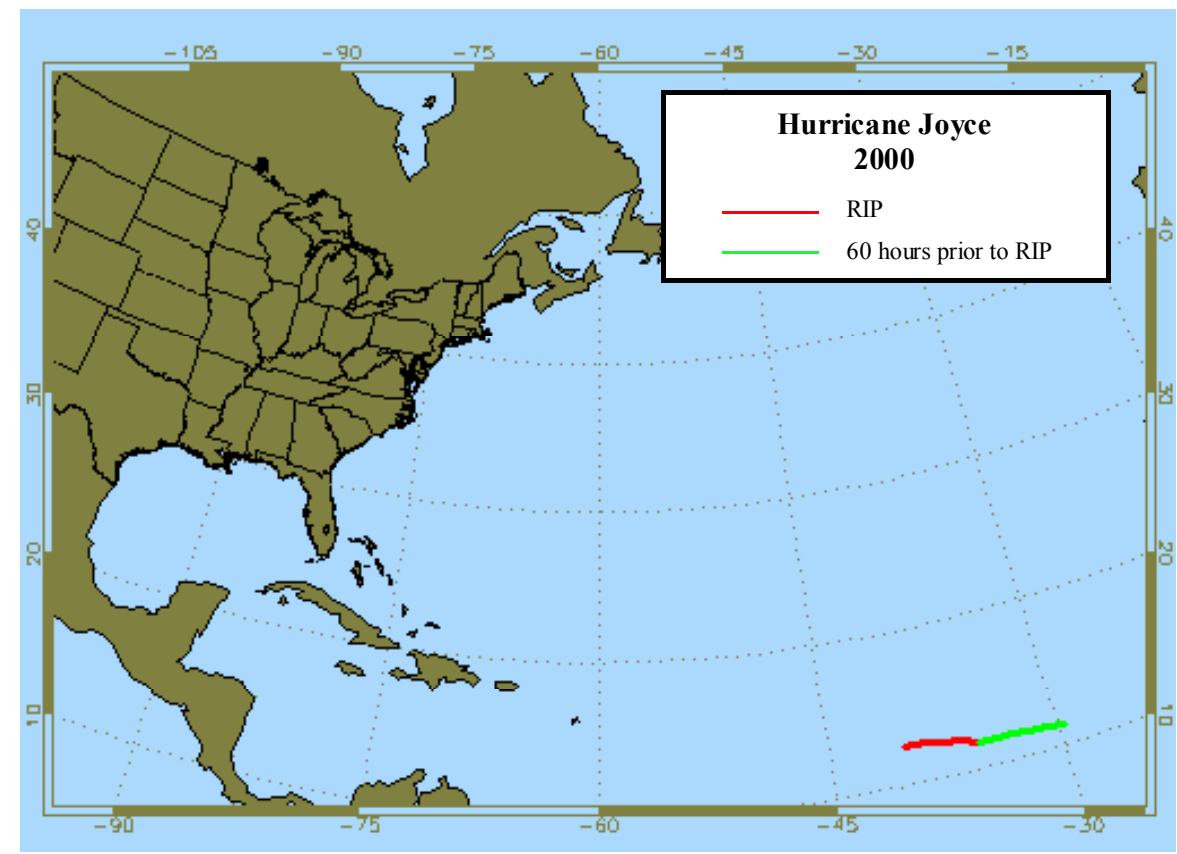

Figure A.81: As in Figure A.1, except for Hurricane Joyce (2000).

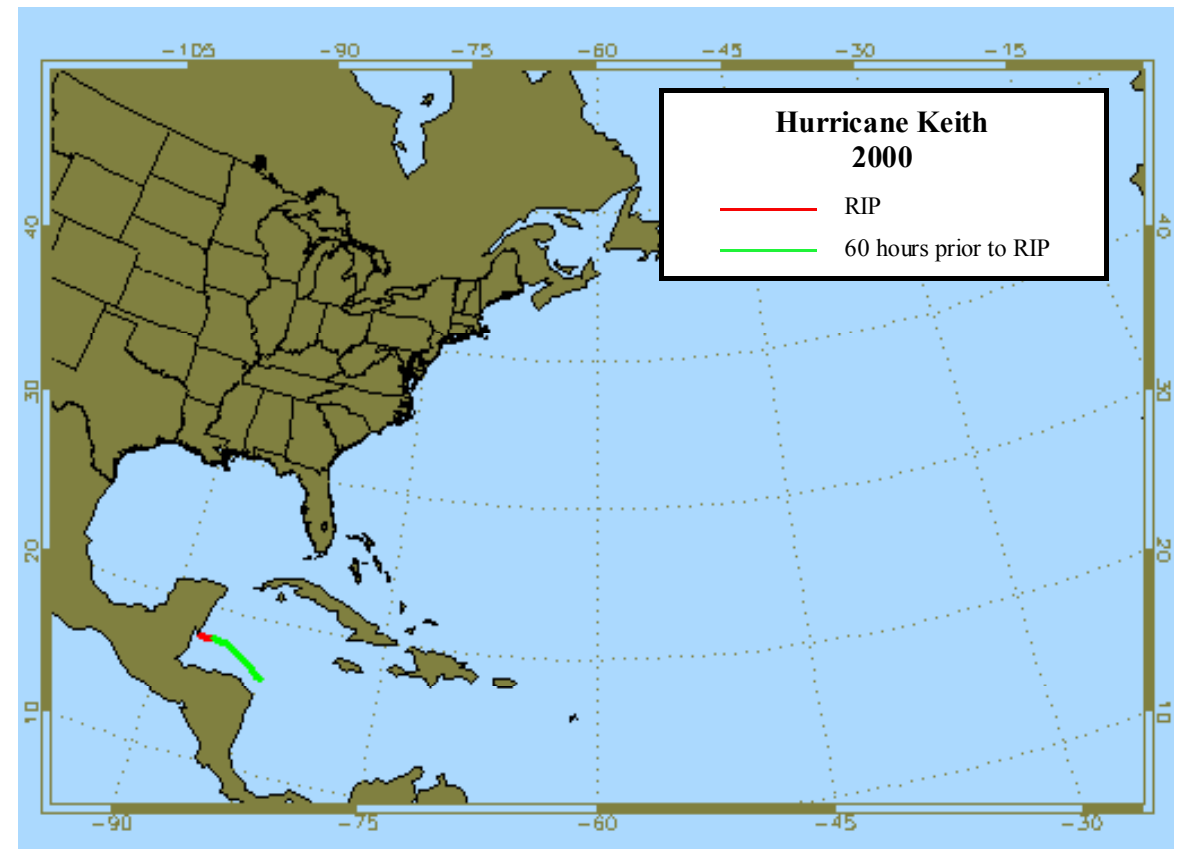

Figure A.82: As in Figure A.1, except for Hurricane Keith (2000). 


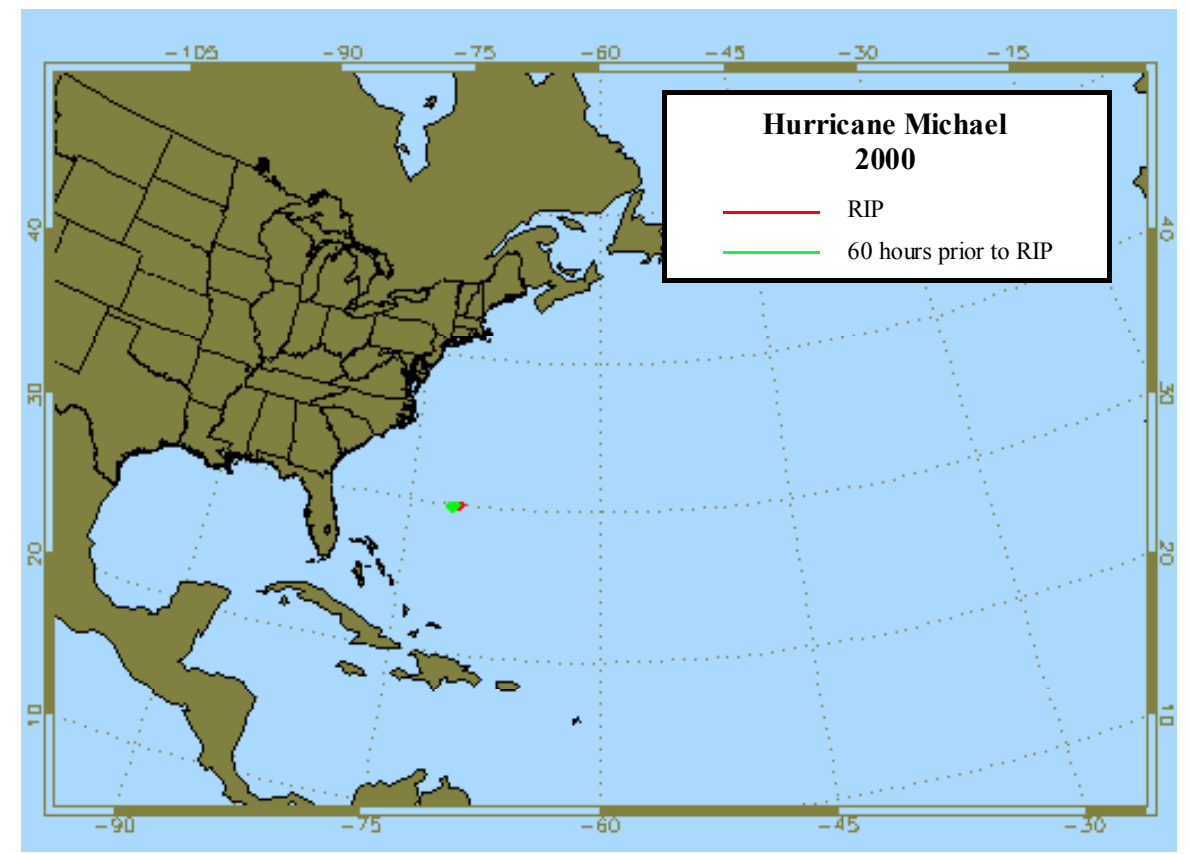

Figure A.83: As in Figure A.1, except for Hurricane Michael (2000).

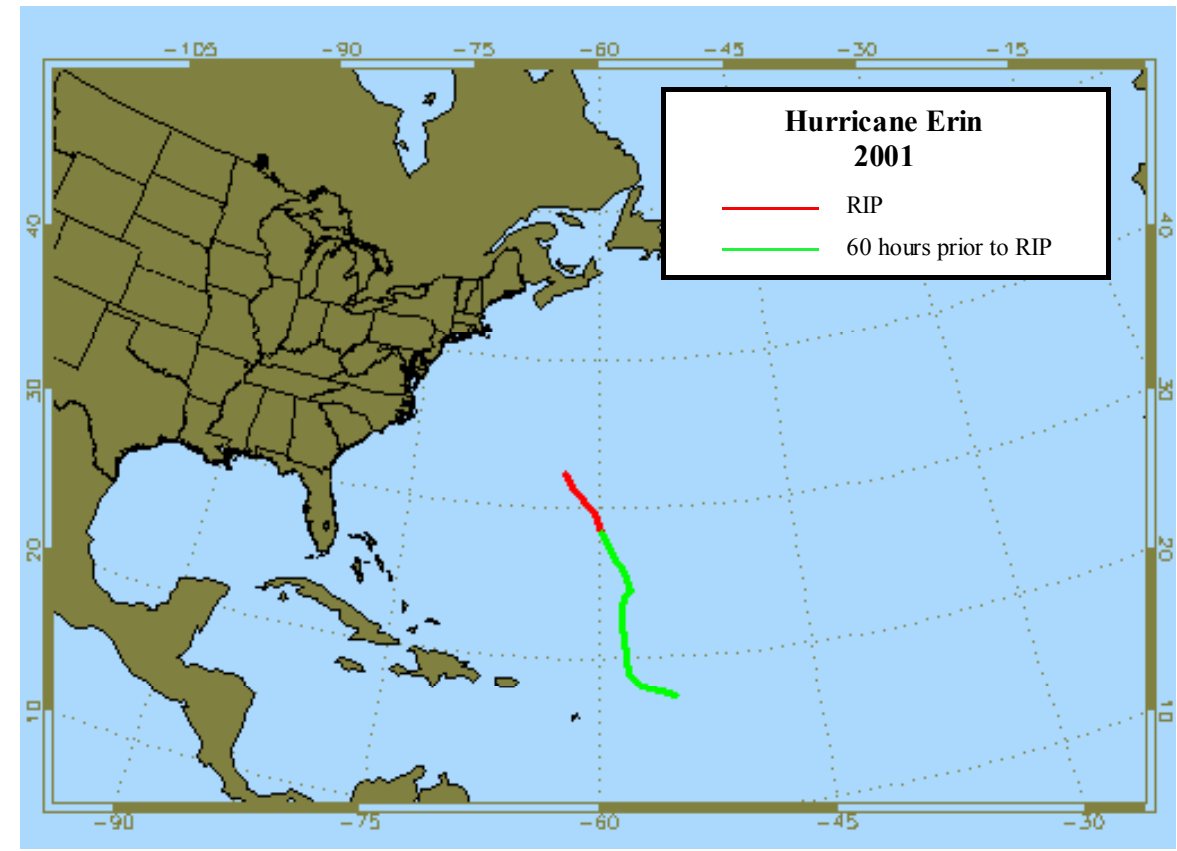

Figure A.84: As in Figure A.1, except for Hurricane Erin (2001). 


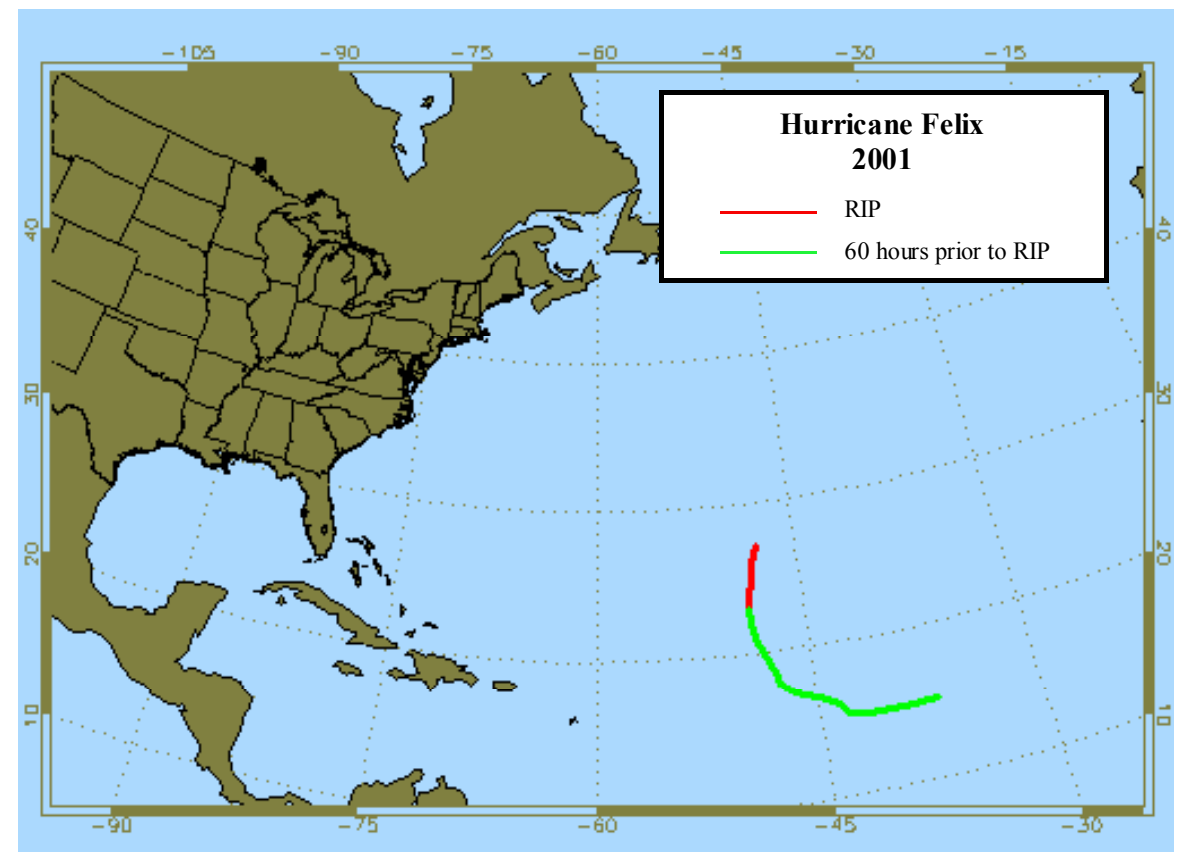

Figure A.85: As in Figure A.1, except for Hurricane Felix (2001).

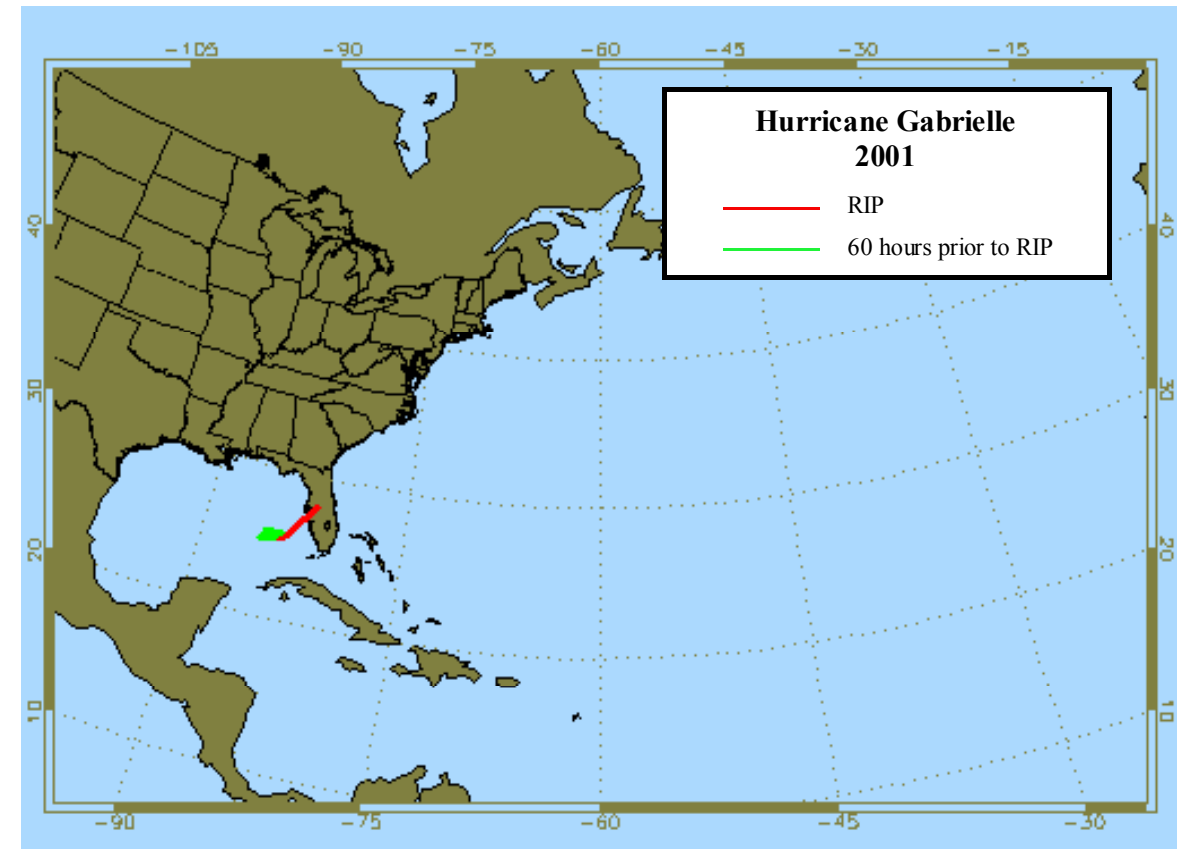

Figure A.86: As in Figure A.1, except for Hurricane Gabrielle (2001). 


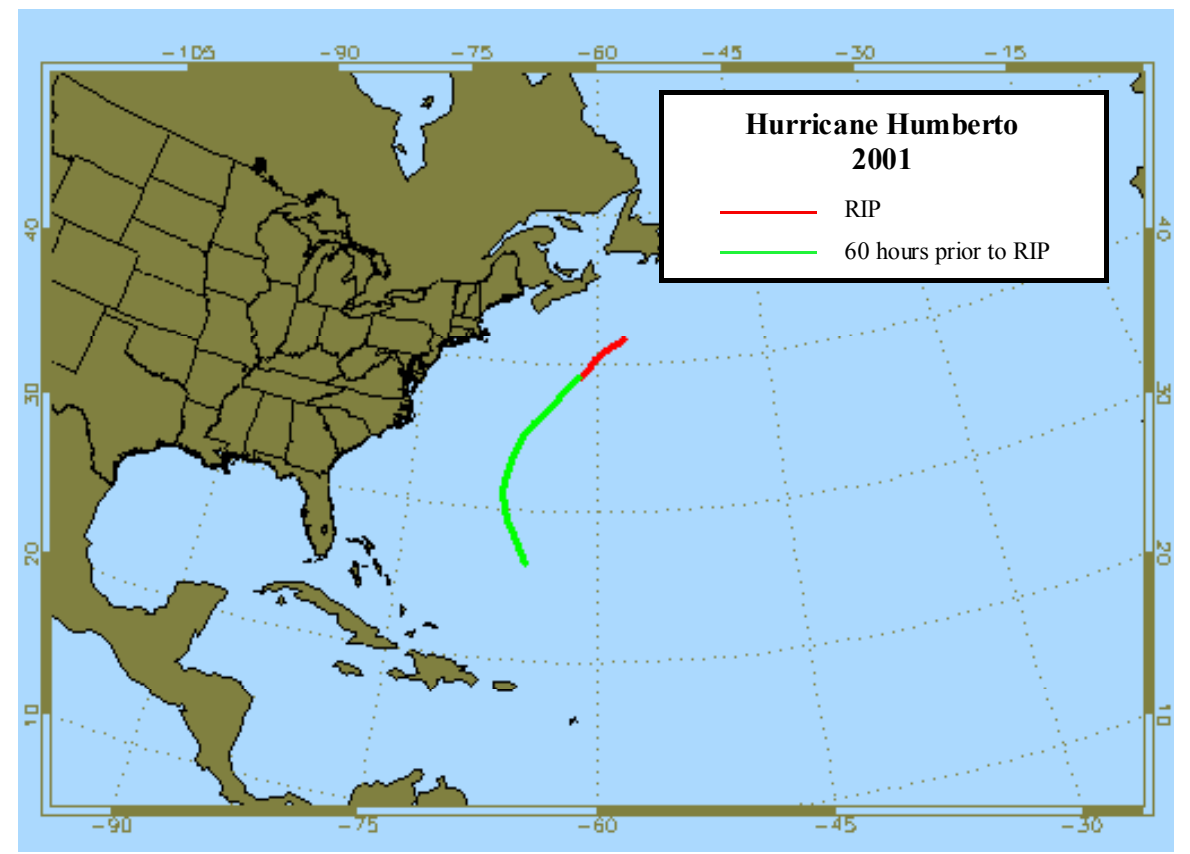

Figure A.87: As in Figure A.1, except for Hurricane Humberto (2001).

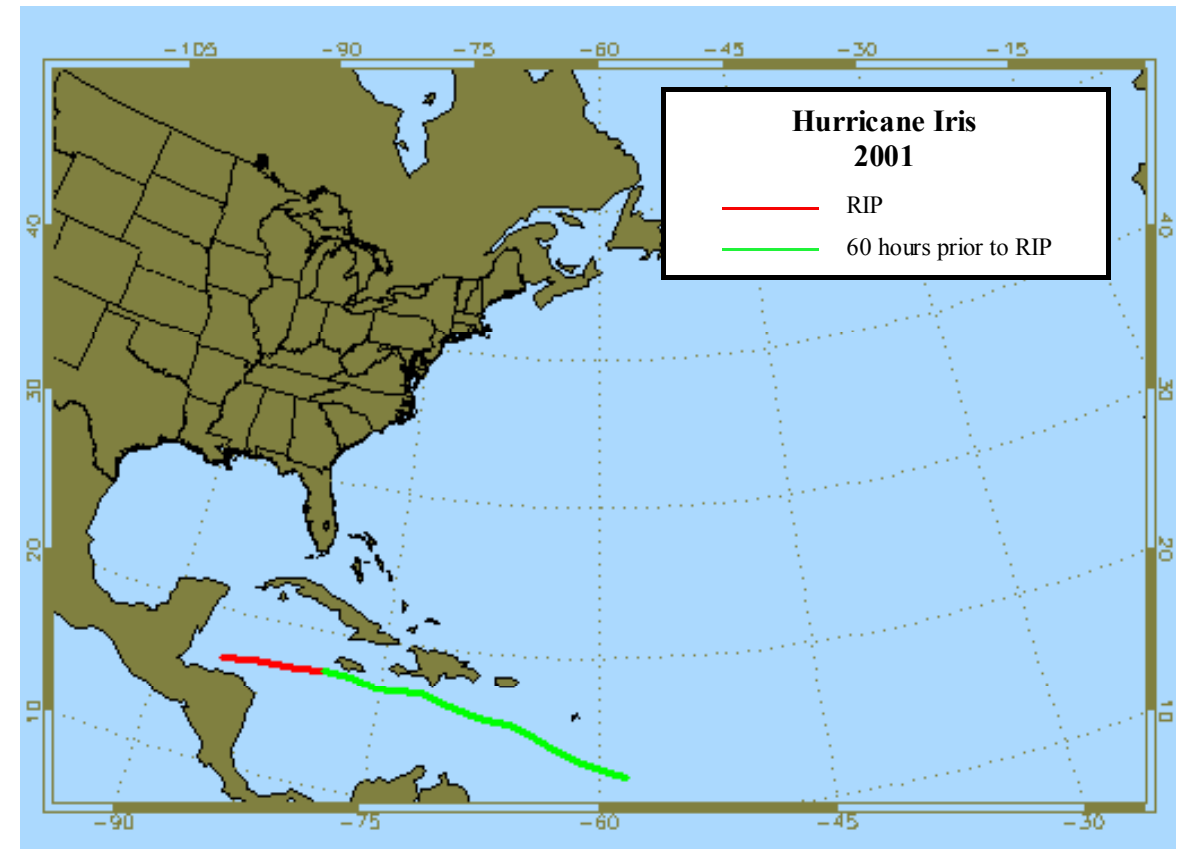

Figure A.88: As in Figure A.1, except for Hurricane Iris (2001). 


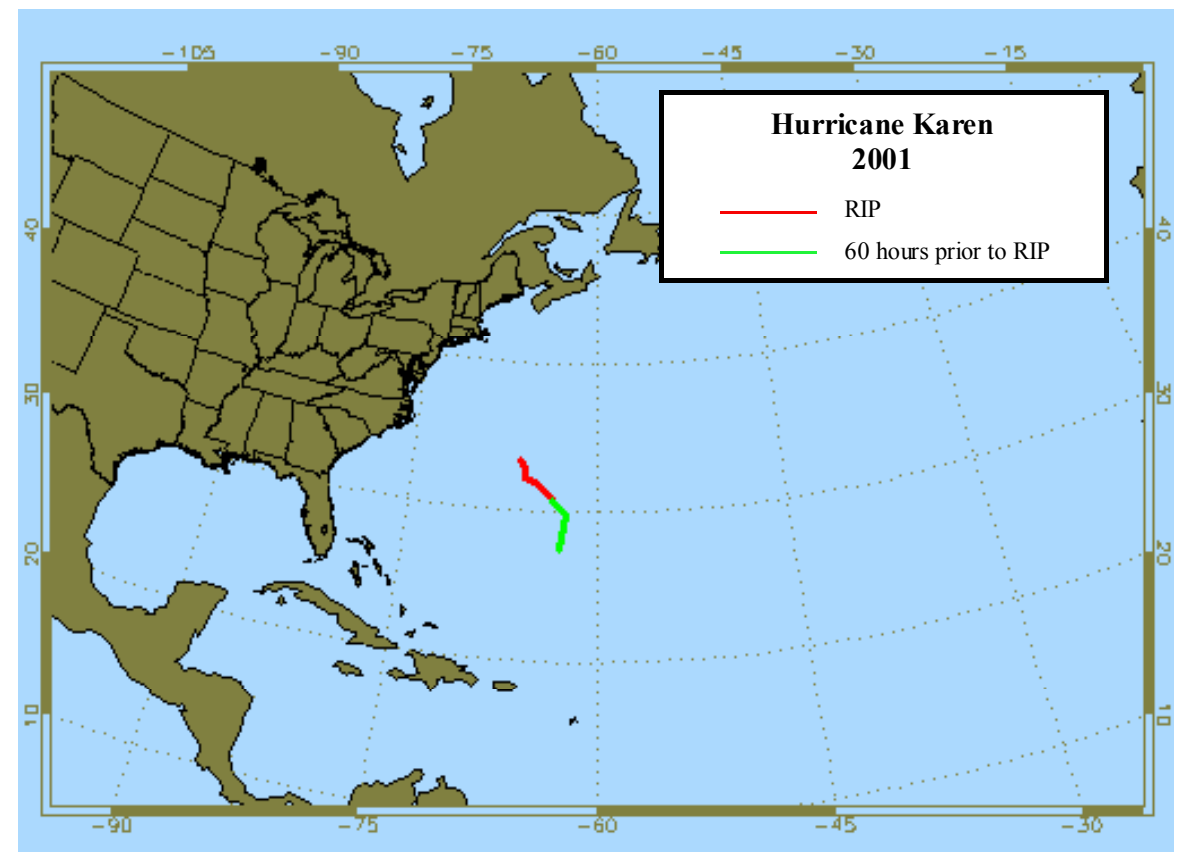

Figure A.89: As in Figure A.1, except for Hurricane Karen (2001).

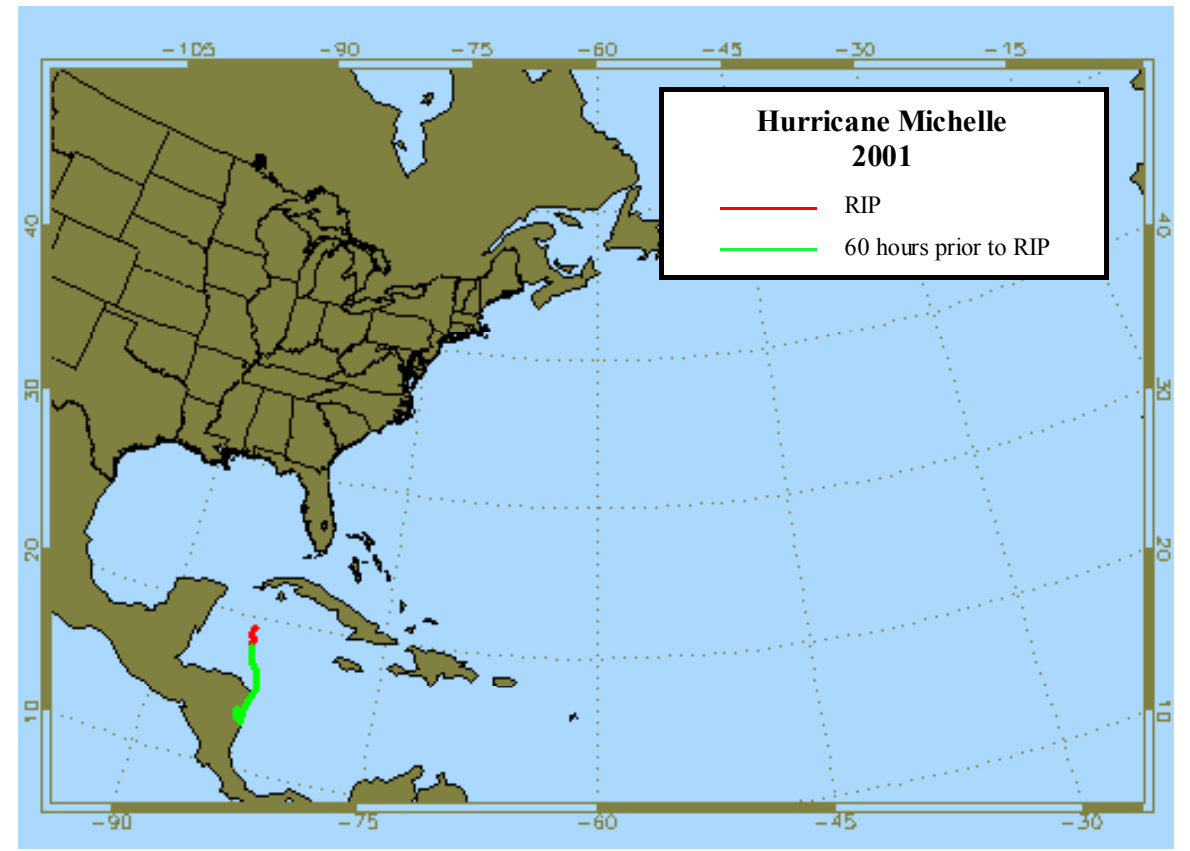

Figure A.90: As in Figure A.1, except for Hurricane Michelle (2001). 


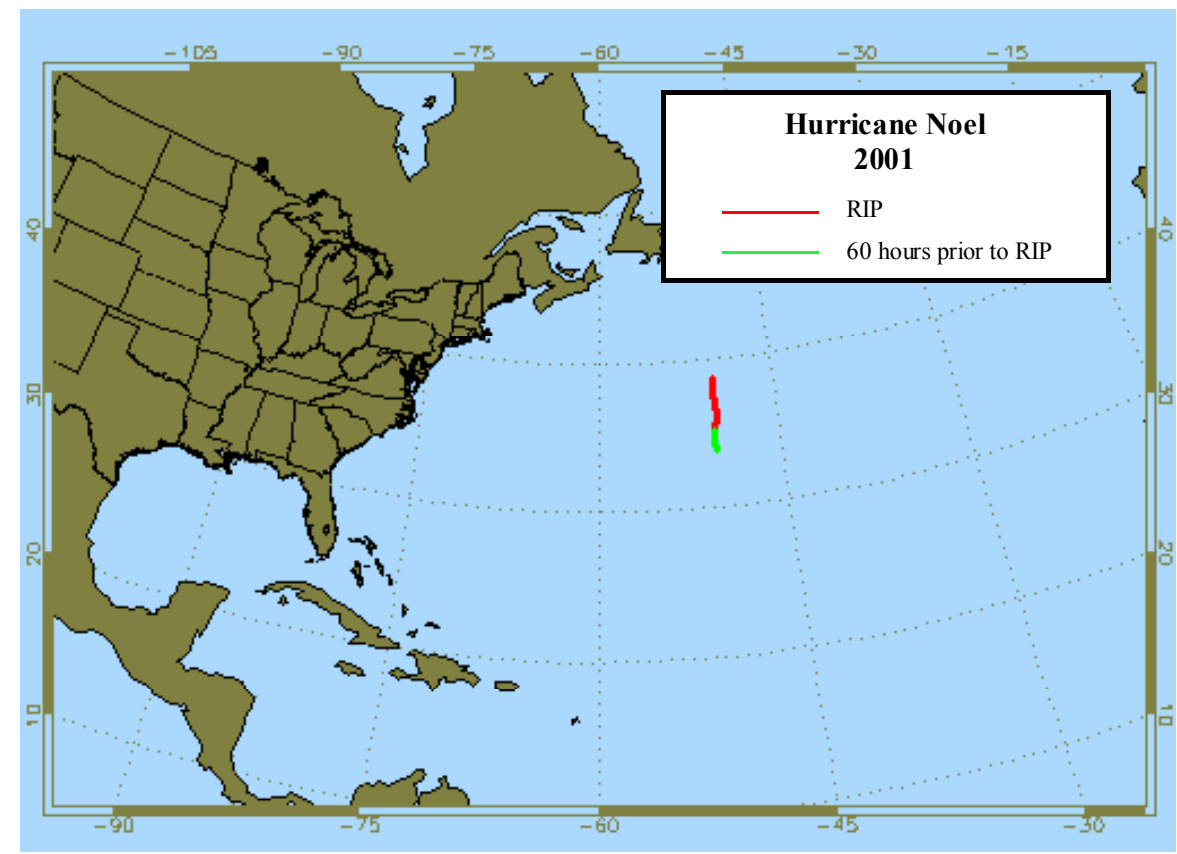

Figure A.91: As in Figure A.1, except for Hurricane Noel (2001).

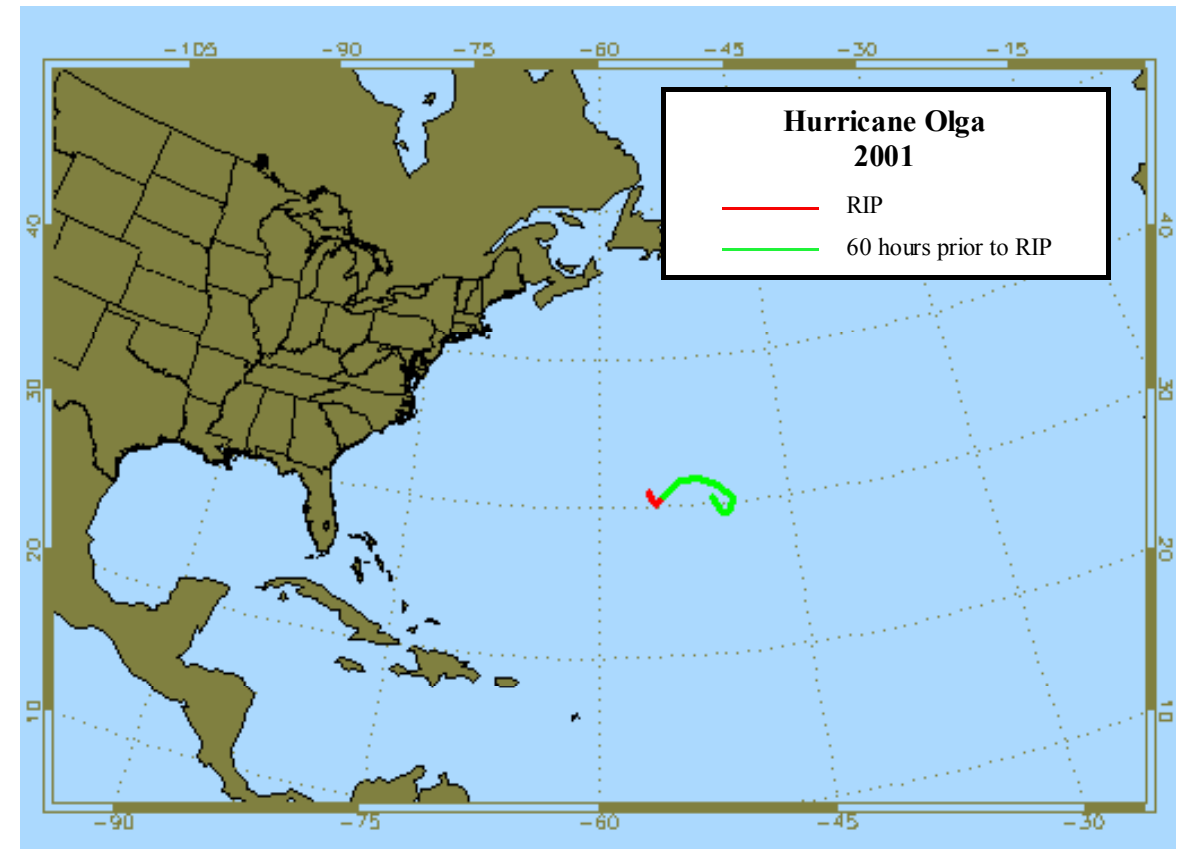

Figure A.92: As in Figure A.1, except for Hurricane Olga (2001). 


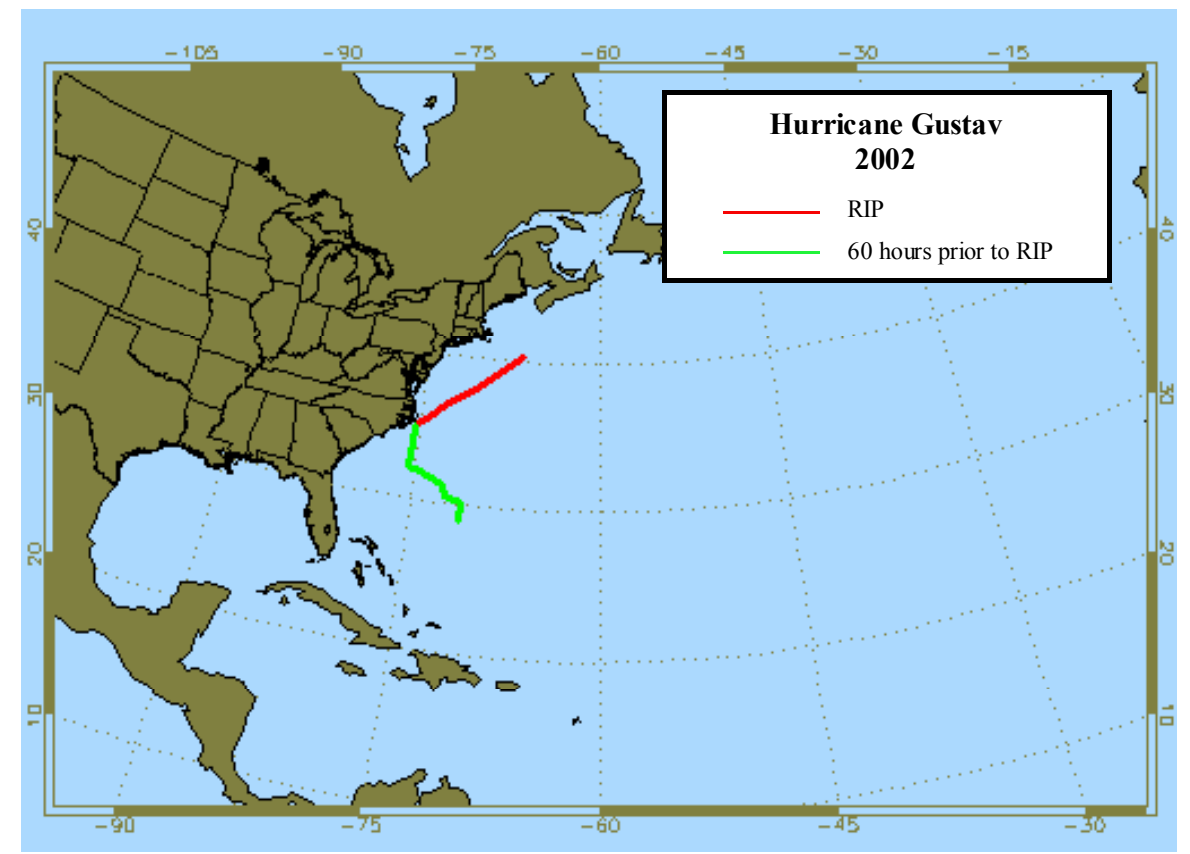

Figure A.93: As in Figure A.1, except for Hurricane Gustav (2002).

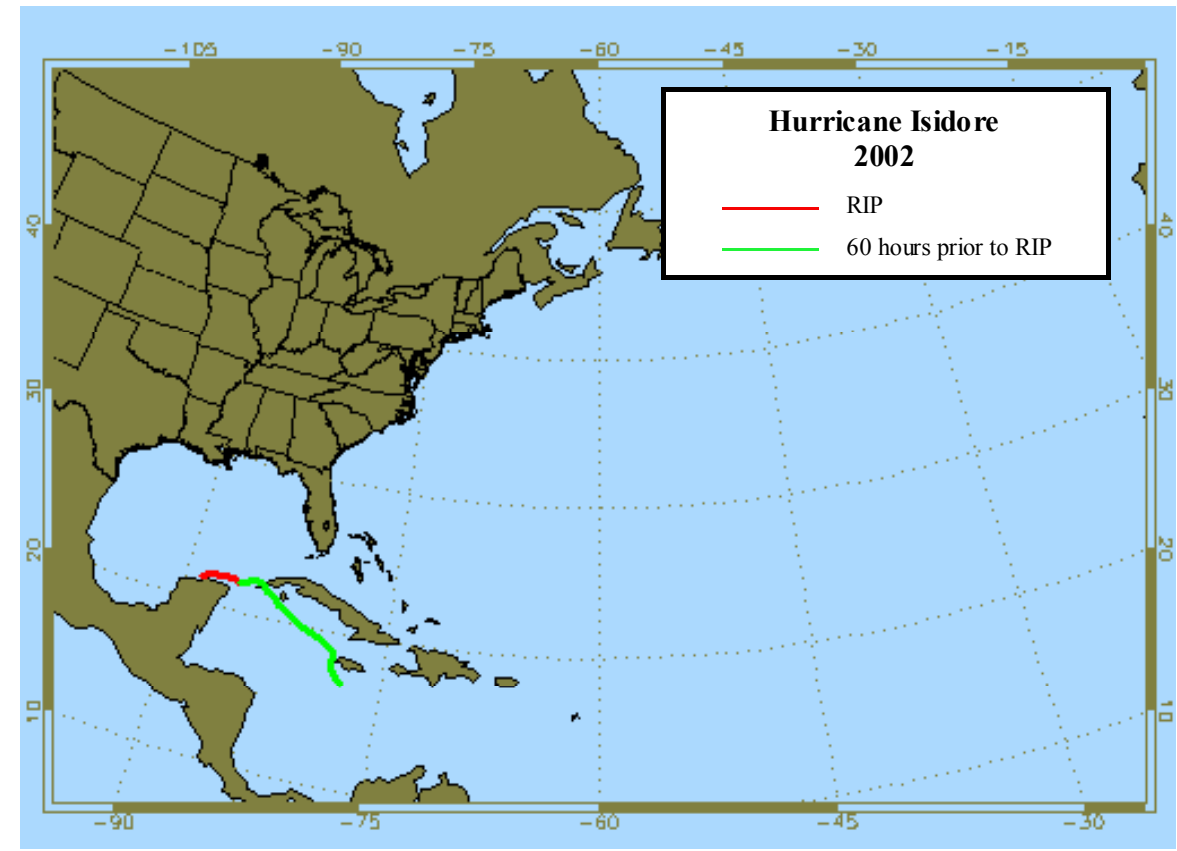

Figure A.94: As in Figure A.1, except for Hurricane Isidore (2002). 


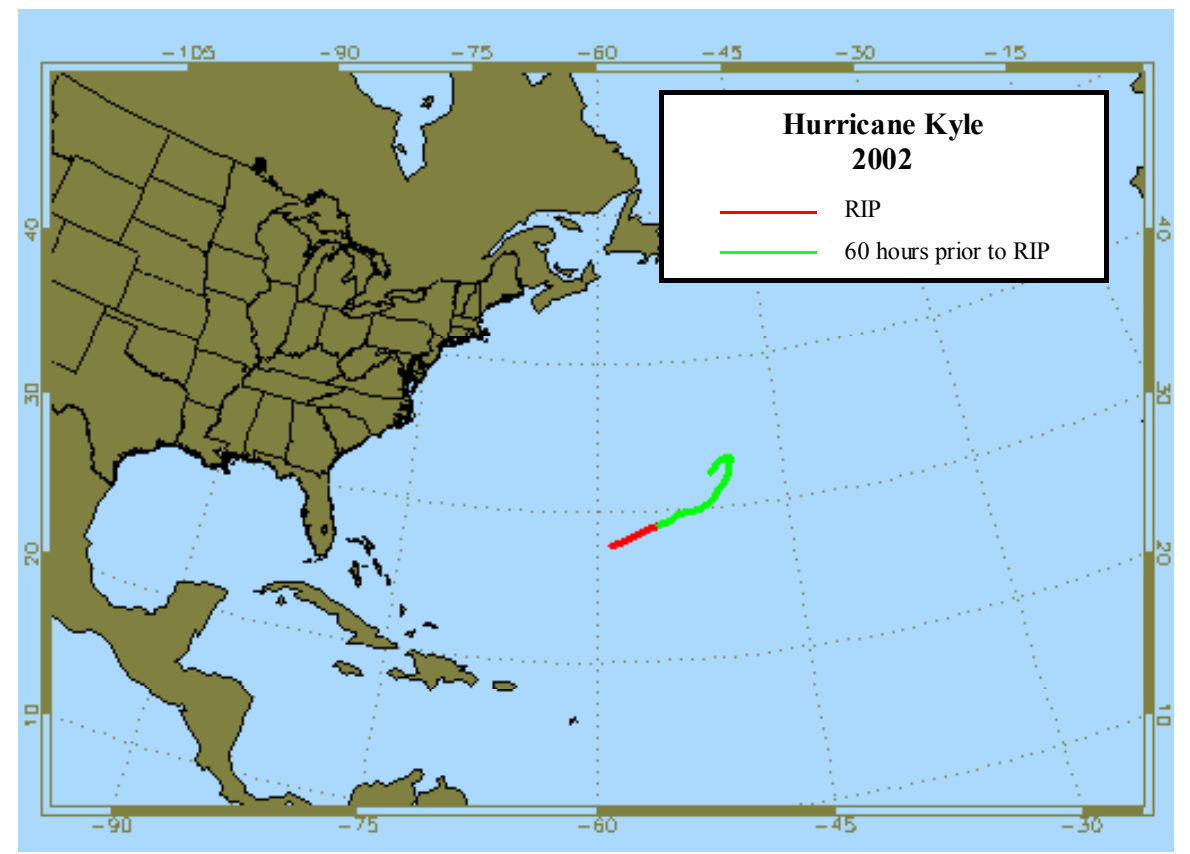

Figure A.95: As in Figure A.1, except for Hurricane Kyle (2002).

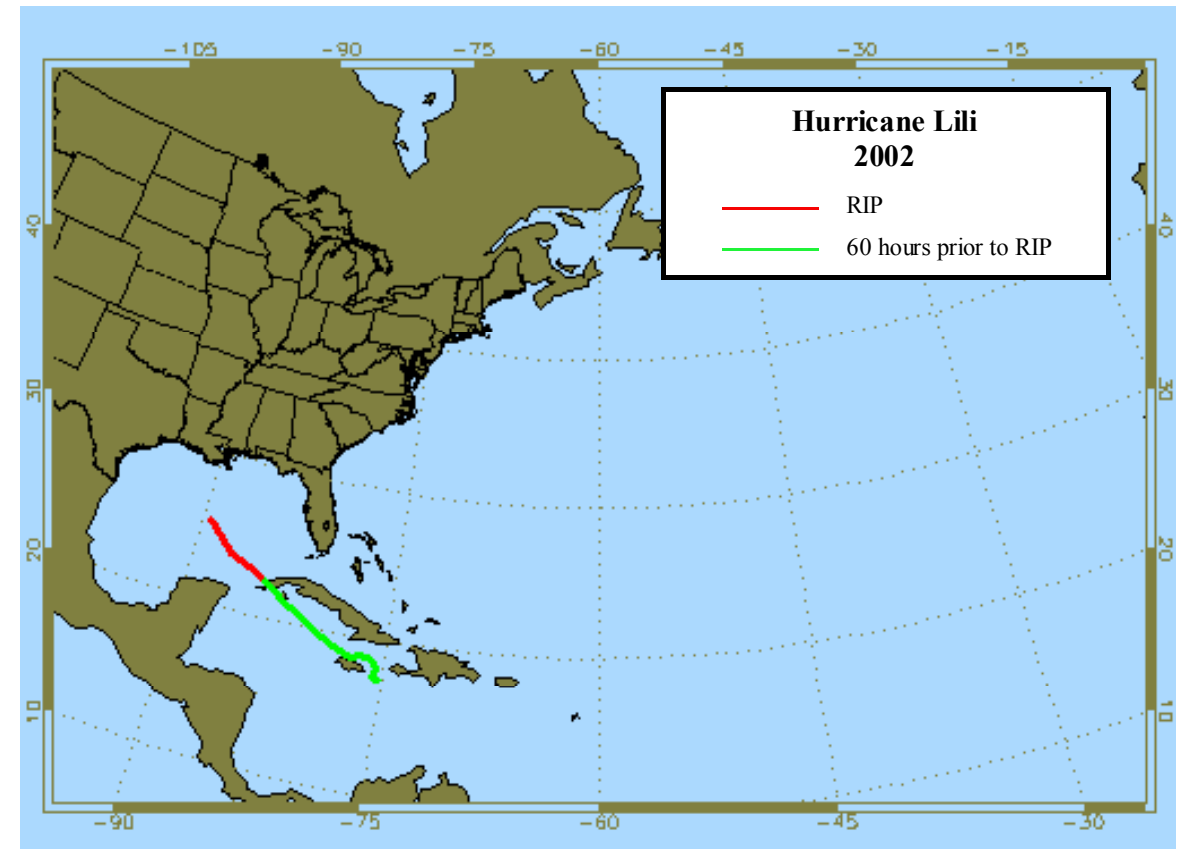

Figure A.96: As in Figure A.1, except for Hurricane Lili (2002). 


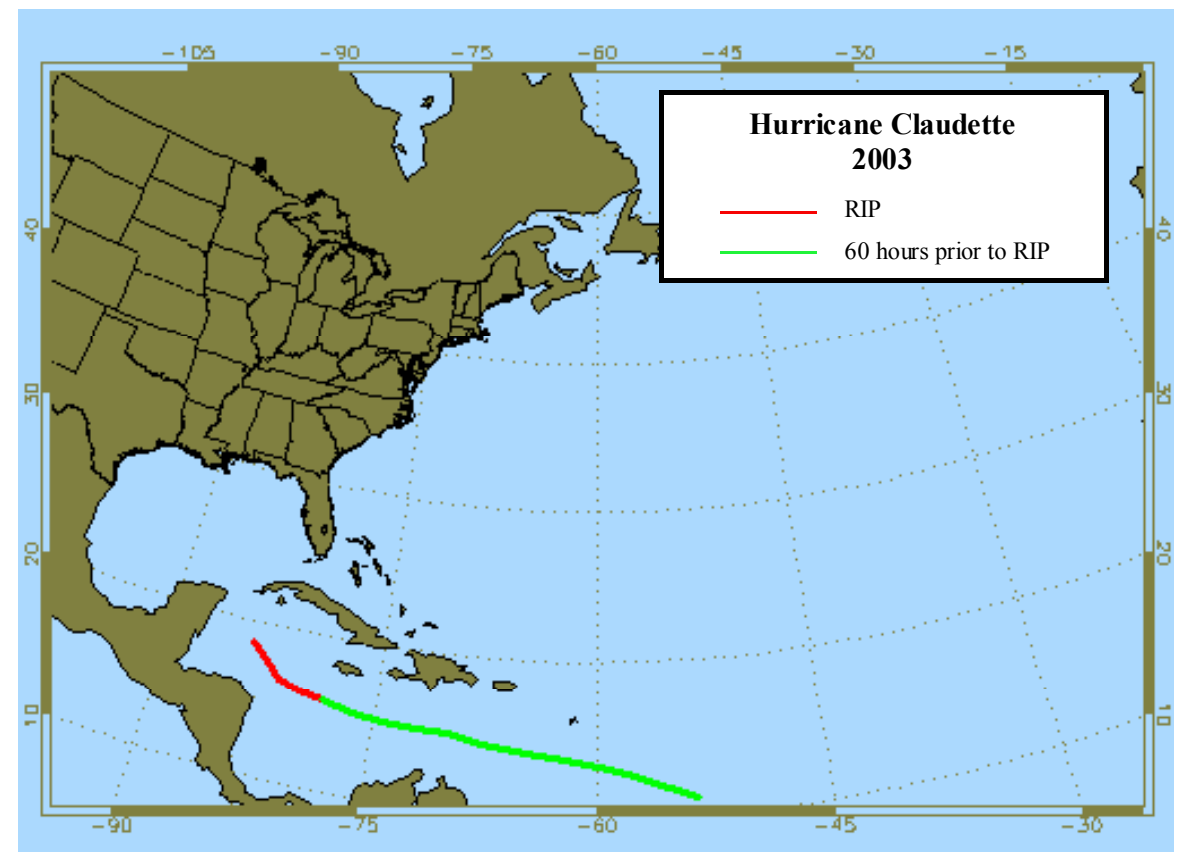

Figure A.97: As in Figure A.1, except for Hurricane Claudette (2003).

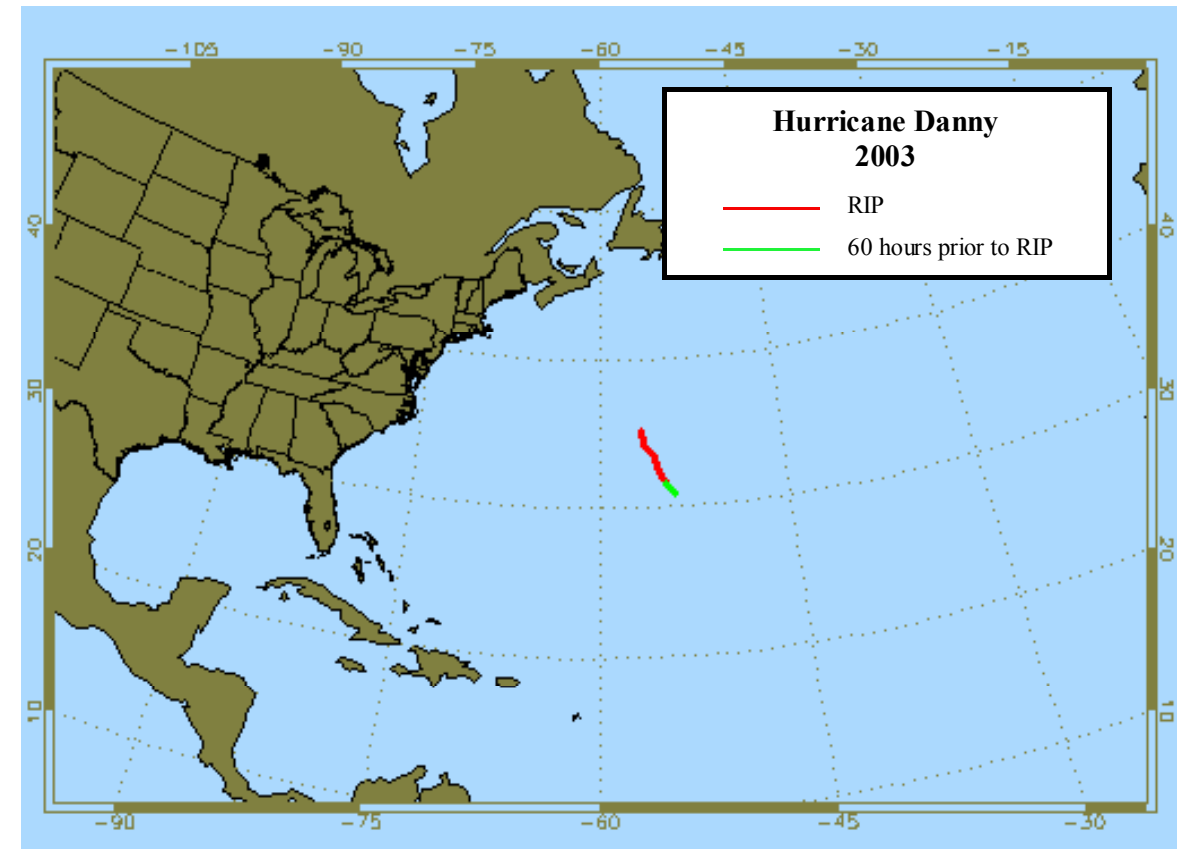

Figure A.98: As in Figure A.1, except for Hurricane Danny (2003). 


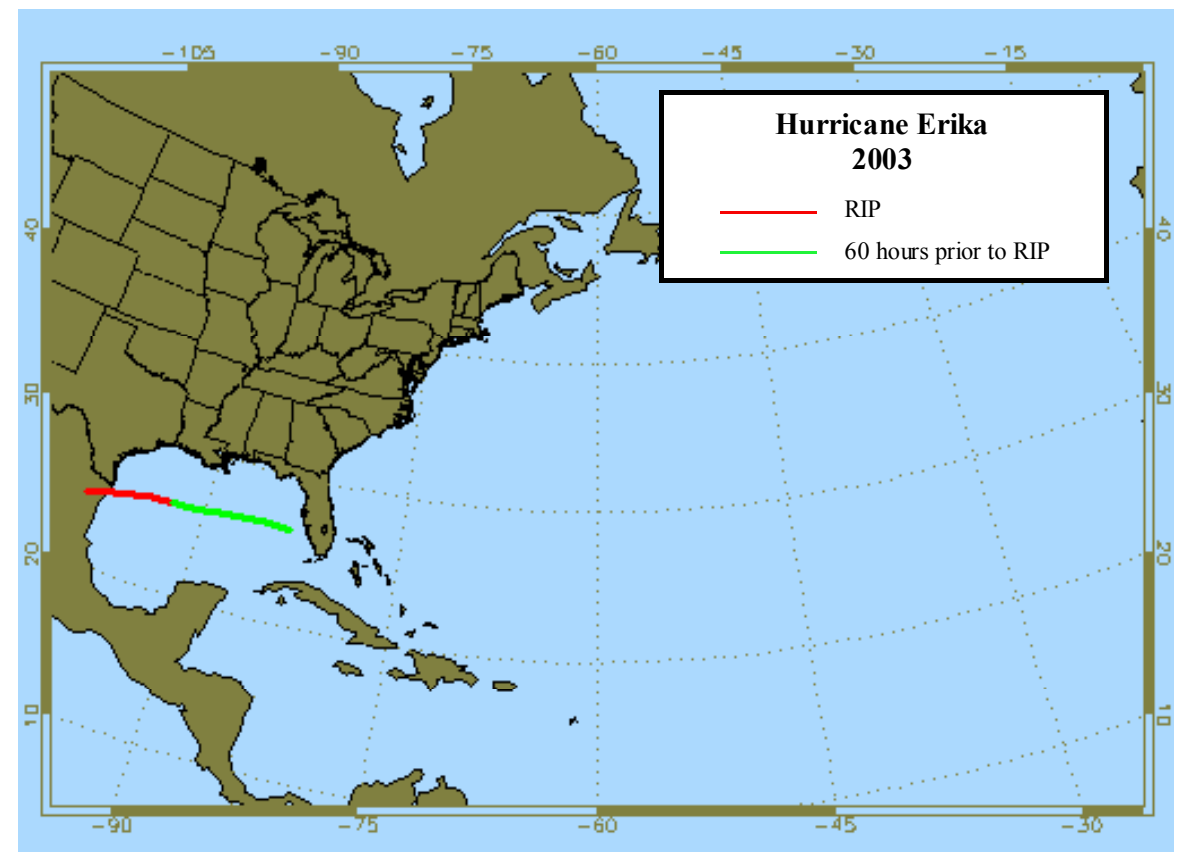

Figure A.99: As in Figure A.1, except for Hurricane Erika (2003).

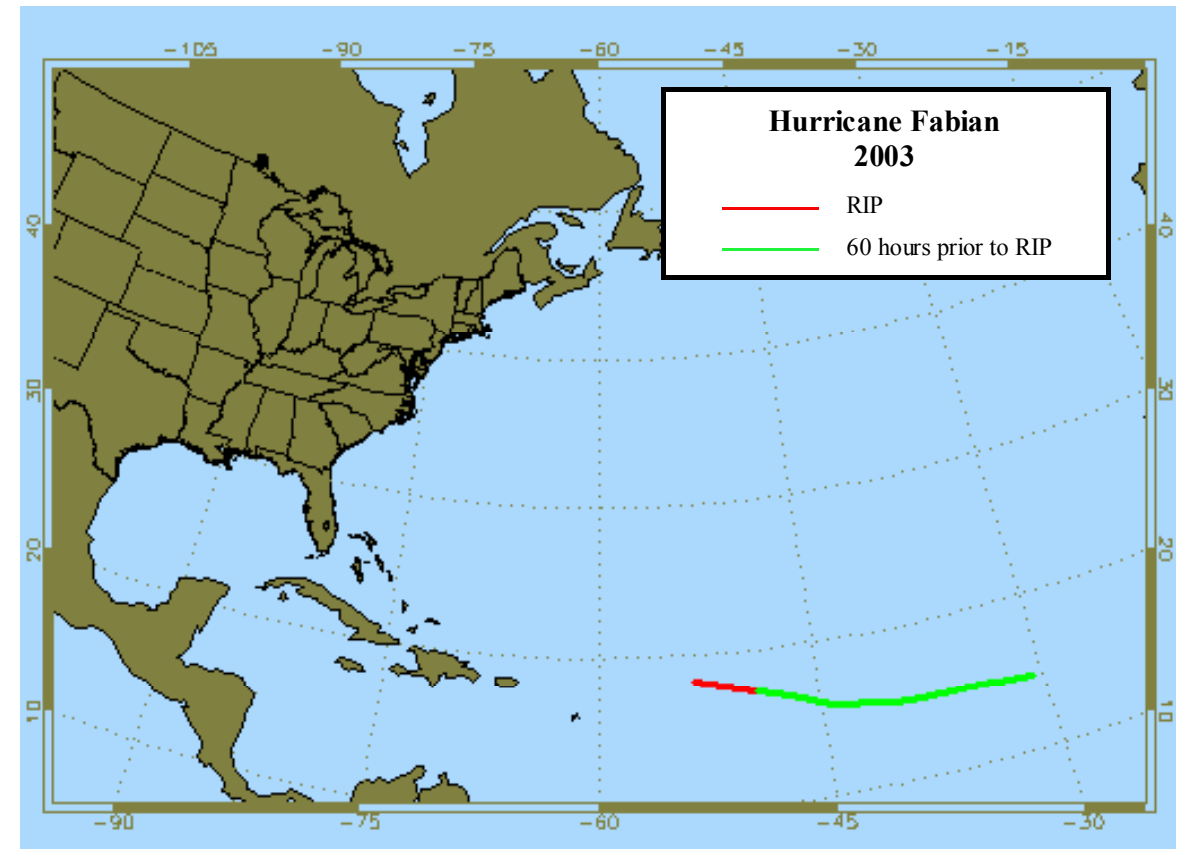

Figure A.100: As in Figure A.1, except for Hurricane Fabian (2003). 


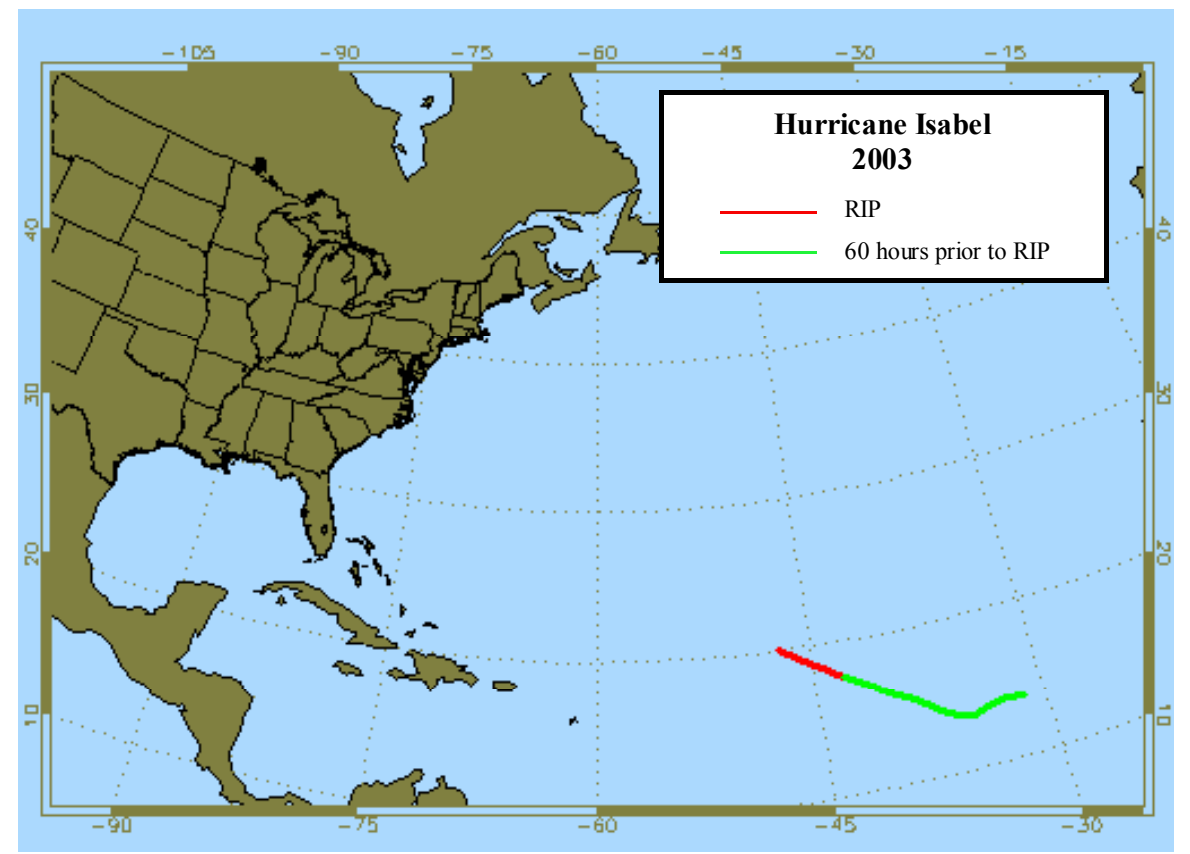

Figure A.101: As in Figure A.1, except for Hurricane Isabel (2003).

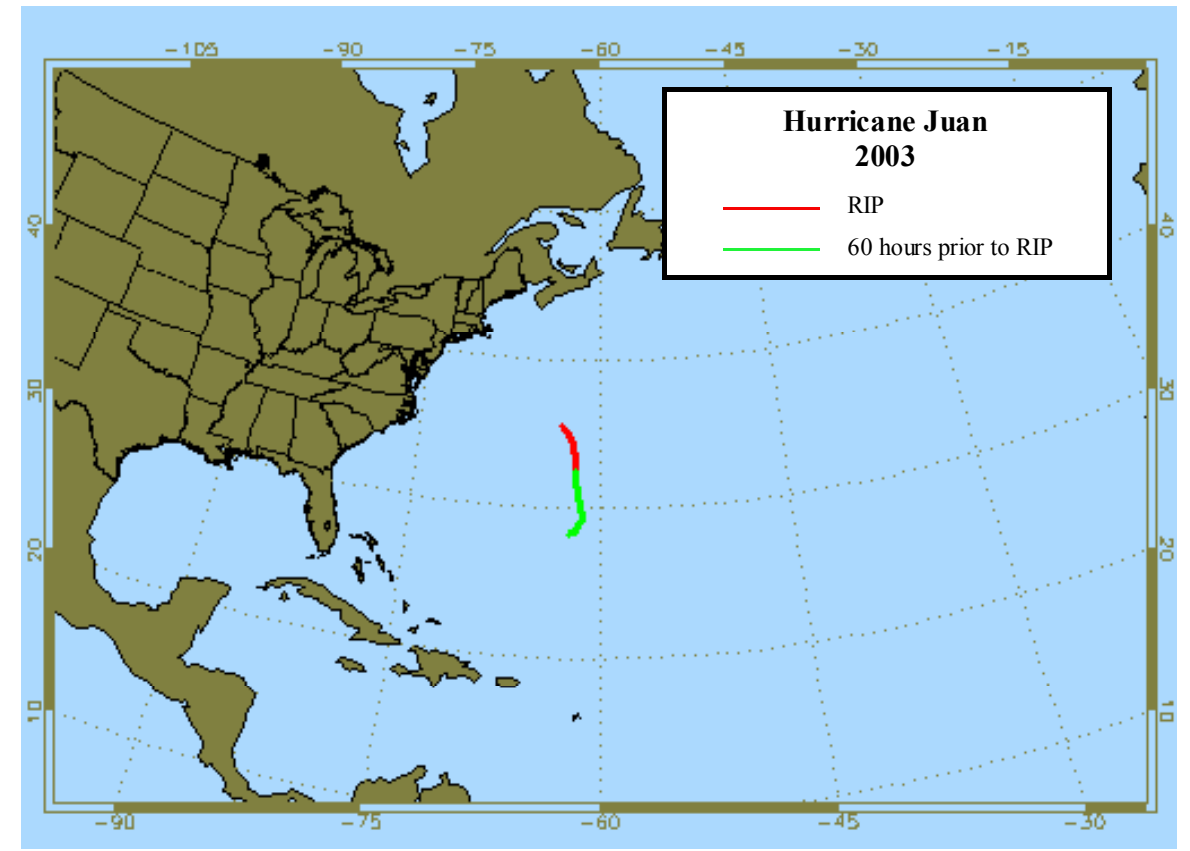

Figure A.102: As in Figure A.1, except for Hurricane Juan (2003). 


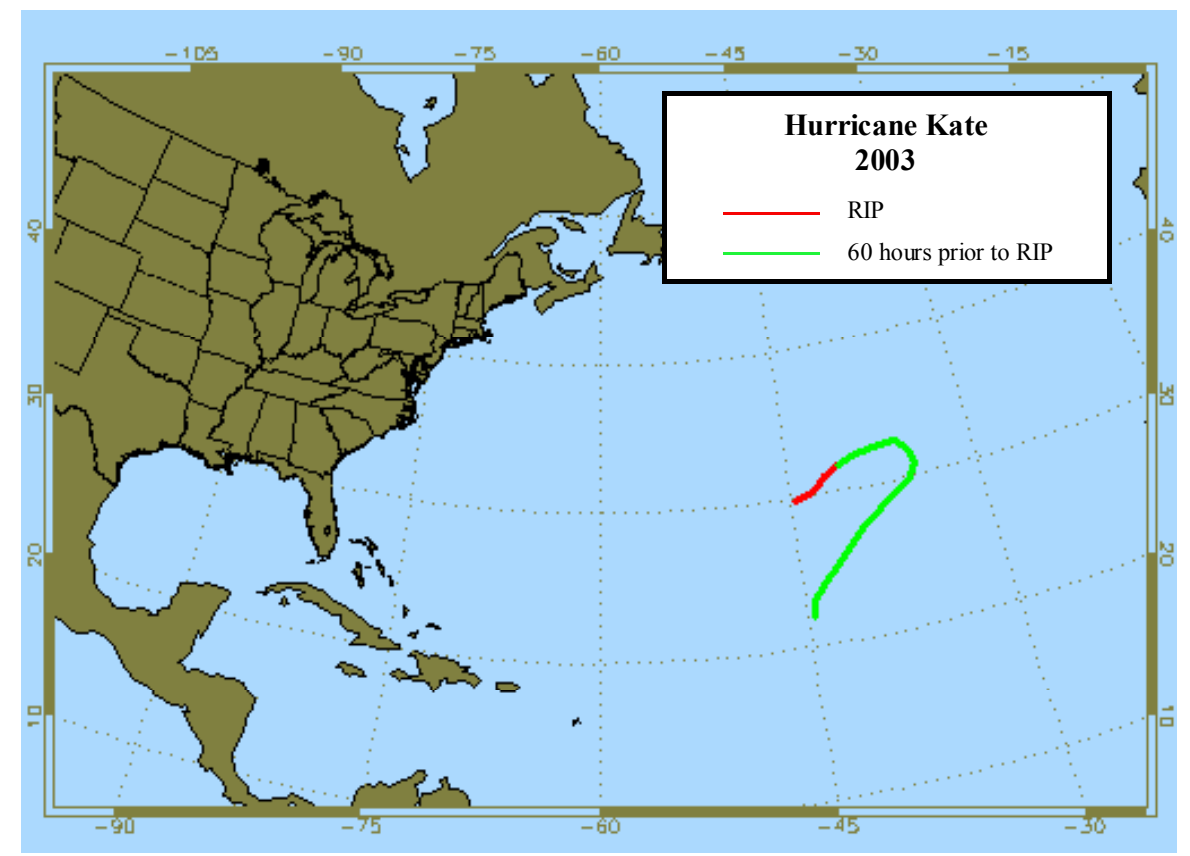

Figure A.103: As in Figure A.1, except for Hurricane Kate (2003). 